UNIVERSIDADE DE BRASÍLIA

FACULDADE DE TECNOLOGIA

DEPARTAMENTO DE ENGENHARIA ELETRICA

\title{
FERRAMENTA COMPUTACIONAL PARA ANÁLISE DE CINTILAÇÕES LUMINOSAS
}

\author{
ROBERTO ALVES MONTEIRO JUNIOR \\ THIAGO FERNANDES DO PRADO
}

ORIENTADOR: ANÉSIO DE LELES FERREIRA FILHO

PROJETO FINAL DE GRADUAÇÃO EM ENGENHARIA ELÉTRICA PUBLICAÇÃO: ENE - 2/2006 BRASÍLIA/DF: DEZEMBRO - 2006 


\author{
UNIVERSIDADE DE BRASÍLIA \\ FACULDADE DE TECNOLOGIA \\ DEPARTAMENTO DE ENGENHARIA ELETRICA
}

\begin{abstract}
FERRAMENTA COMPUTACIONAL PARA ANÁLISE DE CINTILAÇÕES LUMINOSAS
\end{abstract}

\author{
ROBERTO ALVES MONTEIRO JUNIOR \\ THIAGO FERNANDES DO PRADO
}

RELATÓRIO DE PROJETO FINAL SUBMETIDO AO DEPARTAMENTO DE ENGENHARIA ELÉTRICA DA FACULDADE DE TECNOLOGIA DA UNIVERSIDADE DE BRASÍLIA COMO PARTE DOS REQUISÍTOS NECESSÁRIOS PARA A OBTENÇÃO DO GRAU DE ENGENHEIRO ELETRICISTA.

\title{
APROVADO POR:
}

Prof. Anésio de Leles Ferreira Filho,(ENE-UnB) (Orientador)

Prof. Francisco Damasceno Freitas,(ENE-UnB) (Examinador Interno)

Prof. Lélio Ribeiro Soares Júnior,(ENE-UnB) (Examinador Interno)

BRASÍLIA/DF, 18 DE DEZEMBRO DE 2006 


\section{FICHA CATALOGRÁFICA}

MONTEIRO JUNIOR, ROBERTO ALVES; PRADO, THIAGO FERNANDES

Ferramenta Computacional para Análise de Cintilações Luminosas [Distrito Federal] 2006.

xix, 170p., 297 mm (ENE/FT/UnB, Engenheiro, Engenharia Elétrica, 2006)

Projeto Final de Graduação - Universidade de Brasília. Faculdade de Tecnologia.

Departamento de Engenharia Elétrica.
1. Cintilação Luminosa
2. Quantificação

3. Qualificação

4. Pst e Plt

I. ENE/FT/UnB

II. Título(série)

\section{REFERÊNCIA BIBLIOGRÁFICA}

MONTEIRO Jr, R. A., PRADO, T. F. (2006). Ferramenta Computacional Para Análise de Cintilações Luminosas. Projeto Final de Graduação em Engenharia Elétrica, Publicação ENE-2/06, Departamento de Engenharia Elétrica, Universidade de Brasília, Brasília, DF, 190 p.

\section{CESSÃO DE DIREITOS}

AUTORES: Roberto Alves Monteiro Junior, Thiago Fernandes do Prado.

ORIENTADOR: Anésio de Leles Ferreira Filho

TÍTULO: Ferramenta Computacional para Análise de Cintilação Luminosa

GRAU: Engenheiro

ANO: 2006

É concedida à Universidade de Brasília permissão para reproduzir cópias deste relatório de projeto final de graduação e para emprestar ou vender tais cópias somente para propósitos acadêmicos e científicos. Os autores e o orientador reservam outros direitos de publicação e nenhuma parte desse relatório de projeto final de graduação pode ser reproduzida sem autorização por escrito do autor e do orientador.

Roberto Alves Monteiro Junior (AUTOR)

Thiago Fernandes do Prado (AUTOR)

Anésio de Leles Ferreira Filho (ORIENTADOR) 


\section{DEDICATÓRIA(S)}

A minha família e amigos, pela ajuda e carinho dispensados. Roberto Alves Monteiro Junior
Aos meus queridos pais,

Edson e Rosa.

Thiago Fernandes do Prado 


\section{AGRADECIMENTOS}

A Deus em primeiro lugar, por sempre me abençoar e permitir que eu me torne uma pessoa cada vez melhor.

A minha família, pelo amparo e compreensão recebidos sempre que necessitei.

A Raquel, pelo carinho e apoio nesta etapa da minha vida.

Ao amigo Roberto, companheiro de trabalho, pela disponibilidade, entusiasmo e dedicação ao longo deste desafio.

Ao professor Anésio, pela confiança, dedicação e incentivo.

A todos que de alguma maneira contribuíram coma realização deste o projeto.

Aos amigos conquistados no decorrer da minha vida acadêmica.

A todas as pessoas que colaboraram com a minha formação, em especial aos funcionários e professores do Departamento de Engenharia Elétrica.

Thiago Fernandes do Prado

A Deus, por estar sempre ao meu lado.

A meus pais e irmãs, pelo apoio e carinho em todos os momentos.

A Mariana pelo amor e carinho dispensados.

Ao amigo Thiago, companheiro de projeto, pela dedicação e por propiciar um clima agradável para o desenvolvimento deste trabalho.

Ao professor Anésio, pelo apoio e dedicação.

A todos os amigos, que sempre me apoiaram.

Aos amigos conquistados na universidade, que de alguma forma me ajudaram a conquistar esta vitória.

A todas as pessoas que colaboraram com a minha formação, em especial aos funcionários e professores do Departamento de Engenharia Elétrica.

Roberto Monteiro 
SUMÁRIO

\section{Capítulo 1 - INTRODUÇÃO}

$1.1 \quad$ Aspectos Gerais................................................................................. 1

$1.2 \quad$ Estrutura do Trabalho.......................................................................

Capítulo 2 - QUALIDADE DA ENERGIA

2.1 Qualidade da Energia Elétrica............................................................... 5

2.2 Principais Distúrbios...................................................................... 8

2.2.1 Transitórios.............................................................................. 9

2.2.2 Variações de Tensão de Curta Duração.................................... 10

2.2.3 Variações de Tensão de Longa Duração.................................... 11

2.2.4 Desequilíbrios de Tensão............................................................ 12

2.2.5 Distorções da Forma de Onda.................................................... 13

2.2.6 Flutuação de Tensão............................................................... 16

2.2.7 Variações de Freqüência........................................................... 16

Capítulo 3 - CINTILAÇÕES LUMINOSAS

3.1 Conceituação - Flutuação de Tensão...................................................... 18

3.1.1 Definição e Características........................................................ 18

3.1.2 Cálculo das Flutuações de Tensão............................................ 20

3.1.2.1 Circuito Equivalente de Thévenin................................ 20

3.1.2.2 Nível de Curto-Circuito................................................ 23

3.1.3 Fatores que Influenciam as Flutuações de Tensão................... 24

$3.2 \quad$ Principais Cargas Perturbadoras.......................................................... 25

3.2.1 Fornos a Arco Elétricos (FAEs) ................................................ 25

3.2.2 Máquinas Elétricas de Solda..................................................... 27

3.2.3 Laminadores Metálicos............................................................ 28

3.2.4 Partida de Motores................................................................ 28

3.2.5 Cargas Residenciais e Comerciais............................................. 29 
3.2.6 Outras Cargas....................................................................... 29

3.3 Cintilação Luminosa............................................................................ 29

3.3.1 Definição........................................................................... 29

3.3.2 Sensibilidade de Diversos Tipos de Lâmpadas às Flutuações

3.4 Medição da Cintilação Luminosa............................................................ 33

3.4.1 Método Britânico................................................................... 34

3.4.2 Método Francês ou Método das doses..................................... 35

3.4.3 Método Padrão ou Internacional............................................... 38

3.4.3.1 O Medidor de Cintilação Luminosa UIE/IEC............. 38

3.4.3.2 Indicador de Severidade de Flicker de Curto Prazo -

3.4.3.3 Indicador de Severidade de Flicker de Longo Prazo Plt

3.5 Atenuação das Flutuações de Tensão.................................................... 48

3.5.1 Redução da Potência da Carga Perturbadora............................ 48

3.5.2 Fortalecimento do Sistema Supridor......................................... 48

3.5.3 Instalação de Reator de Núcleo Saturado - RNS..................... 49

3.5.4 Instalação de Equipamentos Reguladores de Tensão............... 50

3.6 Normas para Medição e Avaliação da Cintilação Luminosa............... 51

\section{Capítulo 4 - FERRAMENTA COMPUTACIONAL}

4.1 Estrutura do Aplicativo........................................................................ 55

4.2 Banco de Dados............................................................................... 58

$4.3 \quad$ Iniciando o Programa............................................................................ 60

4.4 Módulo de Entrada - Leitura do Banco de Dados................................. 62

4.5 Considerações finais............................................................................. 65

\section{Capítulo 5 - ANÁLISE DA FREQÜÊNCIA DE AQUISIÇÃO}

5.1 Estrutura do Módulo............................................................................... 66

5.2 Estudo de caso................................................................................... 67 
Capítulo 6 - ANÁLISE DA SIMILARIDADE ENTRE DIAS E PERÍODOS DO DIA

6.1 Módulo de Análise de Similaridade entre Dias................................. 74

6.2 Módulo de Análise de Similaridade entre Períodos do Dia................ 75

6.3 Estudo de Caso................................................................................ 76

6.3.1 Comparação entre os dias da Subestação Albras.................... 76

6.3.2 Similaridades entre os Períodos de um dia............................ 79

6.4 Considerações Finais........................................................................ 82

Capítulo 7 - ANÁLISE DA SIMILARIDADE ENTRE FASES

7.1 Estrutura do Módulo..................................................................... 83

Estudo de Caso.............................................................................. 84

7.2.1 Comparação Gráfica Entre as Fases da SE Albrás L1............. 85

7.2.2 Análise dos Valores Médios e Desvios Padrão Entre as Fases da SE Albrás.. 86 Fases da SE Albrás..............................................................

7.3 Considerações Finais................................................................ 88

\section{Capítulo 8 - ANÁLISE DA DISTRIBUIÇÃO NO TEMPO}

8.1 Estrutura do Módulo......................................................................... 89

8.2 Estudo de caso............................................................................. 91

8.2.1 Valores Estatísticos de Pst e Plt........................................... 91

8.2.2 Análise Considerando-se o Valor de P95\% Como Referência 92

8.2.3 Análise Considerando-se o Valor de P99\% Como Referência 98

8.2.4 Análise Considerando-se o Valor Médio Quadrático Como

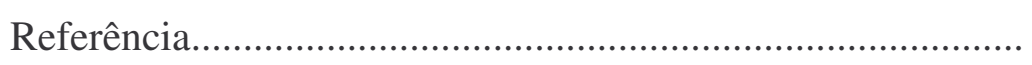

8.3 Considerações Finais......................................................................... 111 


\section{Capítulo 9 - COMPARAÇÃO COM A NORMA}

$9.1 \quad$ Estrutura do Módulo........................................................................... 112

9.2 Estudo de Caso............................................................................... 113

9.3 Considerações Finais...................................................................... 119

Capítulo 10 - ANÁLISE DE CARGA

10.1 Estrutura do Módulo........................................................................... 120

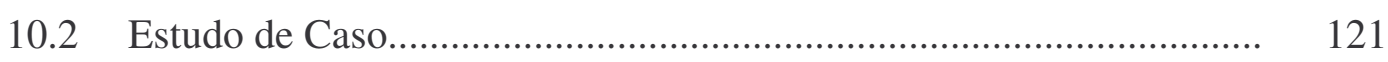

10.2.1 Tensões de Linha................................................................... 121

10.2.2 Correntes de Fase..................................................................... 123

10.2.3 Potências.............................................................................. 125

10.3 Considerações Finais........................................................................ 127

\section{Capítulo 11 - COMPARAÇÃO ENTRE LOCAIS}

$11.1 \quad$ Estudo de Caso................................................................................... 129

11.1.1 Análise da Freqüência de Aquisição........................................ 129

11.1.2 Análise da Similaridade entre Dias......................................... 136

11.1.3 Similaridade entre fases.......................................................... 143

11.1.4 Distribuição no Tempo............................................................ 145

11.1.5 Tensões de Fase.................................................................... 151

11.1.6 Tensões de Linha............................................................... 156

11.1.7 Comparação com a Norma....................................................... 161

11.2 Considerações Finais............................................................................ 164

Capítulo 12 - CONCLUSÃO

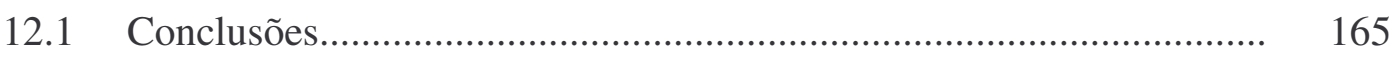

REFERENCIAS BIBLIOGRÁFICAS. 169 


\section{LISTA DE FIGURAS}

Figura 2.1 - Origem dos problemas da QEE......................................................... 6

Figura 2.2 - Custos associados a interrupções com duração de até um minuto (EUA) 7

Figura 2.3 - Vida útil versus sobre-temperatura em capacitores................................... 7

Figura 2.4 - Transitório oscilatório decorrente da eliminação de uma falta................... 10

Figura 2.5 - Transitório impulsivo........................................................................... 10

Figura 2.6 - Variação de tensão de curta duração........................................................ 11

Figura 2.7 - Desequilíbrio de tensão....................................................................... 13

Figura 2.8 - Forma de distorcida pela $5^{\mathrm{a}}$ harmônica................................................... 14

Figura 2.9 - Onda de corrente com presença de inter-harmônicos................................ 14

Figura 2.10 - Corte de tensão................................................................................... 15

Figura 2.11 - Presença de ruído no sinal de tensão....................................................... 15

Figura 3.1 - Tipos de flutuações de tensão................................................................ 19

Figura 3.2 - Equivalente de Thévenin do sistema de suprimento................................... 21

Figura 3.3 - Diagrama fasorial............................................................................... 21

Figura 3.4 - Condição de emissão de cintilação luminosa............................................ 25

Figura 3.5 - Tipos de fornos a arco elétrico................................................................ 26

Figura 3.6 - Curvas de visibilidade e irritação do olho humano devido às flutuações 31

de tensão sobre lâmpadas incandescentes.....................................................................

Figura 3.7 - Fator de ganho de lâmpadas incandescentes e fluorescentes...................... 33

Figura 3.8 - Curva FPCC típica para um forno a arco elétrico....................................... 35

Figura 3.9 - Curva de ponderação em freqüência ou de sensibilidade visual............... 36

Figura 3.10 - Diagrama de bloco do medidor de cintilação luminosa UIE/IEC........... 39

Figura 3.11 - Variação de tensão provocada pela modulação....................................... 42

Figura 3.12 - Curva de ponderação para lâmpada incandescente 60 W / 230 V........... 43

Figura 3.13 - Histograma de classificação de $S_{f}$ por níveis......................................... 44

Figura 3.14 - Curva de variação de tensão versus variações por minuto da IEC 46

60555-3 e Curva Pst = 1pu correspondente (Limiar de irritação) ...................................

Figura 3.15 - Característica VxI do reator saturado...................................................... 49

Figura 4.1 - Medidor ION 7600........................................................................ 58

Figura 4.2 - Exemplo de banco de dados no Microsoft Excel...................................... 60

Figura 4.3 - Tela de apresentação....................................................................... 61

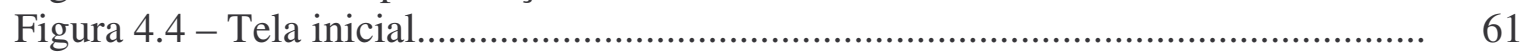

Figura 4.5 - Opção por tipo de banco de dados............................................................ 62

Figura 4.6 - Aviso de banco carregado....................................................................... 62

Figura 4.7 - Janela do módulo de entrada do programa (Banco de Dados).................. 63

Figura 4.8 - Localização da ALBRÁS....................................................................... 64

Figura 4.9 - Sistema Elétrico da Eletronorte próximo a SE ALBRÁS............................ 65

Figura 5.1 - Janela do módulo de análise da frequiência de aquisição de dados............ 67

Figura 5.2 - Gráfico de linha do indicador Pst na fase B.......................................... 68

Figura 5.3 - Gráfico de barras com os valores da tabela 6.1........................................ 69 
Figura 5.4 - Histograma e curva de probabilidade acumulada para freqüência de aquisição de 10 minutos...

Figura 5.5 - Histograma e curva de probabilidade acumulada para freqüência de aquisição de 30 minutos.

Figura 5.6 - Histograma e curva de probabilidade acumulada para frequiência de aquisição de 60 minutos.

Figura 5.7 - Gráfico de linha do indicador Plt na fase B.

Figura 5.8 - Gráfico de barras com os valores da tabela 6.2.

72

Figura 5.9 - Histograma e curva de probabilidade acumulada para frequiência de aquisição de 10 minutos

Figura 5.10 - Histograma e curva de probabilidade acumulada para frequiência de aquisição de 30 minutos

Figura 5.11 - Histograma e curva de probabilidade acumulada para freqüência de aquisição de 60 minutos

Figura 6.1 - Módulo de análise da similaridade entre dias.

Figura 6.2 - Módulo de análise da similaridade entre períodos do dia......................... 75

Figura 6.3 - Comportamento do indicador Pst......................................................... 76

Figura 6.4 - Estatísticas dos valores de Pst para os sete dias................................... 77

Figura 6.5 - Comportamento do indicador Plt........................................................... 78

Figura 6.6 - Estatísticas dos valores de Plt para os sete dias....................................... 79

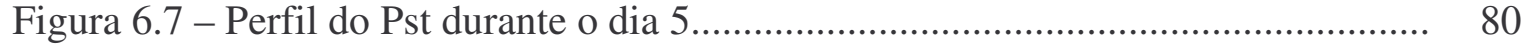

Figura 6.8 - Perfil do Plt durante o dia 5.................................................................. 80

Figura 6.9 - Similaridade entre períodos do dia 05/09, para o indicador Pst............... 81

Figura 6.10 - Similaridade entre períodos do dia 05/09, para o indicador Plt.............. 81

Figura 7.1 - Módulo de análise de similaridade entre fases..................................... 83

Figura 7.2 - Escolha da frequiência de aquisição dos dados....................................... 84

Figura 7.3 - Pst ponto a ponto para cada fase....................................................... 85

Figura 7.4 - Plt ponto a ponto para cada fase ...................................................... 85

Figura 7.5 - Gráfico de barras com os dados da tabela 7.1 ..................................... 86

Figura 7.6 - Gráfico de barras com os dados da tabela 7.2 ..................................... 87

Figura 8.1 - Módulo de análise de distribuição no tempo.......................................... 90

Figura 8.2 - Valores com Pst $\geq 0,156$ versus tempo total de medição em minutos...... 92

Figura 8.3 - Valores com Plt $\geq 0,145$ versus tempo total de medição em minutos....... 92

Figura 8.4 - Intervalos ininterruptos de tempo com valores com Pst $\geq 0,156 \ldots \ldots \ldots \ldots . .93$

Figura 8.5 - Intervalos ininterruptos de tempo com valores com Plt $\geq 0,145 \ldots \ldots \ldots \ldots . .93$

Figura 8.6 - Intervalos ininterruptos de tempo com valores com Pst $\leq 0,156 \ldots \ldots \ldots \ldots . . .94$

Figura 8.7 - Intervalos ininterruptos de tempo com valores com Plt $\leq 0,145 \ldots \ldots \ldots \ldots . .94$

Figura 8.8 - Probabilidade de ocorrência dos intervalos ininterruptos de tempo com Pst $\geq 0,156$.

Figura 8.9 - Probabilidade de ocorrência dos intervalos ininterruptos de tempo com

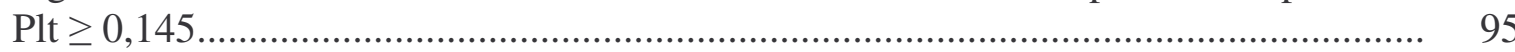

Figura 8.10 - Probabilidade de ocorrência dos intervalos ininterruptos de tempo com Pst $\leq 0,156$. 
Figura 8.11 - Probabilidade de ocorrência dos intervalos ininterruptos de tempo com Plt $\leq 0,145$..

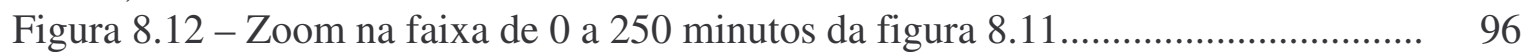

Figura 8.13 - Valores com Pst $\geq 0,336$ versus tempo total de medição em minutos.... 98

Figura 8.14 - Valores com Plt $\geq 0,220$ versus tempo total de medição em minutos.... 98

Figura 8.15 - Intervalos ininterruptos de tempo com Pst $\leq 0,336$............................ 99

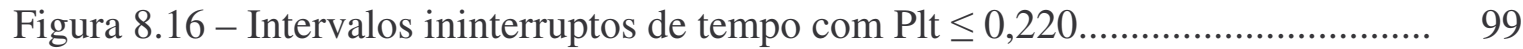

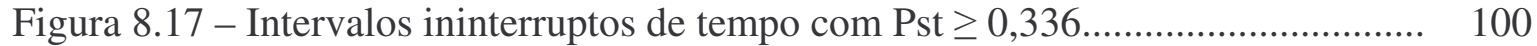

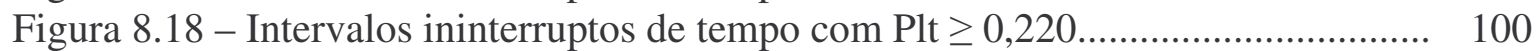

Figura 8.19 - Probabilidades de ocorrência dos intervalos ininterruptos de tempo 101

com Pst $\geq 0,336$.

Figura 8.20 - Probabilidades de ocorrências dos intervalos ininterruptos de tempo

com Plt $\geq 0,220$.

101

Figura 8.21 - Probabilidades de ocorrência dos intervalos ininterruptos de tempo

com Pst $\leq 0,336$

101

Figura 8.22 - Probabilidades de ocorrências dos intervalos ininterruptos de tempo com Plt $\leq 0,220$.

Figura 8.23 - Valores com Pst $\geq 0,198$ versus tempo total de medição em minutos....

Figura 8.24 - Valores com Plt $\geq 0,132$ versus tempo total de medição em minutos.....

Figura 8.25 - Intervalos ininterruptos de tempo com valores de Pst $\geq 0,198 \ldots \ldots \ldots \ldots \ldots$.

Figura 8.26 - Intervalos ininterruptos de tempo com valores de Plt $\geq 0,132 \ldots \ldots \ldots \ldots \ldots$.

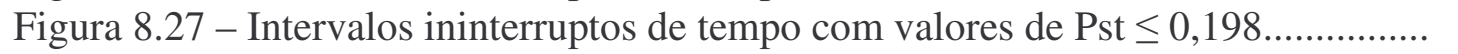

Figura 8.28 - Intervalos ininterruptos de tempo com valores de Plt $\leq 0,132 \ldots \ldots \ldots \ldots \ldots . . . .$.

Figura 8.29 - Probabilidades de ocorrência dos intervalos ininterruptos de tempo

com valores de Pst $\geq 0,198$.

Figura 8.30 - Probabilidades de ocorrência dos intervalos ininterruptos de tempo com valores de Plt $\geq 0,132$.

Figura 8.31 - Probabilidades de ocorrência dos intervalos ininterruptos de tempo com valores de Pst $\leq 0,198$.

Figura 8.32 - Probabilidades de ocorrência dos intervalos ininterruptos de tempo com valores de Plt $\leq 0,132$.

Figura 8.33 - Zoom na figura 8.31 na faixa de 0 a 190 minutos

Figura 8.34 - Zoom da figura 8.32 na faixa de 0 a 200 minutos.

102

103

104

104

105

105

106

106

107

107

108

108

Figura 9.1 - Janela do módulo de comparação com a norma.

Figura 9.2 - Tendência do indicador Pst na fase A, durante a semana em estudo........

Figura 9.3 - Tendência do indicador Pst na fase B, durante a semana em estudo........ 115

Figura 9.4 - Tendência do indicador Pst na fase C, durante a semana em estudo........ 115

Figura 9.5 - Tendência do indicador Plt na fase A, durante a semana em estudo........ 116

Figura 9.6 - Tendência do indicador Plt na fase B, durante a semana em estudo........ 116

Figura 9.7 - Tendência do indicador Plt na fase C, durante a semana em estudo........ 116

Figura 9.8 - Histograma e curva de probabilidade acumulada do indicador Pst na fase A.

Figura 9.9 - Histograma e curva de probabilidade acumulada do indicador Pst na fase B.

Figura 9.10 - Histograma e curva de probabilidade acumulada do indicador Pst na fase $\mathrm{C}$. 
Figura 9.11 - Histograma e curva de probabilidade acumulada do indicador Plt na fase A......

Figura 9.12 - Histograma e curva de probabilidade acumulada do indicador Plt na fase B.

Figura 9.13 - Histograma e curva de probabilidade acumulada do indicador Plt na fase $\mathrm{C}$.

Figura 10.1 - Janela do módulo de análise de carga

Figura 10.2 - Tensões de linha no intervalo de uma semana de medição.................... 122

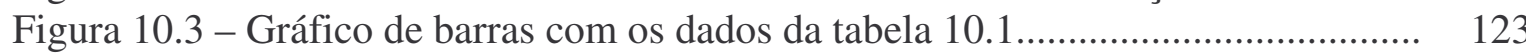

Figura 10.4 - Correntes de fase no intervalo de uma semana de medição................... 124

Figura 10.5 - Gráfico de barras com os dados da tabela 10.2 .................................. 124

Figura 10.6 - Potências aparente, ativa e reativa no intervalo de uma semana de medição.

Figura 10.7 - Gráfico de barras com os dados da tabela 10.3.

Figura 11.1 - Comparação entre a média aritmética indicador Pst das subestações para as diferentes freqüências de aquisição.

Figura 11.2 - Comparação entre a média aritmética do indicador Plt das subestações para as diferentes frequiências de aquisição.

Figura 11.3 - Comparação entre o desvio padrão do indicador Pst das subestações para as diferentes freqüências de aquisição.

Figura 11.4 - Comparação entre o desvio padrão do indicador Plt das subestações para as diferentes frequiências de aquisição.

Figura 11.5 - Comparação entre o P95\% do indicador Pst das subestações para as diferentes freqüências de aquisição.

Figura 11.6 - Comparação entre o P95\% do indicador Plt das subestações para as diferentes freqüências de aquisição.

Figura 11.7 - Comparação entre média aritmética do indicador Pst das subestações para os diferentes dias da semana

Figura 11.8 - Comparação entre média aritmética do indicador Plt das subestações para os diferentes dias da semana.

Figura 11.9 - Comparação entre o desvio padrão do indicador Pst das subestações para os diferentes dias da semana.

Figura 11.10 - Comparação entre o desvio padrão do indicador Plt das subestações para os diferentes dias da semana.

Figura 11.11 - Comparação entre o P95\% do indicador Pst das subestações para os diferentes dias da semana.

Figura 11.12 - Comparação entre o P95\% do indicador Plt das subestações para os diferentes dias da semana.

Figura 11.13 - Médias aritméticas dos valores de Pst que ultrapassaram os índices....

Figura 11.14 - Médias aritméticas dos valores de Plt que ultrapassaram os índices.....

Figura 11.15 - Médias aritméticas dos valores de Plt que ultrapassaram os índices, exceto para CCM

Figura 11.16 - Desvio Padrão dos valores de Pst que ultrapassaram os índices. 
Figura 11.18 - Desvio padrão dos valores de Plt que ultrapassaram os índices,

diferentes subestações

Figura 11.20 - Comparação entre o desvio padrão das amostras de tensão de fase...... 153

Figura 11.21 - Comparação entre o P95\% das amostras de tensão de fase................. 154

Figura 11.22 - Distribuição de ocorrências da tensão de fase Va em p.u.................... 155

Figura 11.23 - Distribuição de ocorrências da tensão de fase Vb em p.u.................... 155

Figura 11.2425 - Distribuição de ocorrências da tensão de fase Vc em

p.u.......................

diferentes subestações

Figura 11.26 - Comparação entre o desvio padrão das amostras de tensão de linha.... 158

Figura 11.27 - Comparação entre o P95\% das tensões de linha.................................. 159

Figura 11.28 - Distribuição de ocorrências da tensão Vab em p.u............................. 160

Figura 11.29 - Distribuição de ocorrências da tensão Vbc em p.u.............................. 160

Figura 11.30 - Distribuição de ocorrências da tensão Vca em p.u............................... 160 


\section{LISTA DE TABELAS}

Tabela 2.1 - Principais distúrbios que afetam a qualidade da energia........................... 8

Tabela 2.2 - Características dos itens de qualidade................................................... 16

Tabela 3.1 - Limites do método britânico...................................................................... 35

Tabela 3.2 - Limites aceitáveis do método francês....................................................... 37

Tabela 3.3 - Métodos de compensação e controle de flutuações de tensão................... 51

Tabela 3.4 - Ajustes para medição de flutuação em função do nível da tensão 52

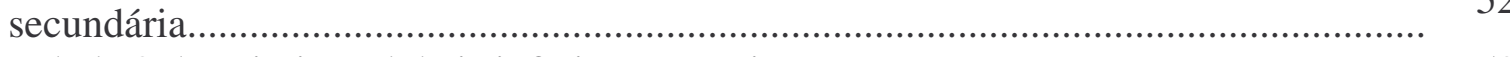

Tabela 3.5 - Limites globais inferior e superior.......................................................... 53

Tabela 3.6 - Valores Típicos dos Fatores de Transferência (FT)................................. 54

Tabela 3.7 - Qualidade da tensão quanto à flutuação................................................... 54

Tabela 4.1 - Formato do banco de dados (tipo 1) ………………………………….. 59

Tabela 4.2 - Dados do banco de dados medido em SE ALBRÁS L1......................... 64

Tabela 5.1 - Valores estatísticos para Pst............................................................... 68

Tabela 5.2 - Valores estatísticos para Plt................................................................... 71

Tabela 6.1 - Valores estatísticos para o Pst................................................................. 77

Tabela 6.2 - Valores estatísticos para o Plt............................................................... 78

Tabela 6.3 - Valores estatísticos para o Pst............................................................... 80

Tabela 6.4 - Valores estatísticos para o Plt............................................................... 81

Tabela 7.1 - Dados estatísticos do Pst........................................................................ 86

Tabela 7.2 - Dados estatísticos do Plt..................................................................... 87

Tabela 8.1 - Dados estatísticos do Pst......................................................................... 91

Tabela 8.2 - Dados estatísticos do Plt..................................................................... 91

Tabela 8.3 - Resumo dos valores observados para o Pst quando a referência é o 97

P95\%.

Tabela 8.4 - Resumo dos valores observados para o Plt quando a referência é o

$\mathrm{P} 95 \%$

Tabela 8.5 - Resumo dos valores observados para o Pst quando a referência é o P99\%

Tabela 8.6 - Resumo dos valores observados para o Plt quando a referência é o P99\%.

Tabela 8.7 - Resumo dos valores observados para o Pst quando a referência é a média quadrática.

Tabela 8.8 - Resumo dos valores observados para o Plt quando a referência é a média quadrática.

Tabela 8.9 - Tabela comparativa entre os índices P95\%, P99\% e média quadrática do Pst da fase C.

Tabela 8.10 - Tabela comparativa entre os índices P95\%, P99\% e média quadrática do Plt da fase C.

6

(3)

37

53

54

59


Tabela 9.1 - Resumo dos indicadores obtidos em campanha de medição iniciada no dia 3 .

Tabela 9.2 - Limite dos indicadores.

Tabela 10.1 - Dados estatísticos das tensões medidas.

Tabela 10.2 - Dados estatísticos das correntes medidas.

Tabela 10.3 - Dados estatísticos das correntes medidas.

Tabela 11.1 - Média aritmética do indicador Pst para as diferentes frequiências de aquisição.

Tabela 11.2 - Média aritmética do indicador Plt para as diferentes frequiências de aquisição.

Tabela 11.3 - Desvio padrão do indicador Pst para as diferentes freqüências de aquisição.

Tabela 11.4 - Desvio padrão do indicador Plt para as diferentes freqüências de aquisição..

Tabela 11.5 - Desvio padrão do indicador Pst dividido pelo respectivo valor médio... Tabela 11.6 - Desvio padrão do indicador Plt dividido pelo respectivo valor médio... Tabela 11.7 - P95\% do indicador Pst para as diferentes frequiências de aquisição....... Tabela 11.8 - P95\% do indicador Plt para as diferentes freqüências de aquisição....... Tabela 11.9 - Média aritmética do indicador Pst para os diferentes dias da semana.... Tabela 11.10 - Média aritmética do indicador Plt para os diferentes dias da semana... Tabela 11.11 - Desvio percentual máximo do indicador Pst dentro dos sete dias consecutivos.

Tabela 11.12 - Desvio percentual máximo do indicador Plt dentro dos sete dias consecutivos.

Tabela 11.13 - Desvio padrão do indicador Pst para os diferentes dias da semana...... Tabela 11.14 - Desvio padrão do indicador Plt para os diferentes dias da semana....... Tabela 11.15 - Desvio padrão do indicador Pst dividido pelo respectivo valor médio. Tabela 11.16 - Desvio padrão do indicador Plt dividido pelo respectivo valor médio. Tabela 11.17 - P95\% do indicador Pst para os diferentes dias da semana.......

Tabela 11.18 - P95\% do indicador Plt para os diferentes dias da semana.....

Tabela 11.19 - Desvio percentual máximo do P95\% do indicador Pst dentro dos sete dias consecutivos.

Tabela 11.20 - Desvio percentual máximo do P95\% do indicador Plt dentro dos sete dias consecutivos

Tabela 11.21 - Média aritmética dos valores de Pst.

Tabela 11.22 - Média aritmética dos valores de Plt

Tabela 11.23 - Maiores médias aritméticas do Pst.

Tabela 11.25 - P90\%, médias aritméticas, desvios padrão e razões entre os desvios e as médias dos valores superiores ao P90\% do Pst.

Tabela 11.26 - P95\%, médias aritméticas, desvios padrão e razões entre os desvios e as médias dos valores superiores ao P95\% do Pst......

Tabela 11.27 - P99\%, médias aritméticas, desvios padrão e razões entre os desvios e as médias dos valores superiores ao P99\% do Pst. 
Tabela 11.28 - P90\%, médias aritméticas, desvios padrão e razões entre os desvios e as médias dos valores superiores ao P90\% do Plt.....

Tabela 11.29 - P95\%, médias aritméticas, desvios padrão e razões entre os desvios e as médias dos valores superiores ao P95\% do Plt.

Tabela 11.30 - P99\%, médias aritméticas, desvios padrão e razões entre os desvios e as médias dos valores superiores ao P99\% do Plt

Tabela 11.30 - Erro relativo entre as médias aritméticas dos valores superiores aos índices do Pst

Tabela 11.31 - Erro relativo entre as médias aritméticas dos valores superiores aos índices do Plt.

Tabela 11.32 - Média aritmética das tensões de fase

Tabela 11.33 - Desvio padrão das amostras de tensão de fase.

Tabela 11.34 - Razão entre os desvios padrão e suas respectivas médias aritméticas..

Tabela 11.35 - P95\% das tensões de fase nos diferentes locais...

153

Tabela 11.36 - Média aritmética das tensões de linha nos locais de medição................

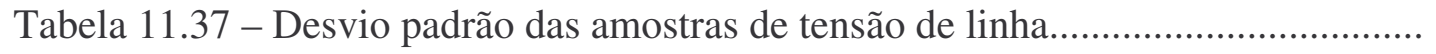

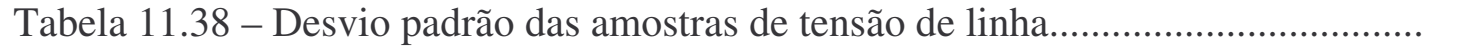

Tabela 11.39 - P95\% das tensões de linha

Tabela 11.40 - Resumo dos indicadores obtidos na campanha de medição na SE

Albras L1.

Tabela 11.41 - Resumo dos indicadores obtidos na campanha de medição na SE

Albras L2.

Tabela 11.42 - Resumo dos indicadores obtidos na campanha de medição na SE

Alumar L1...

Tabela 11.43 - Resumo dos indicadores obtidos na campanha de medição na SE Alumar L2

Tabela 11.44 - Resumo dos indicadores obtidos na campanha de medição na SE

Alunorte.

Tabela 11.45 - Resumo dos indicadores obtidos na campanha de medição na SE

Carajás.

Tabela 11.46 - Resumo dos indicadores obtidos na campanha de medição na SE CCM.

Tabela 11.47 - Resumo dos indicadores obtidos na campanha de medição na SE CVLD.

Tabela 11.48 - Resumo dos indicadores obtidos na campanha de medição na SE

Marabá.

Tabela 11.49 - Limite dos indicadores 


\section{LISTA DE SIGLAS E ABREVIAÇÕES}

$\begin{array}{ll}\text { ALBRAS } & \text { Alumínio Brasileiro S.A. } \\ \text { ALUMAR } & \text { Consórcio de Alumínio do Maranhão } \\ \text { ALUNORTE } & \text { Alumina do Norte do Brasil S.A. } \\ \text { ANEEL } & \text { Agência Nacional de Energia Elétrica } \\ \text { CCM } & \text { Camargo Correa Metais } \\ \text { CVRD } & \text { Companhia Vale do Rio Doce } \\ \text { ELETRONORTE } & \text { Centrais Elétricas do Norte do Brasil S.A. } \\ \text { EPRI } & \text { Electric Power Research Institute } \\ \text { FAE } & \text { Forno a arco elétrico } \\ \text { FPCC } & \text { Função de probabilidade cumulativa complementar } \\ \text { FT } & \text { Fator de transferência } \\ \text { IEC } & \text { International Eletrotechnical Commission } \\ \text { L1 } & \text { Linha 1 } \\ \text { MAE } & \text { Mercado Atacadista de Energia } \\ \text { ONS } & \text { Operador Nacional do Sistema } \\ \text { PAC } & \text { Ponto de acoplamento comum } \\ \text { Pst } & \text { Indicador de severidade de flicker de curto prazo } \\ \text { Pstd95\% } & \text { P95\% das amostras de Pst medidas ao londo de 1 dia } \\ \text { PstD95\% } & \text { Maior valor entre os Pstd95\% de uma semana } \\ \text { Plt } & \text { Indicador de severidade de flicker de longo prazo } \\ \text { PltS95\% } & \text { P95\% das amostras de Plt coletadas em 1 semana } \\ \text { QEE } & \text { Qualidade da Energia Elétrica } \\ \text { RNS } & \text { Reator de núcleo saturado } \\ \text { SE } & \text { Subestação } \\ \text { UIE } & \text { União Internacional de Eletrotermia } \\ \text { VL } & \text { Valor limite } \\ \text { VTCD } & \text { Variações de tensão de curta duração } \\ \text { VTLD } & \text { Variações de tensão longa duração } \\ & \end{array}$




\section{CAPÍTULO 1}

\section{INTRODUÇÃO}

\subsection{Aspectos Gerais}

A reformulação do setor elétrico tornou-se necessária para garantir o crescimento dos demais setores de produção que dependem da energia elétrica. A fim disto, uma série de medidas foram tomadas, como a criação do Mercado Atacadista de Energia (MAE), onde se realizam os contratos de compra e venda de energia elétrica. Nas condições competitivas do MAE, é imprescindível que o órgão fiscalizador (Agência Nacional de Energia Elétrica ANEEL) juntamente com o órgão operador (Operador Nacional do Sistema - ONS), realize a fiscalização da qualidade da energia entregue ao consumidor final, atribuindo eventuais responsabilidades aos agentes causadores de violação dos limites estabelecidos (DECKMANN, 2000).

Na verdade, espera-se da concessionária o fornecimento de energia elétrica com a tensão dentro dos limites normalizados e com a freqüência constante. Porém, o fornecimento, de maneira contínua e livre de perturbações é uma tarefa complicada. A utilização normal de eletricidade gera perturbações e problemas no sistema elétrico, provocados por fenômenos naturais ou por ações deliberadas sobre o sistema (FERNANDES, 1999).

Embora a área Qualidade da Energia Elétrica (QEE) seja relativamente recente, as questões e os problemas relacionados a mesma acompanham a evolução da eletricidade. Os distúrbios sempre existiram, porém mudou-se a maneira de abordá-los, a partir do desenvolvimento de métodos específicos para controle, caracterização, análise e solução (MEDEIROS, 2003).

Vários fatores justificam uma maior preocupação com a qualidade da energia, como o uso cada vez maior de equipamentos mais eficientes energeticamente que degradam a qualidade energia, a utilização de equipamentos mais sensíveis à presença de distúrbios, a proliferação de cargas não-lineares nos setores comercial e residencial, os aspectos 
econômicos, e até mesmo as questões legais relacionadas às atribuições, penalidades e exigências da implementação de métodos corretivos (MEDEIROS, 2003).

Dentre vários fenômenos de perturbação do sinal de tensão, a cintilação luminosa ("lamp flicker”) se destaca, não só pela grande sensibilidade das lâmpadas incandescentes às variações de tensão, mas também pelo fato das variações luminosas trazerem um incômodo direto ao ser humano.

A cintilação é consequiência da presença de flutuações de tensão na rede elétrica e, portanto, a análise deste fenômeno é muito importante, haja vista que as tensões flutuantes podem influenciar o comportamento de outros equipamentos, além de serem capazes de se propagar na rede atingindo um número grande de usuários.

Apesar de uma significativa experiência acumulada em diferentes países relacionada ao estudo do fenômeno da cintilação luminosa, e de se ter avançado no sentido de definir uma metodologia internacional para a medição do fenômeno a partir das variações da tensão, ainda persistem divergências quanto aos limites a serem fixados como aceitáveis, principalmente para médias e altas tensões (DECKMANN, 2000).

No Brasil, o Método Padrão ou Método Internacional é utilizado como referência. As vantagens deste método que se destacam são: concentrar os resultados em um simples valor numérico a cada intervalo de observação, possibilidade de ser implementada digitalmente, permitir análise de diferentes tipos de flutuações de tensão e seus efeitos em termos da cintilação luminosa provocada, permitir medições tanto de curta como de longa duração, e incorporar o tratamento estatístico na análise das variações aleatórias. (DECKMANN, 2000).

Atualmente, pode-se encontrar diversos instrumentos de medição de cintilação luminosa que seguem as recomendações da UIE/IEC. Entretanto são raros os aplicativos que se dedicam ao tratamento dos dados oriundos destes equipamentos. Percebendo esta lacuna, idealizou-se este trabalho, que tem como objetivo contribuir para a análise e a avaliação da cintilação luminosa, através do desenvolvimento de uma ferramenta computacional capaz de quantificar, qualificar e examinar os níveis de flicker. 
O aplicativo é composto de sete módulos de análise independentes entre si, mas complementares. Cada um deles possui uma série de análises estatísticas e algumas opções gráficas que auxiliam na compreensão do que ocorreu durante o período de observação.

Para a apresentação da ferramenta, será executado um estudo de caso ao final de cada capítulo referente ao funcionamento dos módulos do software.

Ao final deste relatório é colocado à apreciação um estudo contemplando vários locais do sistema elétrico da Eletronorte.

\subsection{Estrutura do Trabalho}

Este trabalho apresenta-se desenvolvido, seguindo a estrutura:

- Capitulo 2: Destina-se a apresentar os principais conceitos referentes aos distúrbios de qualidade da energia elétrica, explicitando a importância de se conhecer os fenômenos que a prejudicam.

- Capitulo 3: Orientado a destacar os principais conceitos, definições, características e causadores referentes à cintilação luminosa, trazendo também um resumo das principais normas e recomendações nacionais e internacionais sobre o assunto.

- Capitulo 4: Visa introduzir a ferramenta computacional para análise, quantificação e qualificação de flicker, detalhando a sua estrutura e suas definições matemáticas. Também é apresentado o local que auxiliará os estudos de caso presentes no final de cada capítulo subseqüente.

- Capitulo 5: Dirigido a expor o módulo de análise da frequiência de aquisição dos dados, o qual objetiva verificar se, para o mesmo período, o fenômeno pode ser representado por uma quantidade menor de informação.

- Capitulo 6: Voltado à apresentação dos módulos de análise da similaridade entre dias e entre períodos, que visam inferir a representatividade de um dia ou de um período do dia perante a totalidade das amostras. 
- Capitulo 7: Detalha o funcionamento do módulo de análise da similaridade entre fases, dedicado à verificação do comportamento dos indicadores observados nas três fases, permitindo avaliar o grau de equivalência entres elas.

- Capitulo 8: Dedicado à apresentação do módulo de análise de distribuição no tempo, que permite um estudo criterioso do comportamento da cintilação ao longo do período medido, utilizando para isto recursos estatísticos e probabilísticos.

- Capitulo 9: Orientado a detalhar o módulo de comparação com a norma, destinado a confrontar os valores medidos com os limites adotados para o sistema elétrico brasileiro. Ainda nesta etapa, é possível gerar os gráficos de linha, de barras e de probabilidade acumulada exigidos pelo ONS na elaboração dos relatórios.

- Capitulo 10: Destinado à descrição do módulo de análise de tensão e carga, designado a proporcionar informações referentes ao comportamento dos sinais de tensão e corrente, da potência e da freqüência, ajudando o usuário a descobrir possíveis causas de cintilação.

- Capitulo 11: Realiza um estudo englobando vários pontos do sistema da Eletronorte, utilizando-se dos módulos de análise desenvolvidos na ferramenta computacional.

- Capitulo 12: Constituindo a etapa final, este capítulo traz as conclusões finais a respeito do desenvolvimento do trabalho. 


\section{CAPÍTULO 2}

\section{QUALIDADE DE ENERGIA ELÉTRICA}

Neste capítulo são abordados conceitos e definições básicas para o entendimento da Qualidade da Energia Elétrica (QEE) e dos distúrbios que a compõem. Reconhecendo a relevância do assunto, será dedicado um capítulo à parte para análise das flutuações de tensão.

\section{1 - QUALIDADE DE ENERGIA ELÉTRICA}

Em virtude da maior consciência e informação a respeito de seus direitos, vem se formando um novo tipo de consumidor, interessado por produtos e serviços que se destaquem pelos seus diferenciais qualitativos. Nesta conjuntura, o mercado de energia, a partir das geradoras, distribuidoras, centros de pesquisa e universidades seguem empenhando esforços a fim de se atender as expectativas dos usuários de energia elétrica.

Cumpre enfatizar que sempre estiveram presentes nos sistemas elétricos distúrbios que demandavam investigações devido aos seus efeitos. Entretanto, mudanças na forma de abordá-los ocorreram, principalmente a partir do final da década de 80. No Brasil, nos anos de 1978 e 1980, foram criadas portarias onde já se falava em serviço adequado, condições técnicas e qualidade do serviço de energia elétrica. A atenção, porém, era dada somente aos aspectos de continuidade do fornecimento (qualidade do serviço) e as variação de tensão em regime permanente, diferentemente do enfoque contemporâneo, baseado na qualidade do produto. (RAMOS, 2000; OLIVEIRA, 2000).

Atualmente, observa-se que o objetivo primário de uma concessionária é fornecer energia elétrica com tensão puramente senoidal, com freqüência e amplitude constantes, a consumidores industriais, comerciais e residenciais.

Neste contexto, um problema de qualidade da energia elétrica pode ser formulado como qualquer desvio ou alteração manifestada na amplitude, forma de onda ou freqüência dos sinais de tensão e/ou corrente, que resulte na falha ou operação indevida de instalações, aparelhos ou equipamentos (MEDEIROS, 2003). De fato, o fornecimento de energia 
elétrica de forma confiável, com a tensão dentro dos limites normalizados, é o que se deve esperar das concessionárias. Entretanto, tê-lo de maneira contínua e isenta de perturbações não é uma tarefa realista. Boa qualidade no suprimento não significa uma energia perfeita. A utilização normal da eletricidade e a ocorrência de problemas no sistema elétrico, provocados por fenômenos naturais ou por ações deliberadas sobre o mesmo, geram perturbações. A natureza dessas perturbações, sua severidade e sua freqüência de ocorrência, irão variar de um local para outro, afetando as cargas dos consumidores (FERNANDES, 1999).

Do ponto de vista do consumidor, a qualidade de energia elétrica será definida como sendo a ausência de variações manifestadas na tensão, corrente ou freqüência que resultem em falhas ou má operação de seus equipamentos (DUGAN, 1996).

Nos dias de hoje, porém, quando da discussão das responsabilidades a respeito da QEE, ainda são observados pontos de vista diferentes a respeito da origem dos distúrbios, dificultando a solução eficaz dos problemas advindos dos fenômenos que afetam a qualidade da energia. . A figura 2.1 ilustra a origem dos distúrbios sob os pontos de vista da concessionária e do consumidor.
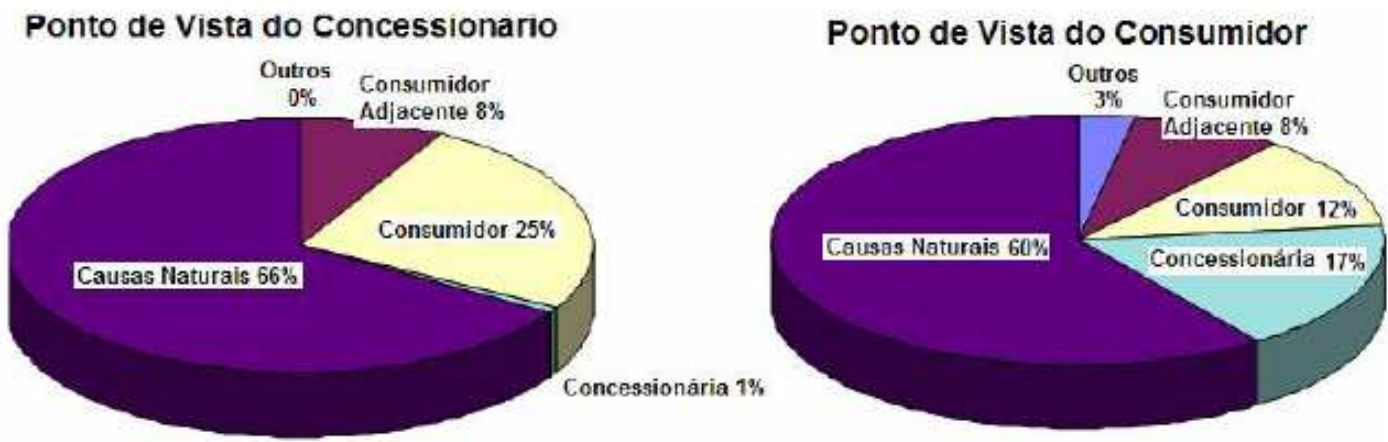

Figura 2.1 - Origem dos problemas da QEE (OLIVEIRA, 2005).

Entretanto, considerando que a qualidade do fornecimento da energia tem relação direta com o tipo de carga conectada aos barramentos do sistema, a questão da QEE deve ser enxergada como sendo de responsabilidade dividida entre todas as partes envolvidas, sejam elas, quem produz, transmite, distribui e consome a energia elétrica (BRONZEADO, 2004). 
Os problemas inerentes à má qualidade da energia elétrica acarretam, dia a dia, prejuízos.

Segundo a EPRI (Electric Power Research Institute), as perdas chegam a mais de 120 bilhões de euros por ano, só nos Estados Unidos (AFONSO, 2004). Obstáculos como a perda de vida útil de equipamentos somam-se aos prejuízos destacados. As figuras $2.2 \mathrm{e}$ 2.3 apresentam os custos associados a interrupções com duração de até um minuto, para alguns setores econômicos nos EUA (OLESKOVICZ, 2004) e a redução da vida útil de capacitores sob o efeito da sobretemperatura.

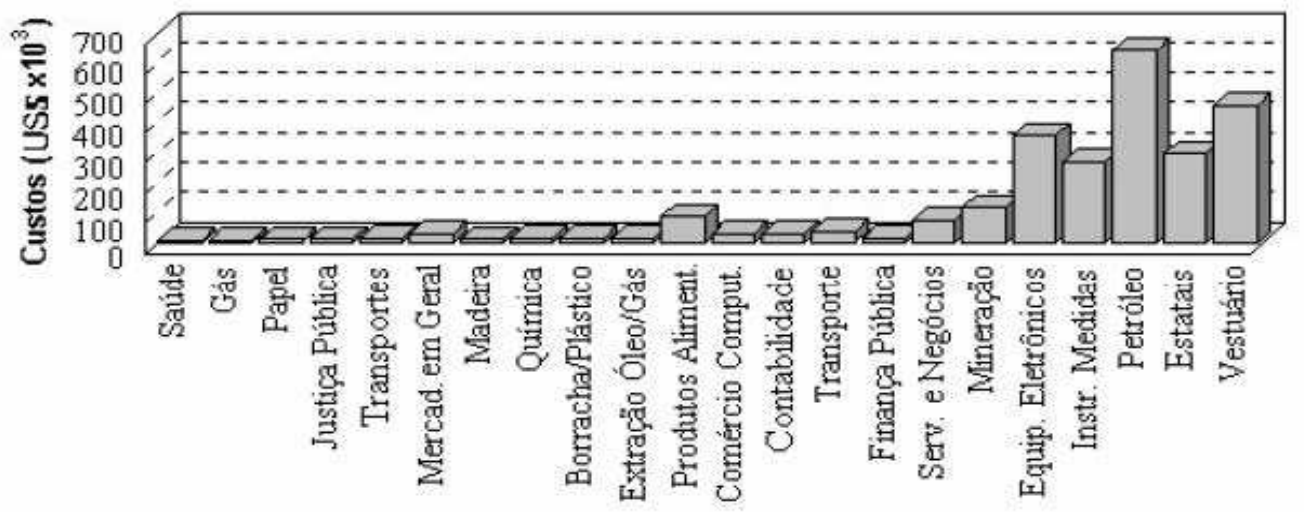

Setores

Figura 2.2 - Custos associados a interrupções com duração de até um minuto (EUA).

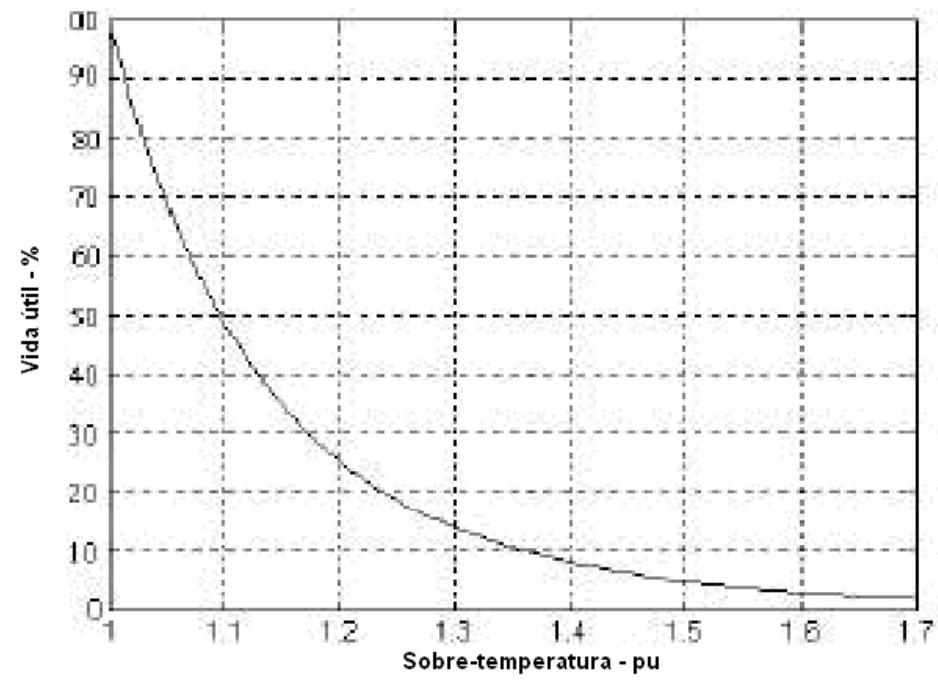

Figura 2.3 - Vida útil versus sobretemperatura em capacitores.

Da figura 2.2, pode-se inferir que setores econômicos de elevada importância, perdem grande quantidade de divisas dado algum problema que acarrete a interrupção do fornecimento. Já a figura 2.3 ilustra um decaimento, praticamente exponencial, na vida útil de capacitores, sob efeitos de sobretemperatura. 
Evidencia-se, portanto, a elevada importância inerente à qualidade de energia nos dias de hoje. Desta forma, é de suma importância, conhecer a fundo os fenômenos que a afetam, bem como determinar normas, limites e procedimentos adequados ao setor elétrico nacional.

\section{2 - PRINCIPAIS DISTÚRBIOS}

Os distúrbios eletromagnéticos associados à qualidade de energia elétrica estão dispostos na tabela 2.1, juntamente com algumas de suas características. Em seguida, é feita uma síntese desses fenômenos.

Tabela 2.1 - Principais distúrbios que afetam a qualidade da energia (OLIVEIRA, 2002).

\begin{tabular}{|c|c|c|}
\hline CATEGORIAS & DURAÇÃO & AMPLITUDE \\
\hline \multicolumn{3}{|l|}{ Transitórios } \\
\hline Impulsivos & $50 \mathrm{~ns}-1 \mathrm{~ms}$ & \\
\hline Oscilatórios & $5 \mathrm{us}-50 \mathrm{~ms}$ & $0-8 \mathrm{pu}$ \\
\hline \multicolumn{3}{|l|}{ Variações de curta duração } \\
\hline Interrupção transitória & 0,5 ciclo $-1 \mathrm{~min}$ & $<0,1 \mathrm{pu}$ \\
\hline Afundamento de tensão & 0,5 ciclo $-1 \mathrm{~min}$ & $0,1-0,9 \mathrm{pu}$ \\
\hline Elevação de tensão & 0,5 ciclo $-1 \mathrm{~min}$ & $1,1-1,8 \mathrm{pu}$ \\
\hline \multicolumn{3}{|l|}{ Variações de longa duração } \\
\hline Interrupção sustentada & $>1 \mathrm{~min}$ & $0,0 \mathrm{pu}$ \\
\hline Subtensão & $>1 \mathrm{~min}$ & $0,8-0,9 \mathrm{pu}$ \\
\hline Sobretensão & $>1 \mathrm{~min}$ & $1,1-1,2 \mathrm{pu}$ \\
\hline Desequilibrios & Reg. permanente & $0,02-0,05 \mathrm{pu}$ \\
\hline \multicolumn{3}{|l|}{ Distorção de forma de onda } \\
\hline Harmônicas & Reg. permanente & $0-0,2 \mathrm{pu}$ \\
\hline Interharmônicas & Reg. permanente & $0-0,02 \mathrm{pu}$ \\
\hline Ruído & Reg. permanente & $0-0,01 \mathrm{pu}$ \\
\hline Nivel CC & Reg. permanente & $0-0,01 \mathrm{pu}$ \\
\hline Flutuação de tensão & Intermitente & $0,001-0,07 \mathrm{pu}$ \\
\hline Variação de freqüência & $<10 \mathrm{~s}$ & \\
\hline
\end{tabular}




\subsection{1 - TRANSITÓRIOS}

São eventos de natureza momentânea. Caracterizam-se por variações bruscas de tensão e duração de subciclos. Apesar de ter duração curtíssima, o transitório é um fenômeno de grande importância, uma vez que submete equipamentos a grandes solicitações de tensão e/ou corrente.

Existem dois tipos de transitórios, os oscilatórios, causados por cargas com operação intermitente, chaveamento de bancos de capacitores, faltas envolvendo a terra e operação de dispositivos de semicondutores e os impulsivos, normalmente causados por descargas atmosféricas.

O transitório oscilatório é caracterizado por uma alteração repentina nas condições de regime permanente da tensão e/ou corrente possuindo valores de polaridade positiva e negativa. São caracterizados pelo seu conteúdo espectral, sendo subdividido em transitórios oscilatórios de baixa, média e alta freqüência. Filtros de alta frequiência e transformadores isoladores podem ser utilizados para proteger as cargas contra esse tipo de fenômeno. Energização de linhas, corte de corrente indutiva, eliminação de faltas, chaveamento de bancos de capacitores e transformadores são algumas das principais causas de transitórios oscilatórios. A figura 2.4 ilustra este fenômeno.

Transitório impulsivo é também caracterizado como uma alteração repentina nas condições de regime permanente da tensão, corrente, ou ambas. Porém este ocorre de forma unidirecional em polaridade, positiva ou negativa, e com freqüência muito diferente da rede elétrica. Devido às altas freqüências, os componentes reativos do sistema tendem a atenuar rapidamente esse fenômeno, fazendo com que este atinja principalmente as cargas mais próximas ao seu causador. Eles podem ainda excitar ressonâncias naturais no sistema elétrico, provocando transitórios oscilatórios. Seu principal efeito está associado à degradação ou falha da isolação de equipamentos com fontes eletrônicas. A figura 2.5 ilustra o fenômeno. 


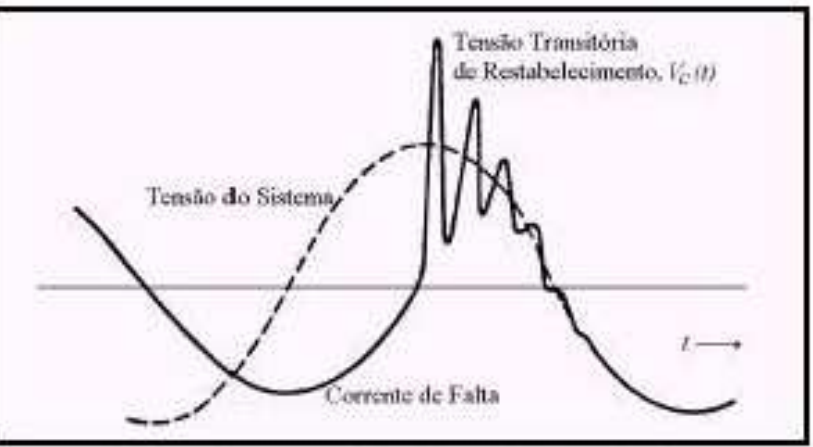

Figura 2.4 - Transitório oscilatório decorrente da eliminação de uma falta.

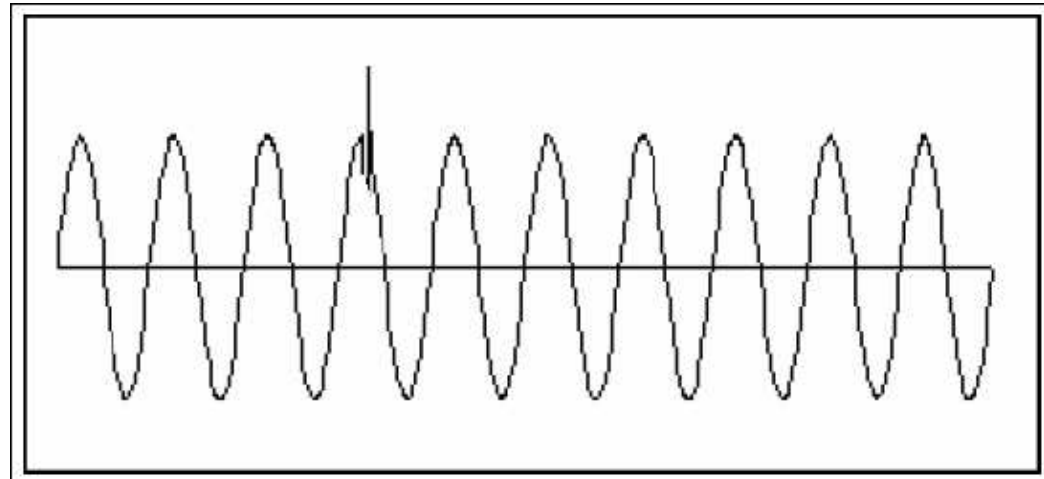

Figura 2.5 - Transitório impulsivo (CARVALHO, 1997).

\subsection{2 - VARIAÇÕES DE TENSÃO DE CURTA DURAÇÃO (VTCD)}

São variações com intervalos de tempo entre 0,5 ciclo e um minuto, podendo ser caracterizadas por alterações instantâneas, momentâneas ou temporárias. Em geral, ocorrem pela energização de grandes cargas que requerem altas correntes de partida, por intermitentes falhas nas conexões dos cabos do sistema, ou por curtos-circuitos no sistema. A VTCD pode causar, dependendo do local da falha e das condições operacionais do sistema, afundamento de tensão, elevação de tensão, ou mesmo uma interrupção completa do sistema elétrico.

Entende-se por interrupção a queda da tensão de suprimento a um valor menor que 0,1 pu por um período de tempo não superior a um minuto. Geralmente este tipo de interrupção é fruto de faltas no sistema de energia, falhas de equipamentos e mau funcionamento de sistemas de controle. Quase sempre levam ao desligamento ou mau funcionamento de eletrodomésticos.

Um afundamento de tensão ou sag, é uma subtensão caracterizada pela redução no valor eficaz da tensão entre 0,1 e 0,9 pu, na freqüência fundamental, com duração entre 0,5 ciclo a 1 minuto. Esta relacionada à entrada de cargas, partida de grandes motores e faltas, 
dentre outros fatores. Quando seu surgimento é devido a uma falta, ela ocorrerá no período compreendido entre a falta e a atuação da proteção, podendo levar a parada do sistema produtivo.

A elevação de tensão ou swell é o aumento da tensão na ordem de $110 \%$ da nominal, tipicamente entre 1,1 e 1,8 pu, em um período de 0,5 ciclo a um minuto. Tem por causa a entrada de bancos de capacitores, a saída de um grande bloco de cargas, porém, com uma incidência pequena se comparada com as elevações provenientes de faltas fase-terra nas redes de transmissão e distribuição.. Esse fenômeno pode provocar falha do isolamento de equipamentos eletrônicos e a queima de varistores e diodos zener.

As elevações de tensão de curta duração são caracterizadas pelas suas magnitudes (valores eficazes) e suas durações. A severidade de uma elevação durante uma condição de falta é função do local da falta, da impedância do sistema e do aterramento. Sua duração está intimamente ligada aos ajustes dos dispositivos de proteção, à natureza da falta (permanente ou temporária) e à sua localização na rede elétrica.

A Figura 2.6 traz, em pu, exemplos de interrupção de tensão, afundamento e elevação de tensão.

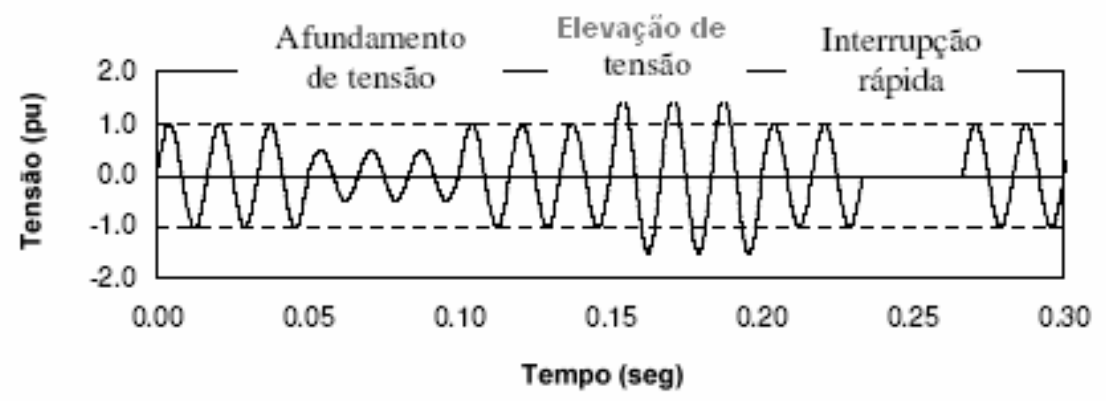

Figura 2.6 - Variação de tensão de curta duração (FERNANDES, 1999).

\subsection{3 - VARIAÇÕES DE TENSÃO LONGA DURAÇÃO (VTLD)}

São caracterizadas por variações da tensão eficaz, na frequiência do sistema, por um período maior do que 1 minuto. São causadas por variações de carga e operações de chaveamento no sistema, podendo ser classificadas como subtensões, sobretensões ou interrupções sustentadas. (OLIVEIRA, 2005). 
As sobretensões são elevações no valor da tensão eficaz acima de $110 \%$ da nominal, por períodos superiores a um minuto. São conseqüência do desligamento de grandes blocos de cargas e energização de bancos de capacitores. Uma opção para prevenção da ocorrência desse fenômeno é a troca de bancos de capacitores fixos por automáticos, possibilitando um controle maior do nível da tensão.

Subtensão é a redução na tensão eficaz de suprimento, para um valor menor do que 0,9 pu, por um período maior que um minuto. É decorrente da energização de grandes blocos de carga, da saída de bancos de capacitores e do carregamento excessivo dos circuitos alimentadores. Pode causar o aumento das perdas por aquecimento em motores de indução, parada de operação de dispositivos eletrônicos e desligamento de sistemas de comando de motores.

Interrupções sustentadas ocorrem devido à redução a zero da tensão eficaz, por um período superior a um minuto, requerendo a intervenção manual do operador para restabelecimento do funcionamento do sistema. As principais causas são falhas nos disjuntores, queima de fusíveis e falhas de componentes do circuito alimentador.

\subsection{4 - DESEQUILÍBRIOS DE TENSÃO}

Em um sistema trifásico ideal, as tensões nas três fases possuem a mesma amplitude e estão defasadas entre si de 120 graus. O desequilíbrio de tensão se manifesta de três formas distintas: amplitudes diferentes, assimetrias nas fases e assimetria conjunta de amplitudes e fases. Uma das formas de se caracterizar os desequilíbrios é a partir da relação entre a magnitude da tensão de seqüência negativa pela magnitude da tensão de seqüência positiva. As principais causas de desequilíbrio de tensão são o emprego de cargas desequilibradas, a conexão desigual de cargas monofásicas em circuitos trifásicos, a ausência de transposição completa de linhas de transmissão e anomalias em bancos de capacitores. (CARVALHO, 1997). Este problema se agrava quando consumidores alimentados de forma trifásica possuem uma má distribuição de carga em seus circuitos internos, impondo correntes desequilibradas no circuito da concessionária. O emprego de dispositivos de compensação pode ser solução para este problema. 
A Figura 2.7 traz uma ilustração das ondas de tensão com o sistema em desequilíbrio.

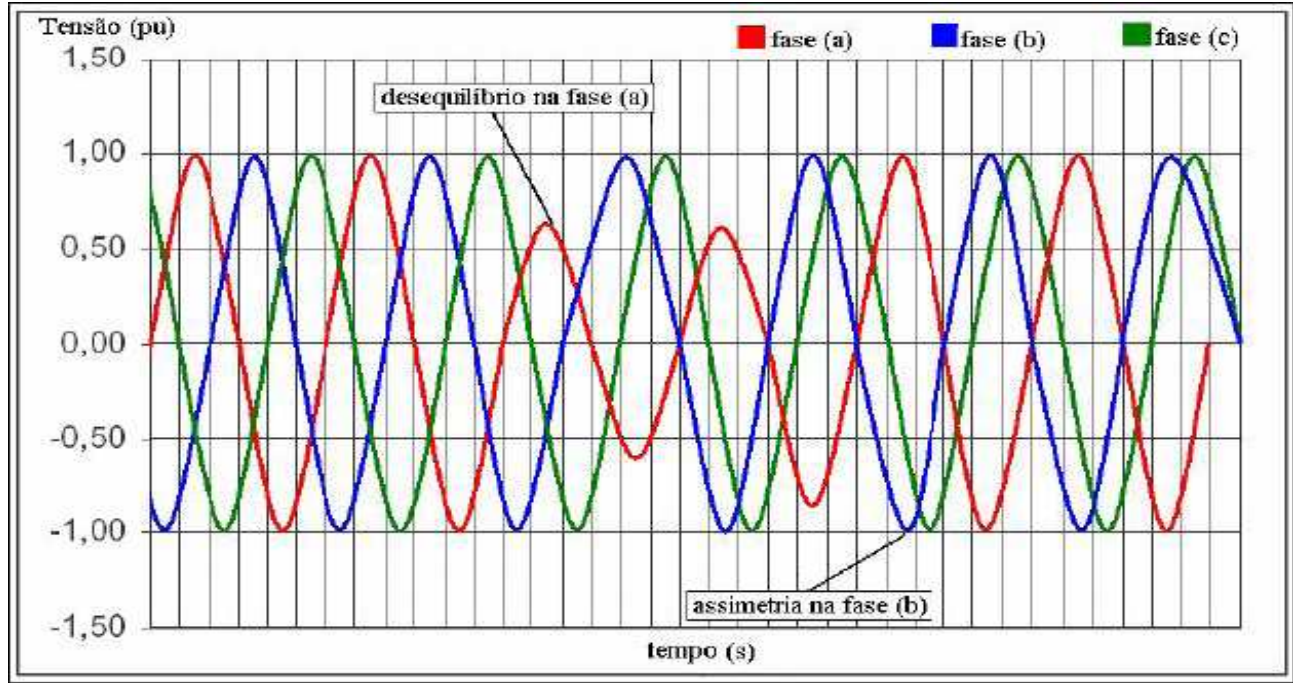

Figura 2.7 - Desequilíbrio de tensão (XAVIER, 2005).

\subsection{5 - DISTORÇÕES DA FORMA DE ONDA}

A distorção da forma de onda é definida como um desvio, em regime permanente, da forma de onda puramente senoidal, na freqüência fundamental, e é caracterizada principalmente pelo seu conteúdo espectral. Os principais tipos de distorção da forma de onda são: harmônicos, inter-harmônicos, ruídos, nível CC e corte (notching).

Harmônicos são tensões ou correntes senoidais que possuem como freqüência um múltiplo inteiro da frequiência fundamental na qual opera o sistema elétrico. Eles são oriundos de equipamentos e cargas com características não-lineares instalados no sistema de energia. São conseqüências deste fenômeno o sobreaquecimento, o mau funcionamento e perda de vida útil de equipamentos. É comumente medido pela distorção harmônica total, DHT, representada pela porcentagem em relação à tensão ou corrente nominal. A figura 2.8 apresenta uma forma de onda distorcida por uma harmônica de $5^{\mathrm{a}}$ ordem. 


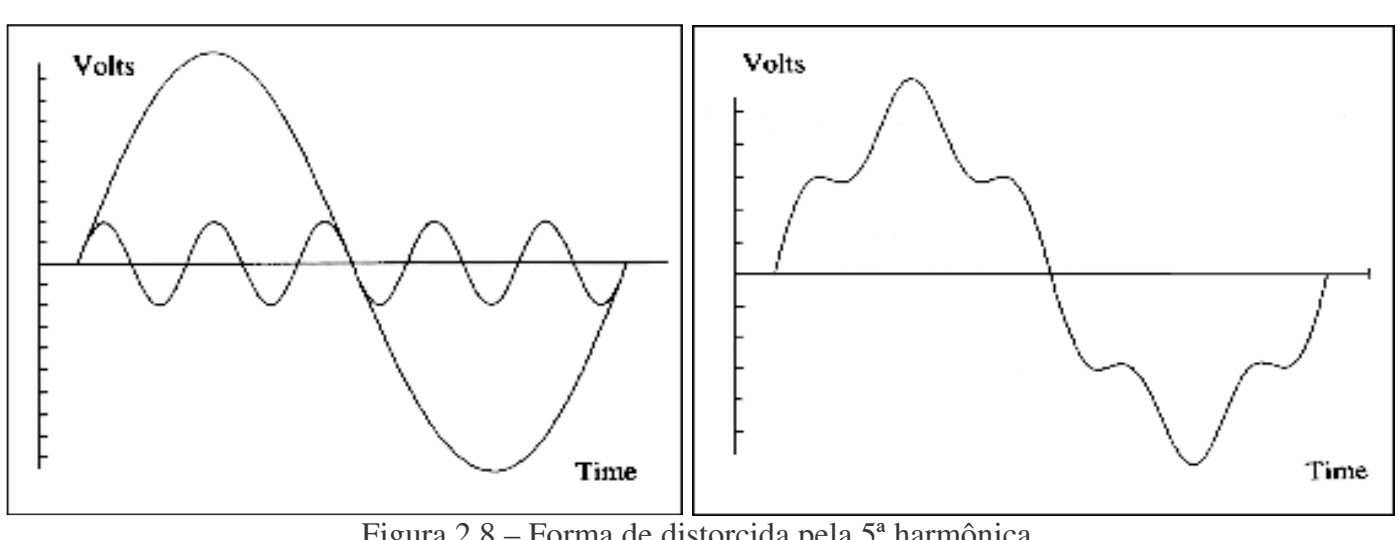

Figura 2.8 - Forma de distorcida pela $5^{a}$ harmônica.

Interharmônicos são componentes de freqüência, em tensão ou corrente, que não são múltiplos inteiros da freqüência fundamental na qual opera o sistema supridor de energia elétrica. Elas podem aparecer como freqüências discretas ou como uma larga faixa espectral. São causados majoritariamente por conversores estáticos de potência, cicloconversores, motores de indução e equipamentos a arco. Este fenômeno pode como efeito, induzir cintilação luminosa.

A Figura 2.9 ilustra uma onda de tensão distorcida pela presença de inter-harmônicas.

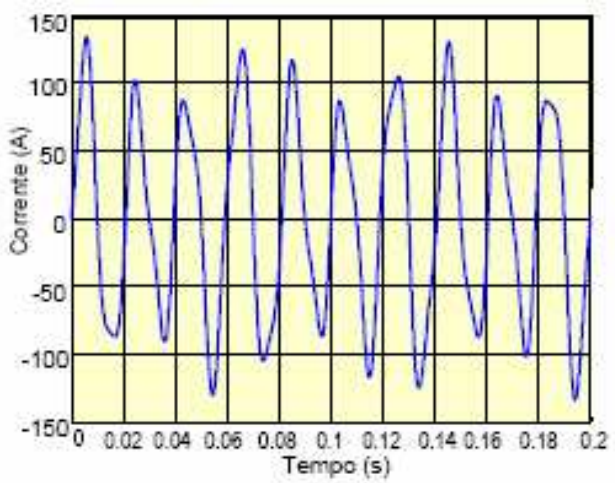

Figura 2.9 - Onda de corrente com presença de inter-harmônicos (AFONSO; MARTINS, 2004).

O desvio no nível CC pode ser caracterizado como a presença de tensão ou corrente contínua em um sistema elétrico CA. Este fenômeno pode ocorrer como o resultado da operação ideal de retificadores de meia-onda. O nível CC em redes de corrente alternada pode levar à saturação de transformadores, resultando em perdas adicionais, redução da vida útil, corrosão de eletrodos de aterramento e stress adicional da isolação. 
O corte de tensão ou notching é um distúrbio de tensão causado pela operação normal de equipamentos de eletrônica de potência quando a corrente é comutada de uma fase para outra. No decorrer da comutação da corrente, ocorre um curto-circuito momentâneo entre duas fases, causando a redução súbita da tensão. Este fenômeno pode ser detectado através do conteúdo harmônico da tensão afetada. As componentes de freqüência associadas com os cortes de tensão são de alto valor e, desta forma, não podem ser medidas pelos equipamentos normalmente utilizados para análise harmônica. A Figura 2.10 ilustra um corte de tensão.

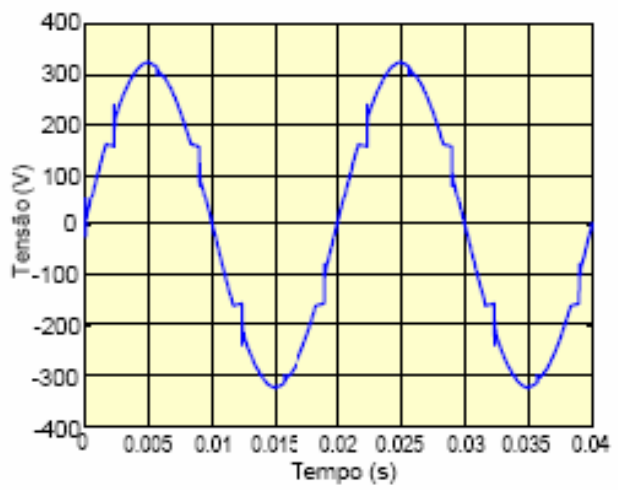

Figura 2.10 - Corte de tensão (AFONSO; MARTINS, 2004).

O fenômeno ruído é definido como um sinal elétrico indesejado, contendo uma larga faixa espectral com freqüências menores que $200 \mathrm{kHz}$, as quais são superpostas às tensões ou correntes de fase, ou encontradas em condutores de neutro. As principais fontes de ruídos são equipamentos eletrônicos de potência, circuitos de controle, equipamentos a arco, retificadores a estado sólido e fontes chaveadas e normalmente estão relacionados com aterramentos impróprios. Podem se propagar até atingir cargas susceptíveis em algum ponto do sistema, tais como microcomputadores e controladores programáveis. A figura 2.11 revela a presença de ruído no sinal de tensão.

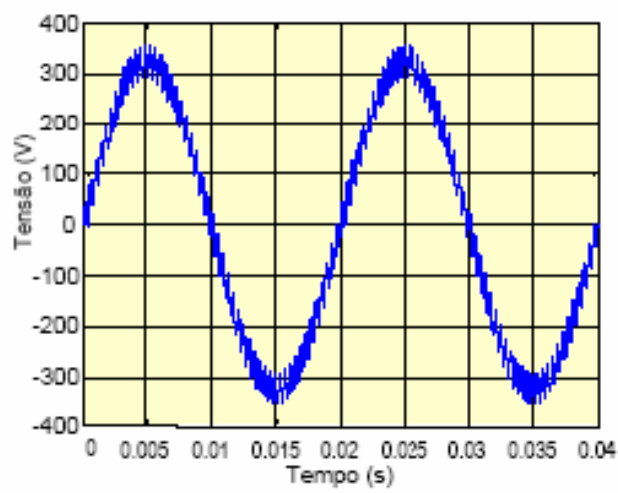

2.11 - Presença de ruído no sinal de tensão (AFONSO; MARTINS, 2004). 


\subsection{6 - FLUTUAÇÃO DE TENSÃO}

Por se tratar do assunto principal do trabalho, esse tópico será apresentado minuciosamente no capítulo seguinte.

\subsection{7 - VARIAÇÕES DE FREQÜÊNCIA}

São desvios na freqüência fundamental do sistema elétrico. A freqüência está diretamente relacionada com a rotação dos geradores e com o balanço entre a carga e a geração disponível. Quando este equilíbrio é alterado pequenas variações de freqüência deverão ocorrer. (DELMONT, 2005).

Pequenas variações de freqüência podem ser observadas como resultado do balanço dinâmico entre carga e geração no caso de alguma alteração (variações na faixa de $60 \pm$ $0,5 \mathrm{~Hz}$ ). Variações de freqüência que ultrapassam os limites para operação normal em regime permanente podem ser causadas por faltas em sistemas de transmissão, saída de um grande bloco de carga ou pela saída de operação de uma grande fonte de geração.

As variações de freqüência são mais fáceis de ocorrer em sistemas isolados, como é o caso da geração própria nas industriais.

A tabela 2.2 apresenta as principais características dos itens de qualidade, em termos de causas, efeitos e soluções.

Tabela 2.2 - Características dos itens de qualidade (PONTES, 2000).

\begin{tabular}{|c|c|c|c|}
\hline $\begin{array}{l}\text { Tipos de } \\
\text { distúrbios }\end{array}$ & Causas & Efeitos & Soluções \\
\hline $\begin{array}{l}\text { Transitórios } \\
\text { impulsivos }\end{array}$ & $\begin{array}{l}\text { - Descargas } \\
\text { atmosféricas; } \\
\text { - Chaveamento de } \\
\text { cargas. }\end{array}$ & $\begin{array}{l}\text { - Excitação de circuitos ressonantes; } \\
\text { - Redução na vida útil de motores, } \\
\text { geradores, transformadores, etc. }\end{array}$ & $\begin{array}{l}\text { - Filtros; } \\
\text { - Detectores de } \\
\text { surtos; } \\
\text {-Transformadores } \\
\text { isoladores. }\end{array}$ \\
\hline $\begin{array}{l}\text { Transitórios } \\
\text { oscilatórios }\end{array}$ & $\begin{array}{l}\text {-Descargas } \\
\text { atmosféricas; } \\
\text {-Chaveamento de } \\
\text { capacitores, linhas, } \\
\text { cabos, cargas e } \\
\text { transformadores. } \\
\end{array}$ & $\begin{array}{l}\text { - Mau funcionamento de } \\
\text { equipamentos controlados } \\
\text { eletronicamente, conversores de } \\
\text { potência, etc.; } \\
\text { - Redução na vida útil de motores, } \\
\text { geradores, transformadores, etc. }\end{array}$ & $\begin{array}{l}\text {-Filtros; } \\
\text {-Detectores de } \\
\text { surtos; } \\
\text {-Transformadores } \\
\text { isoladores. }\end{array}$ \\
\hline $\begin{array}{c}\text { Sub e } \\
\text { sobretensões }\end{array}$ & $\begin{array}{l}\text {-Partida de motores; } \\
\text {-Variação de cargas; } \\
\text { - Chaveamento de } \\
\text { capacitores. }\end{array}$ & $\begin{array}{l}\text { - Pequena redução na velocidade dos } \\
\text { motores de indução e no reativo dos } \\
\text { bancos de capacitores; } \\
\text { - Falhas de equipamentos } \\
\text { eletrônicos; } \\
\text { - Redução da vida útil de maquinas } \\
\text { rotativas, transformadores e cabos. } \\
\text { - Operação indevida de relés de } \\
\text { proteção. }\end{array}$ & $\begin{array}{l}\text { - Reguladores de } \\
\text { tensão; } \\
\text { - Fontes de energia } \\
\text { de reserva; } \\
\text { - Chaves estáticas; } \\
\text { - Geradores de } \\
\text { energia. }\end{array}$ \\
\hline
\end{tabular}




\begin{tabular}{|c|c|c|c|}
\hline Interrupções & $\begin{array}{l}\text { •Curto-circuito; } \\
\text {-Operação de } \\
\text { disjuntores; } \\
\text { •Manutenção. }\end{array}$ & $\begin{array}{l}\text { - Falha de equipamentos eletrônicos } \\
\text { e de iluminação; } \\
\text { - Desligamento de equipamentos; } \\
\text { - Interrupção do processo produtivo } \\
\text { (altos custos). }\end{array}$ & $\begin{array}{l}\text { - Fontes de energia } \\
\text { sobressalentes; } \\
\text { - Sistemas de no- } \\
\text { break; } \\
\text { - Geradores de } \\
\text { energia. }\end{array}$ \\
\hline Desequilíbrios & $\begin{array}{l}\text { - Fornos a arco; } \\
\text {-Cargas monof. e bif. } \\
\text {-Assimetria entre as } \\
\text { impedâncias. }\end{array}$ & $\begin{array}{l}\text { - Redução na vida útil de motores de } \\
\text { indução e máquinas síncronas; } \\
\text { - Geração, pelos retificadores, de } 3^{\text {o }} \\
\text { harmônico e seus múltiplos. }\end{array}$ & $\begin{array}{l}\text { •Operação } \\
\text { simétrica; } \\
\text { •Dispositivos de } \\
\text { compensação. } \\
\end{array}$ \\
\hline Nível CC & $\begin{array}{l}\text { - Operação ideal de } \\
\text { retificadores de meia- } \\
\text { onda, etc. }\end{array}$ & $\begin{array}{l}\text { - Saturação de transformadores; } \\
\text { - Corrosão eletrolítica de eletrodos } \\
\text { de aterramentos e de outros } \\
\text { conectores. }\end{array}$ & \\
\hline Harmônicos & •Cargas não-lineares. & $\begin{array}{l}\text { - Sobreaquecimento de cabo, } \\
\text { transformadores e motores de } \\
\text { indução; } \\
\text { - Danificação de capacitores, etc.; } \\
\text { - Erros de medidores de energia. }\end{array}$ & $\begin{array}{l}\text {-Filtros; } \\
\text {-Transformadores } \\
\text { isoladores. }\end{array}$ \\
\hline Interharmônicos & $\begin{array}{l}\text { - Conversores estáticos } \\
\text { de potência; } \\
\text {-Cicloconversores; } \\
\text { - Motores de indução; } \\
\text { •Equipamentos a arco, } \\
\text { etc. }\end{array}$ & $\begin{array}{l}\text { - Interferência na transmissão de } \\
\text { sinais carrier; } \\
\text { - Indução de Flicker visual no } \\
\text { display de equipamentos. }\end{array}$ & \\
\hline Notching & $\begin{array}{l}\text { •Equipamentos de } \\
\text { eletrônica de potência. }\end{array}$ & $\begin{array}{l}\text { - Redução da vida útil de } \\
\text { equipamentos eletrônicos. }\end{array}$ & $\begin{array}{l}\text {-Aterramento das } \\
\text { instalações; } \\
\text {-Filtros. }\end{array}$ \\
\hline Ruídos & $\begin{array}{l}\text { - Chaveamento de } \\
\text { equipamentos } \\
\text { eletrônicos de } \\
\text { potência; } \\
\text {-Radiações } \\
\text { eletromagnéticas. }\end{array}$ & $\begin{array}{l}\text { - Distúrbios em equipamentos } \\
\text { eletrônicos (computadores e } \\
\text { controladores programáveis). }\end{array}$ & $\begin{array}{l}\text {-Sistemas estáticos } \\
\text { de compensação } \\
\text { de reativos; } \\
\text { - Capacitores série. }\end{array}$ \\
\hline $\begin{array}{l}\text { Flutuações de } \\
\text { tensão }\end{array}$ & $\begin{array}{l}\text { - Cargas intermitentes; } \\
\text {-Fornos a arco; } \\
\text {-Partida de motores. }\end{array}$ & $\begin{array}{l}\text { - Flicker; } \\
\text { - Oscilações de potência e torque nas } \\
\text { máquinas elétricas; } \\
\text { - Queda de rendimento de } \\
\text { equipamentos eletrônicos; } \\
\text { - Interferência nos sistemas de } \\
\text { proteção. }\end{array}$ & \\
\hline $\begin{array}{c}\text { Variação na } \\
\text { freqüência do } \\
\text { sistema elétrico }\end{array}$ & $\begin{array}{l}\text {-Perdas de geração, } \\
\text { perda de linhas de } \\
\text { transmissão, etc. }\end{array}$ & $\begin{array}{l}\text { Pode causar danos severos nos } \\
\text { geradores e nas palhetas das } \\
\text { turbinas, etc. }\end{array}$ & \\
\hline
\end{tabular}




\section{CAPÍTULO 3}

\section{CINTILAÇÃO LUMINOSA}

Neste capítulo são abordados os tópicos concernentes ao entendimento das cintilações luminosas. Para tanto, inicia-se pelas definições, características e causas dos fenômenos. Em seguida são descritos os métodos de medição mais conhecidos, dando-se ênfase ao método UIE /IEC. Logo após, são apresentadas estratégias e tecnologias que visam a atenuar as tensões flutuantes nos barramentos elétricos de potência. Finalmente, é feita uma síntese das principais normas e recomendações que se manifestam a respeito desse tema.

\section{1 - CONCEITUAÇÃO - FLUTUAÇÃO DE TENSÃO}

\subsection{1 - DEFINIÇÃO E CARACTERÍSTICAS}

Um importante indicador de qualidade de energia elétrica (QEE) suprida aos consumidores é a constância do valor eficaz da tensão de alimentação. Isso porque a maior parte das cargas elétricas são previstas para operarem sob condições de tensão nominal constante. $\mathrm{O}$ desempenho inadequado dessas cargas sob tensão variável pode comprometer desde serviços que utilizam eletrodomésticos até processos industriais mais sofisticados, que requerem padrões mínimos de qualidade para os seus produtos. Na prática, manter a tensão constante ao longo do ciclo diário de cargas, que podem entrar ou sair livremente, se constitui uma condição muito difícil de ser atingida. (DECKMANN, 1999).

No tocante as oscilações de tensão, elas podem ser classificadas conforme a taxa de variação do fenômeno, em lentas e rápidas, e de acordo com a freqüência de ocorrência ou persistência, em isoladas e sistemáticas (MEDEIROS, 2003). 
As variações rápidas e sistemáticas do valor eficaz da tensão em torno de seu valor em regime permanente são conhecidas como flutuações de tensão. Estas estão compreendidas entre 0,9 a 1,1 pu e 0,5 até $35 \mathrm{~Hz}$ e podem ser classificadas em aleatórias e repetitivas, de acordo com o funcionamento do agente causador.

Flutuações aleatórias são aquelas causadas por equipamentos com processo de operação irregular e variante, como fornos a arco elétrico, geradores eólicos e partida de motores de forma indefinida ou não sincronizada. Elas são caracterizadas por ter freqüência, forma de onda e/ou amplitude variáveis.

Já flutuações repetitivas são ocasionadas por equipamentos com processo de operação regular. Têm por características variações cíclicas de tensão e seus principais responsáveis são os laminadores metálicos, elevadores de minas, máquinas de solda a resistência e a maioria das cargas ou processos controlados por computador (MEDEIROS, 2003).

A seguir é apresentada a classificação das tensões flutuantes.

Tipo A:

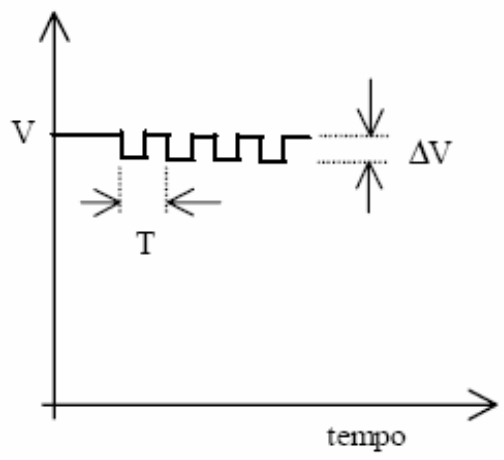

Tipo C:

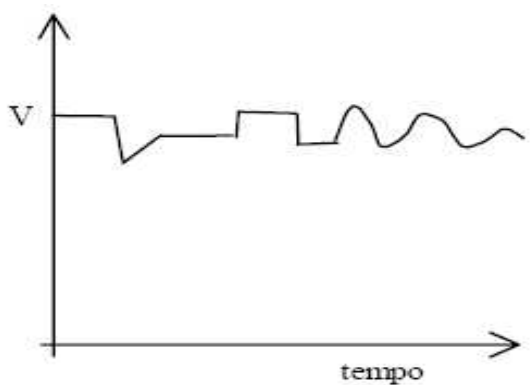

Tipo B:

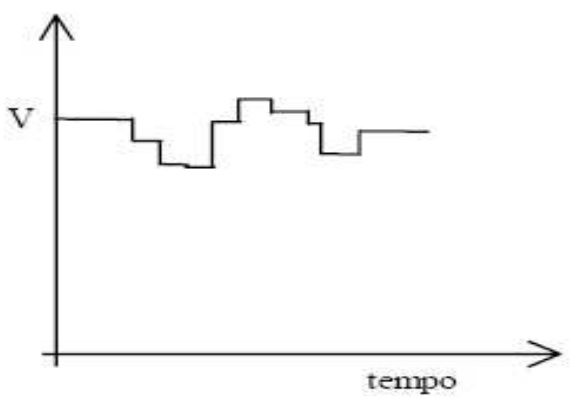

Tipo D:

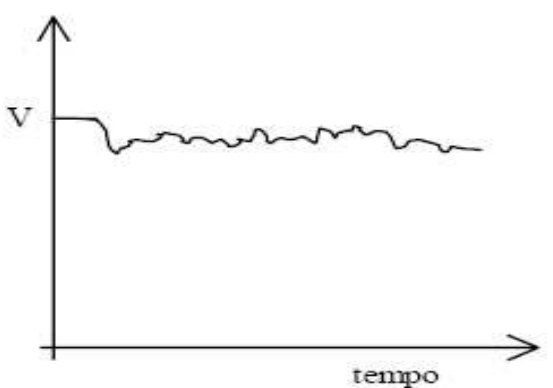

Figura 3.1 - Tipos de flutuações de tensão. 
Flutuações do tipo A são variações retangulares e periódicas em torno de um nível de tensão de referência, com amplitude constante. Este é o tipo padrão utilizado para calibração de medidores de flicker. São provocadas, por exemplo, por máquinas de solda a resistência e pelo chaveamento de múltiplas cargas.

O tipo B de flutuação é composto por uma série irregular de variações bruscas. Possui forma retangular, porém sua amplitude máxima pode ou não ser determinada. Elas são causadas pela entrada e saída de cargas por etapas, como elevadores, laminadores e prensas.

As flutuações enquadradas no tipo $\mathbf{C}$ correspondem a uma série de variações de tensão, sem forma ou período definido, podendo ser brusca (retangular), rampa (triangular) ou oscilatória (senoidal). Este caso permite combinar diferentes cargas tais como motores, prensas, compressores, bombas, etc.

As flutuações do tipo D são compostas por variações continuas e aleatórias. Típicas da utilização de fornos a arco elétrico. Devido a grande capacidade dos fornos, até $120 \mathrm{MW}$, o impacto destas flutuações pode alcançar o sistema de transmissão.

\subsection{2 - CÁlCULO DAS FLUTUAÇÕES DE TENSÃo}

A fim de elucidar como as flutuações de tensão são geradas pelas cargas variáveis, apresenta-se nesta seção duas metodologias utilizadas para cálculo das flutuações em um determinado ponto do sistema elétrico.

\subsubsection{1 - CIRCUITO EQUIVALENTE DE THÉVENIN}

A primeira metodologia baseia-se na obtenção do circuito equivalente de Thévenin do sistema de suprimento, visto do ponto de acoplamento comum (PAC), conforme ilustrado na figura 3.2. 


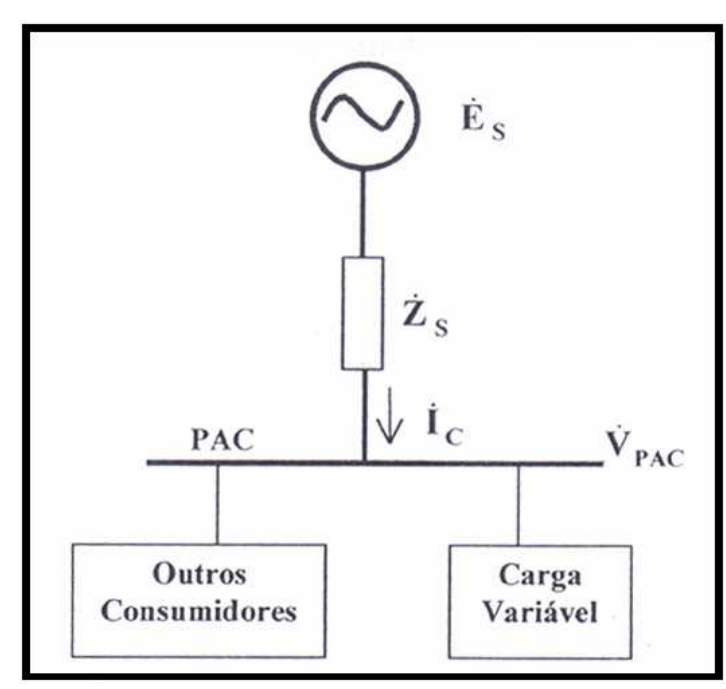

Figura 3.2 - Equivalente de Thévenin do sistema de suprimento.

A partir da figura 3.2 tem-se:

$\dot{E}_{s}-$ Tensão de suprimento;

$\dot{Z}_{s}$ - Impedância equivalente do sistema de suprimento;

$\dot{I}_{c}-$ Corrente de carga;

$\dot{V}_{P A C}-$ Tensão no PAC.

Representando a corrente por $\dot{I}_{c}=I \angle-\varphi$, tem-se o seguinte diagrama fasorial:

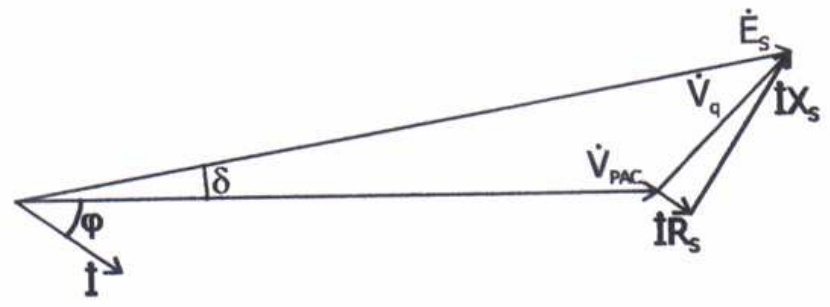

Figura 3.3 - Diagrama fasorial.

A queda de tensão na impedância do sistema será dada por: 


$$
\begin{aligned}
& \dot{V}_{q}=\dot{E}_{s}-\dot{V}_{P A C}= \\
& \left(R_{s}+j X_{s}\right)(I \cos \varphi-j I \operatorname{sen} \varphi) \Rightarrow \\
& \dot{V}_{q}=R_{s} I \cos \varphi+X_{s} I \operatorname{sen} \varphi+j\left(-R_{s} I \operatorname{sen} \varphi+X_{s} I \cos \varphi\right)
\end{aligned}
$$

Considerando o fasor $\dot{E}_{s}$ igual a sua projeção no eixo horizontal temos:

$$
\dot{V}_{q}=\dot{E}_{s}-\dot{V}_{P A C} \cong R_{s} I \cos \varphi+X_{s} I \operatorname{sen} \varphi
$$

Admitindo-se a tensão do sistema $\dot{E}_{s}$ fixa, as variações de queda de tensão na impedância do sistema, causadas pelas variações de corrente da carga variável, implicam em variações no PAC, ou seja,

$$
\Delta V_{P A C}=\Delta V_{q} \cong R_{s} \Delta(I \cos \varphi)+X_{s} \Delta(I \operatorname{sen} \varphi)
$$

Desconsiderando os efeitos das variações de tensão nas correntes, e ainda pequenas variações da tensão no PAC, pode-se escrever:

$$
\Delta(I \cos \varphi)=\frac{\Delta P}{\Delta V_{P A C}} ; \Delta(I \operatorname{sen} \varphi)=\frac{\Delta Q}{\Delta V_{P A C}}
$$

Onde:

$\Delta P$ - Variação de potência ativa solicitada pela carga;

$\Delta Q$ - Variação de potência reativa solicitada pela carga.

Assim, a resultante das equações (3.3) e (3.4) será:

$$
\frac{\Delta V_{P A C}}{V_{P A C}} \cong \frac{R_{s} \Delta P+X_{s} \Delta Q}{V_{P A C}^{2}}
$$

Para pequenas variações em torno de $V_{P A C}=1 p . u$, tem-se: 


$$
\Delta V_{P A C} \cong R_{s} \cdot \Delta P+X_{s} \cdot \Delta Q
$$

Usualmente, em médias e altas tensões temos sistemas com impedância predominantemente reativa (Xs $>$ Rs). E considerando ainda que as variações de potência da carga sejam principalmente reativas, obtêm-se:

$$
R_{s} \cdot \Delta P<X_{s} \cdot \Delta Q
$$

Logo:

$$
\Delta V_{P A C} \cong X_{s} \cdot \Delta Q
$$

A partir da expressão (3.8) pode-se concluir que a flutuação de tensão é causada principalmente pela variação da potencia reativa da carga (PONTES, 2000).

\subsubsection{2 - NÍVEL DE CURTO-CIRCUITO}

Uma segunda forma de se analisar a flutuação de tensão, baseia-se no nível de curtocircuito do ponto de acoplamento comum.

A potência de curto-circuito pode ser calculada através da expressão:

$$
S_{c c}=\dot{E}_{s} \cdot \dot{I}_{c c}^{*}=\frac{\dot{E}_{s}^{2}}{R_{s}-j X_{s}}
$$

Onde:

$S_{c c}$ - Potência de curto circuito no PAC;

$\dot{I}_{c c}^{*}$ - Conjugado da corrente de curto-circuito no PAC. 
Para um sistema predominantemente reativo temos:

$$
\left|S_{c c}\right| \cong \frac{E_{s}^{2}}{X_{s}}
$$

Substituindo a equação (3.10) na (3.8) e considerando $E_{s}=1 p . u$, encontra-se:

$$
\Delta V_{P A C} \cong \frac{\Delta Q}{\left|S_{c c}\right|}
$$

De acordo com a equação (3.11), conclui-se que as flutuações de tensão no PAC serão tão menores quanto maior for o nível de curto-circuito do sistema e/ou menores forem as variações de potência. Sendo assim, o fortalecimento do sistema supridor e por si só uma técnica de atenuação das flutuações de tensão produzidas por cargas variáveis.

\subsection{3 - FATORES QUE INFLUENCIAM AS FLUTUAÇÕES DE TENSÃO}

A relação de curto-circuito $(\mathbf{R} c)$, definida como a razão entre a potência de curtocircuito (Scc), disponível no local onde a carga geradora do distúrbio está ligada, e a potência nominal da carga (Sc), influencia o aparecimento de flutuações de tensão, visto que, via de regra, casos onde a $R_{c c} \geq 50$, não há problemas de oscilação no sistema elétrico. Todavia, para relações de curto-circuito menores que 50, os problemas de curtocircuito são bastante prováveis. A figura 3.4 ilustra esta relação e a possibilidade de ocorrência do efeito de cintilação luminosa.

$$
R_{c c}=\frac{S_{c c}}{S_{c}}
$$




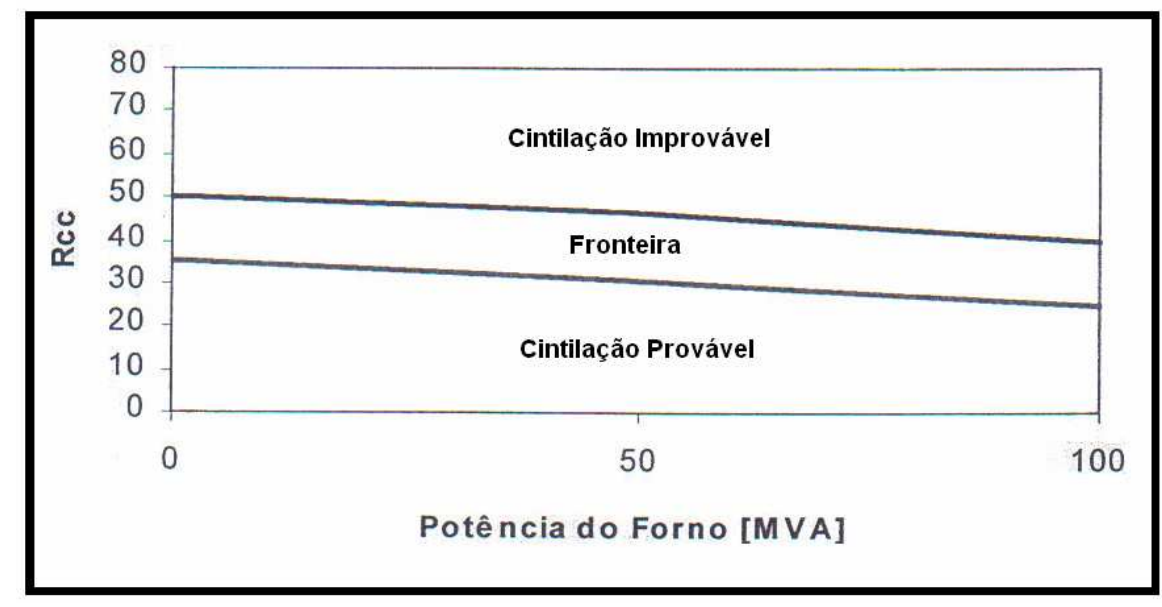

Figura 3.4 - Condição de emissão de cintilação luminosa.

A taxa de variação de corrente $(d i / d t)$ é também um fator determinante na queda de tensão em indutâncias série das redes elétricas, sendo, portanto, responsável pela amplitude das flutuações de tensão. Essa variável assume extrema importância no uso de conversores eletrônicos, uma vez que estes operam através do chaveamento de corrente.

A freqüência das variações de tensão define o tipo de fenômeno que pode ser excitado. Flutuações na faixa de 0,2 a $2 \mathrm{~Hz}$, podem provocar oscilações eletromecânicas. No intervalo até $25 \mathrm{~Hz}$ o fenômeno cintilação luminosa pode ser excitado. $\mathrm{Na}$ faixa compreendida entre 15 e $30 \mathrm{~Hz}$ modos de ressonância subsíncrona podem ser estimulados. Dentre os efeitos supracitados, o mais comum é o da cintilação, uma vez que pode ser observado em lâmpadas incandescentes para variações da amplitude da tensão de apenas $0,3 \%$ na faixa de maior sensibilidade visual, que ocorre em torno de $10 \mathrm{~Hz}$.

\section{2 - PRINCIPAIS CARGAS PERTURBADORAS}

\subsection{1 - FORNOS A ARCO ELÉTRICO (FAES)}

O FAE é um equipamento largamente utilizado nas instalações industriais, destinando-se a fusão do ferro, aço e outras ligas metálicas, através das propriedades do arco elétrico. 
No âmbito da qualidade de energia, os FAEs são as mais problemáticas cargas do sistema elétrico de potência, devido as suas características fortemente não-lineares e assimétricas e ao elevado montante de energia reativa requerida por eles, a qual é, ainda, variante no tempo.

A grande instabilidade elétrica dos FAEs causam diversas perturbações no PAC, tais como: flutuações de tensão, tensões e correntes harmônicas e interharmônicas, desequilíbrio e sobretensões transitórias.

Há três tipos básicos de FAE existentes. São eles o forno a arco direto, a arco-resistência e a arco indireto. A figura 3.5 apresenta os arranjos típicos para tais variações deste equipamento.

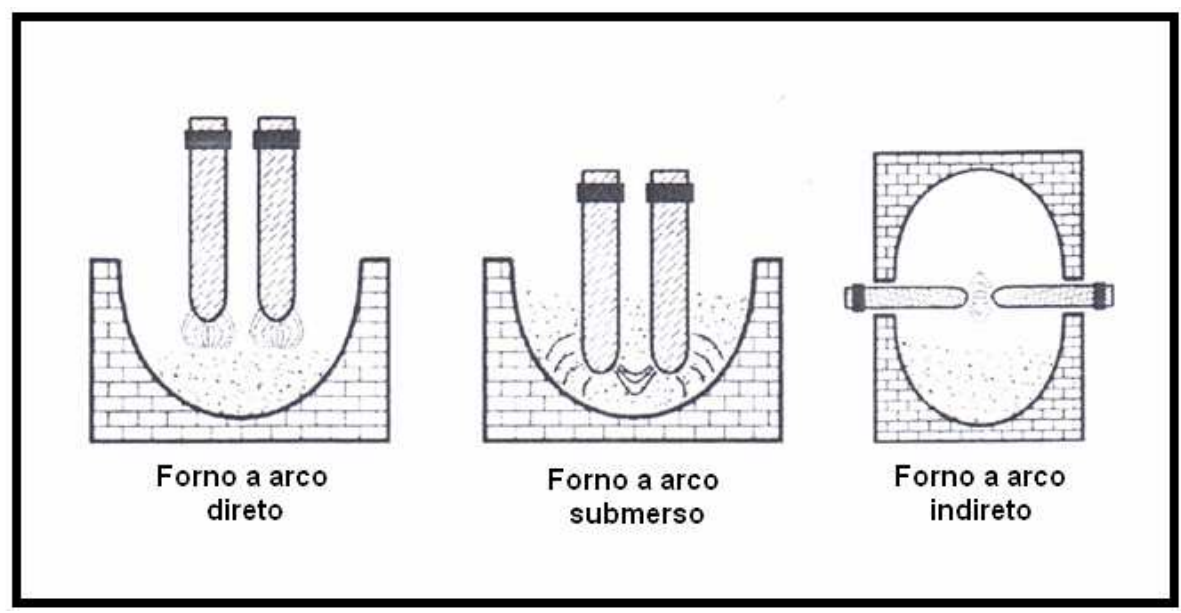

Figura 3.5 - Tipos de fornos a arco elétrico.

Fornos a arco direto são empregados na fusão de minérios de ferro ou sucatas para a produção de lingotes de aço. Possuem uma carcaça cilíndrica com um fundo abaulado e uma tampa, os quais são revestidos internamente com tijolos refratários. Tal estrutura é apoiada sobre um suporte de ferro e resfriada por circulação de água. É dotado de eletrodos de grafite, posicionados verticalmente acima do material a ser fundido, motivo pelo qual são também conhecidos por forno a arco descoberto. 
Os fornos a arco-resistência são também conhecidos por forno a arco submerso, devido ao fato do arco ocorrer sob a carga de material a ser fundido, e por fornos de redução, por fazerem uso de reações químicas de mesmo nome.

Este tipo de equipamento é usado para a produção de ligas de ferro, tais como ferro-silício, ferro-cromo, ferro-manganês, etc.

É trifásico, com eletrodos de carvão amorfo ou do tipo auto-cozimento, dispostos em forma de um triangulo eqüilátero.

Por último, os fornos a arco indireto apresentam pequenas dimensões e são utilizados para a fusão de metais não ferrosos ou de pequenas quantidades de gusa ou aço. São encontrados em menor escala, se comparado aos supracitados. Seus eletrodos estão posicionados horizontalmente acima da carga e o calor é transmitido por irradiação direta do arco ou indireta devido às reflexões nas paredes.

\subsection{2 - MÁQUINAS ELÉTRICAS DE SOLDA}

Soldar consisti em unir duas ou mais peças metálicas empregando a transformação controlada de energia elétrica em calor. A soldagem a arco elétrico e a resistência destacam-se como métodos mais comuns.

A soldagem a arco baseia-se no uso do calor produzido pelo arco, que se estabelece entre um eletrodo apropriado e o elemento a ser soldado. Seu uso pode provocar flutuações de tensão no barramento alimentador e nas circunvizinhanças.

Já a soldagem a resistência é levada a efeito pela circulação de elevadas correntes em baixas tensões, por meio da resistência de contanto formada pelas superfícies das peças que serão unidas. O calor dissipado provoca a fusão dos elementos metálicos. Neste processo é experimentado um curto intervalo de carga pesada, seguido por operação sem carga, produzindo variações de tensão em degraus, correspondentes a entrada e saída da corrente de alimentação. Ocorre, ainda, um largo consumo de energia reativa, o que favorece o surgimento de flutuações nas cercanias destas máquinas. 
A qualidade da solda de uma junta é determinada, entre outros fatores, pela manutenção do controle de calor, corrente constante. Portanto, a ocorrência de variações da tensão de suprimento pode provocar falha durante o processo de soldagem. Este fato é muito provável de ocorrer quando várias máquinas de solda operam fora de sincronismo (PONTES, 2000).

\subsection{3 - LAMINADORES METÁLICOS}

Os laminadores têm por função transformar lingotes metálicos em placas, chapas ou bobinas. Estes dispositivos são geralmente formados por grandes motores de corrente contínua alimentados por conversores $\mathrm{CA} / \mathrm{CC}$, podendo também ser acionados por motores síncronos, de indução com velocidade constante ou ajustável, de acordo com a potência requerida. Potência esta dependente do tipo, volume e temperatura do material a ser laminado. Sua operação é caracterizada por uma movimentação do trem de laminação e o desbaste da peça a ser laminada, com tempos de processos definidos e regulares.

A solicitação de potências ativa e reativa variáveis por parte deste tipo de equipamento leva a grande variações de corrente elétrica que acarretam flutuações de tensão. Além disso, o uso de retificadores tiristorizados para o acionamento dos motores CC produz correntes harmônicas características e não características na rede CA (MEDEIROS, 2003).

\subsection{4 - PARTIDA DE MOTORES}

Motores elétricos, no momento da partida, solicitam do sistema supridor uma elevada corrente, várias vezes maior que aquela de regime permanente. Esta alta exigência transitória pode ocasionar flutuações de tensão. Todavia, isto irá ocorrer quando a partida for feita de forma intermitente e aleatória, tal como em elevadores, guindastes, bombas e refrigeradores.

O fortalecimento do barramento de alimentação é uma das maneiras existentes de se prevenir ou atenuar os impactos causados pela alta corrente transitória. A partida indireta através de autotransformador, chave estrela - triângulo ou conversor de frequiência também trabalha para reduzir os problemas oriundos do acionamento de motores elétricos. 


\subsection{5 - CARGAS RESIDENCIAIS E COMERCIAIS}

Cargas elétricas de pequena potência podem também gerar o efeito da cintilação luminosa, a partir do momento que trabalhem com repetidos chaveamentos ou outras formas periódicas de variação da potência.

Instalações residenciais e comerciais sofrem comumente com oscilações luminosas quando da energização de chuveiros, geladeiras, aparelhos de ar-condicionado, ferramentas portáteis, etc. Entretanto, devido à baixa potência destes equipamentos, as oscilações ficam restritas ao local. Consumidores com baixo nível de curto-circuito são mais suscetíveis ao fenômeno.

\subsection{6 - OUTRAS CARGAS}

Outras cargas mais específicas podem também gerar flutuação. Como exemplo pode-se citar as ferrovias elétricas, os aceleradores de partículas, entrada de bancos de capacitores, aparelhos de raios-X, tomógrafos, aparelhos de ressonância nuclear magnética, aplicações com robôs, entre outros. Que por sua especificidade não serão detalhadas neste trabalho.

\section{3 - CINTILAÇÃO LUMINOSA}

\subsection{1 - DEFINIÇÃO}

A variação do fluxo luminoso emitido por uma lâmpada sob o efeito de tensões flutuantes é definida como cintilação luminosa ou "flicker". A intensidade deste efeito pode variar desde uma simples percepção a uma situação de incômodo, desconforto ou irritação visual. Ligado a isto, há um outro aspecto da cintilação luminosa, que é a perturbação de natureza psicológica, a qual pode ser agravada pela repetição do processo, uma vez que o cérebro relembra uma variação luminosa anterior e relaciona com a seguinte. Ademais, níveis fortes de cintilação podem prejudicar em especial pessoas propensas à epilepsia (MEDEIROS, 2003). 
A cintilação luminosa esta diretamente relacionada com a sensibilidade e reação de cada pessoa. Este fenômeno é um estudo com base em resultados de experimentos baseados na fisiologia humana, os quais tratam o conjunto lâmpada/olho/cérebro como um sistema neurofisiológico complexo e não-linear. A intensidade da perturbação causada pela cintilação luminosa depende principalmente da amplitude, da freqüência e do tempo de exposição às flutuações (PONTES, 2000).

Os fatores mais relevantes que determinam à cintilação luminosa serão expostos, de forma resumida, a seguir.

A amplitude das variações de tensão se reflete diretamente sobre a intensidade das oscilações luminosas. Todavia, a sensibilidade do olho humano depende da freqüência da oscilação luminosa, a qual é dependente da frequiência das flutuações de tensão. As lâmpadas possuem duas propriedades sujeitas à freqüência das variações de tensão, sendo elas a inércia térmica e o fator de ganho, que exprime a razão entre a variação luminosa relativa e a variação da tensão relativa. A cintilação é observada até determinadas frequiências, a partir das quais, a fusão de imagens se faz possível. O limite superior levando em conta a constante de tempo das lâmpadas incandescentes é de aproximadamente $35 \mathrm{~Hz}$ para variações de tensão menores que 10\%. Oscilações luminosas provocadas por flutuações de tensão da ordem de $0,3 \%$ em torno de $9 \mathrm{~Hz}$, já são capazes de provocar irritação. É certo que variações de tensão abruptas implicam em transições mais bruscas do nível de luminosidade e causam um maior incomodo visual que as mais suaves.

A cintilação afeta os indivíduos de maneira diferente. Por esta razão, a avaliação é feita levando em conta a percepção média testada em várias pessoas. Observou-se ainda que em ambientes pouco iluminados o efeito da cintilação é mais perceptível. Do ponto de vista fisiológico, mesmo quando infreqüentes, a persistência dos estímulos visuais pode levar a uma sensação de desconforto devido à capacidade de memorização do cérebro. Esta sensação depende do tempo decorrido entre flutuações subseqüentes e da intensidade das mesmas. 
Da observação sistemática de grande número de indivíduos, chegaram-se as curvas de distúrbios causados pela tensão de alimentação de uma lâmpada incandescente em função da amplitude e freqüência de variação da mesma. Essas curvas estão expostas na figura 3.6.

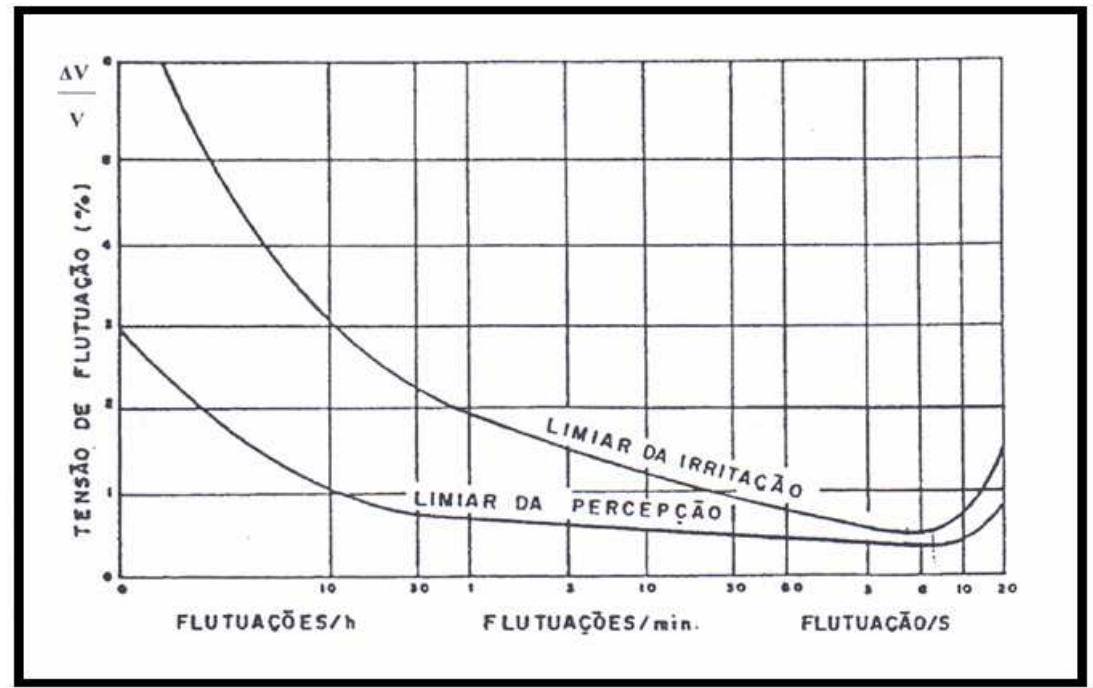

Figura 3.6 - Curvas de visibilidade e irritação do olho humano devido às flutuações de tensão sobre lâmpadas incandescentes (PONTES, 2000).

\subsection{2 - SENSIBILIDADE DE DIVERSOS TIPOS DE LÂMPADAS AS FLUTUAÇÕES DE TENSÃO}

As lâmpadas incandescentes quando submetidas a flutuações de tensão, amplificam as oscilações da luz emitida por elas. Tal amplificação recebe o nome de fator de ganho e é definido como a relação entre as variações de fluxo luminoso e de tensão.

O ensaio realizado para calcular o fator de ganho de uma lâmpada consiste em colocá-la no interior de uma câmara escura, para em seguida, através do controle da amplitude e freqüência das flutuações da tensão de alimentação do dispositivo, medir o fluxo luminoso emitido por esta, utilizando-se um fotômetro calibrado para simular o olho humano. Em posse destes valores, a variação da luz emitida é calculada através da equação (3.13).

$$
\Delta R I=R I_{\max }-R I_{\min }
$$


Onde:

$\Delta R I$ - Variação do fluxo luminoso emitido pela lâmpada sob ensaio;

$R I_{\max }$ - Fluxo luminoso máximo emitido pela lâmpada sob ensaio;

$R I_{\text {min }}$ - Fluxo luminoso mínimo emitido pela lâmpada sob ensaio.

Em seguida, calcula-se a variação da tensão através da equação (3.14).

$$
\Delta V=V_{R M S \max }-V_{R M S \min }
$$

Onde:
$\Delta V$ - Amplitude da modulação da tensão;
$V_{R M S \max }$ - Amplitude máxima da modulação da tensão;
$V_{R M S \min }$ - Amplitude mínima da modulação da tensão.

Para finalizar, faz-se uso das grandezas calculadas por meio das equações (3.13) e (3.14) e determina-se o fator de ganho.

$$
F G=\frac{\Delta R I \%}{\Delta V \%}
$$

Caso a variação relativa do fluxo luminoso seja maior que a variação percentual da flutuação de tensão, diz-se que a lâmpada tem um efeito ampliador da cintilação luminosa.

Nas lâmpadas incandescentes o fator de ganho diminui com o aumento da frequiência devido à inércia térmica do filamento. Por possuir um filamento mais fino, a lâmpada de $230 \mathrm{~V}$ tem um fator de ganho maior que o de uma lâmpada de $120 \mathrm{~V}$. Por este motivo, quão maior for a tensão nominal, maior será o nível de cintilação. 
As lâmpadas fluorescentes apresentam fator de ganho praticamente constante e inferior à unidade, o que faz com que elas apresentem o efeito cintilação luminosa de forma quase imperceptível.

A figura 3.7 ilustra a variação do fator de ganho em função da frequiência, de uma lâmpada incandescente e uma fluorescente com reator eletrônico.

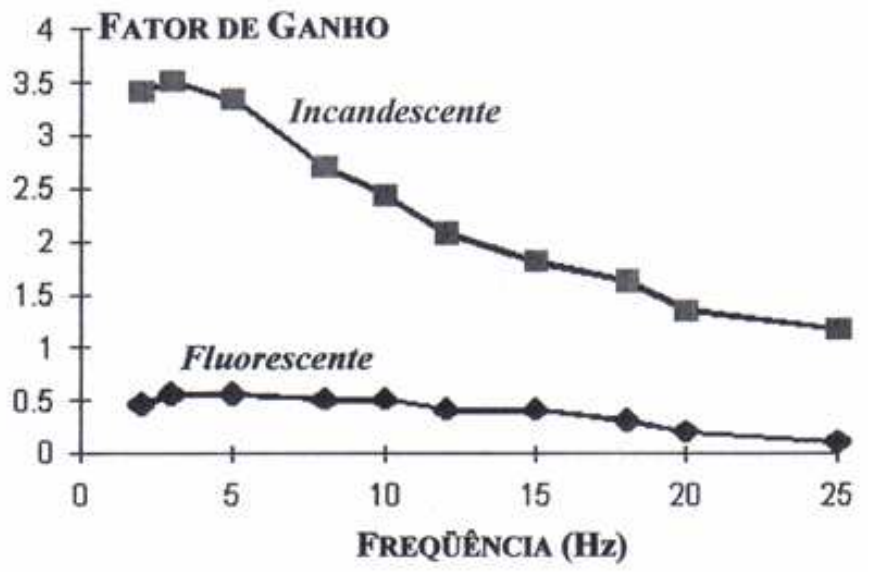

Figura 3.7 - Fator de ganho de lâmpadas incandescentes e fluorescentes (MEDEIROS, 2003).

\section{4 - MEDIÇÃO DA CINTILAÇÃO LUMINOSA}

A quantificação do efeito cintilação provocado pelas flutuações de tensão tem sido objeto de estudo de longa data. Uma das primeiras constatações foi a de que os sistemas de corrente alternada usados para a iluminação publica não poderiam operar com menos do que $35 \mathrm{~Hz}$, pois nessa faixa de freqüência as variações de emissão luminosa das lâmpadas incandescente eram perceptíveis (DECKMANN, 1999).

Devido a não-linearidades e fatores subjetivos envolvidos na conversão de variações de tensão em percepção das variações luminosas, o processo de avaliação do fenômeno seguiu diferentes caminhos e metodologias de análises em países como Inglaterra, França, Alemanha, EUA, Japão, etc.

Os principais métodos formulados são o britânico, o francês e o padrão. Estes possuem filosofias distintas, porém, alguns fundamentos comuns podem ser destacados: 
- A lâmpada incandescente é adotada como referência para a quantificação do efeito de cintilação luminosa;

- Os procedimentos se baseiam no principio de modulação de sinais;

- Os métodos britânico e padrão empregam tratamento estatístico, considerando o caráter aleatório das flutuações de tensão;

- Os métodos francês e padrão levam em consideração as freqüências existentes em um sinal modulante do sinal fundamental, as quais podem causar maior ou menor incomodo visual, de acordo com a distância relativa a sensibilidade em freqüência critica do olho humano.

Dado o fato do método padrão, aceito internacionalmente hoje, ter por base alguns dos preceitos oriundos das antigas metodologias de avaliação, estas serão apresentadas de forma resumida no transcorrer desse trabalho.

\subsection{1 - MÉTODO BRITÂNICO}

De acordo com este método mede-se o valor RMS da tensão de flutuação $V f$ (sinal modulante) na faixa de 0.5 a $27 \mathrm{~Hz}$, obtido após demodulação através de um filtro RC com constante de tempo de $100 \mathrm{~ms}$ para obter valores médios por minuto. A partir do histograma de valores médios por minuto se construía a função de probabilidade cumulativa para determinar o nível de flutuações violado em 1\% do tempo. A figura 3.8 apresenta uma curva da função probabilidade cumulativa para um forno a arco elétrico. 


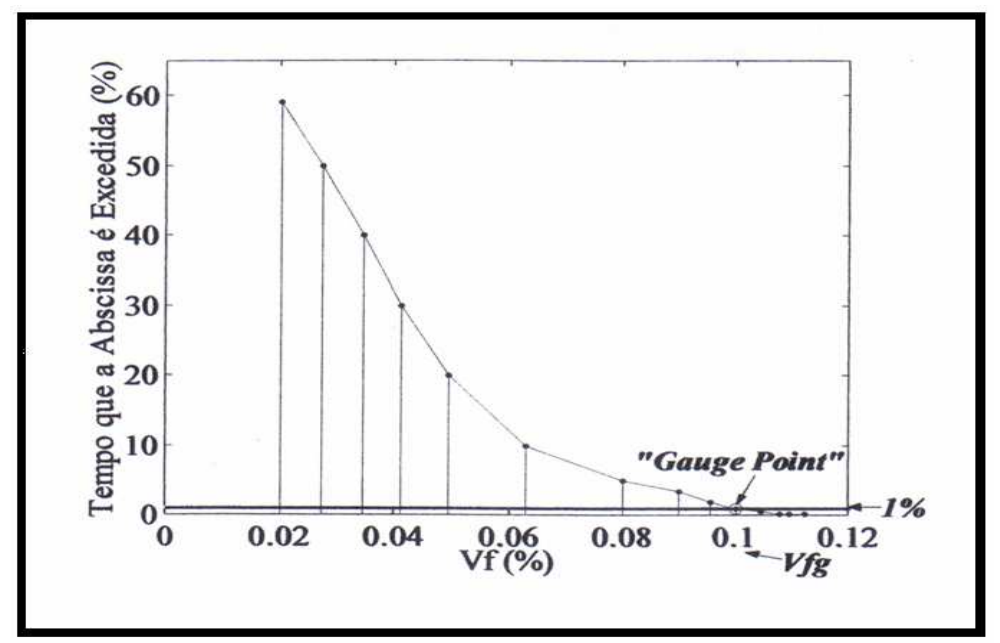

Figura 3.8 - Curva FPCC típica para um forno a arco elétrico.

Esse valor era designado como ponto de teste ( $V f g$, gauge point voltage). O valor limite era definido como sendo:

Tabela 3.1 - Limites do método britânico.

\begin{tabular}{|c|c|}
\hline Nível de tensão & Limite \\
\hline Menor ou igual a $138 \mathrm{kV}$ & $V f g=0,25 \%$ \\
\hline Maior que $138 \mathrm{kV}$ & $V f g=0,20 \%$ \\
\hline
\end{tabular}

A principal crítica atribuída a este método é a de não considerar a sensibilidade visual para caracterizar a cintilação luminosa e, portanto se aplicar apenas a instalações com fornos a $\operatorname{arco.}$

\subsection{2 - MÉTODO FRANCÊS OU MÉTODO DAS DOSES}

O método francês tem como pilar uma série de experiências, nas quais pessoas praticavam a atividade de leitura sob um sistema de iluminação composto por lâmpadas incandescentes, alimentadas por tensão variada em amplitude com freqüências de 0,1 a 25 Hz. Os resultados alcançados a partir deste ensaio podem ser resumidos em:

- O incômodo sentido por um observador médio é função do quadrado da amplitude da flutuação de tensão e de sua duração; 
- Para uma determinada amplitude, o maior incômodo é sentido na freqüência de variação próxima a $10 \mathrm{~Hz}$ com o limiar de tolerância da variação de tensão igual a $0,3 \%$;

- A superposição de varias freqüências e suas amplitudes, ponderadas convenientemente, conduz a mesma sensação de incômodo na flutuação senoidal em $10 \mathrm{~Hz}$.

Com base nestas considerações, este método fornece a equivalência de qualquer componente de freqüência entre 0,5 e $25 \mathrm{~Hz}$ para a freqüência de $10 \mathrm{~Hz}$. Para isso, é empregada a curva de ponderação em freqüência, normalizada em $10 \mathrm{~Hz}$, ilustrada na figura 3.9.

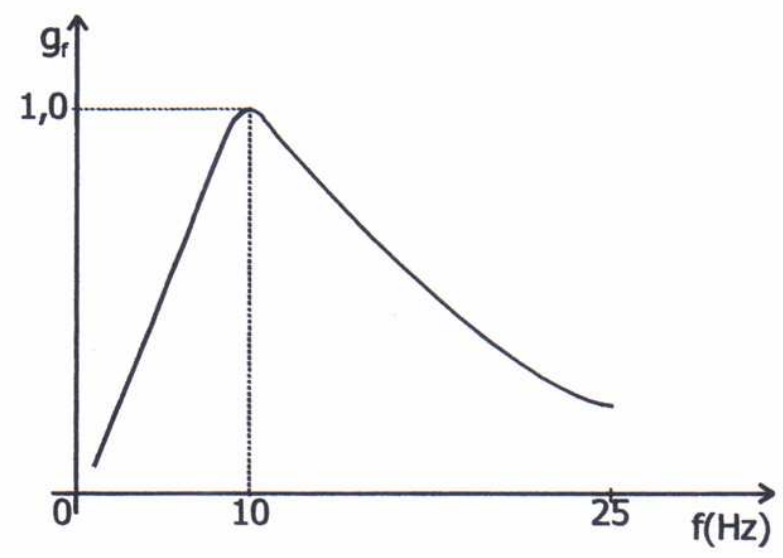

Figura 3.9 - Curva de ponderação em freqüência ou de sensibilidade visual.

A amplitude equivalente para a frequiência de máxima sensibilidade é dada por:

$$
a_{10}=\sqrt{\sum_{k=0,5}^{25} a_{k}^{2} \cdot g f_{k}^{2}}
$$

Onde:

$a_{k}$ - amplitude da componente da flutuação de tensão na freqüência $f_{k}$;

$g f_{k}$ - coeficiente de ponderação associado à $f_{k}$ obtido da curva de sensibilidade visual. 
O efeito acumulado da cintilação luminosa é definido como:

$$
D u_{i}=\int_{0}^{1 \min } a_{10}^{2} d t
$$

Onde:

$D u_{i}$ - dose unitária.

Para determinar os limites aceitáveis pelo método francês, tem-se que a percepção visual equivalente a uma dose unitária, tem como limiar de tolerância $\Delta V \%=0,3 \%$. Esse valor convertido em unidades de cintilação equivale a $0,09(\%)^{2} \cdot \min$. Para a aceitabilidade de uma instalação devido ao nível de cintilação produzido, recomenda-se analisar o comportamento das doses unitárias por um período de 15 minutos consecutivos. Assim, o limite para aceitação será:

$$
G(t)=\sum_{i=1}^{15} D u_{i} \leq 15 \cdot 0,09=1,35(\%)^{2} \cdot \min
$$

A tabela 3.2 resume os limites aceitáveis para avaliar-se a cintilação luminosa segundo a metodologia francesa.

Tabela 3.2 - Limites aceitáveis do método francês.

\begin{tabular}{|c|c|}
\hline \multicolumn{2}{|c|}{ Limites de tolerância } \\
\hline Dose unitária (1 minuto): & Dose acumulada (15 minutos): \\
$\leq 0,09(\%)^{2} \cdot \min$ & $\leq 1,35(\%)^{2} \cdot \mathrm{min}$ \\
\hline
\end{tabular}

Vale ressaltar que a ponderação das flutuações pela curva de sensibilidade visual foi incorporada pela metodologia padrão. 
A crítica mais relevante feita ao método é que o mesmo dilui as variações rápidas e de grande intensidade ao realizar a integração durante um minuto.

\subsection{3 - MÉTODO PADRÃO OU INTERNACIONAL}

Em julho de 1982 foi publicado pela União Internacional de Eletrotermia - UIE um estudo intitulado "UIE Flickermeter - functional and design specifications". Era a primeira vez que se propunha o que mais tarde passou a se constituir na metodologia recomendada internacionalmente pela IEC - Internacional Electrotechnical Commission. Anterior a isso, os métodos descritos acima eram utilizados.

O método padrão agregou características dos métodos pregressos, investigações teóricas e experiências em campo e teve como princípio simular o processo de conversão das flutuações de tensão em variações luminosas, associadas à percepção visual humana simulando, portanto, o sistema lâmpada/olho/cérebro. Fundamentando-se pois nestas premissas e levando-se em conta o comportamento aleatório e o grau de persistência do fenômeno, cientistas, engenheiros e oftalmologistas participaram dos trabalhos de elaboração do medidor de cintilação UIE/IEC.

\subsubsection{1 - O MEDIDOR DE CINTILAÇÃO LUMINOSA UIE/IEC}

A metodologia internacional UIE/IEC realiza a avaliação da cintilação luminosa a partir das flutuações de tensão da rede fazendo uso do medidor de flicker mostrado na figura 3.9. Tal equipamento é capaz de avaliar o mal estar causado a um observador humano submetido às variações do fluxo luminoso.

O medidor de cintilação luminosa é composto por cinco estágios, a saber:

- Estágio 1 - adaptação da tensão de entrada;

- Estágio 2 - demodulação do sinal adaptado;

- Estágio 3 - ponderação em frequiência;

- Estágio 4 - média quadrática;

- Estágio 5 - tratamento estatístico. 


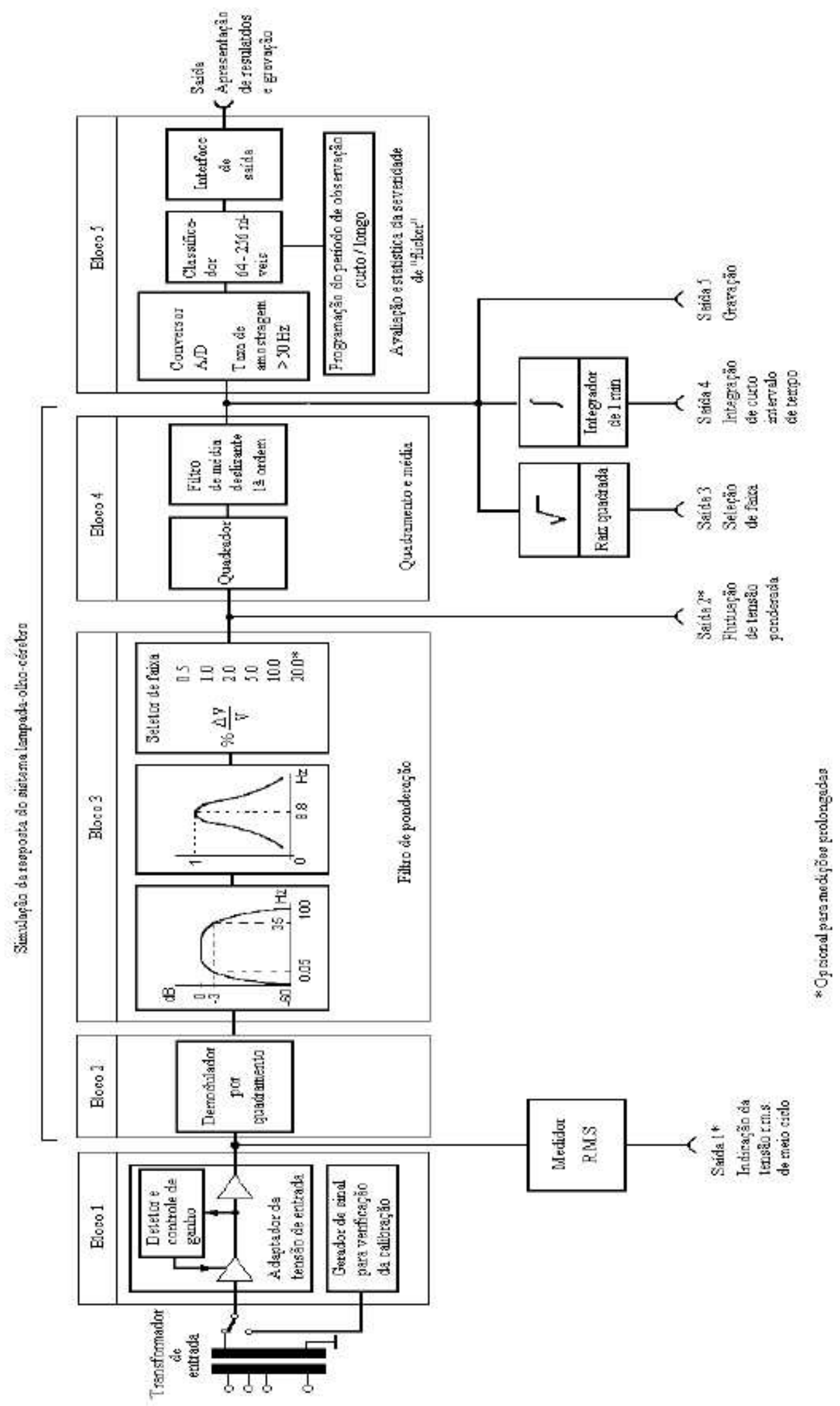

Figura 3.10 - Diagrama de bloco do medidor de cintilação luminosa UIE/IEC. 


\section{Estágio 1 - Adaptação da tensão de entrada}

Diferentes níveis padronizados de alimentação são utilizados no sistema supridor de baixa tensão. Por isso, faz-se necessária a presença deste primeiro estágio, o qual normaliza as variações de tensão, expressando-as em termos percentuais da tensão de referência. Isso permite entre outras vantagens, comparar diretamente os efeitos das mesmas variações relativas, observadas em diferentes níveis de tensão.

O circuito adaptador de tensão tem por finalidade, normalizar a tensão de entrada pelo valor da média móvel do último minuto. Isto significa que variações lentas, com tempo de acomodação maior que um minuto, não contribuem para o cálculo da cintilação. Variações mais rápidas são expressas em termos percentuais da tensão da referência móvel:

$$
\Delta V \%=\frac{V-V_{r e f}}{V_{r e f}} \cdot 100 \%
$$

Onde

$V$ - tensão atual da rede;

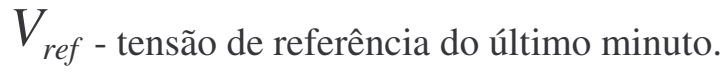

\section{Estágio 2 - Demodulação do sinal adaptado}

Depois de normalizado pela referência móvel, o sinal de tensão é demodulado para extrair o sinal modulante, responsável pelas flutuações da tensão. Uma vez que não se trata efetivamente de uma modulação perfeita, devido à assimetria das variações dos ciclos positivos e negativos da onda portadora de 50/60 Hz, sugere-se que a demodulação seja realizada através de quadramento do sinal, pois este processo de conversão simula a forma como são produzidas as variações do fluxo luminoso emitido pelas lâmpadas incandescentes, sujeitas às flutuações da tensão. Para ilustrar o processo de demodulação, considere-se uma onda modulada senoidalmente, representada pela função: 


$$
v(t)=V_{p} \cdot \cos \left(\omega_{p} t\right)\left[1+m \cdot \cos \left(\omega_{m} t\right)\right]
$$

Onde

$V_{p}$ - tensão de pico da portadora sem modulação;

$\omega_{p}$ - frequiência da portadora;

$\omega_{m}$ - freqüiencia da modulante;

$m$ - índice de modulação.

Ao se tomar o quadrado do sinal modulado resulta:

$$
v^{2}(t)=\frac{V_{p}^{2}}{2}\left(1+\cos \left(2 \omega_{p} t\right)\left[1+2 m \cos \left(\omega_{m} t\right)+m^{2} \cos ^{2}\left(\omega_{m} t\right)\right]\right.
$$

Onde

$\frac{V_{p}^{2}}{2}-$ nível CC;

$\frac{V_{p}^{2}}{2} \cos \left(2 \omega_{p} t\right)$ - componente de dupla frequiência da portadora;

$2 m \frac{V_{p}^{2}}{2}\left(\cos \omega_{m} t\right)-$ termo modulante.

sendo que os demais termos tornam-se desprezíveis para níveis de modulação abaixo de 3\%. Eliminando-se o nível médio e a dupla freqüência da portadora através de filtragem, realizada no terceiro estágio do medidor, resulta como sinal filtrado a parcela:

$$
v_{f}^{2}(t)=m V_{p}^{2} \cos \left(\omega_{m} t\right)
$$

Que pode ser normalizado pela amplitude da portadora: 


$$
\Delta v(t)=\frac{v_{f}(t)}{V_{p}}=m V_{p} \cos \left(\omega_{m} t\right)
$$

De modo a expressar o sinal modulante normalizado. Deve-se observar que $m V_{p}$ representa a amplitude do sinal modulante e que isso corresponde à metade da variação da amplitude da tensão, usada para quantificar as variações segundo a norma IEC. A figura 3.11 ilustra essa diferença, que é importante para a calibração correta do instrumento que quantifica as variações relativas de tensão.

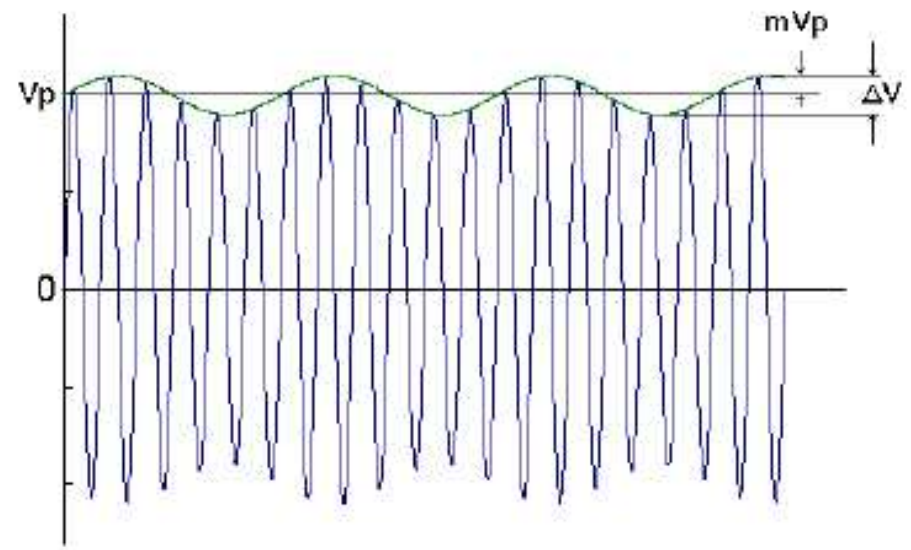

Figura 3.11 - Variação de tensão provocada pela modulação (DECKMANN, 1999).

\section{Estágio 3 - Filtragem e ponderação em freqüência}

Este estágio tem por finalidade filtrar o sinal quadrático do estágio anterior, completando o processo de demodulação, e ponderar o sinal de freqüência, a fim de simular a dependência da resposta do sistema iluminação/olho humano com esta variável. Nas freqüências próximas de zero e acima de $35 \mathrm{~Hz}$, onde a sensibilidade do olho é muito pequena, o ganho resultante dos filtros é próximo de zero.

Este estágio é constituído basicamente por três filtros em série (Os dois primeiros filtros foram ilustrados nas equações do segundo estágio). O primeiro elimina o nível CC do sinal de saída do estágio anterior. O segundo elimina as componentes de dupla freqüência da portadora (sinal de freqüência fundamental). A resposta em freqüência deste filtro leva em conta o fato de que a componente é também atenuada pelo próximo filtro. O terceiro filtro 
de ponderação propriamente dito, que simula a resposta em freqüência de uma lâmpada incandescente de referência combinada ao sistema visual humano, para flutuações de tensão moduladas senoidalmente. Esta resposta é baseada no limiar de percepção sentido em cada freqüência por $50 \%$ das pessoas que foram submetidas a testes de laboratório adequados, ou seja, é representativa do "observador médio". A lâmpada escolhida inicialmente como referência, foi a mais usual na época do desenvolvimento inicial do medidor, isto é, a incandescente de $60 \mathrm{~W} / 230 \mathrm{~V}$ para o sistema de $50 \mathrm{~Hz}$ (padrão europeu) (MEDEIROS, 2003).

A figura 3.12 ilustra a curva de ponderação para a lâmpada de referência. A curva esta normalizada para a freqüência de maior sensibilidade, $8,8 \mathrm{~Hz}$. Para frequiências próximas de zero e acima de $35 \mathrm{~Hz}$ os níveis de cintilação tornam-se praticamente irrelevantes.

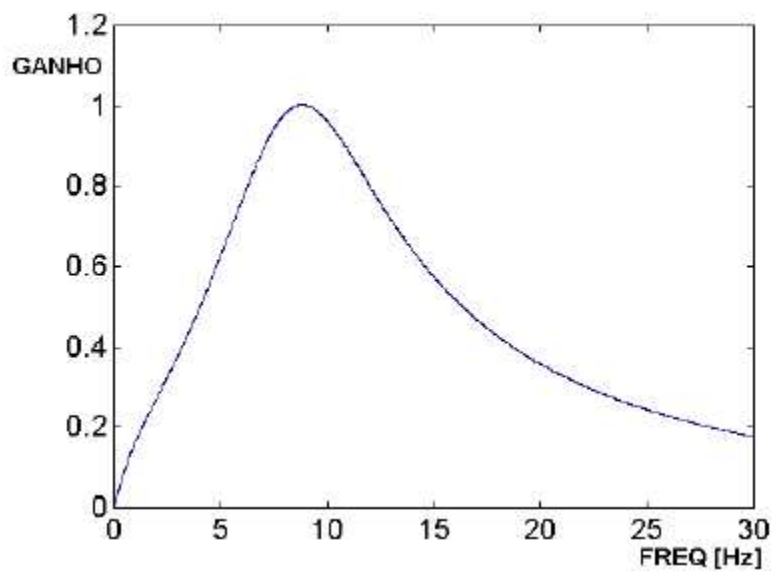

Figura 3.12 - Curva de ponderação para lâmpada incandescente 60 W / 230 V (DECKMANN, 1999).

\section{Estágio 4 - Média móvel quadrática}

Para simular o processo não linear de conversão das flutuações de tensão em variação da energia luminosa percebida pelo olho humano, é obtido o valor quadrático médio das flutuações ponderadas. O sinal resultante dessa média é designado como sensação instantânea de flicker $S_{f}$, expresso por:

$$
S_{f}=\frac{1}{T} \int_{t}^{t+T}\left[a_{f} \cdot \Delta v(t)\right]^{2} d t
$$


Onde

$T$ - constante de tempo para média móvel $(\mathrm{t}=300 \mathrm{~ms})$;

$a_{f}$ - ponderação em freqüência dependendo da lâmpada incandescente;

$\Delta v(t)$ - flutuação normalizada de tensão.

A constante de tempo de 300ms representa a característica de acomodação da retina do olho humano às variações de luminosidade. Justifica-se assim a quantificação da cintilação luminosa a partir das variações de tensão como um processo de simulação da característica lâmpada / olho / cérebro.

\section{Estágio 5 - Tratamento estatístico.}

A sensação instantânea de flicker $S_{f}$ assume a forma de um sinal positivo variável, que tende para zero quando a tensão de entrada $(50 / 60 \mathrm{~Hz})$ possui amplitude constante. Devido ao ganho unitário do filtro de ponderação em torno de $8.8 \mathrm{~Hz}$, as flutuações nessa freqüência não são atenuadas e, portanto produzem a máxima sensação de flicker. Para as demais freqüências as variações de tensão são atenuadas em diferentes graus, dependendo da frequiência dos eventos. Como na prática as variações de tensão podem variar tanto em amplitude como em freqüência aleatoriamente, a sensação instantânea $S_{f}$ varia aleatoriamente, requerendo um tratamento estatístico para sua análise. O tratamento estatístico consiste em obter o histograma dos níveis de ocorrência de $S_{f}$, a partir do qual se calcula a curva ou função de probabilidade cumulativa complementar - FPCC. A partir dos valores dessa curva pode-se estabelecer os indicadores de flicker, como descrito no próximo item.

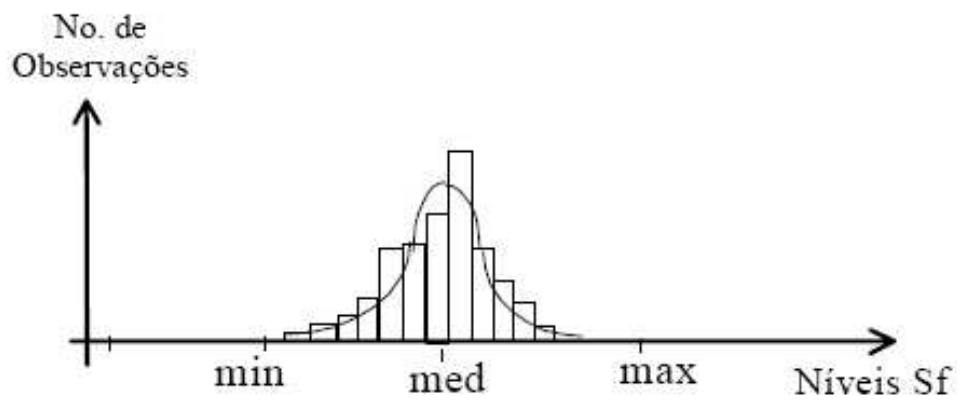


Figura 3.13 - Histograma de classificação de $S_{f}$ por níveis.

\subsubsection{2 - INDICADOR DE SEVERIDADE DE FLICKER DE CURTO PRAZO - Pst}

O Pst (short-term probability) é um índice de quantificação estatística da sensação instantânea de flicker, obtido a partir da FPCC, a qual, por sua vez, fornece níveis de $S_{f}(t)$ que foram excedidos por determinadas percentagens do tempo de observação ou intervalo de cálculo do Pst.

Experimentalmente, verificou-se que para caracterizar os principais processos industriais causadores de flicker, tais como os fornos de arco elétrico, era necessário um tempo de observação mínimo de 10 minutos para obter histogramas representativos das diferentes fases de operação (fusão, recarga e refino). Essa foi uma das razões para se fixar como base de tempo para avaliação de flicker de curto prazo um intervalo de 10 minutos de observação.

Em acordo com investigações a respeito do grau de irritação humano a cintilação, desenvolveu-se uma expressão para o cálculo do Pst onde diversos níveis de $S_{f}$ recebem diferentes pesos, conforme demonstrado na equação que segue.

$$
P s t=\sqrt{3,14 P_{0,1}+5,25 P_{1 s}+6,57 P_{3 s}+28,0 P_{10 s}+8,0 P_{50 s}}
$$

Onde: $P_{0,1}, P_{1 s}, P_{3 s}, P_{10 s}, P_{50 s}$ são os níveis da sensação instantânea de flicker que excedem em 0,1, 3, 10 e 50\% o tempo de observação respectivamente, obtidos da FPCC.

O sufixo "s" indica que os valores suavizados devem ser usados, os quais são dados por:

$$
\begin{aligned}
& P_{1 s}=\left(P_{0,7}+P_{1}+P_{1,5}\right) / 3 \\
& P_{3 s}=\left(P_{2,2}+P_{3}+P_{4}\right) / 3 \\
& P_{10 s}=\left(P_{6}+P_{8}+P_{10}+P_{13}+P_{17}\right) / 5 \\
& P_{50 s}=\left(P_{30}+P_{50}+P_{80}\right) / 3
\end{aligned}
$$


Os coeficientes da equação do Pst foram ajustados tendo como referência a curva de limite de variações de tensão retangulares versus mudanças por minuto, dada pela IEC 60555-3 a qual foi elaborada baseada em investigações de sensibilidade do olho humano.

A figura 3.14 compara a curva dada pela IEC 60555-3 e a correspondente curva Pst $=1 \mathrm{pu}$ (curva de limiar de irritação).

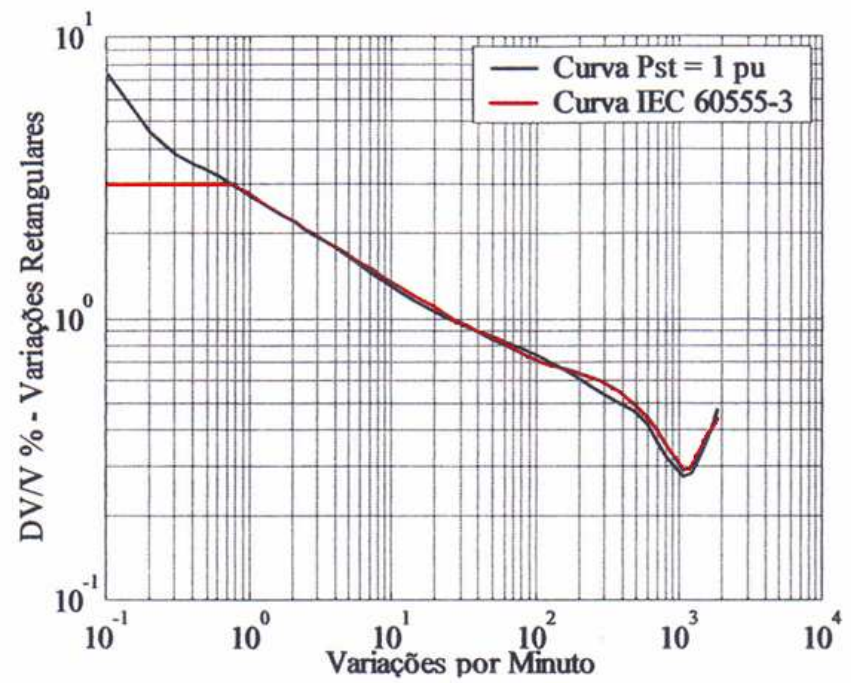

Figura 3.14 - Curva de variação de tensão versus variações por minuto da IEC 60555-3 e

Curva Pst $=1$ pu correspondente (Limiar de irritação).

Vale ressaltar que o Pst indica o grau de desconforto visual, sendo Pst $=1 \mathrm{pu}$, representativo da ocorrência do limiar de irritação do "ser humano médio" devido a cintilação luminosa.

A avaliação da severidade de flicker pelo método de curta duração é, adequadamente, empregada quando se realiza a análise de distúrbios causados por fontes individuais. Quando da existência de várias fontes de perturbação, ou cargas com longos e variáveis ciclos, torna-se necessária e conveniente uma análise criteriosa através do índice de severidade de flicker de longa duração ou Plt. 


\subsubsection{3 - INDICADOR DE SEVERIDADE DE FLICKER DE LONGO PRAZO - PIt}

Para avaliar o efeito de flicker durante longos períodos de observação foi definida a grandeza Plt (long-term probability), como sendo uma média cúbica de 12 valores consecutivos de Pst, obtidos de registros contínuos, o que correspondente a uma janela de 2 horas de medição contínua. Com esse indicador pode-se expressar o efeito da cintilação luminosa para longos períodos de medição cobrindo, por exemplo, um ciclo semanal de operação de cargas variáveis. O Plt é calculado por:

$$
P l t=\sqrt[3]{\frac{1}{12} \sum_{k=1}^{12} P_{S T k}^{3}}
$$

Por fim, ressaltam-se as características favoráveis ao método padrão, para em seguida destacar as limitações do mesmo.

- Avalia, simultaneamente, as flutuações de tensão em termos das amplitudes e freqüências;

- Permite analisar os efeitos de diferentes tipos de flutuações;

- Realiza medições de curta e longa duração;

- Incorpora o tratamento estatístico na analise das variações aleatórias;

- Os resultados finais se resumem em valores numéricos dos índices Pst e Plt, o que permite compará-los diretamente com limites de recomendações e normas.

Como limitações citam-se:

- Não pode ser usada na fase de planejamento de ligação de cargas perturbadoras;

- Dificulta a divisão de responsabilidades no caso de múltiplas fontes perturbadoras;

- Os índices não têm nenhuma vinculação com a sensibilidade, alteração de funcionamento e de desempenho de outros equipamentos, além de lâmpadas incandescentes. 


\section{5 - ATENUAÇÃO DAS FLUTUAÇÕES DE TENSÃO}

A fim de atenuar os principais problemas causados pelas flutuações de tensão é necessário escolher adequadamente a aplicação de uma técnica que leve em consideração a intensidade do impacto que as oscilações causam em outros consumidores e os custos de implementação. Este custo pode representar uma fração significativa do valor de toda a planta. Por esta razão é essencial que a análise do problema seja realizada já durante a fase de planejamento da instalação.

Em geral, à medida que aumenta a potência da carga variável, aumenta a ordem dos problemas causados pelas flutuações. O custo da solução normalmente se eleva com o tamanho da carga variável. Porém, entre as alternativas disponíveis, a solução aparentemente mais simples e eficaz pode mostrar-se anti-econômica, e vice-versa.

A seguir são apresentadas as principais formas de redução da cintilação luminosa.

\subsection{1 - REDUÇÃO DA POTÊNCIA DA CARGA PERTURBADORA}

A solução através da redução da potência solicitada pela carga perturbadora é, normalmente, utilizada como um recurso provisório, enquanto outras providências estão sendo tomadas. Isto porque, esta medida poderá incorrer em redução no faturamento, face a redução da capacidade de produção (PONTES, 2000).

\subsection{2 - FORTALECIMENTO DO SISTEMA SUPRIDOR}

Esta técnica consiste no aumento do nível de curto-circuito no PAC e pode ser realizada através de:

- Aumento do número de condutores do alimentador e/ou ampliação da seção transversal do mesmo, a fim de reduzir a impedância série;

- Elevação no nível de tensão no PAC, reduzindo, assim, a corrente de linha;

- Redução da reatância equivalente do alimentador através de compensação série capacitiva ou outra forma;

- Instalação de compensador síncrono. 
Estas alternativas embora representem soluções técnicas relativamente simples, envolvem alto custo de implementação.

\subsection{3 - INSTALAÇÃO DE REATOR DE NÚCLEO SATURADO - RNS}

Este equipamento foi o primeiro a ser usado na compensação de flutuações de tensão oriundas de cargas de porte industrial, no final da década de 1950 (MEDEIROS, 2003). Trata-se de um dispositivo eletromagnético, dimensionado para operar na região de saturação magnética do núcleo, e conectado em paralelo com a carga variável. Devido à característica VxI quase plana da região de saturação o RNS pode acomodar grandes variações de corrente quando submetido a pequenas variações de tensão. Dessa maneira, o RNS absorve as variações reativas da carga ao mesmo tempo em que confere uma boa regulação à tensão terminal. Como essa ação reguladora é intrínseca, não requerendo qualquer malha de controle adicional, diz-se que o RNS tem capacidade de auto-regulação da tensão (DECKMANN, 1999). A figura 3.15 ilustra a característica VxI do reator saturado.

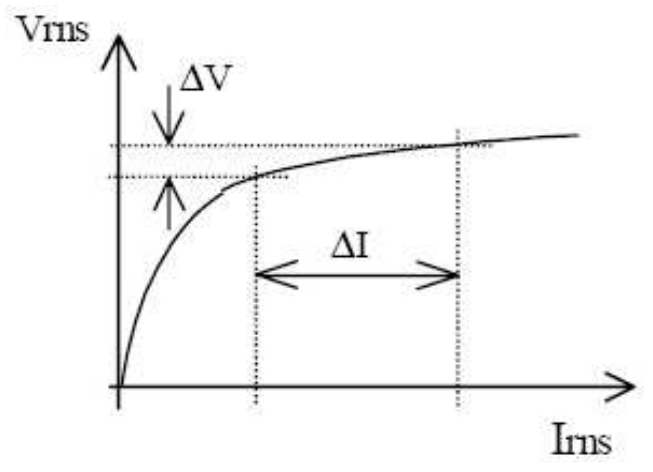

Figura 3.15 - Característica VxI do reator saturado.

Existem, no entanto, algumas desvantagens que comprometem a relação custo/benefício dessa solução como:

- Perdas ferromagnéticas elevadas devido à operação do núcleo sob saturação, criando problemas de aquecimento;

- Geração de distorção harmônica devido à não-linearidade da característica VxI do material ferromagnético; 
- Baixo fator de potência do RNS, aumentando o déficit de reativos da instalação.

\subsection{4 - INSTALAÇÃO DE EQUIPAMENTOS REGULADORES DE TENSÃO}

Outra solução para amenizar os problemas das flutuações consiste na instalação de dispositivos reguladores, equipados com controles adequados e capazes de responder as variações de tensão impostas. Estes dispositivos promovem a compensação de potência ativa e/ou reativa, de forma a reduzir as oscilações de corrente no PAC, devidas à operação da carga perturbadora.

Essa abordagem, utilizando os princípios de controle moderno, permite combinar técnicas de processamento analógico e digital para obter sistemas de compensação rápidos e precisos, a custos cada vez mais acessíveis.

Entre as alternativas de redução das flutuações de tensão através da instalação de reguladores, tem-se:

- Capacitor chaveado por tiristores (CCT);

- Reator controlado por tiristores (RCT);

- Soluções mistas, compensação série e paralela.

Foge ao escopo do presente trabalho a discussão aprofundada sobre os dispositivos supracitados.

A tabela seguinte apresenta uma comparação entre as vantagens e desvantagens dos principais métodos de atenuação da cintilação luminosa. 
Tabela 3.3 - Métodos de compensação e controle de flutuações de tensão (DECKMANN, 1999).

\begin{tabular}{|c|c|c|c|}
\hline Objetivo & Quando se aplica & Vantagens & Desvantagens \\
\hline $\begin{array}{c}\text { Aumentar a } \\
\text { capacidade dos } \\
\text { condutores }\end{array}$ & Alimentador próprio & $\begin{array}{c}\text { Fácil aplicação, } \\
\text { permite expansão }\end{array}$ & Custo dos condutores \\
\hline $\begin{array}{c}\text { Aumentar o nível } \\
\text { de tensão }\end{array}$ & Disponibilidade local & $\begin{array}{c}\text { Fácil execução, } \\
\text { aumenta capacidade }\end{array}$ & Custo de isolação \\
\hline $\begin{array}{c}\text { Compensação } \\
\text { série }\end{array}$ & Alimentador longo & Ação eficaz & $\begin{array}{c}\text { Risco de ressonância } \\
\text { e de sobretensões }\end{array}$ \\
\hline $\begin{array}{c}\text { Compensação } \\
\text { síncrona }\end{array}$ & Geração própria & Aumenta a autonomia & $\begin{array}{c}\text { Custo de instalação, } \\
\text { operação e } \\
\text { manutenção }\end{array}$ \\
\hline $\begin{array}{c}\text { Capacitor } \\
\text { Chaveado por } \\
\text { Tiristores }\end{array}$ & $\begin{array}{c}\text { Insuficiência de reativos } \\
\text { Capacitor } \\
\text { Controlado por } \\
\text { Tiristores }\end{array}$ & $\begin{array}{c}\text { Não produz distorções, } \\
\text { corrige fator de } \\
\text { potência }\end{array}$ & $\begin{array}{c}\text { Resposta lenta, risco } \\
\text { de ressonância }\end{array}$ \\
\hline $\begin{array}{c}\text { Compensação } \\
\text { série/paralela }\end{array}$ & $\begin{array}{c}\text { Alimentador longo/ forno } \\
\text { de grande capacidade }\end{array}$ & $\begin{array}{c}\text { Combina ação série } \\
\text { eficaz com capacidade } \\
\text { shunt reduzida }\end{array}$ & $\begin{array}{c}\text { Coordenar dois tipos } \\
\text { de compensação }\end{array}$ \\
\hline $\begin{array}{c}\text { Reator de Núcleo } \\
\text { Saturado }\end{array}$ & Cargas de pequeno e \\
médio porte & Ação automática & $\begin{array}{c}\text { Perdas adicionais, } \\
\text { produz harmônicas, } \\
\text { baixa o fator de } \\
\text { potência }\end{array}$ \\
\hline
\end{tabular}

Por fim, no caso da cintilação luminosa provocada por dispositivos eletrônicos, a solução mais adequada parece ser a adoção de critérios de controle de emissão, conforme os previstos pela IEC. Esse procedimento pode ser aplicado a reatores eletrônicos, dimmers, dispositivos de acionamento e outros similares.

\section{6 - NORMAS PARA MEDIÇÃO E AVALIAÇÃO DA CINTILAÇÃO LUMINOSA}

De acordo com o escopo deste trabalho, esta seção tem por interesse apresentar a resolução em vigor no Brasil, tanto para medição, como para avaliação do fenômeno cintilação luminosa.

O submódulo 2.8 dos Procedimentos de Rede estabelece que a apuração dos indicadores de flutuação de tensão será conduzida sob a forma de campanhas de medição de sete dias 
consecutivos. Considerar-se-á os valores dos indicadores integralizados em intervalos de 10 minutos, em barras da Rede Básica onde existam registros de reclamações e/ou cujo desempenho de cargas não lineares ou especiais nela conectadas implique na ocorrência de valores expressivos dos referidos indicadores, pode ser necessária a realização de uma medição contínua, cuja caracterização foge ao objetivo do presente documento (Re. ONS 2.1-028/2005).

A respeito da medição dos indicadores de flutuação de tensão, o submódulo 2.8 dos Procedimentos de Rede do ONS estabelece que o equipamento utilizado no processo de apuração deve ter desempenho compatível com os requisitos estabelecidos na norma IEC 61000-4-15. Norma esta que dispõe a respeito do medidor de cintilação luminosa, conhecido também por Flickermeter, exposto na subseção 3.4.3.1 do presente capítulo.

A tensão de referência dos instrumentos de medição de cintilação será ajustada em função da tensão secundária de distribuição preponderante nos Agentes conectados ao barramento da Rede Básica. Como usualmente os instrumentos possuem tensões de referência de 120 V ou $230 \mathrm{~V}$, os ajustes devem ser feitos de acordo com a tabela 3.4.

Tabela 3.4 - Ajustes para medição de flutuação em função do nível da tensão secundária

\begin{tabular}{|c|c|}
\hline Tensão Secundária Preponderante & Tensão de referência do flickermeter \\
\hline $127 \mathrm{~V}$ & $120 \mathrm{~V}$ \\
\hline $220 \mathrm{~V}$ & $230 \mathrm{~V}$ \\
\hline
\end{tabular}

Quando não for possível caracterizar a preponderância de uma ou outra tensão secundária nos sistemas alimentados pelo barramento em medição, ou quando esta informação não estiver disponível no início da campanha de medição, os instrumentos de medição devem ser ajustados para $230 \mathrm{~V}$. Pois este ajuste fornece resultados mais conservativos.

Os instrumentos devem fornecer resultados de Pst para cada uma das três fases, em intervalos de 10 minutos, perfazendo um total de 1008 amostras consecutivas por fase. Devem ainda ser fornecidos resultados de Plt, com a mesma freqüência de aquisição anterior, perfazendo um total de 996 amostras consecutivas de Plt por fase. Os valores de Plt podem ser obtidos de duas formas distintas diretamente pelo instrumento de medição, desde que seja feito por janela deslizante a cada 10 minutos, considerando as leituras de Pst 
das últimas duas horas ou por pós-processamento dos dados de Pst, usando a equação (3.27) para cada intervalo de 10 minutos, considerando os 12 últimos registros de Pst.

Os indicadores de severidade de cintilação, adotados como representativos da flutuação de tensão num dado barramento da Rede Básica, serão o Pstd95\%, que representa o valor do indicador Pst que foi superado em apenas $5 \%$ dos registros obtidos no período de um dia (24 horas), e o PltS95\%, representando o valor do indicador Plt que foi superado em apenas $5 \%$ dos registros obtidos no período de uma semana. O maior valor do indicador Pstd95\% obtido nos sete dias da campanha resulta no indicador PstD95\% que deve ser comparado ao padrão.

Dois limites são adotados para a avaliação do incômodo causado pela cintilação. São eles, o limite global inferior e superior. Seus valores foram definidos para sistemas de tensão secundária de $220 \mathrm{~V}$. A tabela 3.5 apresenta os limites.

Tabela 3.5 - Limites globais inferior e superior.

\begin{tabular}{|c|c|c|}
\hline Limite & PstD95\% & PItS95\% \\
\hline Limite global inferior & $1 \frac{p u}{F T}$ & $0,8 \frac{p u}{F T}$ \\
\hline Limite global superior & $2 \frac{p u}{F T}$ & $1,6 \frac{p u}{F T}$ \\
\hline
\end{tabular}

Onde FT (fator de transferência) é a atenuação esperada entre as redes Básica e secundária de distribuição. Este deve ser obtido através da relação entre os indicadores PltS95\% da Rede Básica e PltS95\% do barramento de distribuição secundária eletricamente mais próximo, obtidos por medição. Caso o FT entre os barramentos em questão seja desconhecido, podem-se adotar os seguintes valores típicos expostos na tabela 3.6. A metodologia aplicada na ferramenta computacional levou em consideração os valores típicos tabelados para o fator de transferência. 
Tabela 3.6 - Valores Típicos dos Fatores de Transferência (FT).

\begin{tabular}{|c|c|}
\hline Tensão nominal do barramento & FT \\
\hline$\geq 230 \mathrm{kV}$ & 0,65 \\
\hline$\geq 69 \mathrm{kV} \mathrm{e}<230 \mathrm{kV}$ & 0,8 \\
\hline$<69 \mathrm{kV}$ & 1,0 \\
\hline
\end{tabular}

Por fim, a qualidade da tensão deve ser inferida, por meio da tabela 3.7 que compara os índices PstD95\% e PltS95\% aos limites impostos pela resolução.

Tabela 3.7 - Qualidade da tensão quanto à flutuação.

\begin{tabular}{|c|c|c|}
\hline Qualidade da tensão & Indicadores & Ação \\
\hline Adequada & $\begin{array}{c}\text { PstD95\% e PltS95\% } \\
\text { limite global inferior }\end{array}$ & Nada a fazer \\
\hline \multirow{2}{*}{ Estado de observação } & Limite Global Inferior $<$ & Caso haja queixas de \\
& PstD95\% ou PltS95\% $=$ & consumidores, ONS busca \\
& Limite Global Superior & Pstduções junto aos agentes. \\
\hline \multirow{2}{*}{ Inadequada } & PstD95\% ou PltS95\% $>$ & ONS define ações \\
& Limite Global Superior & mitigadoras após \\
& & investigações. \\
\hline
\end{tabular}

Quando da apresentação dos resultados, o ONS exige a existência de gráficos de linha, mostrando a tendência dos indicadores Pst e Plt, durante toda a campanha de medição, para cada uma das fases. Bem como, a apresentação de histogramas dos valores dos índices obtidos em cada fase medida. Cada histograma deverá conter um eixo horizontal com pelo menos dez categorias da variável aleatória, Pst ou Plt, e dois eixos verticais, o primeiro contendo o número de ocorrências em cada categoria e o segundo contendo a probabilidade acumulada. 


\section{CAPÍTULO 4}

\section{FERRAMENTA COMPUTACIONAL}

O presente capítulo dedica-se a apresentar o objeto deste trabalho, a saber, o aplicativo intitulado PROGRAMA DE QUALIDADE DA ENERGIA ELETRICA - MÓDULO DE ANÁLISE DE CINTILAÇÃO LUMINOSA. O software consiste em uma ferramenta para auxiliar a quantificação e qualificação da cintilação luminosa presente no sistema elétrico, valendo-se de recursos gráficos e análises simples e objetivas. Sua motivação está baseada em três questões fundamentais:

- A necessidade de um tratamento estatístico / probabilístico dos dados colhidos nas medições de cintilações luminosas;

- A possibilidade de uma análise da cintilação luminosa em qualquer ambiente, observando e comparando os resultados com os limites estabelecidos pela norma;

- O grande volume de dados gerado pelas medições.

\subsection{ESTRUTURA DO APLICATIVO}

O aplicativo que será apresentado a seguir foi desenvolvido em linguagem MATLAB 6.5 licença $n^{\circ}$ 242255. Mais que um software líder na área de computação numérica/cientifica, o MATLAB é um ambiente integrado de computação numérica e modelagem de sistemas, adotado como ferramenta de desenvolvimento padrão pelas principais universidades e empresas, no Brasil e no mundo.

O MATLAB é o núcleo de um ambiente de computação numérica baseado em matrizes que integra:

- Funções de tratamento numérico de alta performance;

- Sofisticados recursos de geração de gráficos para visualização de dados;

- Linguagem de programação de alto nível. 
Para a execução do aplicativo, e até mesmo para a instalação do MATLAB 6.5 recomenda-se um microcomputador PC Pentium III - $1.0 \mathrm{GHz}$ ou superior e com no mínimo 256 MB de memória RAM.

O aplicativo é constituído por oito módulos, descritos sucintamente a seguir:

- Módulo de Entrada (Leitura do Banco de Dados): a partir dele tem-se acesso aos outros módulos do programa, onde serão realizadas as análises. Nesta etapa carrega-se o banco de dados desejado. Também são mostradas informações sobre o banco.

- Freqüência de Aquisição dos Dados: permite a comparação entre diferentes frequiências de aquisição de dados, através de ferramentas estatísticas, inferindo se para o mesmo período o fenômeno pode ser representado por uma quantidade menor de informação.

- Similaridade entre dias: caracteriza o banco de dados com relação à ocorrência de similaridade entre os diversos dias de medição, permitindo também a observação das curvas características dos indicadores, Pst e Plt, para cada dia medido.

- Similaridade entre períodos: possibilita a análise das diferenças nos perfis nos indicadores, Pst e Plt, entre os diversos períodos de um determinado dia de medição.

- Similaridade entre fases: habilita o usuário a comparar as diferentes fases do sistema trifásico medido, verificando se há similaridade entre elas através de uma análise estatística em todo o período observado.

- Análise de Distribuição no Tempo: torna possível a investigação do comportamento das amostras por meio da comparação do banco de dados frente a um determinado valor limite do indicador, P99\%, P95\%, média quadrática, ou outro valor escolhido como referência. É realizada uma análise temporal e probabilística da distribuição dos dados medidos com relação ao valor limite escolhido. 
- Comparação com a norma: permite uma análise comparativa entre o banco de dados em estudo e a norma em vigor. Permite também a obtenção dos gráficos ponto-a-ponto e dos histogramas dos valores de Pst e Plt obtidos em cada fase durante a campanha.

- Análise de Carga: aqui é feita uma análise estatística e gráfica do perfil de tensão, corrente e potência, caso o banco de dados disponibilize essas grandezas para análise. O módulo tem o objetivo de verificar a influência que algumas perturbações no sistema exercem nos valores de cintilação medidos.

Em todos os módulos de análise são disponibilizadas estatísticas das grandezas em avaliação, a saber: valores máximos, mínimos, médias aritméticas e quadráticas, desvio padrão, e valores de P95\% e P99\%, de acordo com as definições a seguir (MEYER, 1983):

- Máximo: Valor máximo de um vetor de dados numéricos;

- Mínimo: Valor mínimo de um vetor de dados numéricos;

- Média Aritmética: A média aritmética, $\mu$, de um conjunto de $\mathrm{N}$ elementos $x_{1}$, $x_{2}, \ldots, x_{N}$, é definida como a soma dos valores do grupo de dados dividida pelo número de elementos, equação 4.1:

$$
\mu=\frac{x_{1}+x_{2}+\ldots+x_{N}}{N}
$$

- Média Quadrática: A média quadrática de um conjunto de $\mathrm{N}$ elementos $x_{1}$, $x_{2}, \ldots, x_{N}$, é definida como a razão entre a raiz quadrada da soma dos quadrados dos valores do grupo de dados e a raiz quadrada do número de elementos, equação 4.2:

$$
\varphi=\sqrt{\frac{\sum_{i=1}^{N}\left(x_{i}\right)^{2}}{N}}
$$

- Desvio Padrão: O desvio padrão de $\mathrm{N}$ elementos aleatórios $x_{1}, x_{2}, \ldots, x_{N}$, é definido conforme a equação 4.3 abaixo: 


$$
\sigma=\sqrt{\frac{\sum_{i=1}^{N}\left(x_{i}-\mu\right)^{2}}{N}}
$$

- P95\%: Indica, para um dado conjunto de dados, o valor com probabilidade de $95 \%$ de não ser excedido;

- P99\%: Indica, para um dado conjunto de dados, o valor com probabilidade de $99 \%$ de não ser excedido.

A seguir será apresentada a estrutura do banco de dados e o módulo de entrada do programa.

\subsection{BANCO DE DADOS}

Para a captura das amostras de indicadores de severidade de flicker (Pst e Plt) é necessário dispor de instrumentos de medição específicos, capazes de calcular estes indicadores de acordo com a metodologia padrão. No caso do banco de dados analisado neste trabalho, utilizou-se o medidor ION 7600. Trata-se de um medidor trifásico composto de quatro entradas de tensão e cinco entradas de corrente. A Figura 4.1 ilustra o display frontal deste equipamento:

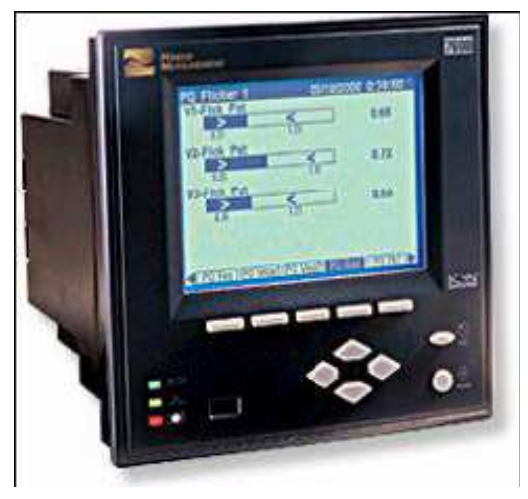

Figura 4.1 - Medidor ION 7600

Colhidos os dados, é necessário gerar o banco de dados no formato “*.xls”. O arquivo pode ser gerado manualmente no Microsoft Excel, desde que obedeça ao padrão estabelecido pelo aplicativo: seu tamanho poderá ser variável, dependendo do número de grandezas medidas pelo equipamento. Há dois tipos de banco de dados aceito pelo 
programa: os que são dotados de informações para análise de carga (tipo 1) e os que não possuem as medições necessárias para o estudo em questão (tipo 2).

- A primeira linha informará as grandezas medidas: tempo, valores de Pst, valores de Plt, tensões, correntes, potências e freqüência;

- A primeira coluna deverá ser a do tempo. O arquivo gerado a partir do medidor já traz as informações de data e hora da medição;

- Após a coluna do tempo, estarão as colunas com valores de Pst, Plt, tensões de fase, tensões de linha, correntes de fase, potências (ativa, reativa e aparente) e frequiência, respectivamente, caso o banco de dados seja do tipo 1. Se o banco for do tipo 2, ele conterá além da coluna do tempo as colunas com valares de Pst e Plt.

Normalmente, ao se fazer medições, o arquivo gerado é composto por várias planilhas. Cada planilha refere-se a um determinado assunto. Como além da análise da cintilação luminosa o aplicativo possibilita um estudo das tensões e carga, é necessário unificar as duas planilhas.

A tabela 4.1 a seguir resume o formato de banco de dados aceito pelo programa e a figura 4.2 ilustra a tela de um arquivo admitido pelo aplicativo.

Tabela 4.1 - Formato do banco de dados (tipo 1)

\begin{tabular}{|c|c|c|c|c|c|c|c|c|c|}
\hline Tempo & Pst & Plt & Freq. & VF & VL & IF & $\mathbf{K W}$ & KVAr & KVA \\
\hline $\begin{array}{l}\text { Data e } \\
\text { Hora }\end{array}$ & $\begin{array}{l}\text { Colunas: } \\
\text { Pst da fase } \\
\text { a, b, c }\end{array}$ & $\begin{array}{l}\text { Colunas: } \\
\text { Plt da fase } \\
\text { a, b, c }\end{array}$ & $\begin{array}{l}\text { Coluna: } \\
\text { Freqüência }\end{array}$ & $\begin{array}{c}\text { Colunas: } \\
\text { Tensões } \\
\text { de fase } \\
\text { a, b, c }\end{array}$ & $\begin{array}{l}\text { Colunas: } \\
\text { Tensões } \\
\text { de linha } \\
\text { ab, bc, ca }\end{array}$ & $\begin{array}{c}\text { Colunas: } \\
\text { correntes } \\
\text { de fase } \\
\text { a, b, c }\end{array}$ & \multicolumn{3}{|c|}{$\begin{array}{c}\text { Colunas: potências } \\
\text { ativa, reativa e } \\
\text { aparente }\end{array}$} \\
\hline
\end{tabular}




\begin{tabular}{|c|c|c|c|c|c|c|c|}
\hline \multicolumn{7}{|c|}{ IX Microsoft Excel - Albras L1 setembro } & 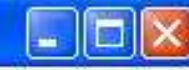 \\
\hline \multicolumn{7}{|c|}{ 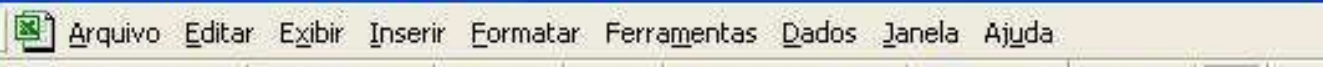 } & $-a x$ \\
\hline$\Gamma$ & 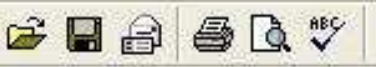 & 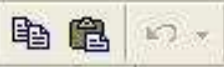 & $8 \Sigma f_{x} \stackrel{A}{Z}$ & 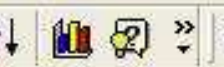 & $11 \cdot$ & $\mathbf{N} \overline{\underline{\underline{\underline{Z}}}}$ & 覃 \\
\hline \multicolumn{8}{|c|}{ 盗 } \\
\hline \multicolumn{8}{|c|}{$\mathrm{R} 1 \quad-\quad=\mathrm{W}$ tot mean } \\
\hline \multicolumn{2}{|r|}{$\mathrm{A}$} & B & $\mathrm{C}$ & D & \multicolumn{2}{|c|}{$E$} & $F=$ \\
\hline 1 & Local Time & V1-FIck Pst & V2-FIck Ps & V3-Flck Pst & V1-FI & k Pltd & V2-Flck \\
\hline 2 & 2006-set-01 00:00:00,000 & 0,088851541 & 0,094999224 & 0,100334175 & \multicolumn{2}{|c|}{0,121997073} & $0.12638^{3}$ \\
\hline 3 & 2006-set-01 00:10:00,000 & 0,072166629 & 0,085377865 & 0,083382487 & \multicolumn{2}{|c|}{0,120832264} & 0,12555 \\
\hline 4 & 2006-set-01 00:20:00,000 & 0,080880813 & 0,093152426 & 0,10096319 & \multicolumn{2}{|c|}{0,117301852} & 0,12181 \\
\hline 5 & 2006 -set-01,00:30:00,000 & 0,071080223 & 0,07590159 & 0,082860149 & \multicolumn{2}{|c|}{0,114804745} & 0,11940 \\
\hline 6 & 2006 -set-01 00:40:00,000 & 0,056462642 & 0,061278831 & 0,062180094 & \multicolumn{2}{|c|}{0,114512682} & 0,11857 \\
\hline 7 & 2006-set-01,00:50:00,000 & 0,065888084 & 0,072628319 & 15565 & & & 836. \\
\hline 8 & 2006-set-01 01:00:00,000 & 0,121029973 & 2208 & 9073 & & & 536 \\
\hline 9 & $101: 10: 00,000$ & 0,08 & 0,0 & 918 & & & 61 \\
\hline 10 & 2006-set-01 01:20:00,000 & 0,11 & 0,1 & 996 & & & 0 , \\
\hline 11 & 2006-set-01 01:30:00,000 & 0,150 & 0,1 & 813 & & & 0 \\
\hline 12 & 2006 -set-01 01:40:00,000 & 0,104 & 6618 & 131 & & & 603 \\
\hline 13 & 2006-set-01 01:50:00,000 & 0,11 & 1961 & 872 & & 99 & 0,09813 \\
\hline 14 & 2006-set-01 02:00:00,000 & 0,076633386 & 0,098105401 & 0,105593584 & & 18 & \\
\hline 15 & 2006-set-01 02:10:00,000 & 0,101487309 & 0,117377989 & 0,114558846 & & 31 & 926 \\
\hline 16 & 2006-set-01 02:20:00,000 & 0,133632988 & 0,141931921 & 0,150323153 & 0,0 & 651617 & 0,1 \\
\hline 17 & 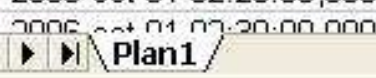 & & & 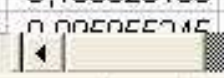 & & & 1. \\
\hline Pror & & & Soma $=4584068$ & 3339 & & & \\
\hline
\end{tabular}

Figura 4.2 - Exemplo de banco de dados no Microsoft Excel.

\subsection{INICIANDO O PROGRAMA}

O programa deve ser aberto dentro do Matlab 6.5. Após a sua iniciação, escolhe-se o diretório que contém a pasta do aplicativo no menu "Current Directory". O próximo passo é digitar o nome do arquivo de inicialização "flicker", na janela "Command Window”. Aparecerá a tela de apresentação do programa, mostrada na figura 4.3, que se fecha após 4 segundos. Automaticamente, abre-se a tela inicial, ilustrada pela figura 4.4. Nesta tela, há o botão "Iniciar Programa", que ao ser clicado, inicia o módulo de entrada. 


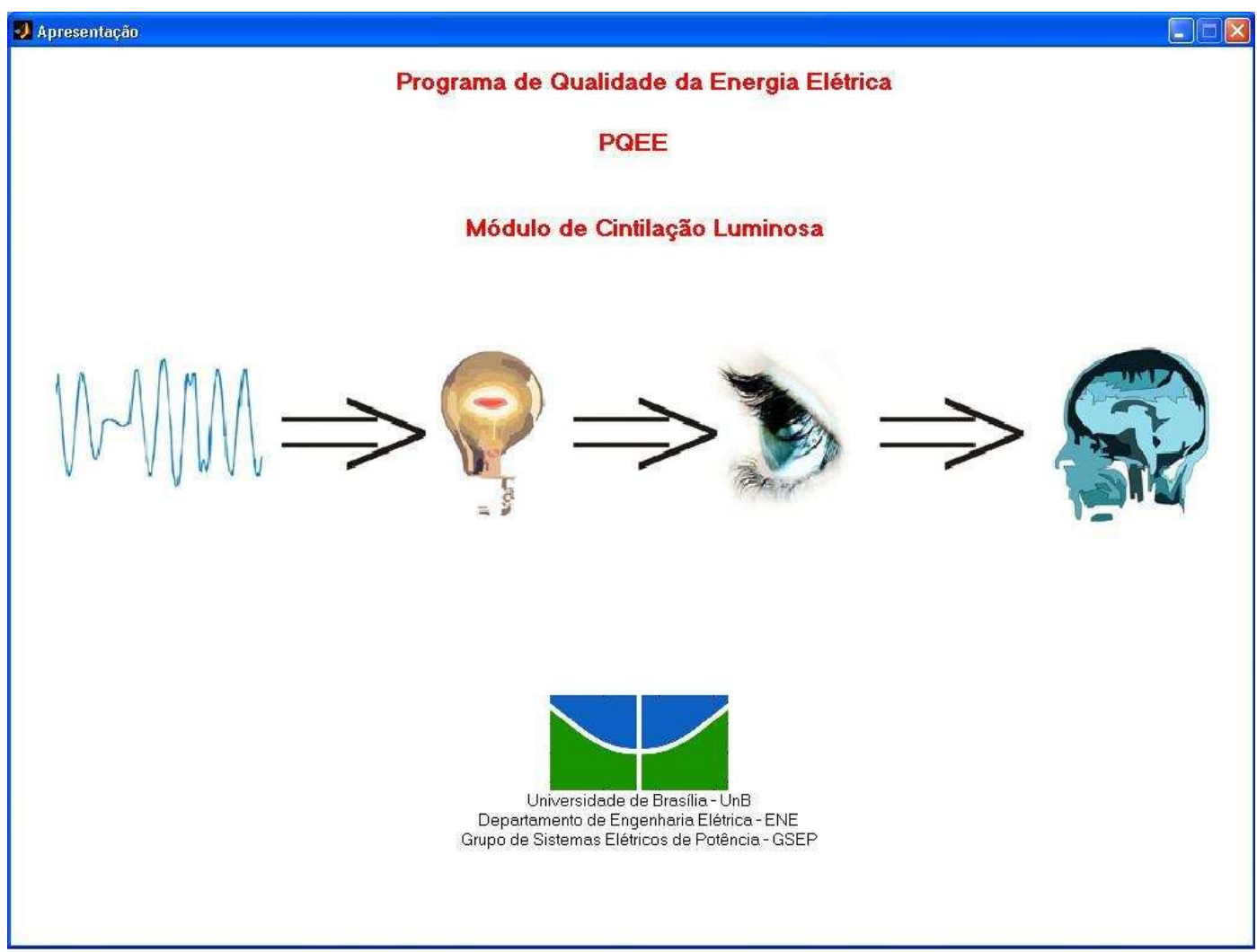

Figura 4.3 - Tela de apresentação

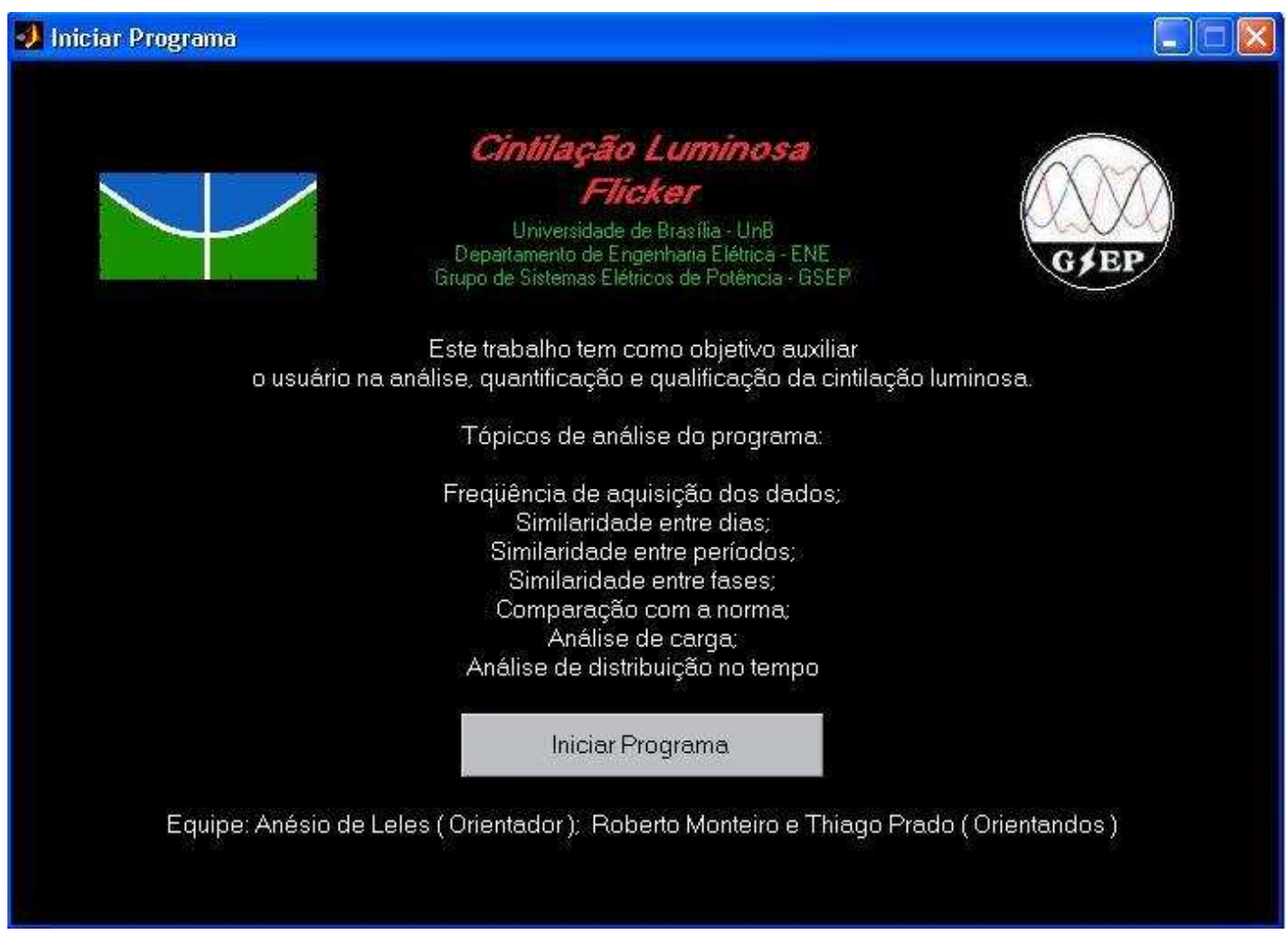

Figura 4.4 - Tela inicial 


\subsection{MÓDULO DE ENTRADA - LEITURA DO BANCO DE DADOS}

O módulo de entrada é responsável por carregar os dados medidos e fornecer acesso aos módulos de análise. Os botões de entrada ficam inativos até que o banco seja carregado. O menu superior permite o acesso a todas opções oferecidas pelo programa. No item "Ajuda" do menu, é possível ver a resolução do ONS referente à flutuação de tensão, que aborta a cintilação luminosa.

Para que o software leia o banco de dados, é necessário clicar sobre o botão "Leitura dos Dados". Aparecerá uma janela que pergunta se o banco de dados possui grandezas para análise de tensão e carga, como mostra a figura 4.5. Caso não haja estas medições de tensão e carga, a opção "Análise de Tensão e Carga" permanecerá inativa.

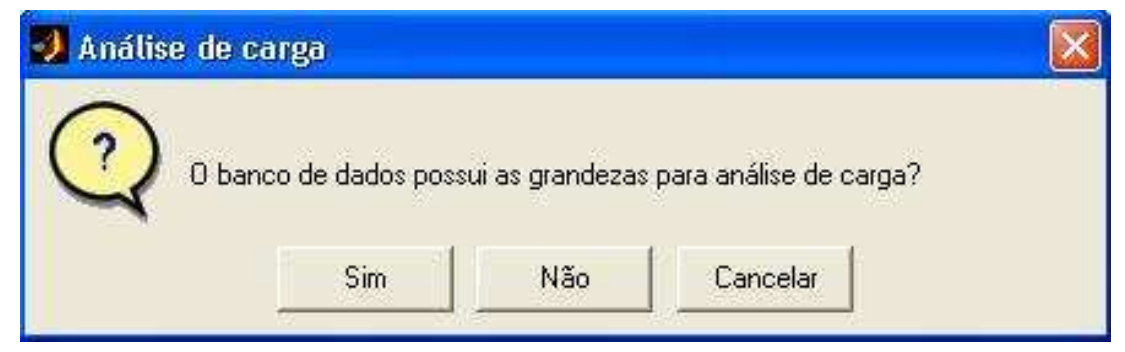

Figura 4.5 - Opção por tipo de banco de dados

Definido o tipo de banco de dados, seleciona-se o arquivo desejado. Se carregado corretamente, um aviso será mostrado com a mensagem "Dados Colhidos com Sucesso", como ilustra a figura 4.6.

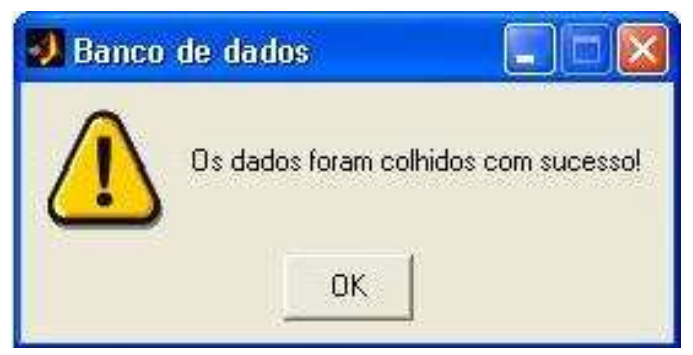

Figura 4.6 - Aviso de banco carregado 
Concluída esta etapa, as seguintes informações sobre o banco utilizado estarão disponíveis na tela do módulo de entrada: nome do arquivo, data e hora de início e fim da medição e quantidade de dias medidos. A figura 4.7 expõe a janela deste módulo.

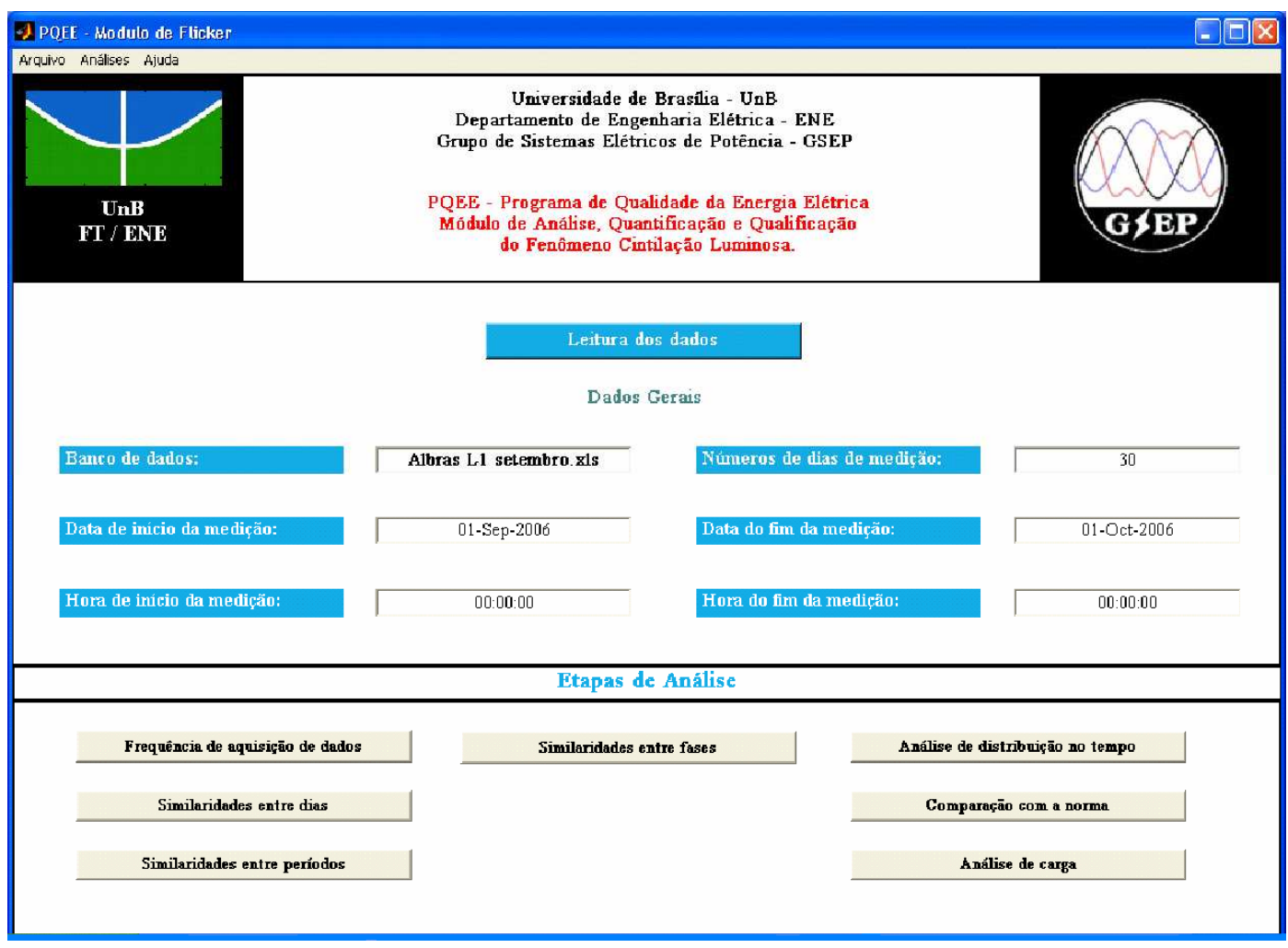

Figura 4.7 - Janela do módulo de entrada do programa (Banco de Dados)

Nos capítulos subseqüentes os demais módulos da ferramenta serão detalhadamente apresentados. A estrutura do módulo e suas funções de análise são descritas, sua tela é exibida e na seqüência são realizados estudos de caso que mostram a aplicação de cada módulo.

Os dados utilizados são procedentes da linha 1 (L1) da subestação "SE ALBRÁS", que é parte do sistema da Eletronorte.

A ALBRÁS, Alumínio Brasileiro S.A., é uma indústria de produção de alumínio composta basicamente por 4 conjuntos de retificadores industriais a diodo de 36 pulsos, não controlados, os quais alimentam, em corrente contínua, os processos de produção (04 linhas de cubas). 
Esse consumidor, cuja demanda atual é de cerca de 800 MW, é suprido através de uma subestação própria denominada SE ALBRÁS, que por sua vez, está conectada à Rede Básica na SE Vila do Conde. Tal conexão se dá por meio de uma linha em $230 \mathrm{kV}$, circuito duplo (L1 e L2), de comprimento igual a $1.6 \mathrm{~km}$.

A tabela 4.2 resume as características do banco de dados medido. A figura 4.8 traz sua localização.

Tabela 4.2 - Informações do banco de dados medido em SE ALBRÁS L1

\begin{tabular}{|c|c|}
\hline Banco de dados & Albras L1 setembro.xls \\
\hline Data de início da medição & 01 de setembro de 2006 \\
\hline Hora de início da medição & $00: 00 \mathrm{~h}$ \\
\hline Data do fim da medição & 01 de outubro de 2006 \\
\hline Hora do fim da medição & $00: 00 \mathrm{~h}$ \\
\hline Número de dias da medição & 30 \\
\hline
\end{tabular}

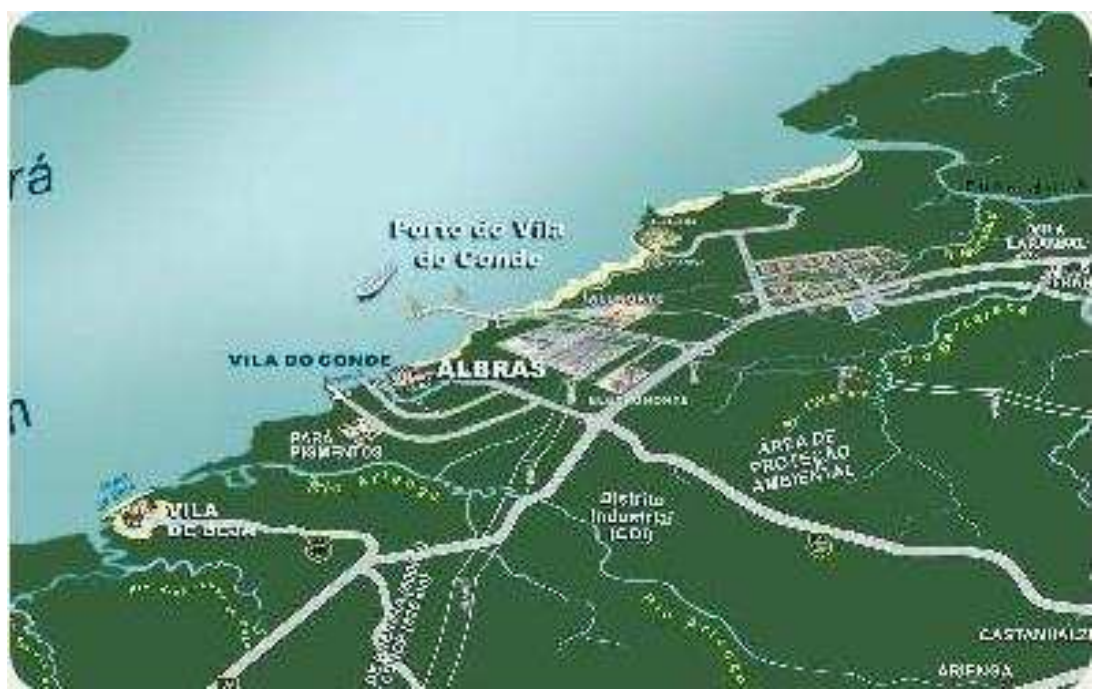

Figura 4.8 - Localização da ALBRÁS

A figura 4.9, na próxima página, mostra o sistema elétrico da Eletronorte próximo à subestação SE ALBRÁS. 


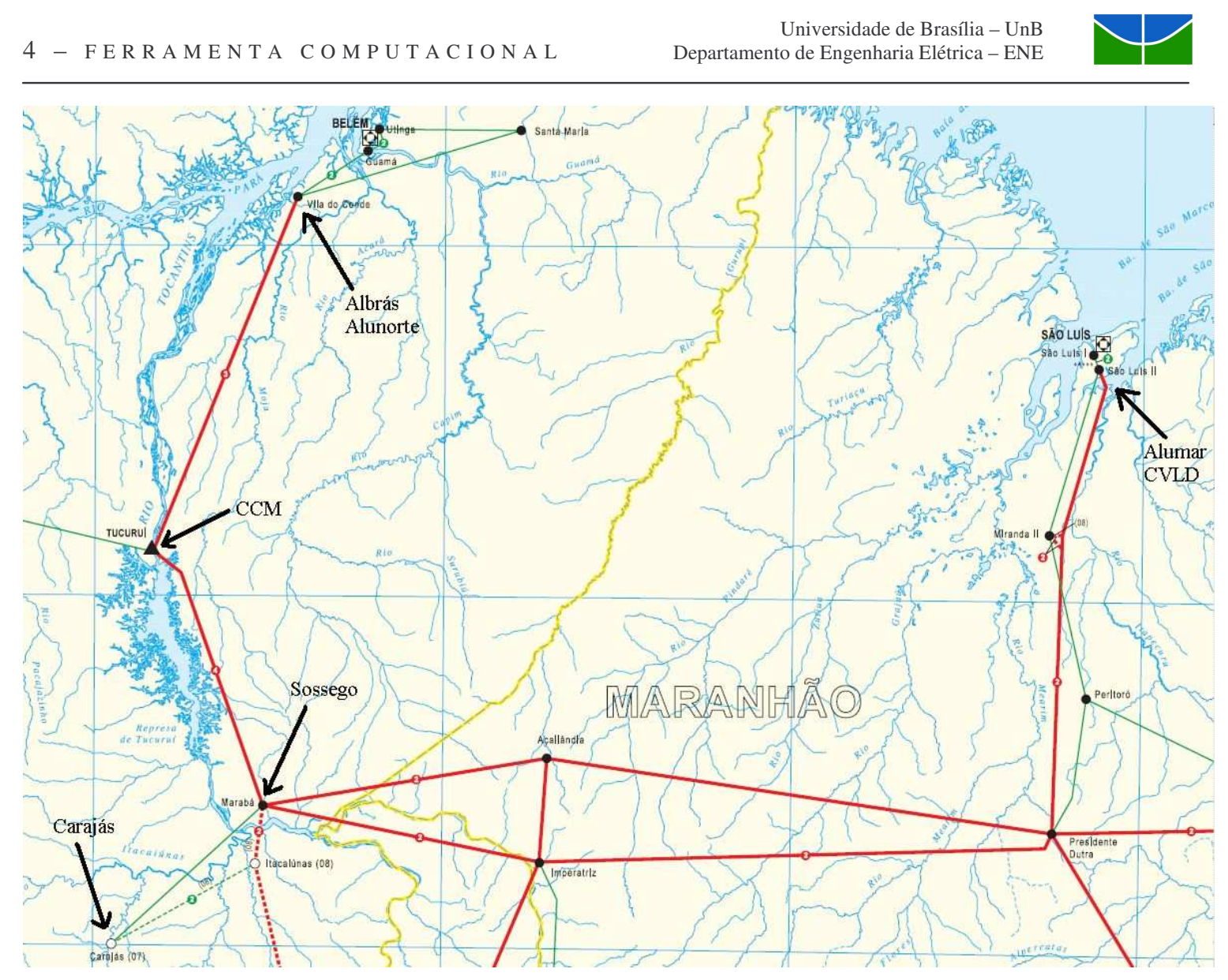

Figura 4.9 - Sistema Elétrico da Eletronorte próximo a SE ALBRÁS

\subsection{CONSIDERAÇÕES FINAIS}

O presente capítulo apresentou a ferramenta computacional para análise de cintilação luminosa, trazendo uma visão geral sobre sua estrutura, bem como sobre o formato do banco de dados utilizado. Nos capítulos seguintes serão descritos cada módulo do programa, trazendo sempre uma análise do banco de dados da subestação SE ALBRÁS L1 e comprovando sua relevância para o estudo da cintilação. 


\section{CAPÍTULO 5}

\section{ANÁLISE DA FREQÜ̂̂NCIA DE AQUISIÇÃO DE DADOS}

O presente capítulo apresentará o módulo de análise da freqüência de aquisição de dados. Esta etapa permite, com auxílio do ferramental estatístico, a comparação entre diferentes intervalos de aquisição de dados, a saber: de 10 em 10, de 30 em 30 e de 60 em 60 minutos. Concluindo-se a respeito da descaracterização ou não dos dados, sobretudo, quantificando-se os erros cometidos quanto às diferentes amostragens.

Para tanto, será realizado um estudo de caso, como forma de ilustrar a relevância da presente ferramenta no estudo das cintilações luminosas. Caso se verifique ser possível a utilização de medições com dados colhidos em maiores intervalos de registro, ganha-se pela menor exigência de memória dos equipamentos e velocidade no processamento das informações.

\subsection{ESTRUTURA DO MÓDULO}

Esta etapa de análise pode ser acessada a partir do botão intitulado "Freqüência de aquisição de dados", na tela do módulo de entrada ou a partir do menu superior "Análises". Abrir-se-á a janela ilustrada na Figura 5.1.

À esquerda ficam disponíveis os indicadores para análise Pst e Plt, as fases do sistema elétrico e o quadro para a definição do período de análise. Basta proceder às escolhas na seqüência indicador, fase e data, respectivamente, marcando "Ok” após cada opção.

Realizado este procedimento, os dados estatísticos são calculados automaticamente pelo software, para cada intervalo de frequiência de aquisição e apresentados em uma tabela, exposta a direita das seleções. Estão disponíveis os valores máximo e mínimo, médias aritmética e quadrática, o desvio padrão, o P95\% e o P99\%. 
Ficam habilitadas também as análises gráficas, em três botões abaixo da tabela, onde há opção de gráficos de linha das amostras, gráfico de barras dos valores estatísticos e o histograma, junto a curva de probabilidade acumulada.

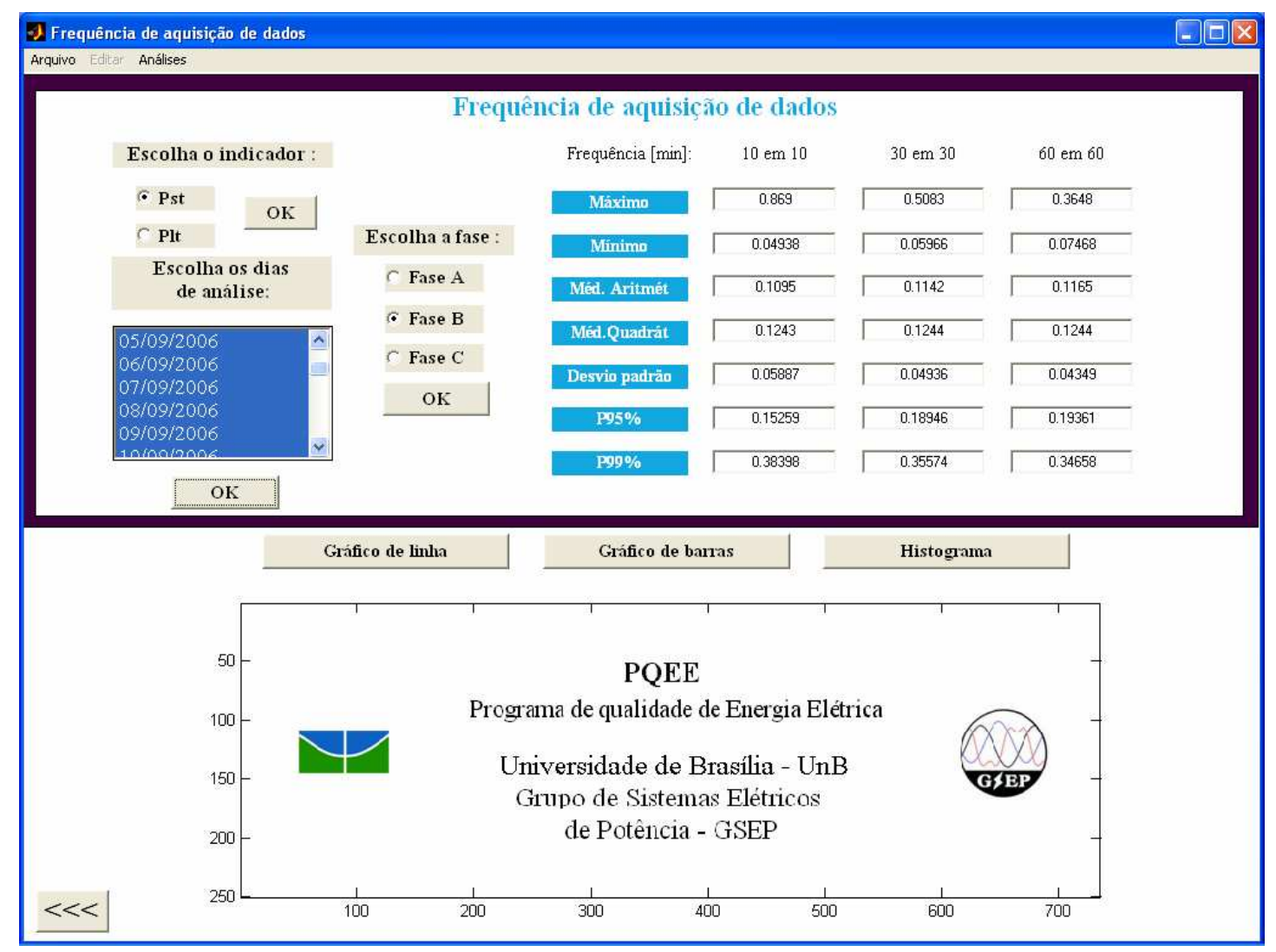

Figura 5.1 - Janela do módulo de análise da freqüência de aquisição de dados

\subsection{ESTUDO DE CASO}

Tendo em vista a avaliação da aplicabilidade deste módulo, será feita uma análise gráfica e estatística das amostras dos indicadores de severidade de flicker de curta e longa duração (Pst e Plt), na fase B, para diferentes intervalos de aquisição. O banco de dados utilizado é o da subestação ALBRAS da Eletronorte, medido durante 30 dias, de $1^{\circ}$ de setembro de 2006 a $1^{\circ}$ de outubro do mesmo ano, e com amostras adquiridas a cada 10 minutos. Visando a melhor visualização dos resultados, esturdar-se-á a semana iniciada no dia 3 de setembro.

Trabalhando inicialmente com os dados referentes ao Pst, têm-se os valores estatísticos alcançados pela ferramenta expostos na tabela 5.1. A figura 5.2 traz o comportamento do indicador Pst para os diferentes intervalos de medição. 
Tabela 5.1 - Valores estatísticos para Pst.

\begin{tabular}{|c|c|c|c|}
\cline { 2 - 4 } \multicolumn{1}{c|}{} & $\mathbf{1 0} \mathbf{~ e m ~ 1 0}$ & $\mathbf{3 0} \mathbf{~ e m ~ 3 0}$ & $\mathbf{6 0} \mathbf{~ e m ~ 6 0}$ \\
\hline Máximo & 0,869 & 0.5083 & 0.3648 \\
\hline Mínimo & 0.04938 & 0.05966 & 0.07468 \\
\hline Média aritmética & 0.1095 & 0.1142 & 0.1165 \\
\hline Média quadrática & 0.1243 & 0.1244 & 0.1244 \\
\hline Desvio padrão & 0.05887 & 0.04936 & 0.04349 \\
\hline P99\% & 0.15259 & 0.18946 & 0.19361 \\
\hline
\end{tabular}

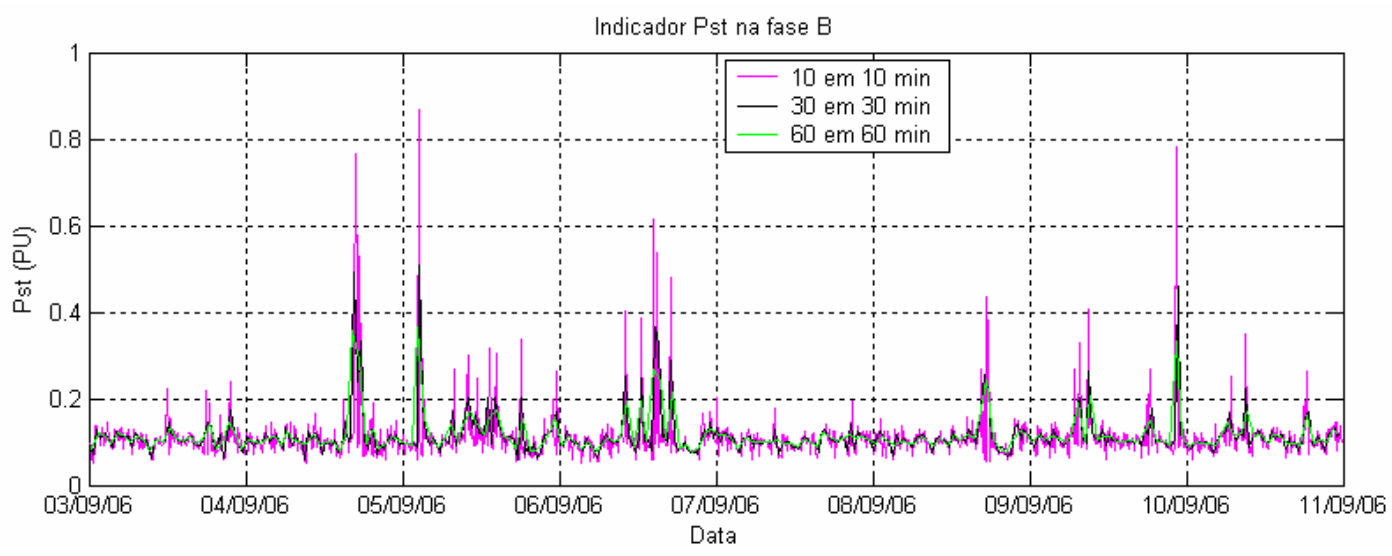

Figura 5.2 - Gráfico de linha do indicador Pst na fase B.

Pode-se observar da figura 5.2 que as curvas para as três frequiências de aquisição assemelham-se entre si. Todavia, as amostras colhidas de 10 em 10 minutos apresentam maiores variações em termos de amplitude. Da tabela 5.1, observa-se uma redução no desvio padrão, à medida que a frequiência de aquisição é elevada. Isso faz com que os valores colhidos de 30 em 30 e de 60 em 60 minutos sejam atenuados, excluindo-se os picos de Pst.

A figura 5.3 apresenta o gráfico de barras dos valores estatísticos, com o intuito de facilitar a comparação entre estes. 


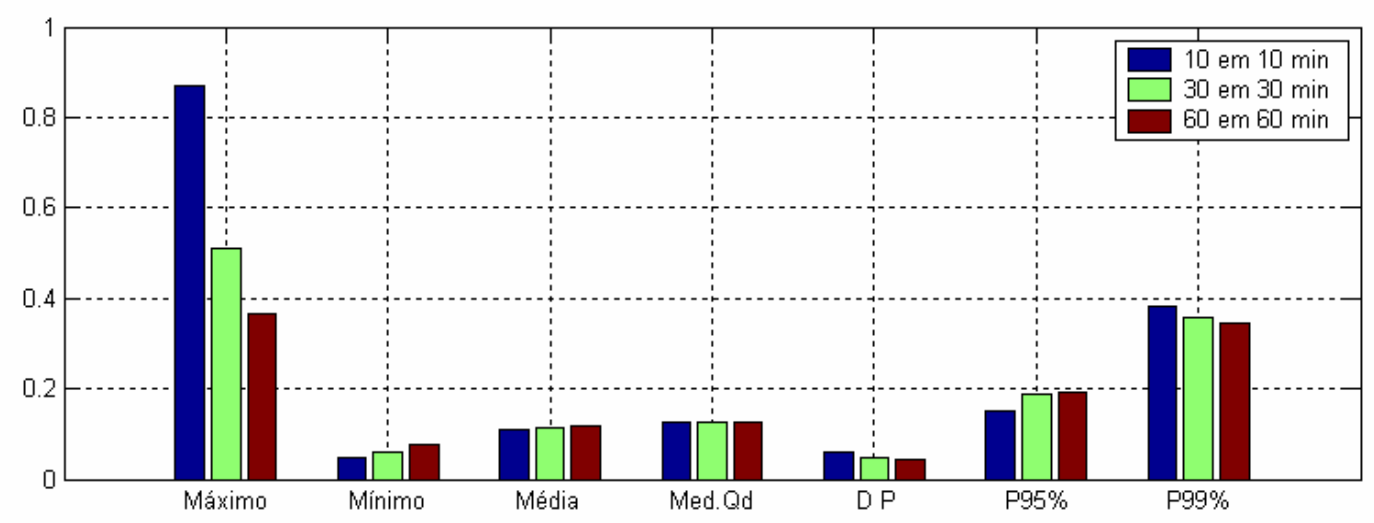

Figura 5.3 - Gráfico de barras com os valores da tabela 6.1.

Fica claro, ao se analisar a figura 5.3, que os valores de máximo e mínimo são bastante divergentes entre si. Encontra-se um erro relativo percentual na casa de $138 \%$ entre os picos de Pst, considerando-se os valores máximos adquiridos para cada freqüência. Contudo, os valores extremos não representam o comportamento geral das amostras em todo o período de medição. Comparando-se os resultados alcançados para média aritmética, tem-se uma discrepância máxima de 6,4\%. Já a média quadrática permaneceu praticamente constante, alcançando $0,08 \%$ de diferença entres os intervalos de aquisição. Ao se analisar os dados referentes ao percentis, percebe-se que o P95\%, indicador utilizado como valor representativo pela resolução brasileira, obteve uma variação próxima a 26,9\%, entre as freqüências de aquisição de 10 e 60 minutos, enquanto o P99\% apresentou 10,79\% de diversidade.

As figuras 5.4, 5.5 e 5.6 ilustram o estudo da distribuição estatística das amostras coletadas.

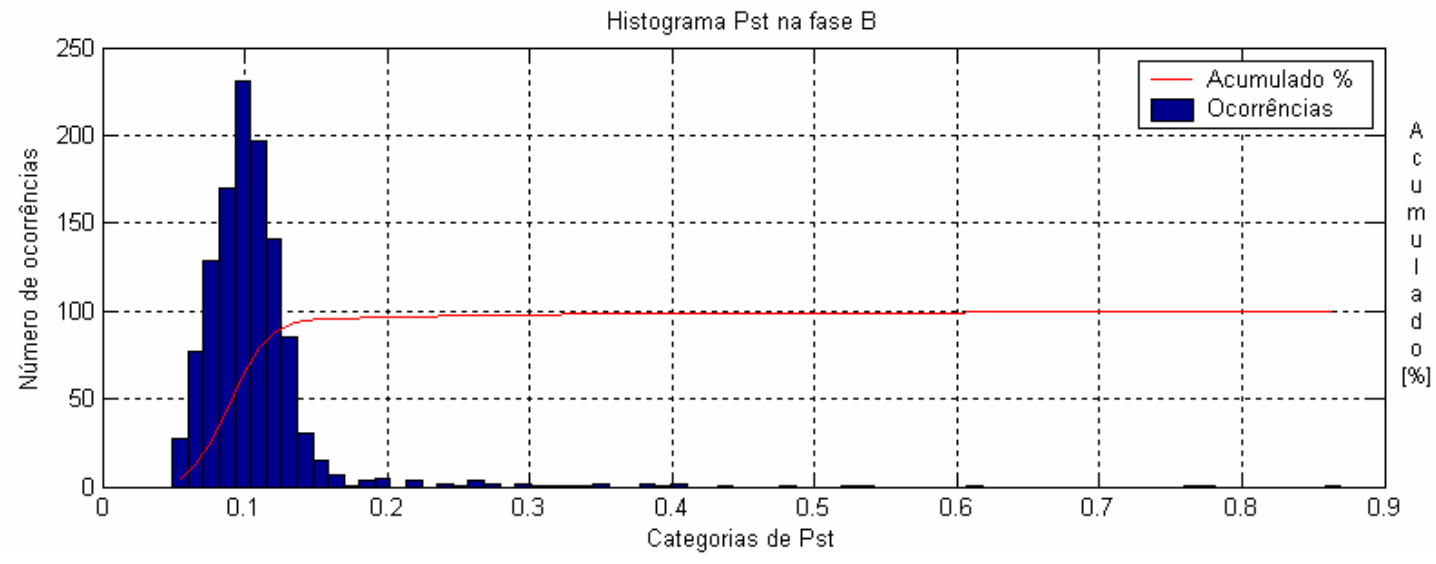

Figura 5.4 - Histograma e curva de probabilidade acumulada para freqüência de aquisição de 10 minutos. 


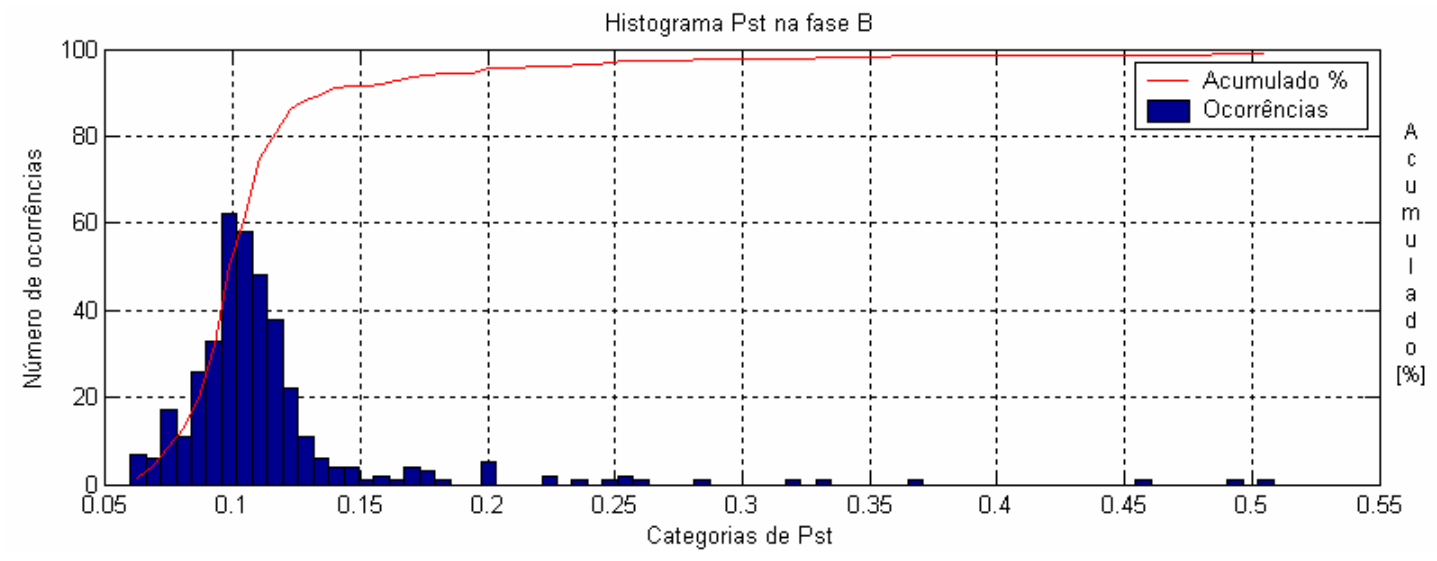

Figura 5.5 - Histograma e curva de probabilidade acumulada para freqüência de aquisição de 30 minutos.

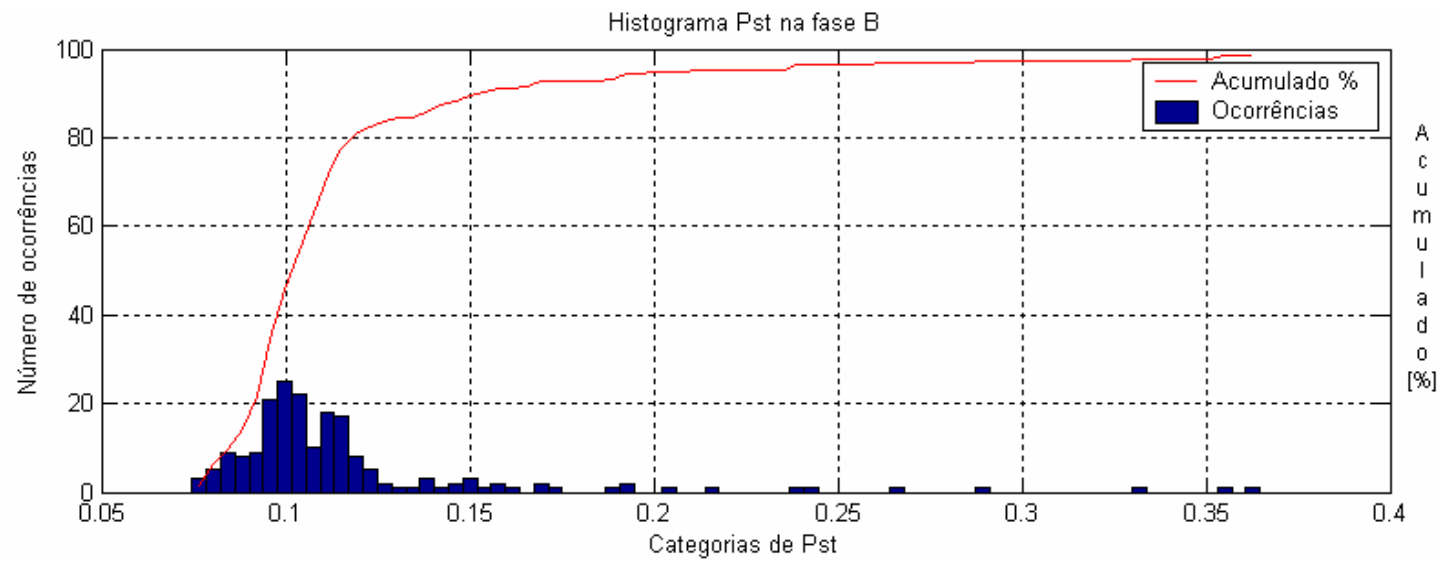

Figura 5.6 - Histograma e curva de probabilidade acumulada para freqüência de aquisição de 60 minutos.

A partir das figuras 5.4, 5.5 e 5.6, percebe-se que para todas as frequiências de aquisição estudadas, a maior fração dos valores coletados situam-se em torno de $0,1 \mathrm{pu}$, fato este confirmado pelos valores médios calculados. Fica claro ainda a semelhança entre os perfis de distribuição.

Com base nos resultados alcançados pelo módulo de análise da freqüência de aquisição, conclui-se que a discrepância entre os valores encontrados para Pst ultrapassam o limite de diversidade de 5\%, utilizado neste trabalho como patamar de erro para as comparações, caracterizando assim a impossibilidade de utilização de intervalos de medição diferentes. Todavia é importante refletir acerca do valor da média quadrática apresentar apenas 0,08\% de discrepância. 
Repetindo o estudo para o indicador de severidade de flicker de longa duração (Plt) têm-se os dados apresentados na tabela 5.2. A figura 5.7 ilustra o comportamento do Plt para as diferentes freqüências de aquisição.

Tabela 5.2 - Valores estatísticos para Plt.

\begin{tabular}{|c|c|c|c|}
\cline { 2 - 4 } \multicolumn{1}{c|}{} & $\mathbf{1 0} \mathbf{~ e m ~ 1 0}$ & $\mathbf{3 0} \mathbf{~ e m ~ 3 0}$ & $\mathbf{6 0} \mathbf{~ e m ~ 6 0}$ \\
\hline Máximo & 0.2493 & 0.2454 & 0.24 \\
\hline Mínimo & 0.07328 & 0.0758 & 0.07655 \\
\hline Média aritmética & 0.1096 & 0.1097 & 0.1098 \\
\hline Dédia quadrática & 0.1117 & 0.1117 & 0.1117 \\
\hline P 95\% & 0.0217 & 0.02126 & 0.02074 \\
\hline P99\% & 0.15034 & 0.14606 & 0.14528 \\
\hline
\end{tabular}

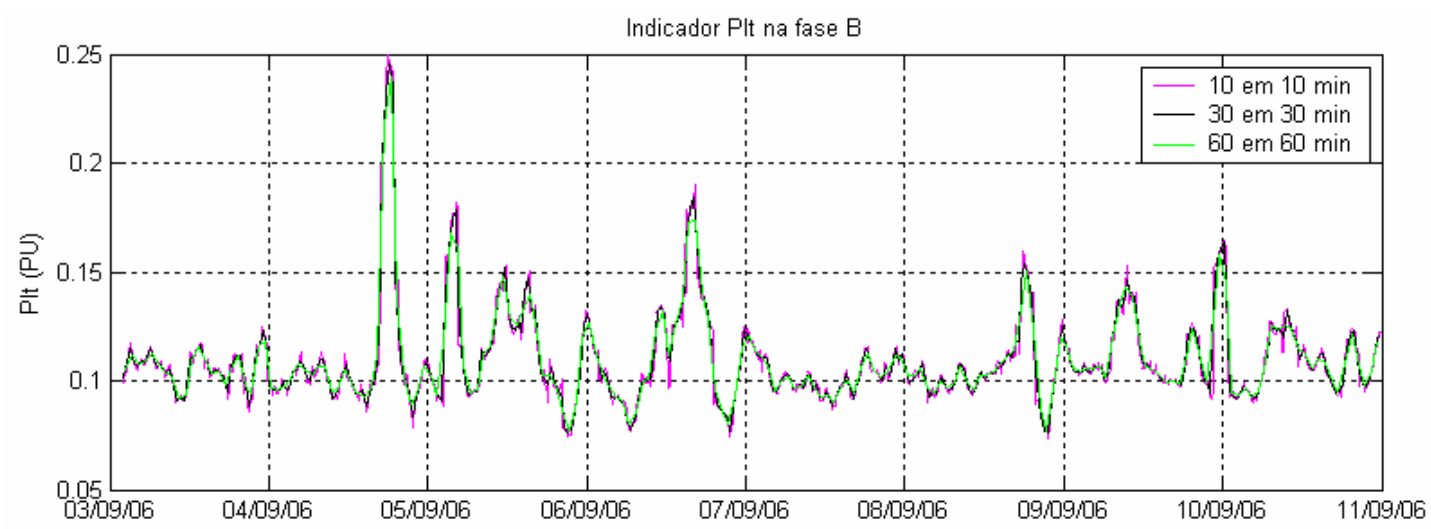

Figura 5.7 - Gráfico de linha do indicador Plt na fase B.

Da curva exposta na figura 5.7 verifica-se a alta semelhança entre o comportamento do indicador, segundo os intervalos analisados. Comparando-se os valores estatísticos, encontra-se uma discrepância percentual máxima, entre as médias aritméticas, igual a $0,18 \%$, sendo que os valores médios quadráticos são praticamente idênticos. Quanto aos indicadores $\mathrm{P} 95 \%$ e P99\%, a diferença entre as freqüências de 10 e 60 minutos, não ultrapassa os $4 \%$.

De posse destes dados, já é possível concluir que a medição do indicador Plt pode ser realizada utilizando-se 10, 30 ou 60 minutos como intervalos de aquisição dos dados. Entretanto, é apresentado ainda o gráfico de barras dos valores estatísticos, figura 5.8, bem como os gráficos de distribuição de probabilidade, figuras 5.9, 5.10 e 5.11. 


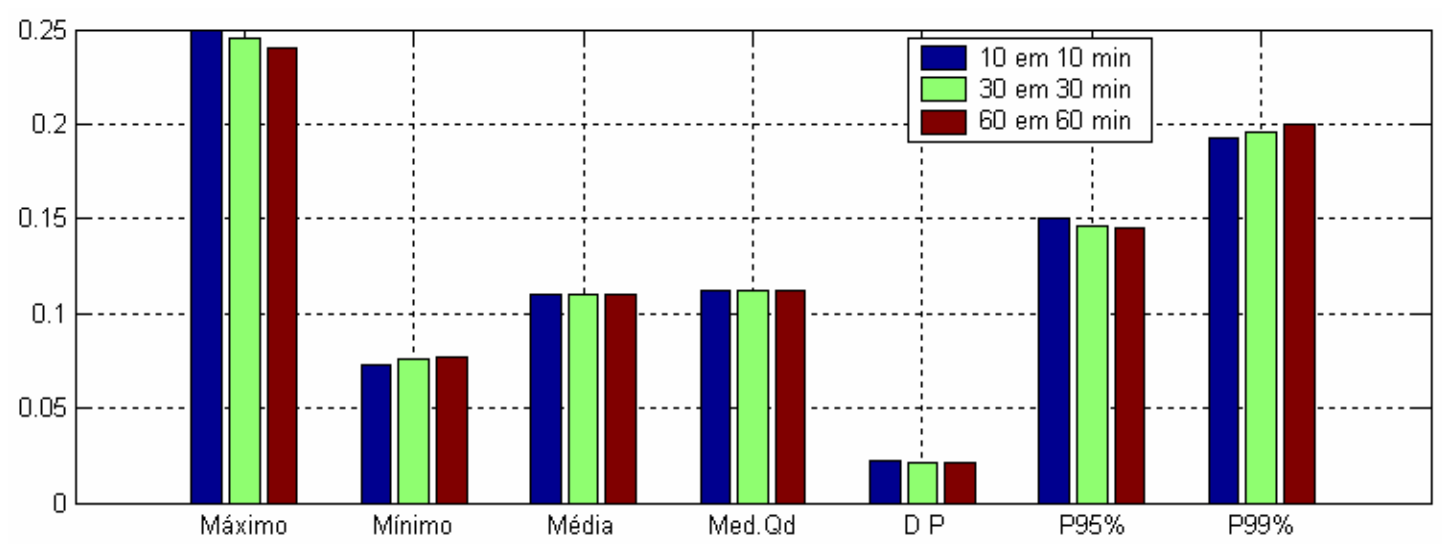

Figura 5.8 - Gráfico de barras com os valores da tabela 6.2.

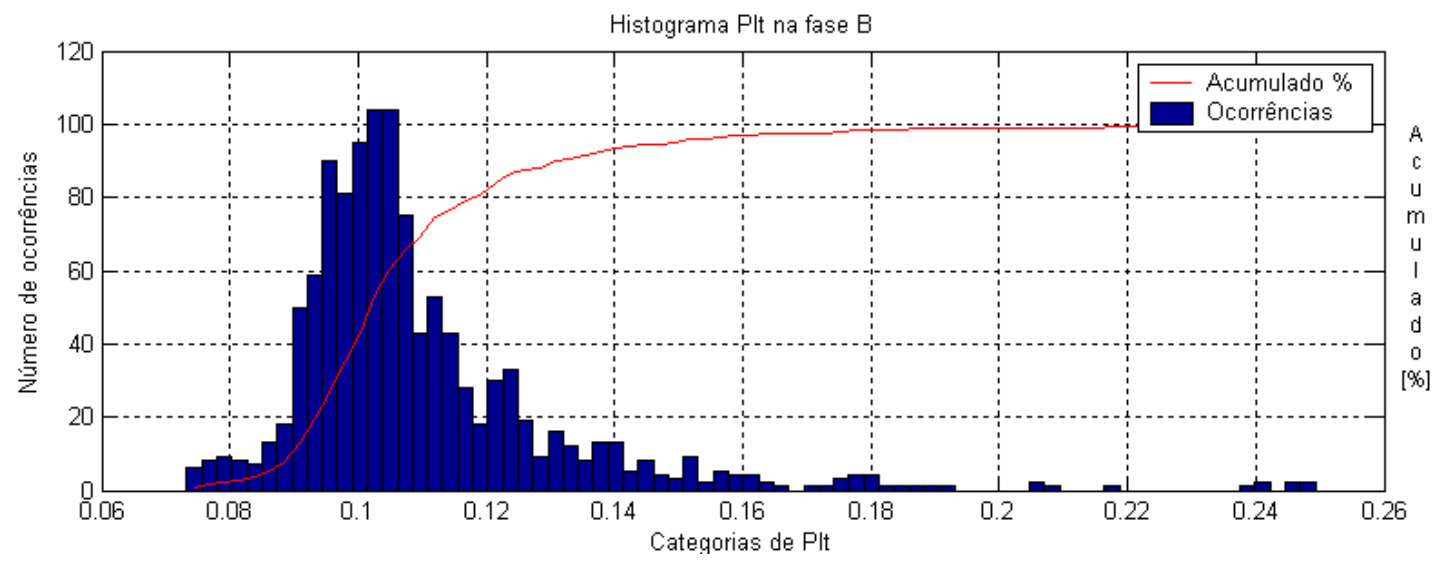

Figura 5.9 - Histograma e curva de probabilidade acumulada para freqüência de aquisição de 10 minutos.

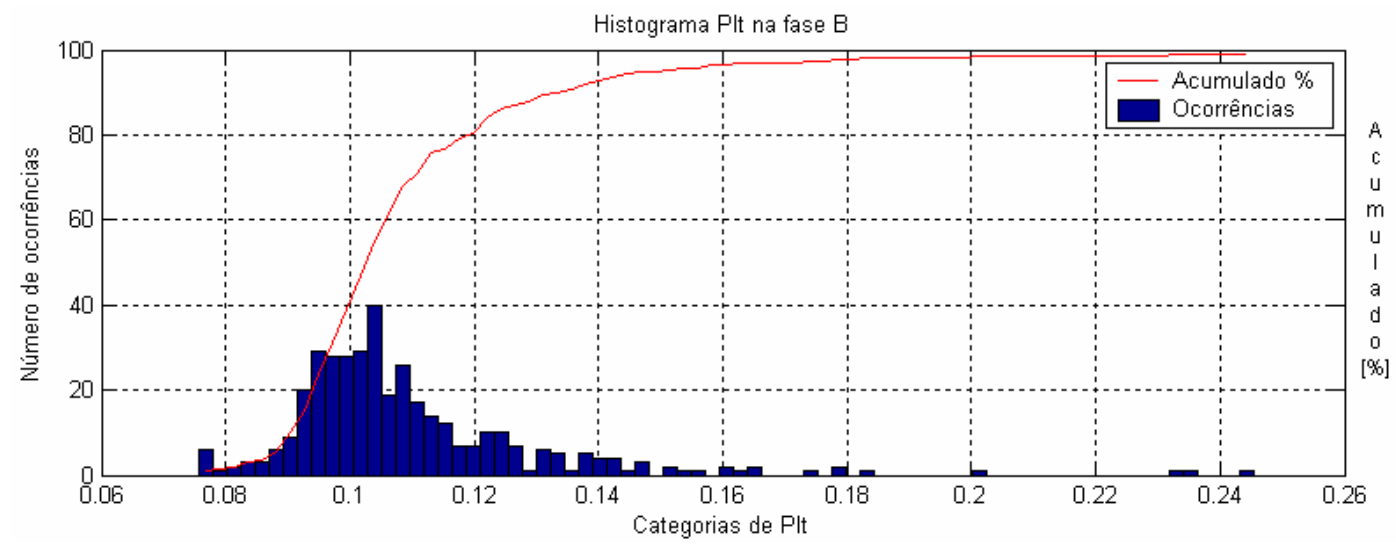

Figura 5.10 - Histograma e curva de probabilidade acumulada para frequiência de aquisição de 30 minutos. 


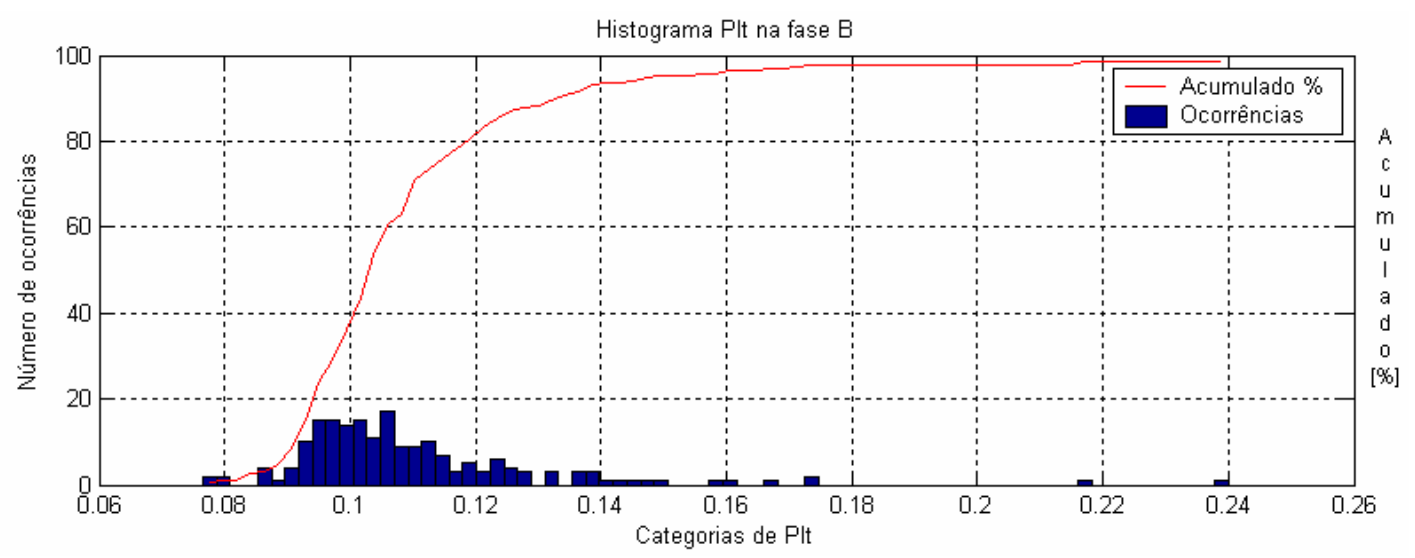

Figura 5.11 - Histograma e curva de probabilidade acumulada para frequiência de aquisição de 60 minutos.

As figuras 5.8, 5.9, 5.10 e 5.11 reforçam a idéia de que para flutuações de tensão provenientes do funcionamento de cargas com longo ciclo de operação, ou seja, avaliadas pelo Plt, a frequiência de aquisição dos dados não tem grande influência sobre o resultado final.

\subsection{CONSIDERAÇÕES FINAIS}

Este capítulo descreveu o módulo de análise da freqüência de aquisição de dados, realizando um estudo com dados da subestação ALBRAS da Eletronorte. Constatou-se que o indicador Pst não apresenta similaridade entre os diferentes intervalos de medição. Entretanto o índice Plt é altamente semelhante, podendo-se assim utilizar qualquer um dos intervalos de medição, sem prejuízo para a caracterização do banco de dados. No capítulo seguinte será descrito o módulo de análise da similaridade entre dias, para o mesmo banco de dados. 


\section{ANÁLISE DA SIMILARIDADE ENTRE DIAS E ENTRE PERÍODOS DO DIA}

As principais normas e recomendações nacionais ou internacionais adotam um intervalo de medição semanal como período total de monitoramento. Esta etapa visa constatar se um intervalo menor de medição é suficiente para a tomada de conclusões acertadas. Busca-se ainda comprovar a existência ou não da similaridade entre os períodos de um único dia. Este estudo se presta, portanto, para determinação do período ótimo de medições, com o intuito de se possibilitar rapidez e segurança no processamento dos dados.

\section{1 - Módulo de análise de similaridades entre dias}

A análise da similaridade entre dias pode ser iniciada clicando-se no botão intitulado "Similaridade entre dias", ou por meio do menu "Análises", ambos localizados na tela de entrada da ferramenta. A Figura 6.1 apresenta a estrutura e disposição do módulo em estudo.

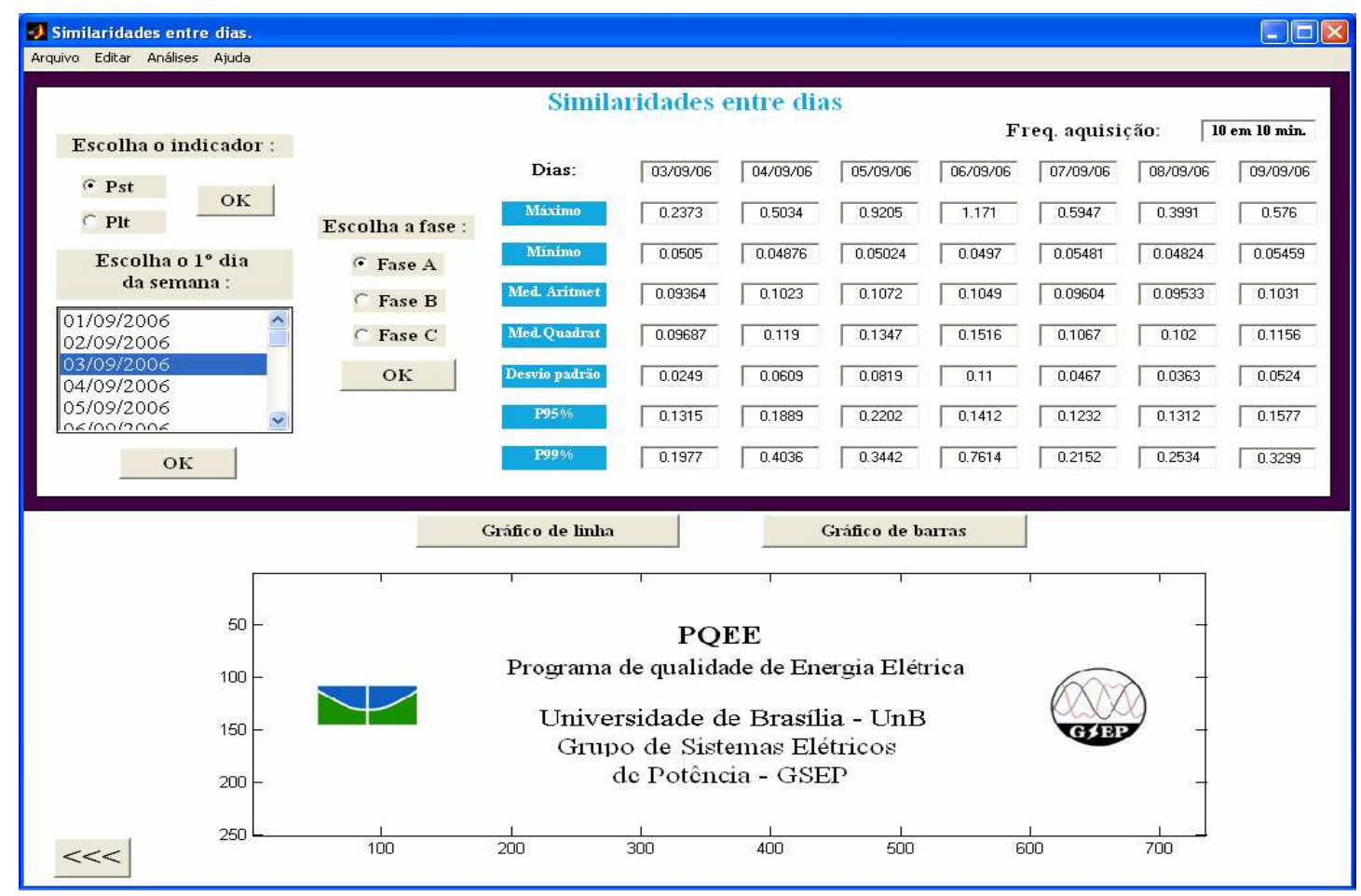

Figura 6.1 - Módulo de análise da similaridade entre dias. 
Conforme ilustrado na figura 6.1, procede-se a escolha do indicador, da fase, e por último seleciona-se o primeiro dos sete dias a serem estudados, marcando-se "Ok" após cada seleção. Depois de o usuário determinar a semana em análise, a ferramenta perguntará sobre qual freqüência de aquisição os cálculos estáticos devem ser baseados.

\section{2 - Módulo de análise de similaridades entre períodos do dia}

O módulo do aplicativo referente a essa análise divide o dia em três intervalos préestabelecidos e permite ao usuário a escolha de um outro período arbitrário. Os intervalos para comparação definidos pelo aplicativo são períodos de 8 horas de duração. São eles: de 00:00 às 08:00 horas, de 08:00 às 16:00 horas e de 16:00 às 24:00 horas. São também oferecidos valores estatísticos e opções gráficas. A figura 6.2 apresenta o módulo.

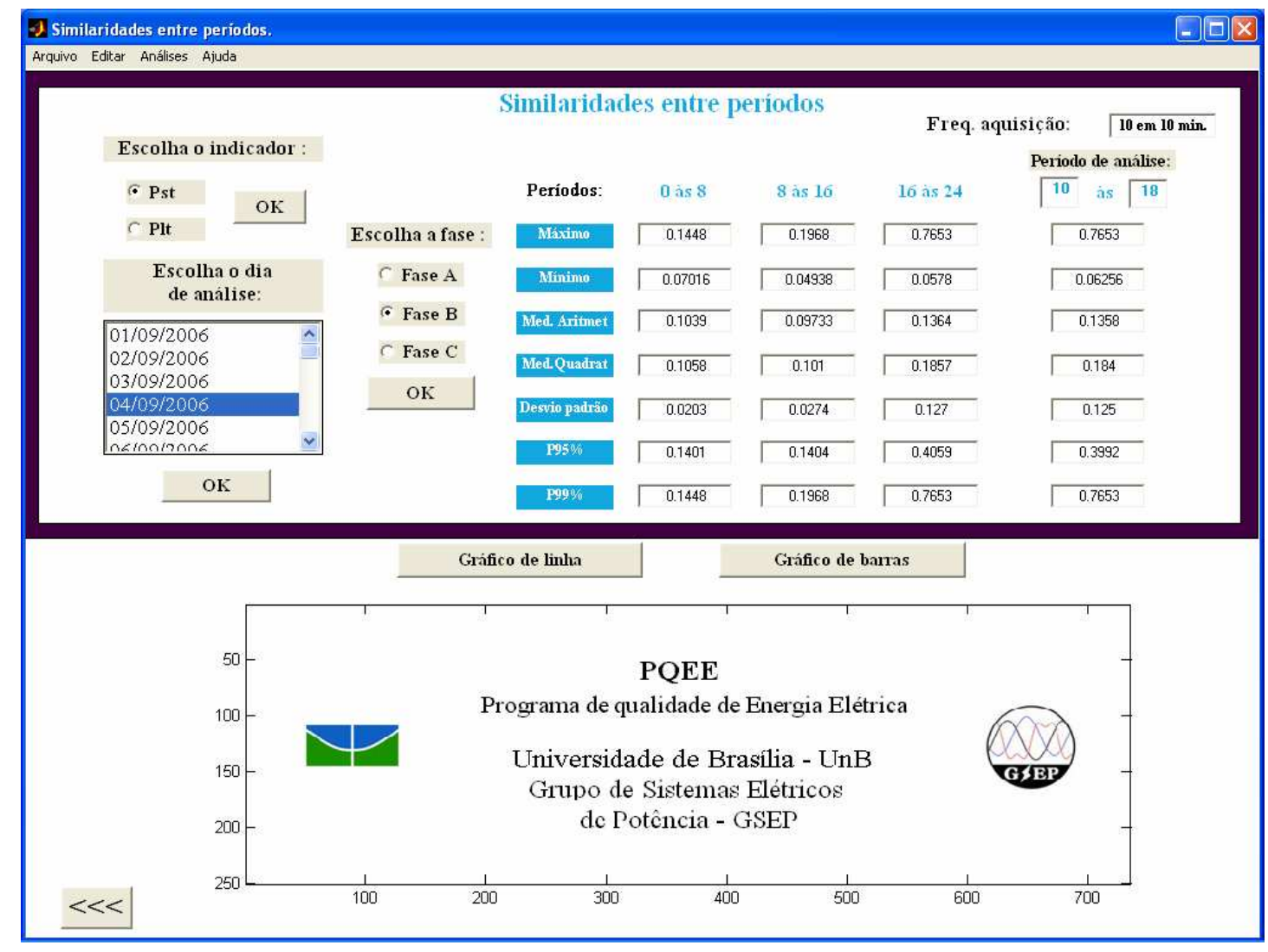

Figura 6.2 - Módulo de análise da similaridade entre períodos do dia.

Seguindo a execução, seleciona-se o indicador a ser analisado, confirmando no botão "Ok". Sucessivamente, escolhe-se a fase, bem como o dia a se estudar. Imediatamente após, na janela "Frequiência de Aquisição", escolhe-se uma opção para que se realize o 
cálculo dos índices estatísticos. São gerados gráficos ao se clicar nos botões gráfico de linha e de barras, que permitem uma comparação mais precisa do perfil dos índices de cintilação luminosa em cada faixa de intervalo.

\section{3 - Estudo de caso}

O propósito agora é caracterizar a similaridade entre dias da Subestação ALBRAS da Eletronorte. Para constatar a similaridade ou não entre os dias, recorre-se a dois métodos: análise gráfica da similaridade entre os dias e discussão das estatísticas encontradas. Ao todo, são considerados nesta análise, sete dias, constituindo uma semana: de 10/09/06 a 16/09/06. O estudo será empregado para os dois indicadores de cintilação, Pst e Plt.

\subsection{1 - Comparação entre os dias da subestação ALBRAS}

A figura 6.3 ilustra o comportamento do indicador Pst, tomado na fase B da subestação, durante a semana de medição.

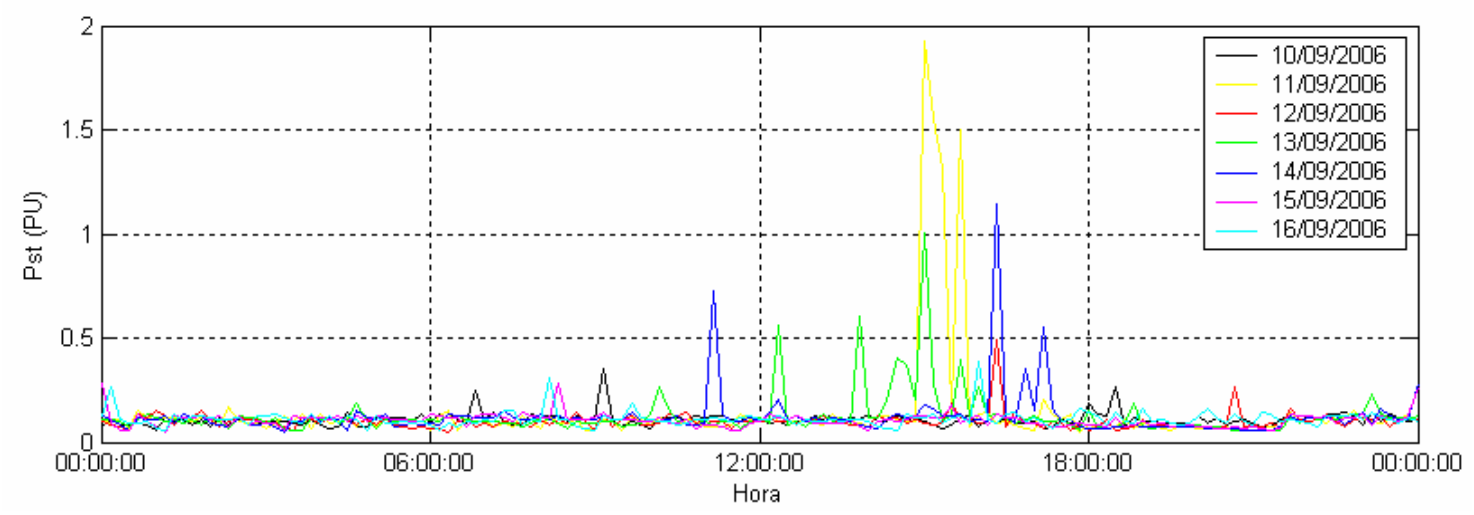

Figura 6.3 - Comportamento do indicador Pst.

A partir da figura 6.3, constata-se que o indicador permaneceu próximo a 0,1 pu, durante todos os dias em análise. É visto que em determinadas horas houve picos que excederam 1,0 pu. Todavia, estas elevações não causam demasiada preocupação por se saber que elas serão filtradas quando do estudo dos percentis. Fica claro que os maiores valores do indicador foram durante o meio da semana. Para auxiliar a análise, as estatísticas calculadas para esta subestação estão dispostas na tabela 6.1, e expostas no gráfico comparativo da figura 6.4. 
Tabela 6.1 - Valores estatísticos para o Pst.

\begin{tabular}{|c|c|c|c|c|c|c|c|}
\cline { 2 - 7 } \multicolumn{1}{c|}{} & $\mathbf{1 0 / 0 9}$ & $\mathbf{1 1 / 0 9}$ & $\mathbf{1 2 / 0 9}$ & $\mathbf{1 3 / 0 9}$ & $\mathbf{1 4 / 0 9}$ & $\mathbf{1 5 / 0 9}$ & $\mathbf{1 6 / 0 9}$ \\
\hline Máximo & 0.3501 & 1.928 & 0.4895 & 1.004 & 1.145 & 0.2861 & 0.3869 \\
\hline Mínimo & 0.0584 & 0.05213 & 0.04623 & 0.05294 & 0.05153 & 0.05213 & 0.05745 \\
\hline Média & 0.1082 & 0.1388 & 0.1003 & 0.1251 & 0.1215 & 0.1053 & 0.112 \\
\hline Med.quadrát. & 0.1134 & 0.2824 & 0.1089 & 0.1644 & 0.1655 & 0.1107 & 0.1183 \\
\hline Desvio p. & 0.0339 & 0.247 & 0.0426 & 0.107 & 0.113 & 0.0343 & 0.0383 \\
\hline P 95\% & 0.1405 & 0.156 & 0.1445 & 0.2695 & 0.1674 & 0.1383 & 0.1538 \\
\hline P99\% & 0.2657 & 1.573 & 0.2775 & 0.6282 & 0.7494 & 0.286 & 0.3086 \\
\hline
\end{tabular}

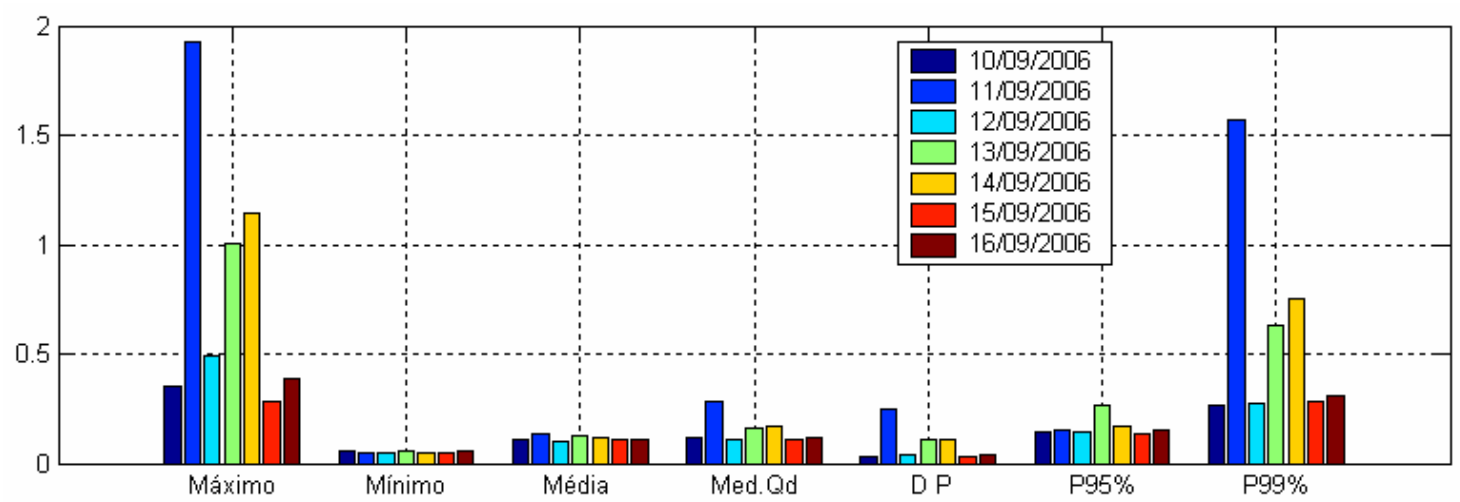

Figura 6.4 - Estatísticas dos valores de Pst para os sete dias.

A partir da tabela 6.1 e das figuras 6.3 e 6.4, pode-se perceber a grande disparidade entre os valores máximos do indicador, bem como a constância de seu valor mínimo. Todavia, é mais interessante analisar o resultado médio das amostras. Desta forma, tem-se um valor médio praticamente constante. A média quadrática apresenta discrepância máxima igual a 61,4\%. Entretanto, seus valores não ultrapassam 0,3 pu. Analisando o P95\% nota-se que, excetuando-se o dia 13, todos os outros dias apresentaram valores próximos a 0,15 pu. Encontrando-se a maior diferença entre os dias 13 e 15, sendo igual a 48,7\%. 
Trabalhando agora com o indicador de longa duração, Plt, tem-se a curva ilustrada na figura 6.5.

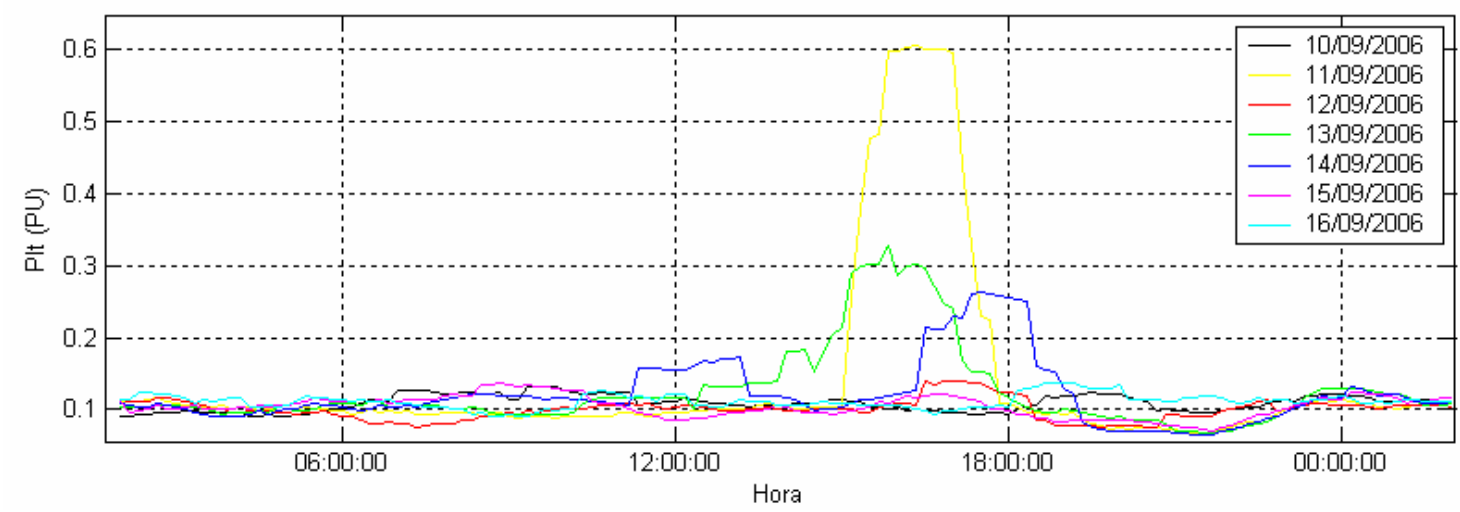

Figura 6.5 - Comportamento do indicador Plt.

Das curvas acima, percebe-se semelhanças entre os dias da semana, excetuando-se os momentos onde há picos. Os dias 11, 13 e 14 são os únicos a apresentar grandes diferenças no comportamento do indicador. Os valores calculados pelo ferramental estatístico, expostos na tabela 6.2 e na figura 6.6, comprovam a pouca diferença entre os dias da semana estudada.

Tabela 6.2 - Valores estatísticos para o Plt.

\begin{tabular}{|c|c|c|c|c|c|c|c|}
\cline { 2 - 8 } \multicolumn{1}{c|}{} & $\mathbf{1 0 / 0 9}$ & $\mathbf{1 1 / 0 9}$ & $\mathbf{1 2 / 0 9}$ & $\mathbf{1 3 / 0 9}$ & $\mathbf{1 4 / 0 9}$ & $\mathbf{1 5 / 0 9}$ & $\mathbf{1 6 / 0 9}$ \\
\hline Máximo & 0.1328 & 0.6034 & 0.1403 & 0.3269 & 0.2629 & 0.1359 & 0.1384 \\
\hline Mínimo & 0.09018 & 0.06743 & 0.07489 & 0.06679 & 0.06488 & 0.0714 & 0.09041 \\
\hline Média & 0.1091 & 0.1385 & 0.1005 & 0.1249 & 0.1209 & 0.1045 & 0.1119 \\
\hline Med.quadrát. & 0.1096 & 0.1887 & 0.1015 & 0.1365 & 0.1284 & 0.1055 & 0.1124 \\
\hline Desvio p. & 0.0113 & 0.129 & 0.0141 & 0.0554 & 0.0435 & 0.015 & 0.00981 \\
\hline P 95\% & 0.1265 & 0.5956 & 0.1319 & 0.2896 & 0.2346 & 0.1324 & 0.131 \\
\hline P99\% & 0.1319 & 0.6017 & 0.1392 & 0.3027 & 0.2604 & 0.1341 & 0.1383 \\
\hline
\end{tabular}




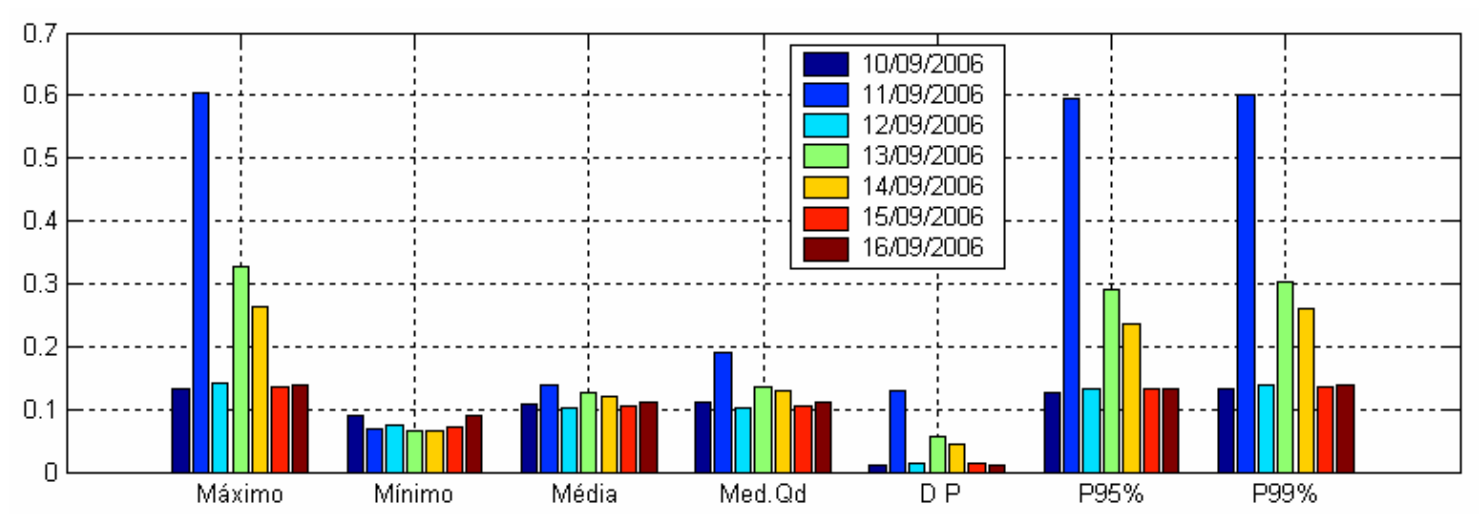

Figura 6.6 - Estatísticas dos valores de Plt para os sete dias.

Inferi-se da tabela 6.2 e da figura 6.6 que os valores médios do indicador Plt estiveram sempre próximos a $0,1 \mathrm{pu}$, ocorrendo uma distorção máxima de $27,4 \%$ para a média aritmética e 46,2\% para a quadrática. Com relação ao P95\% e ao P99\%, percebe-se grande semelhança entre eles. É fato que há um elevado desnível entre os valores calculados para os percentis, todavia, deve-se perceber que ambos estão abaixo dos limites estipulados pela resolução.

Fica claro que os resultados encontrados durante o meio da semana são superiores aos de fim de semana. Todavia, um maior entendimento dos processos desenvolvidos nesta subestação é demandado para que se possa tecer conclusões consistentes sobre esses resultados.

Assim, apesar das diferenças constatadas nos valores dos indicadores, Pst e Plt, para os sete dias, as baixas discrepâncias entre os patamares médios apresentados permitem que um dia seja tomado como representativo aos demais. Para este propósito aconselhasse um dia útil.

\subsection{2 - Similaridades entre os períodos de um dia}

Com o intuito de se identificar um intervalo mínimo de medição no qual se possa obter um valor representativo aos dados em análise, tem-se a figura 6.7 e 6.8 que apresentam o comportamento do Pst e do Plt durante o dia 5 de setembro de 2006 (terça-feira). Para esta análise, além dos três períodos fixados pelo aplicativo, será utilizado o período de 10:00 às 18:00 horas. 


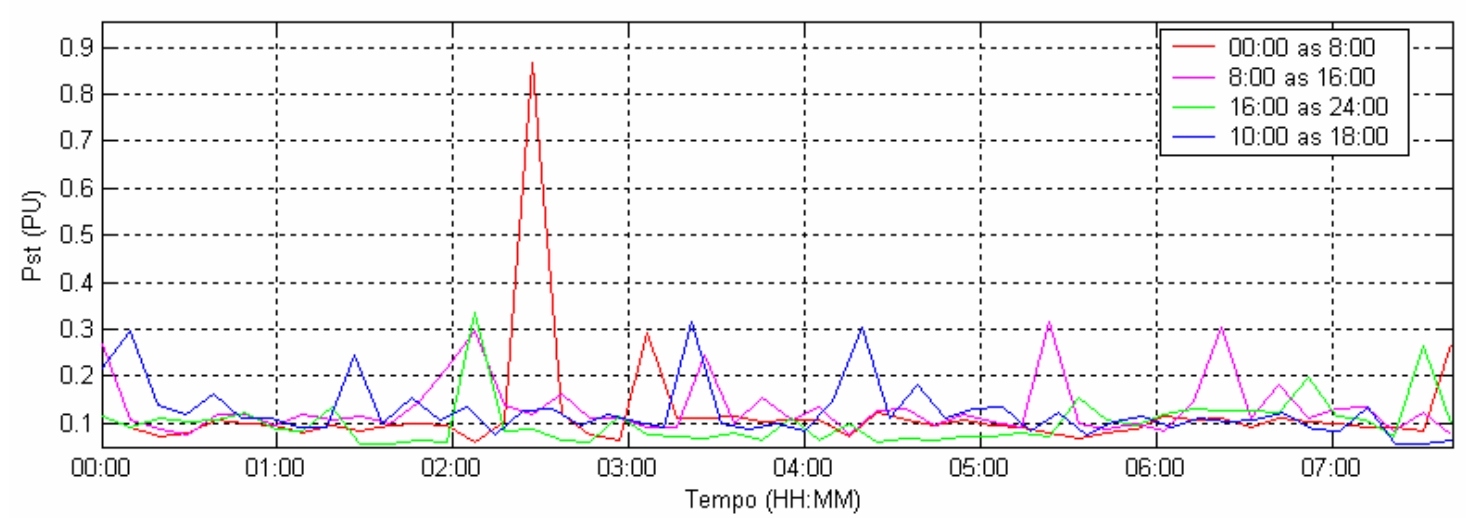

Figura 6.7 - Perfil do Pst durante o dia 5.

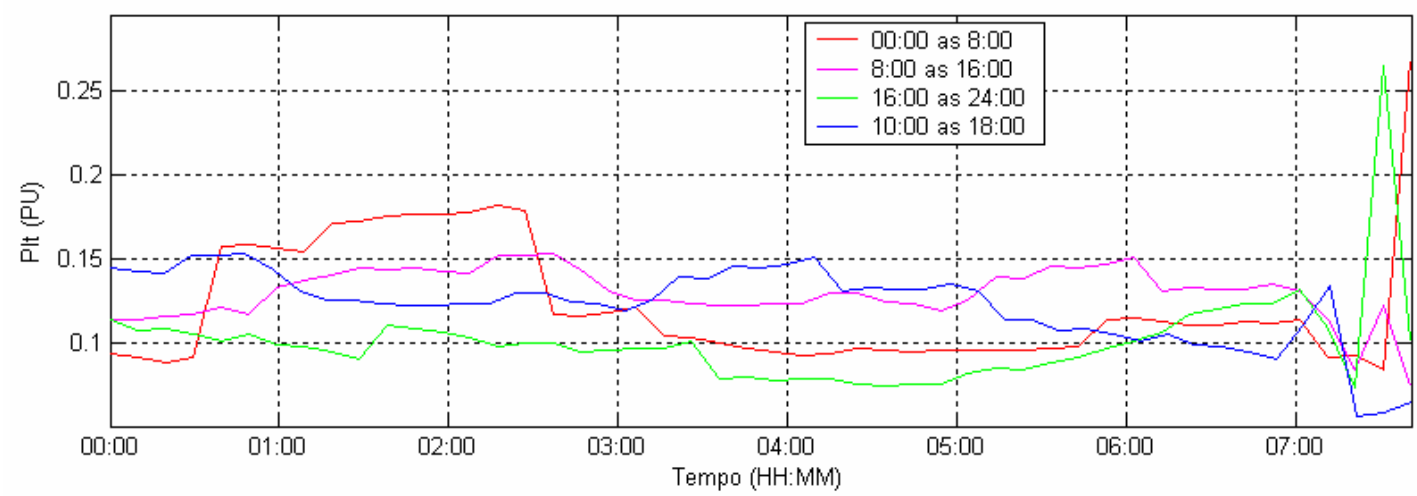

Figura 6.8 - Perfil do Plt durante o dia 5.

Observa-se das figuras 6.7 e 6.8 que o nível de cintilação permanece mais elevado durante o horário comercial, das 08:00 às 18:00 horas. Todavia, o maior pico de Pst ocorre durante a madrugada, próximo às duas e meia da manhã.

As tabelas 6.3 e 6.4 e as figuras 6.9 e 6.10 apresentam os valores estatísticos e o respectivo gráfico de barras para os períodos em estudo.

Tabela 6.3 - Valores estatísticos para o Pst.

\begin{tabular}{|c|c|c|c|c|}
\cline { 2 - 5 } \multicolumn{1}{c|}{} & $\mathbf{0}$ às 8 & $\mathbf{8}$ às 16 & $\mathbf{1 6}$ às 24 & $\mathbf{1 0}$ às 18 \\
\hline Máximo & 0.869 & 0.3177 & 0.3352 & 0.3177 \\
\hline Mínimo & 0.05808 & 0.07433 & 0.05568 & 0.05568 \\
\hline Média aritmética & 0.1193 & 0.1319 & 0.102 & 0.1254 \\
\hline Média quadrática & 0.1667 & 0.1446 & 0.1139 & 0.1381 \\
\hline Desvio padrão & 0.118 & 0.0597 & 0.0514 & 0.0586 \\
\hline P 95\% & 0.2712 & 0.2982 & 0.2039 & 0.2982 \\
\hline P99\% & 0.869 & 0.3177 & 0.3352 & 0.3177 \\
\hline
\end{tabular}


Tabela 6.4 - Valores estatísticos para o Plt.

\begin{tabular}{|c|c|c|c|c|}
\cline { 2 - 5 } \multicolumn{1}{c|}{} & $\mathbf{0}$ às 8 & $\mathbf{8}$ às 16 & $\mathbf{1 6}$ às 24 & $\mathbf{1 0}$ às $\mathbf{1 8}$ \\
\hline Máximo & 0.1819 & 0.1529 & 0.1322 & 0.1529 \\
\hline Mínimo & 0.08852 & 0.06145 & 0.07431 & 0.08789 \\
\hline Média aritmética & 0.119 & 0.1274 & 0.09743 & 0.125 \\
\hline Média quadrática & 0.1229 & 0.1288 & 0.09847 & 0.1261 \\
\hline Desvio padrão & 0.0311 & 0.0196 & 0.0144 & 0.0172 \\
\hline P 95\% & 0.1779 & 0.1522 & 0.1229 & 0.1522 \\
\hline P99\% & 0.1819 & 0.1529 & 0.1322 & 0.1529 \\
\hline
\end{tabular}

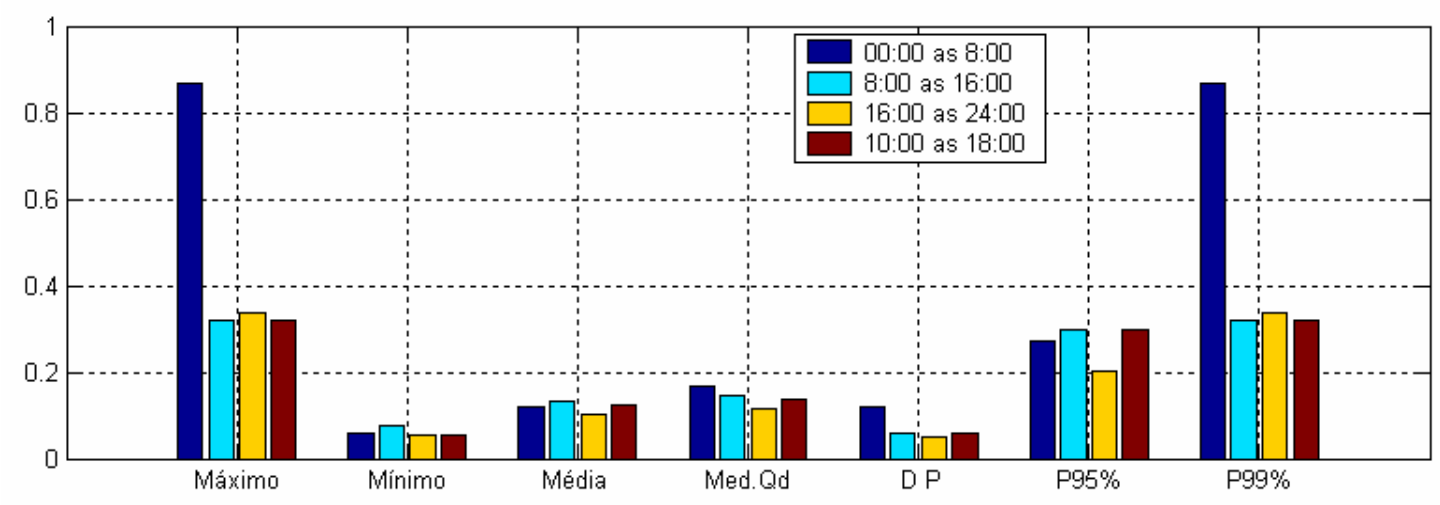

Figura 6.9 - Similaridade entre períodos do dia 05/09, para o indicador Pst.

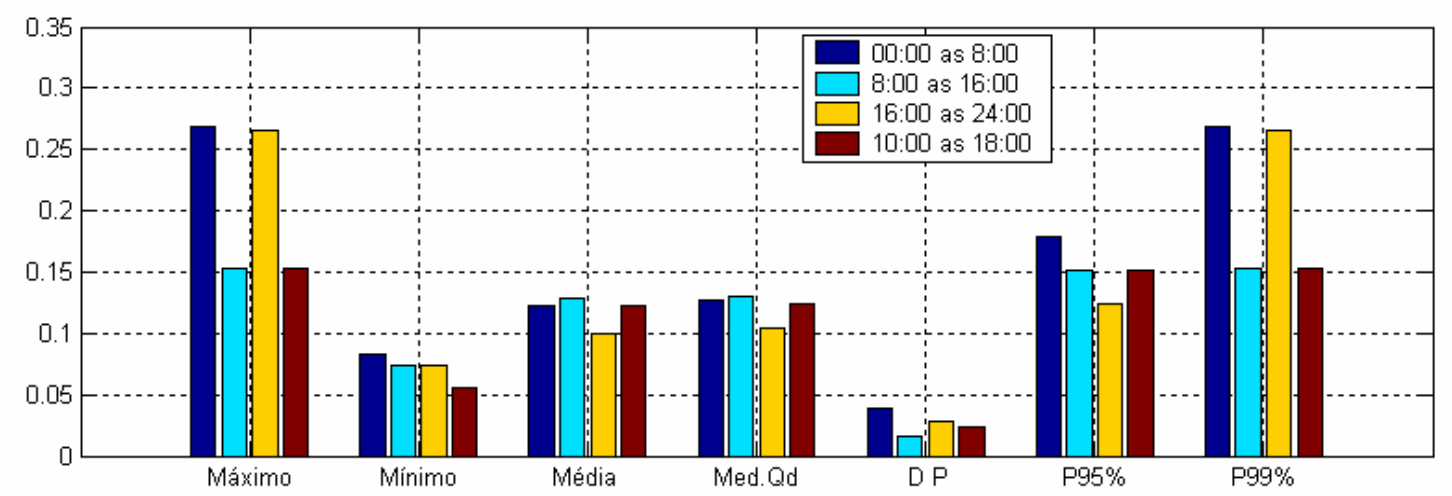

Figura 6.10 - Similaridade entre períodos do dia 05/09, para o indicador Plt.

Das tabelas 6.3 e 6.4 e das figuras 6.9 e 6.10 nota-se que no período da noite são encontradas as menores médias. Todavia, para o presente dia analisado, a média encontrada para o período referente a 00:00 às 08:00 horas apresenta um acréscimo devido 
o fato de uma perturbação ter sido verificada próxima as 02:30 horas, o que representa uma anomalia.

Percebe-se que não há um padrão de comportamento entre os valores apresentados neste tópico, que permita concluir sobre a representatividade de um único período no tocante ao processo de aquisição de dados.

\section{4 - Considerações finais}

Buscou-se neste capítulo observar a similaridade entre os dias em estudo com vistas a constatar se o intervalo semanal, recomendado pela maior parte das normas, é, de fato, o mais adequado. A partir dos resultados obtidos das análises gráficas e dos valores estatísticos percebeu-se a não similaridade entre os dias, para o indicador Pst, diferentemente do que ocorre com o Plt. Investigou-se, ainda, a similaridade entre períodos de um dia de modo que, apesar de haver disparidade entre os valores dos indicadores nos diferentes intervalos, verificou-se que em média os valores máximos ocorrem no período de 09:00 às 18:00 horas. Assim, para o local em estudo, não se recomenda a limitação dos dias de medição, pelo fato de surtos ocorrerem de forma distribuída entre os dias. 


\section{CAPÍTULO 7}

\section{ANÁLISE DE SIMILARIDADE ENTRE FASES}

As principais normas / recomendações internacionais determinam a monitoração e análise das cintilações luminosas de todas as fases de tensão. Busca-se aqui, a partir da aplicação de métodos de análise, comprovar a existência ou não de similaridade entre os valores de Pst e Plt observados nas três fases de tensão, no intervalo de medição. Deseja-se verificar a possibilidade de se adotar uma fase como representativa às demais. Como consequiência ter-se-á uma redução do volume de dados a serem processados.

\subsection{ESTRUTURA DO MÓDULO}

A figura 7.1 mostra a tela do aplicativo dedicada à análise de similaridade entre fases.

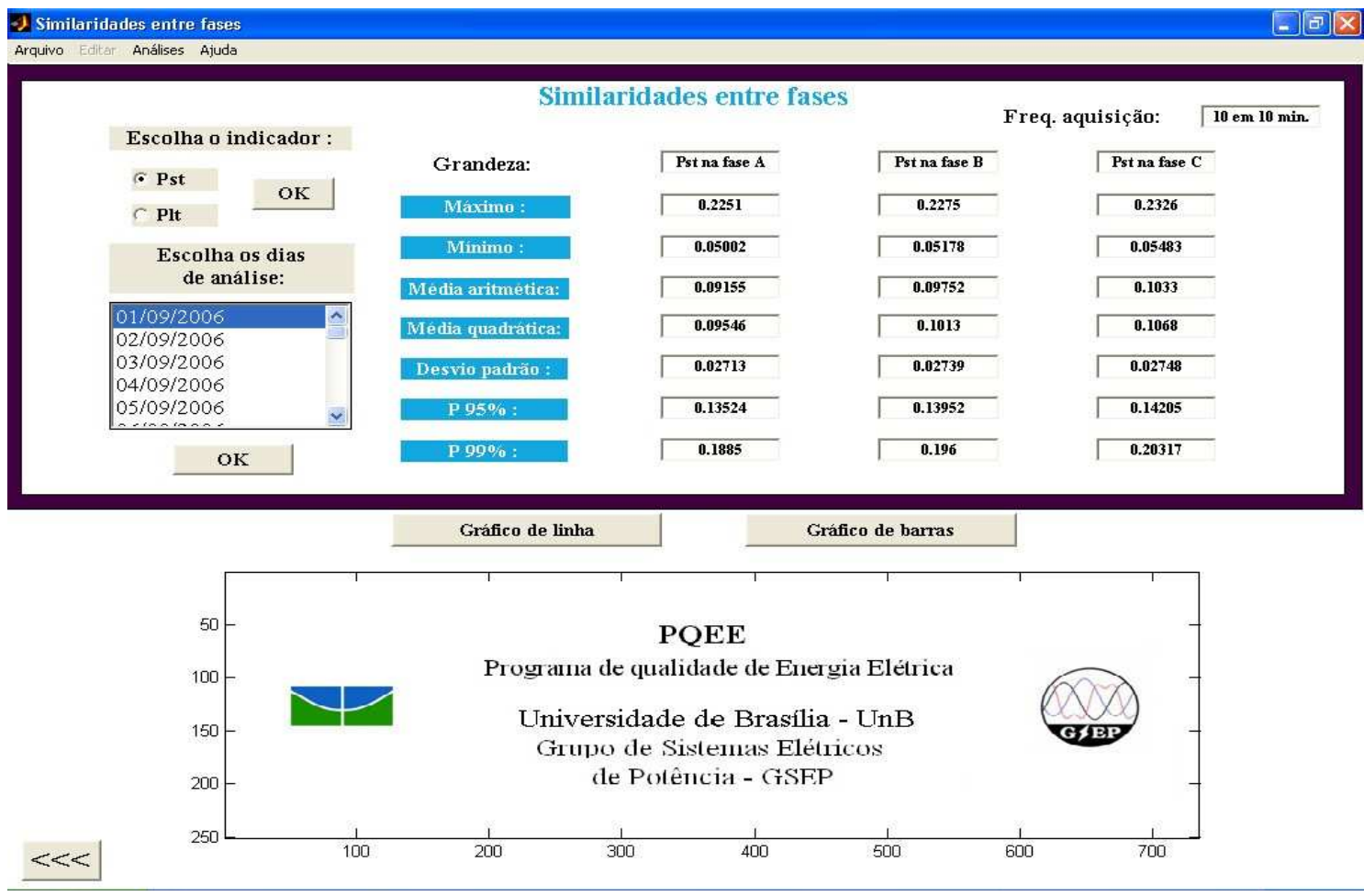

Figura 7.1 - Módulo de análise de similaridade entre fases. 
A análise da similaridade entre fases pode ser iniciada por meio do botão "Similaridade entre Fases" ou pelo menu "Análises", ambos localizados na tela de entrada. A avaliação se inicia com a seleção da grandeza a ser comparada nas três fases, escolhe-se o dia ou os dias a serem analisados e clica-se no botão "OK" localizado abaixo das datas. Abrir-se-á uma janela com três freqüências de aquisição. O usuário deverá selecionar uma das opções e clicar em "OK”. A figura 7.2 ilustra a janela de freqüência de aquisição dos dados.

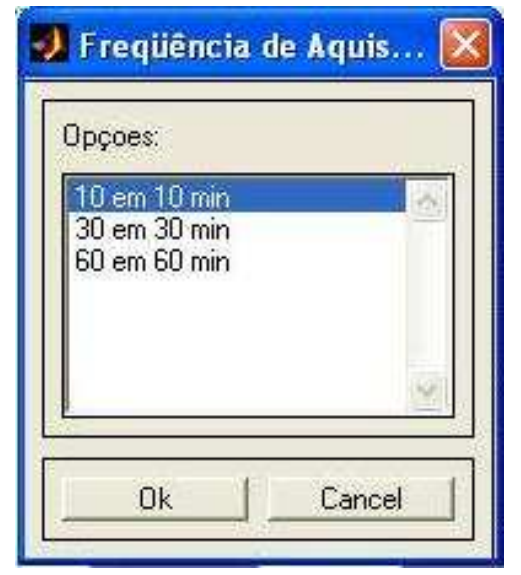

Figura 7.2 - Escolha da frequiência de aquisição dos dados

Para conclusão a respeito da similaridade entre as fases disponibilizam-se dados estatísticos em uma tabela, além de opções de análises gráficas ponto a ponto e de barras.

\subsection{ESTUDO DE CASO}

A fim de se examinar a similaridade ou não entre as fases, analisar-se-á as amostras medidas por três diferentes métodos: comparação gráfica, estudo dos valores médios e desvios padrão e o P95\%. São considerados nesse estudo os dados coletados com uma freqüência de aquisição de 10 minutos, durante 7 dias consecutivos: de 01/09/06 a 07/09/06. 


\subsubsection{COMPARAÇÃO GRÁFICA ENTRE AS FASES DA SE ALBRAS L1}

As figuras 7.3 e 7.4 exibem o comportamento dos indicadores de severidade de flicker

Pst e Plt, medido nas três fases, no decorrer do período de uma semana.

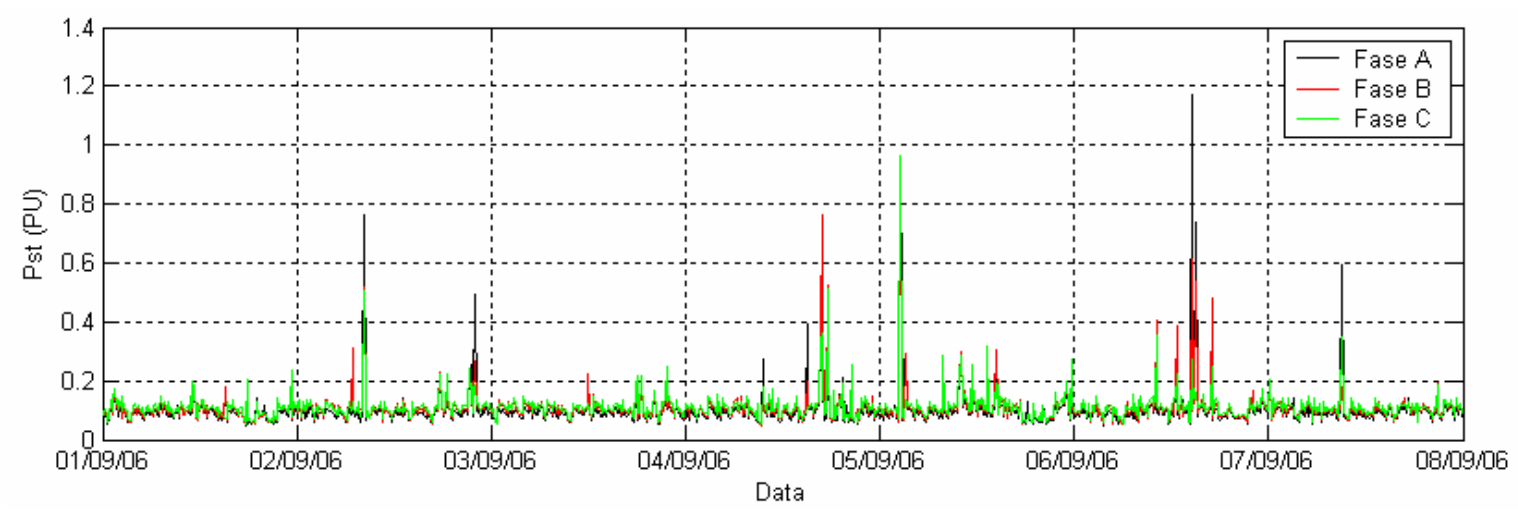

Figura 7.3 - Pst ponto a ponto para cada fase

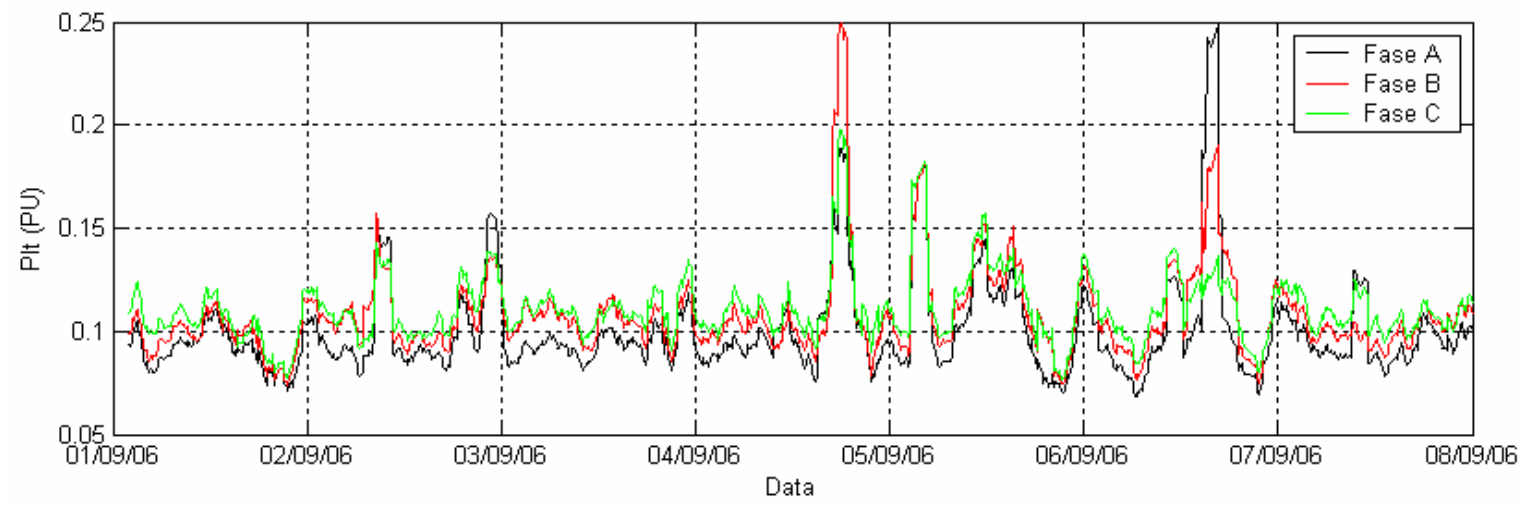

Figura 7.4 - Plt ponto a ponto para cada fase

Diante das figuras, observa-se que para a maioria das amostras, os valores de Pst se encontram abaixo de 0,5 e os valores de Plt estão abaixo 0,2. Verifica-se que para quase todo o período de medição os indicadores de severidade de flicker das três fases possuem valores próximos entre si.

As amostras de Pst se sobrepõem durante a maior parte do período, mas os valores da fase c se mostram um pouco mais elevados que os valores das demais fases. Observando a figura 7.4 percebe-se claramente que os valores da fase c são maiores que os das fases a e c. Porém os valores continuam próximos entre si. Esta afirmação é baseada no fato do valor do Plt ser a média cúbica de 12 valores consecutivos de Pst. 
A análise gráfica é bastante útil para o estudo da similaridade entre as fases, mas não é suficiente para concluir qual fase é melhor para representar o comportamento dos indicadores. A fim de complementar o estudo do perfil das três fases ao longo da semana de observação, realizar-se-á a comparação entre os valores estatísticos dos indicadores Pst e Plt entre as mesmas.

\subsubsection{ANÁLISE DOS VALORES MÉDIOS E DESVIOS PADRÃO ENTRE AS FASES DA SE ALBRAS L1}

A tabela 7.1 apresenta os valores estatísticos referentes ao Pst das três fases. A figura 7.5 dispõe esses dados num gráfico de barras.

Tabela 7.1 - Dados estatísticos do Pst

\begin{tabular}{|c|c|c|c|}
\hline Grandeza: & Psta (p.u.) & Pstb (p.u.) & Pstc (p.u.) \\
\hline Máximo & 1,171 & 0,869 & 0,962 \\
\hline Mínimo & 0,049 & 0,049 & 0,054 \\
\hline Méd. Aritm. & 0,099 & 0,107 & 0,111 \\
\hline Méd.Quad. & 0,119 & 0,122 & 0,120 \\
\hline Desvio Padrão & 0,067 & 0,057 & 0,047 \\
\hline P95\% & 0,144 & 0,153 & 0,155 \\
\hline P99\% & 0,365 & 0,365 & 0,286 \\
\hline
\end{tabular}

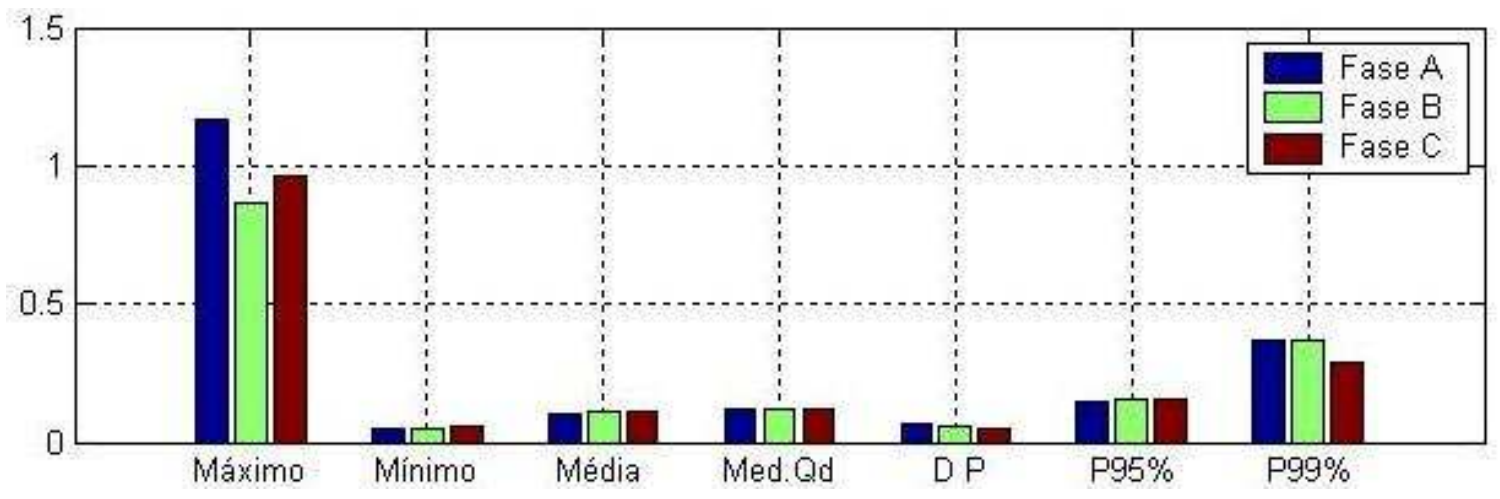

Figura 7.5 - Gráfico de barras com os dados da tabela 7.1

A tabela 7.2 apresenta os valores estatísticos referentes ao Plt das três fases. A figura 7.6 dispõe esses dados num gráfico de barras. 
Tabela 7.2 - Dados estatísticos do Plt

\begin{tabular}{|c|c|c|c|}
\hline Grandeza: & Plta (p.u.) & Pltb (p.u.) & Pltc (p.u.) \\
\hline Máximo & 0,248 & 0,249 & 0,198 \\
\hline Mínimo & 0,068 & 0,073 & 0,076 \\
\hline Méd Aritm. & 0,099 & 0,107 & 0,111 \\
\hline Méd Quad. & 0,102 & 0,110 & 0,112 \\
\hline Desvio Padrão & 0,024 & 0,022 & 0,017 \\
\hline P95\% & 0,147 & 0,145 & 0,138 \\
\hline P99\% & 0,188 & 0,205 & 0,179 \\
\hline
\end{tabular}

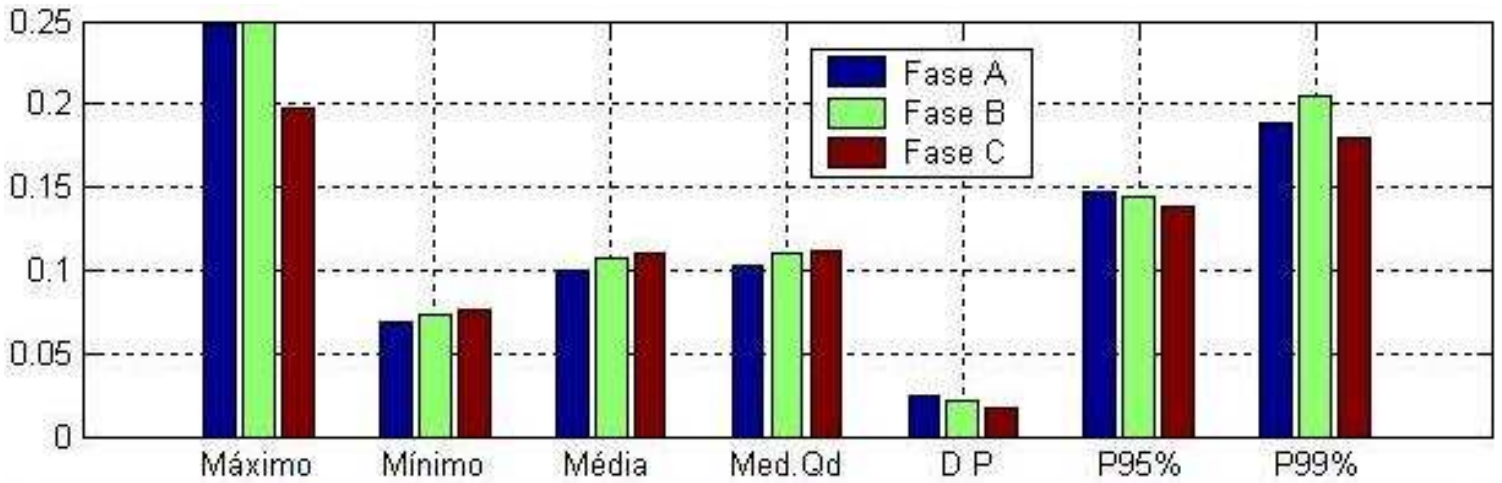

Figura 7.6 - Gráfico de barras com os dados da tabela 7.2

Examinando a tabela 7.1 e a figura 7.5, tem-se que a variação máxima da média aritmética é de $10,8 \%$ e da média quadrática é de $8,93 \%$, detectada quando da avaliação das fases a e c.

Observa-se, a partir da tabela 7.2 e da figura 7.6, que a variação máxima da média aritmética é de $10,8 \%$ e da média quadrática é de $8,9 \%$, detectadas quando da avaliação das fases a e c.

Das tabelas 7.1 e 7.2, verifica-se que o maior desvio padrão ocorre no Pst da fase a e ele representa 67,6\% do seu respectivo valor médio. Entende-se, portanto que há uma grande variação das amostras em questão em relação à média aritmética.

Das figuras 7.5 e 7.6, observa-se que para esta subestação, o desvio padrão e o valor médio das amostras relacionam-se de maneira inversa. Quanto maior a média, menor o desvio apresentado. 
Tem-se também das tabelas 7.1 e 7.2 que a P95\% de cada fase apresenta valores próximos de 1,5 p.u. e de 1,45 p.u., respectivamente. A variação máxima dos dois indicadores entre as três fases é de 7,1\%. Desta forma, destaca-se a semelhança dos valores de P95\% entre as três fases de todos os dias em estudo. Outro ponto que merece ressalva concentra-se no fato dos valores P95\% estarem próximos das médias aritméticas e quadráticas e mais distantes dos valores máximos apresentados.

\subsection{CONSIDERAÇÕES FINAIS}

A partir da análise executada e com auxílio das figuras 7.5 e 7.6, pode-se concluir que, mesmo com os valores elevados de desvios padrão, tem-se um comportamento semelhante entre as três fases. Durante quase todo o período de medição, os valores de Pst das fases a, b e c apresentam valores próximos entre si, mas na maioria dos pontos eles não se sobrepõem.

Nota-se partir das figuras 7.3 e 7.4, que apesar dos gráficos ponto a ponto do Pstc e do Pltc serem similares aos dos Psta e Pstb e dos Plta e Pltb, na maior parte da semana estudada os valores de Pstc e de Pltc são superiores aos valores dos demais. Empregarse-á, portanto, a fase c para as demais análises deste estudo. O próximo capítulo trará uma análise de distribuição no tempo, valendo-se dos módulos correspondentes do aplicativo. 


\section{CAPÍTULO 8}

\section{ANÁLISE DE DISTRIBUIÇÃO NO TEMPO}

Este estudo propõe uma metodologia para análise da distribuição no tempo das amostras com valores superiores a média quadrática e aos indicadores com probabilidade de $95 \%$ e $99 \%$ de não serem excedidos. Fazendo-se uso de tais resultados, será possível aos fabricantes e interessados, a partir dos limites de suportabilidade de cada equipamento frente às cintilações luminosas, determinar se o seu equipamento suporta ou não os níveis detectados, em função do tempo de exposição.

Da metodologia, pode-se ainda avaliar quão representativos são os índices de média, P95\% e P99\% não serem excedidos, quando das suas utilizações em representação aos demais valores medidos. Esses patamares caracterizam-se como os indicadores comumente presentes nas recomendações / normas mundialmente conhecidas. Logo, considerando-se os resultados deste trabalho, tem-se a possibilidade de se reconhecer a eficácia ou não dos indicadores praticados pelos supra mencionados documentos, frente aos dados oriundos de medições de interesse do usuário. A seguir, será apresentado o módulo de análise de distribuição no tempo.

\subsection{ESTRUTURA DO MÓDULO}

Este módulo, ilustrado na figura 8.1, pode ser iniciado pelo botão "Análise de Distribuição no Tempo" ou pelo menu "Análises" ambos localizados na tela de entrada. Inicia-se a execução selecionando uma grandeza para análise.

Depois de confirmada a escolha da grandeza, deve-se proceder a especificação de um valor limite (VL) para se investigar o ambiente em estudo com relação aos limites impostos pelas principais Normas e Recomendações, limites de suportabilidade de equipamentos elétricos do local em estudo, níveis de cintilação em função do seu tempo de exposição, etc. 
Nota-se da figura 8.1 que há uma análise numérica que disponibiliza:

- Total da medição em minutos

- Tempo no qual a grandeza fica acima do Valor Limite especificado (VL)

- Máximo intervalo de tempo ininterrupto com um valor acima de VL

- Máximo intervalo de tempo ininterrupto com um valor abaixo de VL

Há também uma análise gráfica que revela:

- Valores acima de VL

- Valores abaixo de VL

- Intervalos de tempo ininterruptos com valor acima de VL

- Probabilidade de ocorrência de intervalos ininterruptos com valores acima de VL

- Intervalos de tempo ininterruptos com valores abaixo de VL

- Probabilidade de ocorrência de intervalos ininterruptos com valores abaixo de $\mathrm{VL}$

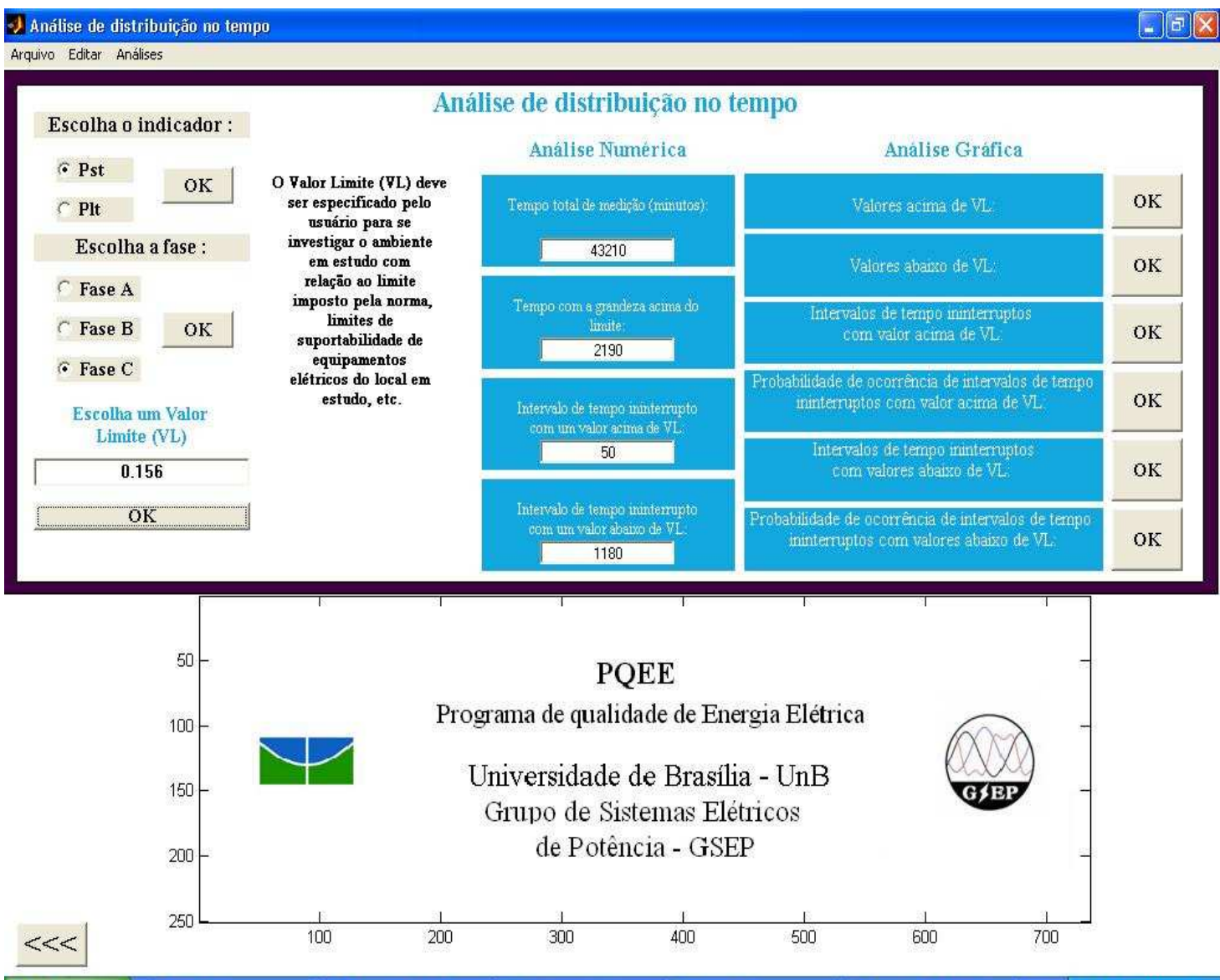

Figura 8.1 - Módulo de análise de distribuição no tempo 


\subsection{ESTUDO DE CASO}

As informações contidas no banco de dados serão processadas, culminando-se, dentre outros, em gráficos de intervalos ininterruptos de tempo com valores acima e abaixo dos valores médio quadrático, P95\% e P99\%. Analisar-se-á amostras de Pst e Plt da fase C, provenientes das medições de 30 dias consecutivos na linha 1 da SE ALBRAS.

\subsubsection{VALORES ESTATÍSTICOS DE PST E PLT}

As tabelas 8.1 e 8.2 ilustram os resultados estatísticos, de Pst e Plt respectivamente, calculados a partir das amostras coletadas no período citado. Para as análises a seguir, estes indicadores serão empregados como referência para os estudos aqui propostos.

Tabela 8.1 - Dados estatísticos do Pst

\begin{tabular}{|c|c|}
\hline Grandeza: & Pst (p.u.) \\
\hline Máximo & 8,296 \\
\hline Mínimo & 0,049 \\
\hline Média Aritmética & 0,115 \\
\hline Média Quadrática & 0,198 \\
\hline Desvio Padrão & 0,161 \\
\hline P95\% & 0,156 \\
\hline P99\% & 0,336 \\
\hline
\end{tabular}

Tabela 8.2 - Dados estatísticos do Plt

\begin{tabular}{|c|c|}
\hline Grandeza: & Plt (p.u.) \\
\hline Máximo & 1,323 \\
\hline Mínimo & 0,065 \\
\hline Média Aritmética & 0,115 \\
\hline Média Quadrática & 0,132 \\
\hline Desvio Padrão & 0,065 \\
\hline P95\% & 0,145 \\
\hline P99\% & 0,220 \\
\hline
\end{tabular}




\subsubsection{ANÁLISE CONSIDERANDO-SE O VALOR DE P95\% REFERÊNCIA}

O valor de P95\% calculado a partir dos dados em estudo foi de 0,156 para o Pst e de 0,145 para o Plt. As figuras 8.2 e 8.3 apresentam os gráficos de Pst $\geq 0,156$ e Plt $\geq$ 0,145 , respectivamente, versus tempo total de medição em minutos.

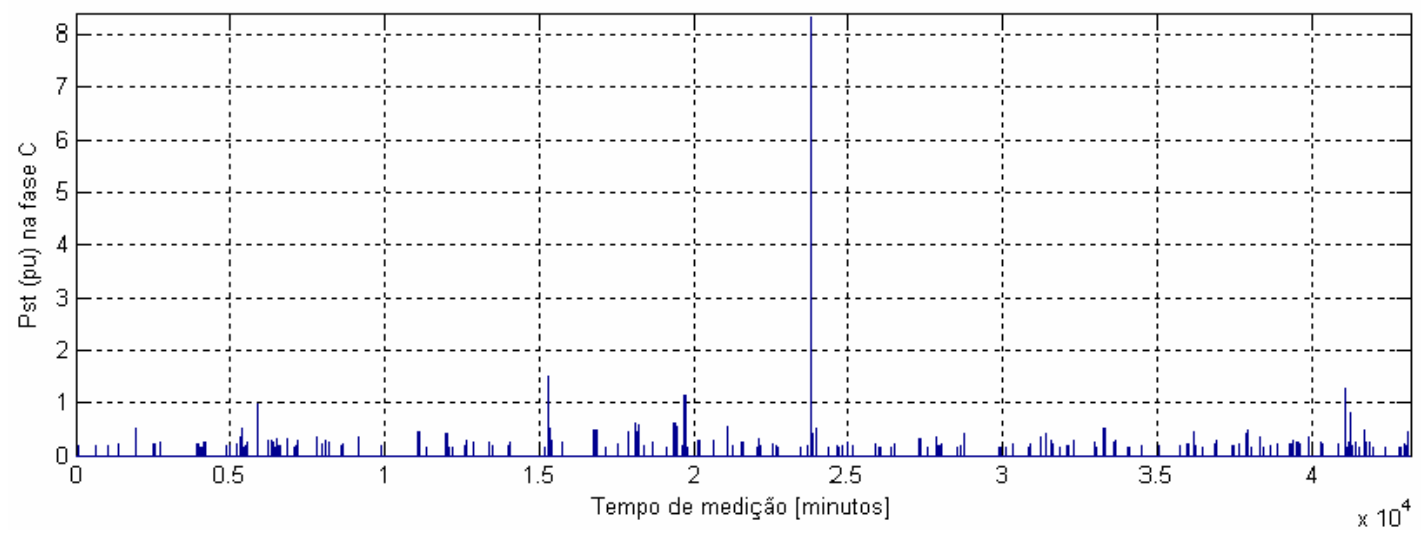

Figura 8.2 - Valores com Pst $\geq 0,156$ versus tempo total de medição em minutos.

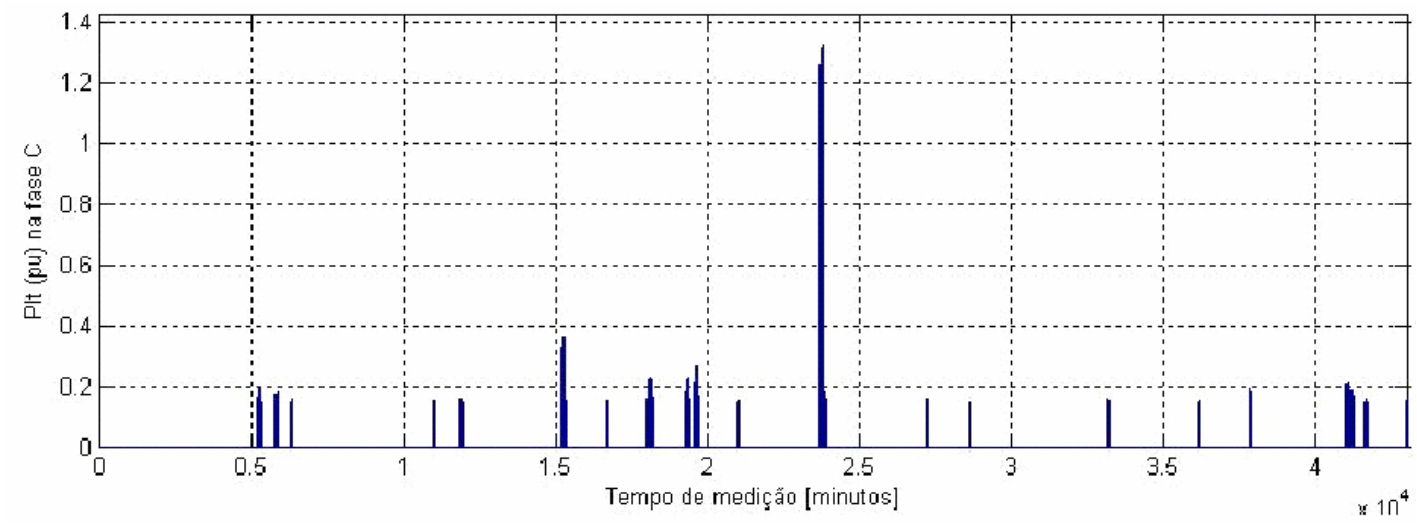

Figura 8.3 - Valores com Plt $\geq 0,145$ versus tempo total de medição em minutos.

Da figura 8.2 e com a análise numérica disponível no programa, observa-se que, de todo o período de medição em análise, aproximadamente 43210 minutos, cerca de 2190 minutos (5\% do tempo total de medição), apresentam Pst $\geq 0,156$. Nota-se da mesma figura que os valores de Pst $\geq 0,156$ estão distribuídos ao longo do período em observação. 
Da figura 8.3 e com a análise numérica disponível no programa, observa-se que, de todo o período de medição em análise, aproximadamente 43090 minutos, cerca de 2200 minutos (5,1\% do tempo total de medição), apresentam Plt $\geq 0,145$.

O período de medição do Pst difere do tempo de observação do Plt devido ao fato do indicador de longo prazo levar em consideração os últimos doze valores consecutivos do Pst. Logo, os primeiros 120 minutos de medição do Plt sofrem influência dos valores de Pst observados no período anterior ao desejado.

As figuras 8.4 e 8.5 mostram os gráficos com os intervalos ininterruptos de tempo com valores de Pst $\geq 0,156$ e valores de $\mathrm{Plt} \geq 0,145$, respectivamente.

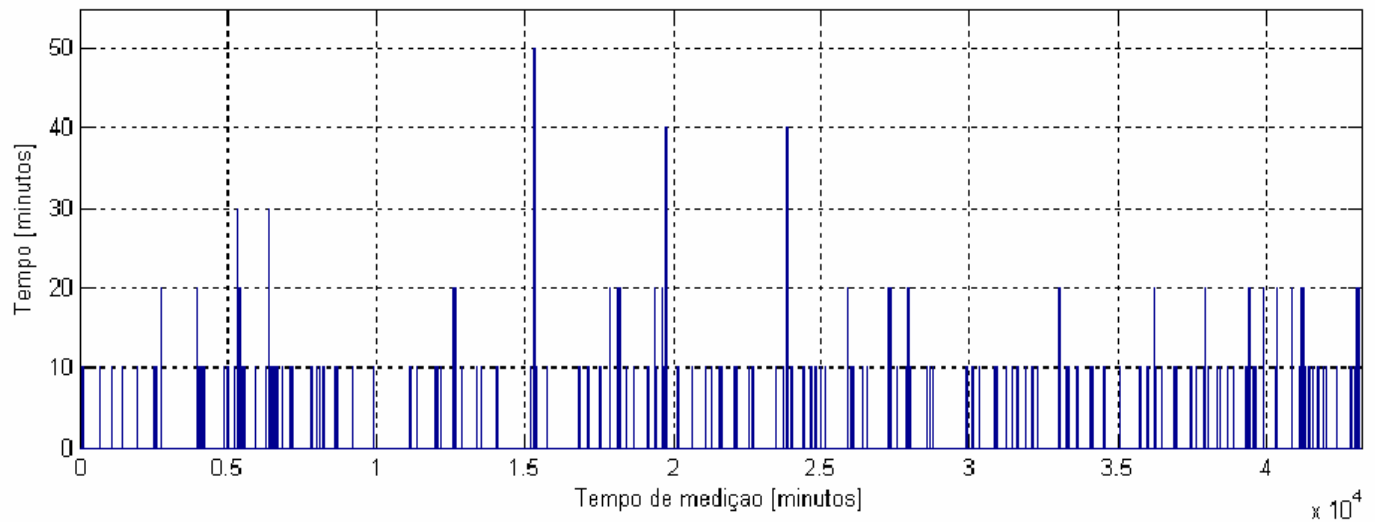

Figura 8.4 - Intervalos ininterruptos de tempo com valores com Pst $\geq 0,156$

Da figura 8.4, tem-se que o máximo intervalo ininterrupto de tempo com Pst $\geq 0,156$ é de aproximadamente 50 minutos, que representa $0,116 \%$ do total da medição.

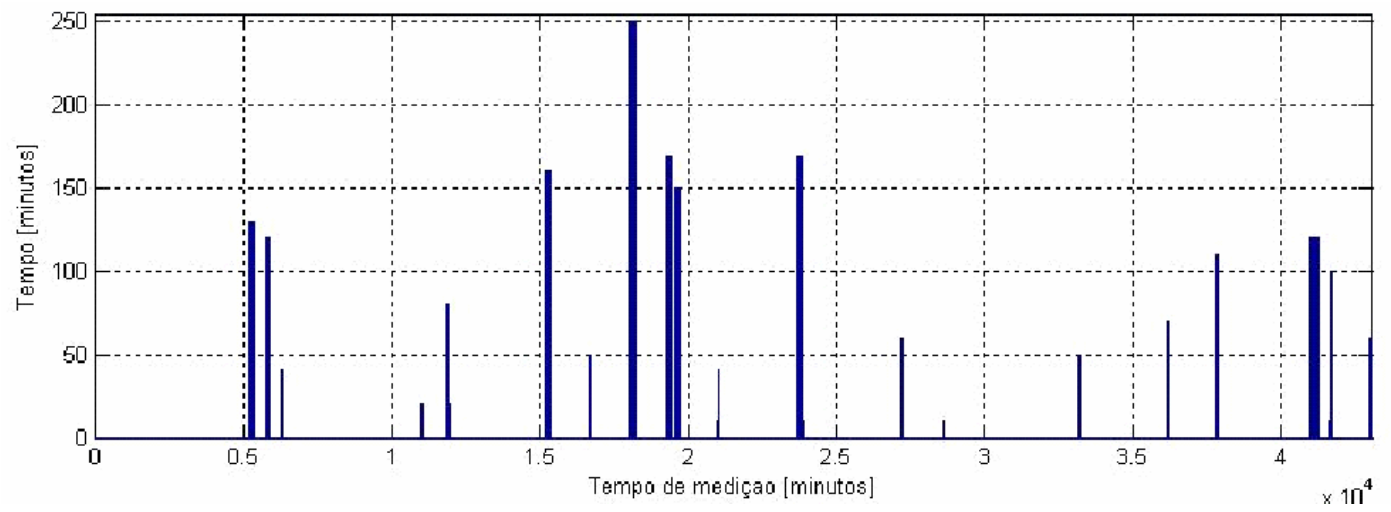

Figura 8.5 - Intervalos ininterruptos de tempo com valores com Plt $\geq 0,145$ 
Da figura 8.5, tem-se que o máximo intervalo ininterrupto de tempo com Plt $\geq 0,145$ é de 250 minutos, que representa $0,58 \%$ do total da medição.

As figuras 8.6 e 8.7 apresentam os gráficos com os intervalos ininterruptos de tempo com valores de Pst $\leq 0,156$ e valores de Plt $\leq 0,145$, respectivamente.

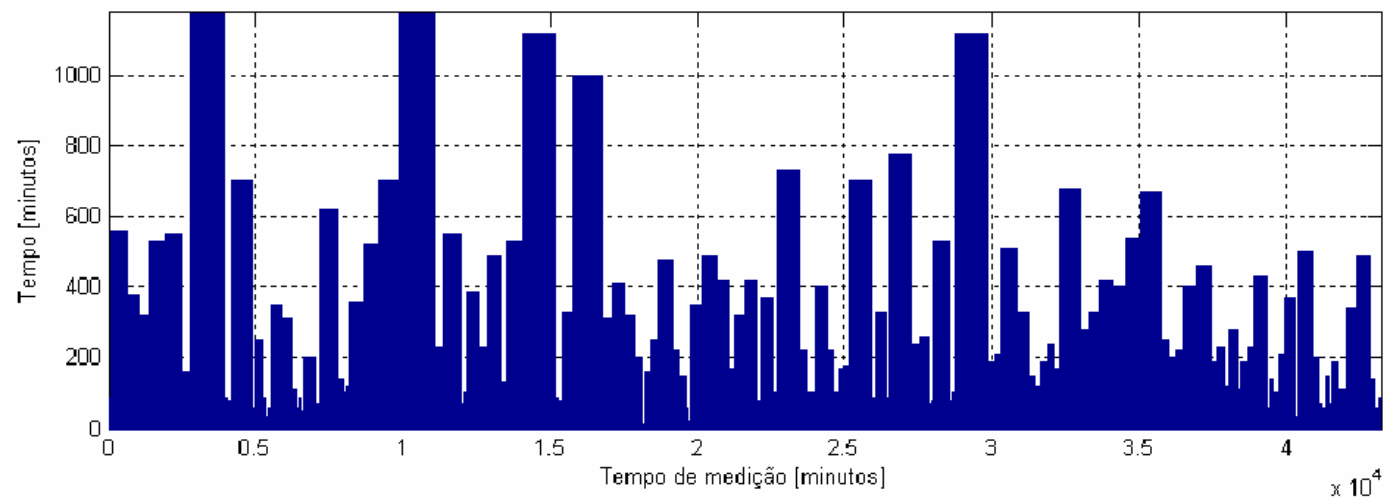

Figura 8.6 - Intervalos ininterruptos de tempo com valores com Pst $\leq 0,156$

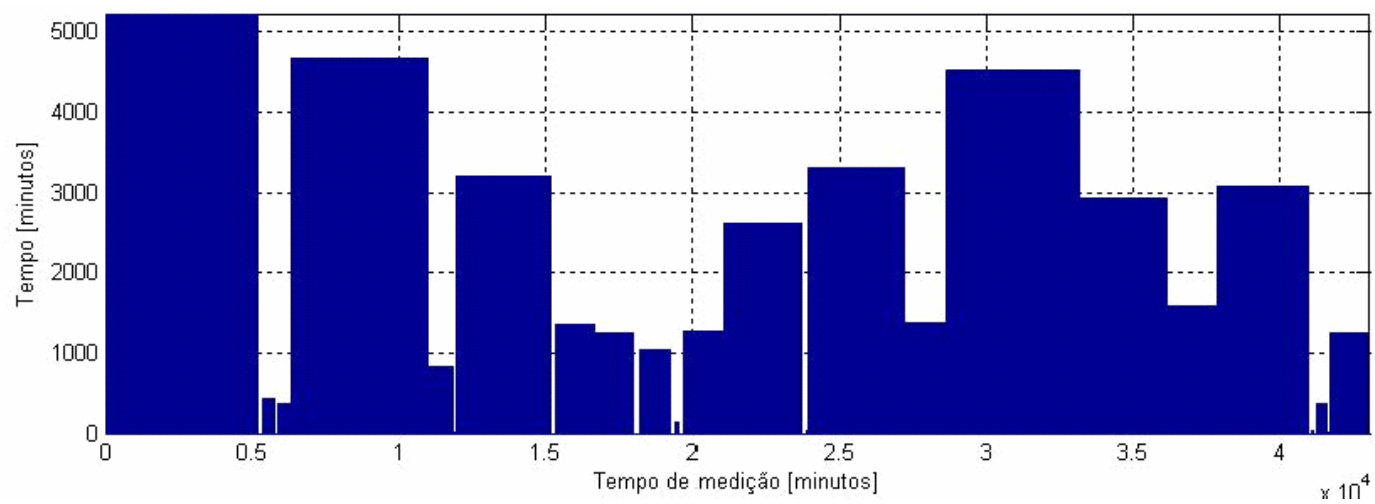

Figura 8.7 - Intervalos ininterruptos de tempo com valores com Plt $\leq 0,145$

Da figura 8.6, tem-se que o maior intervalo ininterrupto de tempo com Pst $\leq 0,156$ é de aproximadamente 1200 minutos, ou seja, 20 horas, de um total de 43210 minutos (aproximadamente 720 horas). Da figura 8.7, tem-se que o maior intervalo ininterrupto de tempo com Plt $\leq 0,145$ é de aproximadamente 5220 minutos( 87 horas), mais de três dias consecutivos com Plt $\leq 0,145$.

As figuras 8.8 e 8.9 ilustram os gráficos com as probabilidades de ocorrências dos intervalos ininterruptos de tempo com Pst $\geq 0,156$ e Plt $\geq 0,145$, respectivamente. 


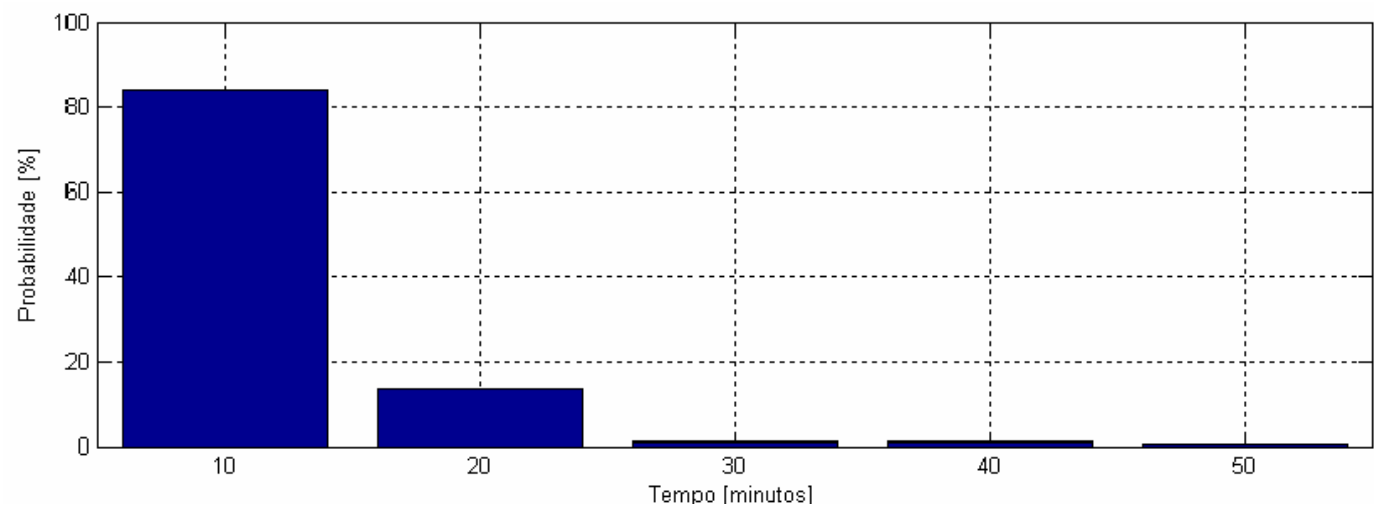

Figura 8.8 - Probabilidade de ocorrência dos intervalos ininterruptos de tempo com Pst $\geq 0,156$

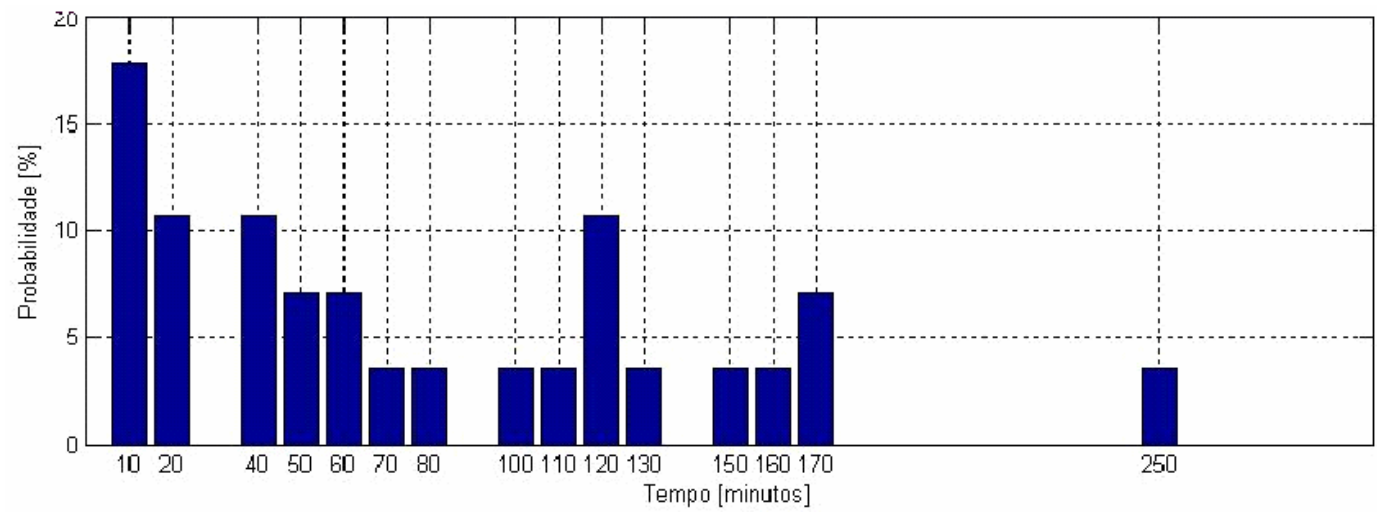

Figura 8.9 - Probabilidade de ocorrência dos intervalos ininterruptos de tempo com Plt $\geq 0,145$

Da figura 8.8 obtêm-se que mais de $80 \%$ dos intervalos ininterruptos de tempo com Pst $\geq 0,156$, possuem 10 minutos de duração. Da figura 8.9 obtêm-se que cerca de $38,5 \%$ dos intervalos ininterruptos de tempo com Plt $\geq 0,145$ possuem até 40 minutos de duração. Ressalta-se, ainda da figura 8.9, a existência de intervalos ininterruptos de tempo com Plt $\geq 0,145$ com 150, 160, 170 e 250 minutos de duração.

As figuras 8.10 e 8.11 ilustram os gráficos com as probabilidades de ocorrências dos intervalos ininterruptos de tempo com Pst $\leq 0,156$ e Plt $\leq 0,145$, respectivamente. A figura 8.12 mostra o resultado da utilização do zoom, na figura 8.11, para obter uma melhor visualização da faixa de 0 a 250 minutos. 


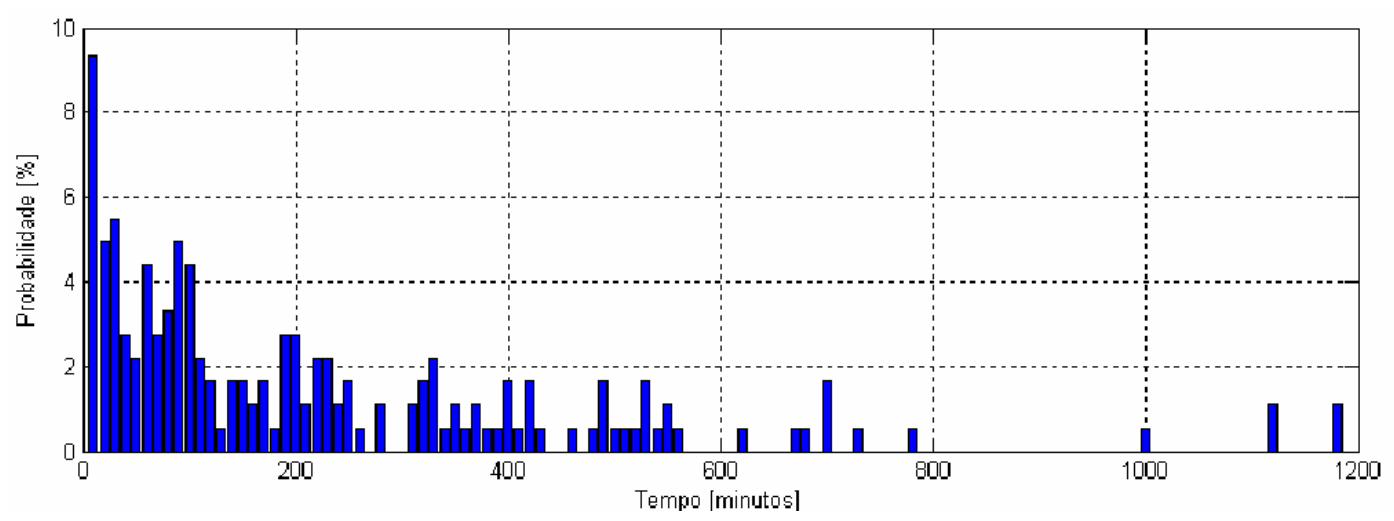

Figura 8.10 - Probabilidade de ocorrência dos intervalos ininterruptos de tempo com Pst $\leq 0,156$

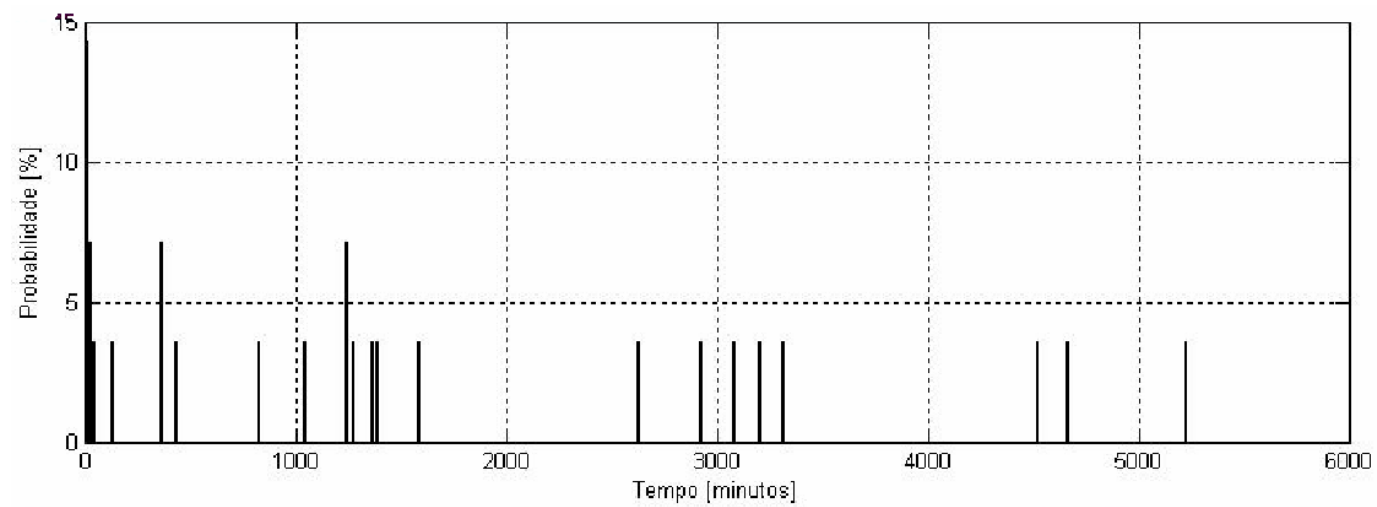

Figura 8.11 - Probabilidade de ocorrência dos intervalos ininterruptos de tempo com Plt $\leq 0,145$

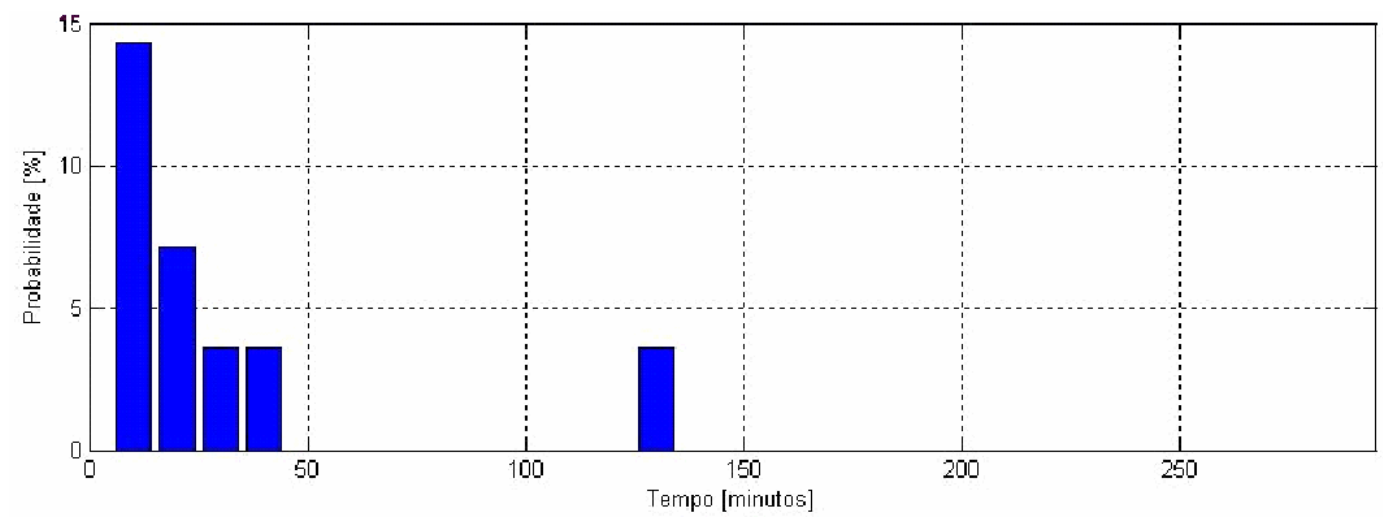

Figura 8.12 - Zoom na faixa de 0 a 250 minutos da figura 8.11 
Da figura 8.10, tem-se que cerca de $44 \%$ dos intervalos ininterruptos de tempo com Pst $\leq 0,156$, possuem até 100 minutos de duração. Da figura 8.12 , tem-se que cerca de $28 \%$ dos intervalos ininterruptos de tempo com Plt $\leq 0,145$ possuem até 40 minutos de duração. Observando-se a figura 8.11 ressalta-se a existência de 14 intervalos com mais de 1000 minutos de duração, sendo um deles com mais de 5040 minutos (84 horas) de duração.

As tabelas 8.3 e 8.4 apresentam um resumo dos dados observados ao decorrer desta análise.

Tabela 8.3 - Resumo dos valores observados para o Pst quando a referência é o P95\%

\begin{tabular}{|c|c|c|}
\hline 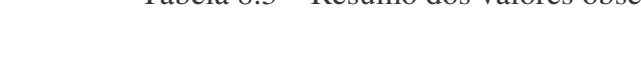 & \multicolumn{2}{|c|}{ Fase $\mathrm{C}$} \\
\hline P95\% do Pst $=0,156$ & Duração (minutos) & Em \% do total \\
\hline Tempo total com Pst $\geq P 95 \%$ & 2190 & 5,07 \\
\hline $\begin{array}{c}\text { Máximo intervalo de tempo ininterrupto } \\
\text { com Pst } \geq \mathbf{P 9 5} \%\end{array}$ & 50 & 0,11 \\
\hline $\begin{array}{l}\text { Probabilidade de ocorrência de intervalo } \\
\text { de tempo ininterrupto com Pst } \geq \mathbf{P 9 5 \%}\end{array}$ & 10 & 80 \\
\hline $\begin{array}{c}\text { Máximo intervalo de tempo ininterrupto } \\
\text { com Pst } \leq \mathrm{P} 95 \%\end{array}$ & 1200 & 2,77 \\
\hline $\begin{array}{l}\text { Probabilidade de ocorrência de intervalo } \\
\text { de tempo ininterrupto com Pst } \leq \mathbf{P 9 5 \%}\end{array}$ & até 100 & 44 \\
\hline
\end{tabular}

Tabela 8.4 - Resumo dos valores observados para o Plt quando a referência é o P95\%

\begin{tabular}{|c|c|c|}
\cline { 2 - 3 } \multicolumn{1}{c|}{ P95\% do PIt = 0,145 } & Duração (minutos) & Em \% do total \\
\hline Tempo total com PIt $\geq \mathbf{P 9 5 \%}$ & 2200 & 5,1 \\
\hline $\begin{array}{c}\text { Máximo intervalo de tempo ininterrupto } \\
\text { com PIt } \geq \mathbf{P 9 5 \%}\end{array}$ & 250 & 0,58 \\
\hline $\begin{array}{c}\text { Probabilidade de ocorrência de intervalo } \\
\text { de tempo ininterrupto com PIt } \geq \mathbf{P 9 5 \%}\end{array}$ & até 40 & 38,5 \\
\hline $\begin{array}{c}\text { Máximo intervalo de tempo ininterrupto } \\
\text { com Plt } \leq \mathbf{P 9 5 \%}\end{array}$ & 5220 & 12,11 \\
\hline $\begin{array}{c}\text { Probabilidade de ocorrência de intervalo } \\
\text { de tempo ininterrupto com PIt } \leq \mathbf{P 9 5 \%}\end{array}$ & até 40 & 28 \\
\hline
\end{tabular}


Evidencia-se, portanto, que para os 30 dias em estudo, os diversos valores de Pst $\geq$ 0,156 estão, predominantemente, concentrados em intervalos de 10 minutos de duração e que os diversos valores de Plt $\geq 0,145$ estão concentrados em intervalos de 40 minutos de duração. Contudo, das análises gráficas dos valores destacam-se a existência de intervalos ininterruptos com Plt $\geq 0,145$ com 150, 160, 170 e 250 minutos de duração.

\subsubsection{ANÁlISE CONSIDERANDO-SE O VALOR DE P99\% COMO REFERÊNCIA}

O valor de P99\% calculado a partir dos dados em estudo foi de 0,336 para o Pst e de 0,220 para o Plt. As figuras 8.13 e 8.14 apresentam os gráficos de Pst $\geq 0,336$ e Plt $\geq$ 0,220 , respectivamente, versus tempo total de medição em minutos.

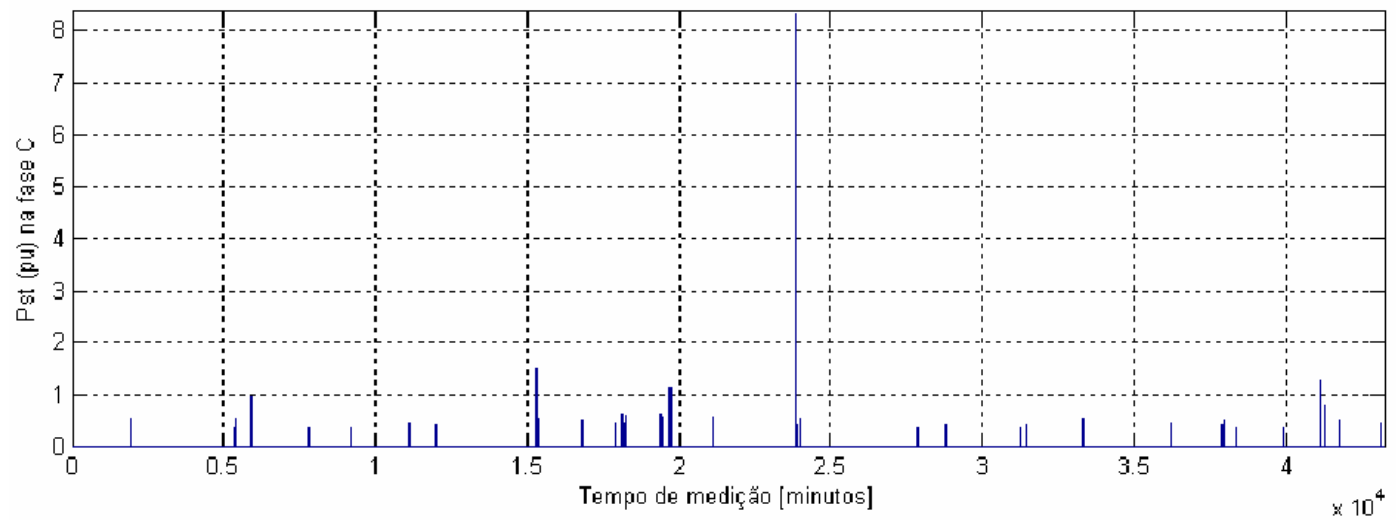

Figura 8.13 - Valores com Pst $\geq 0,336$ versus tempo total de medição em minutos

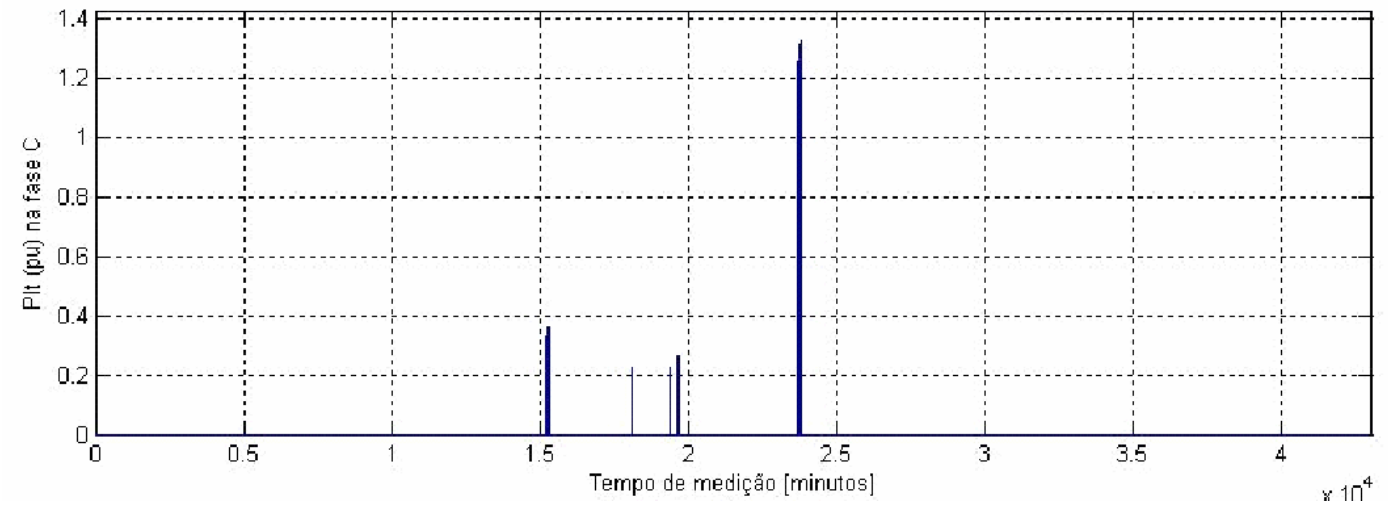

Figura 8.14 - Valores com Plt $\geq 0,220$ versus tempo total de medição em minutos 
Da figura 8.13 e com a análise numérica disponível no programa, observa-se que, de todo o período de medição em análise, aproximadamente 43210 minutos, cerca de 430 minutos ( $1 \%$ do tempo total de medição), apresentam Pst $\geq 0,336$.

Da figura 8.14 e com a análise numérica disponível no programa, observa-se que, de todo o período de medição em análise, aproximadamente 43090 minutos, cerca de 430 minutos ( $1 \%$ do tempo total de medição), apresentam Plt $\geq 0,220$. Nota-se da mesma figura que os valores de Plt $\geq 0,220$ concentram-se acentuadamente em dois grupos dos cinco que são observados.

As figuras 8.15 e 8.16 apresentam o gráficos com os intervalos ininterruptos de tempo com valores de Pst $\leq 0,336$ e valores de Plt $\leq 0,220$, respectivamente.

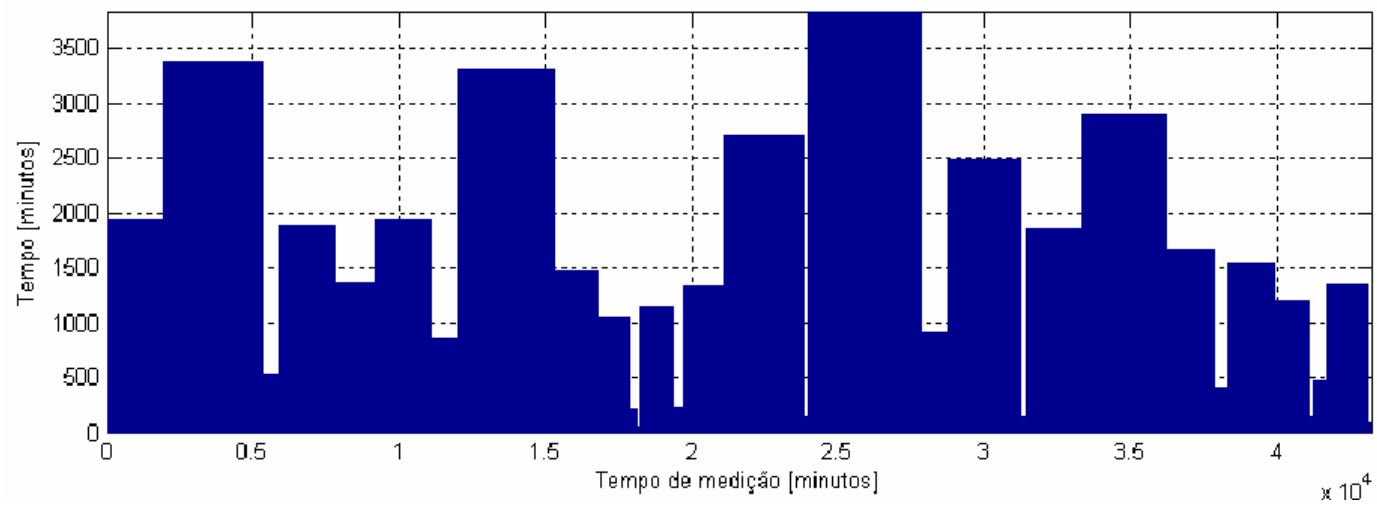

Figura 8.15 - Intervalos ininterruptos de tempo com Pst $\leq 0,336$

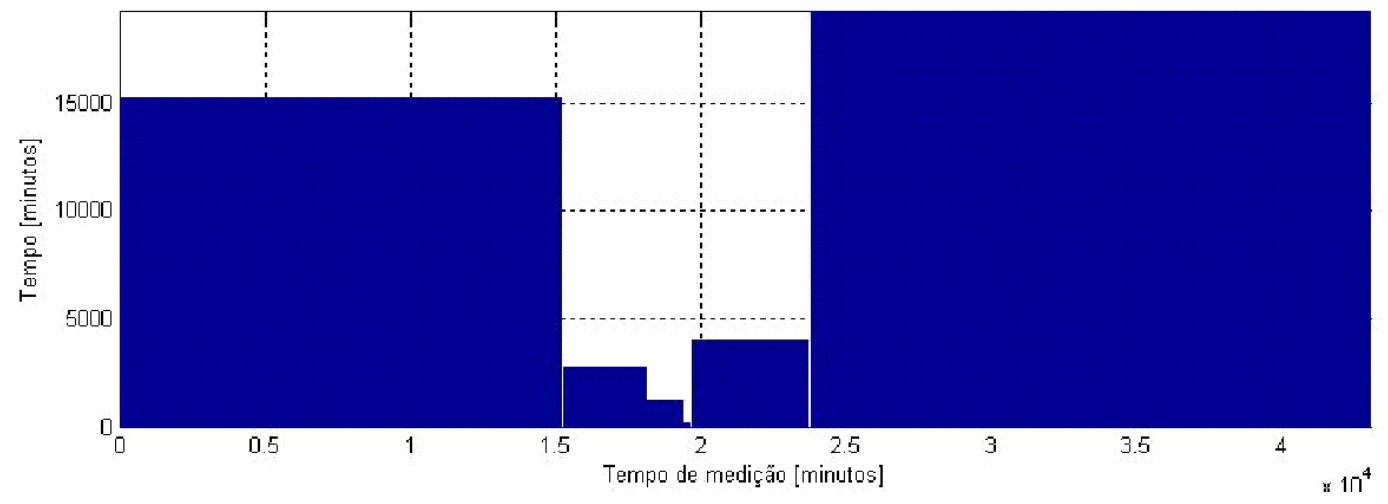

Figura 8.16 - Intervalos ininterruptos de tempo com Plt $\leq 0,220$

Da figura 8.15, tem-se que o maior intervalo ininterrupto de tempo com Pst $\leq 0,336$ é de aproximadamente 3840 minutos (64 horas), de um total de 43210 minutos. Da figura 
8.16, tem-se que o maior intervalo ininterrupto de tempo com Plt $\leq 0,220$ é de aproximadamente 19260 minutos (321 horas), mais de 13 dias consecutivos.

As figuras 8.17 e 8.18 apresentam os gráficos com os intervalos ininterruptos de tempo com valores de Pst $\geq 0,336$ e valores de Plt $\geq 0,220$, respectivamente.

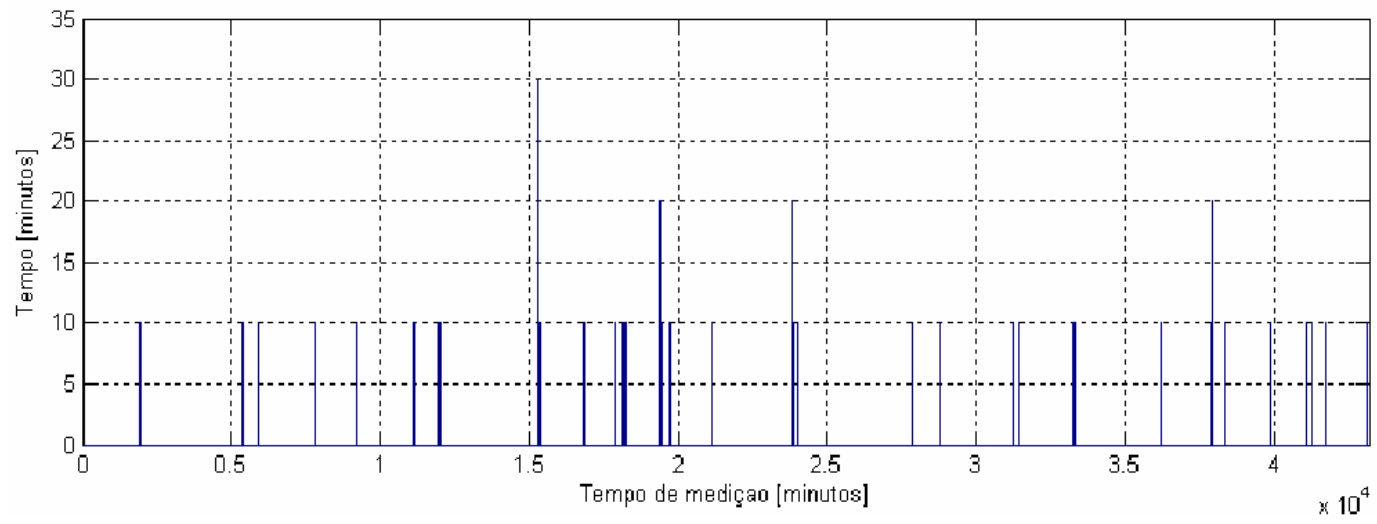

Figura 8.17 - Intervalos ininterruptos de tempo com Pst $\geq 0,336$

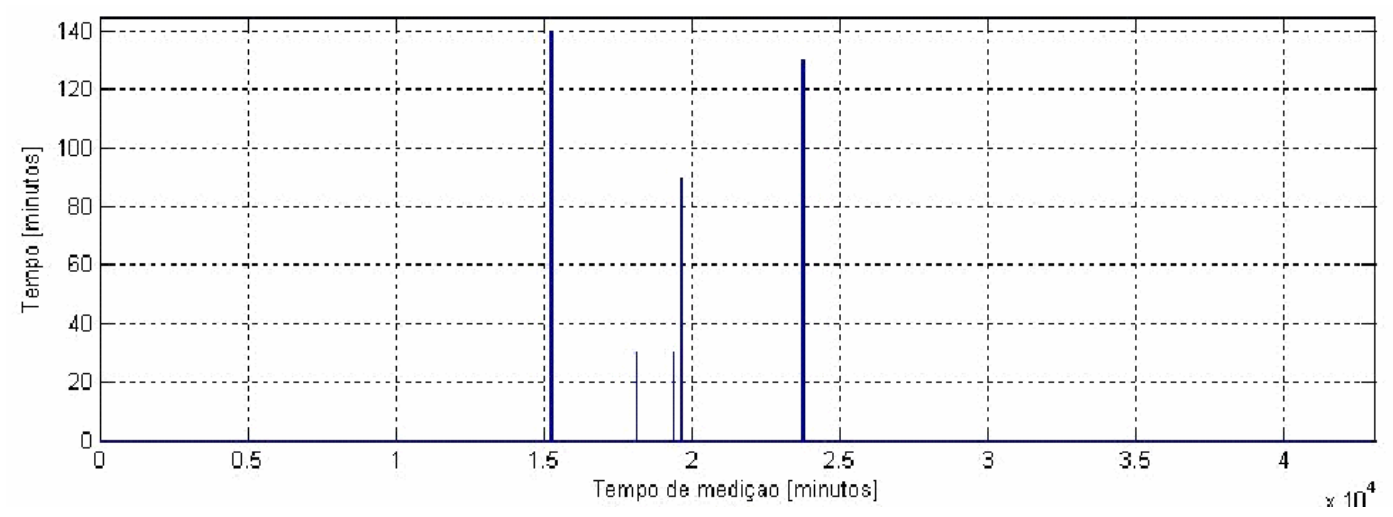

Figura 8.18 - Intervalos ininterruptos de tempo com Plt $\geq 0,220$

Da figura 8.17, tem-se que o máximo intervalo ininterrupto de tempo com Pst $\geq 0,336$ é de 30 minutos ( aproximadamente $0,07 \%$ do total de minutos). Da figura 8.18, tem-se que o máximo intervalo ininterrupto de tempo com Plt $\geq 0,220$ é de 140 minutos $(0,32 \%$ do total de tempo da medição).

As figuras 8.19 e 8.20 , na página seguinte, ilustram os gráficos com a probabilidade de ocorrência dos intervalos ininterruptos de tempo com Pst $\geq 0,336$ e Plt $\geq 0,220$, respectivamente. 
Nota-se da figura 8.19 que mais de $85 \%$ dos intervalos ininterruptos de tempo com Pst $\geq$ 0,336 possuem 10 minutos de duração. Da figura 8.20, tem-se que aproximadamente $50 \%$ dos intervalos ininterruptos de tempo com Plt $\geq 0,220$ possuem até 30 minutos de duração.

As figuras 8.21 e 8.22 ilustram os gráficos com a probabilidade de ocorrência dos intervalos ininterruptos de tempo com Pst $\leq 0,336$ e Plt $\leq 0,220$, respectivamente.

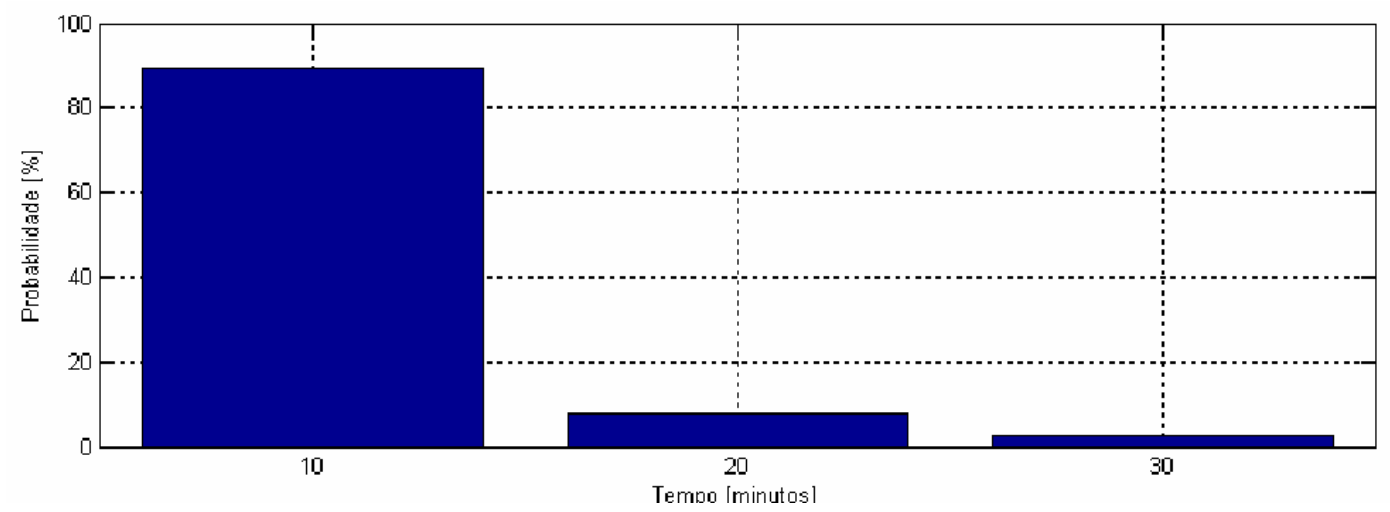

Figura 8.19 - Probabilidades de ocorrência dos intervalos ininterruptos de tempo com Pst $\geq 0,336$

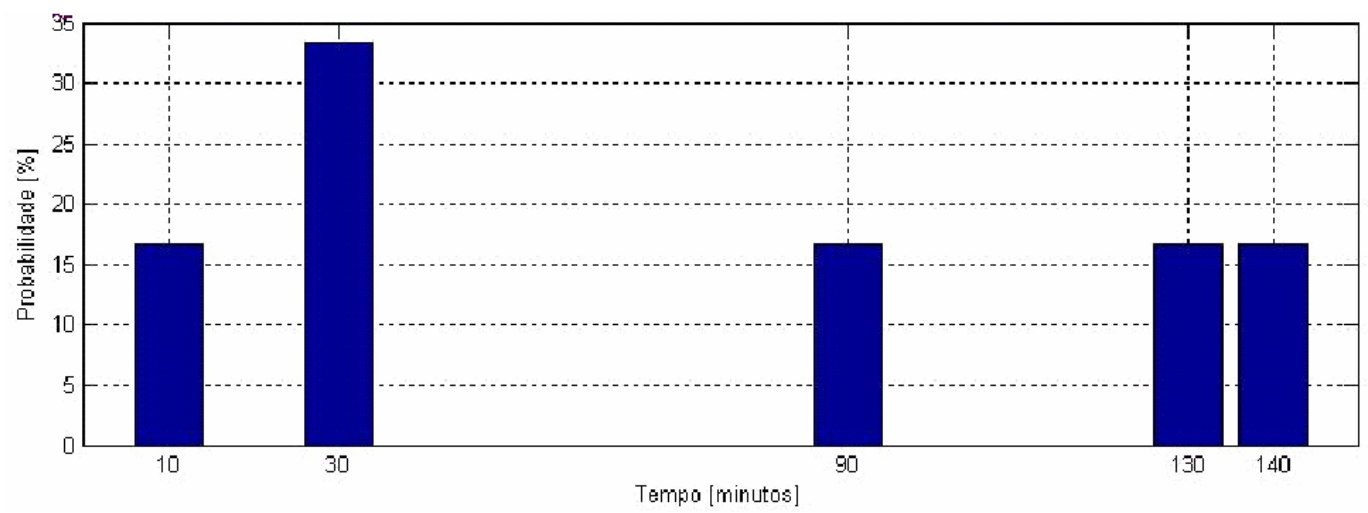

Figura 8.20 - Probabilidades de ocorrências dos intervalos ininterruptos de tempo com Plt $\geq 0,220$

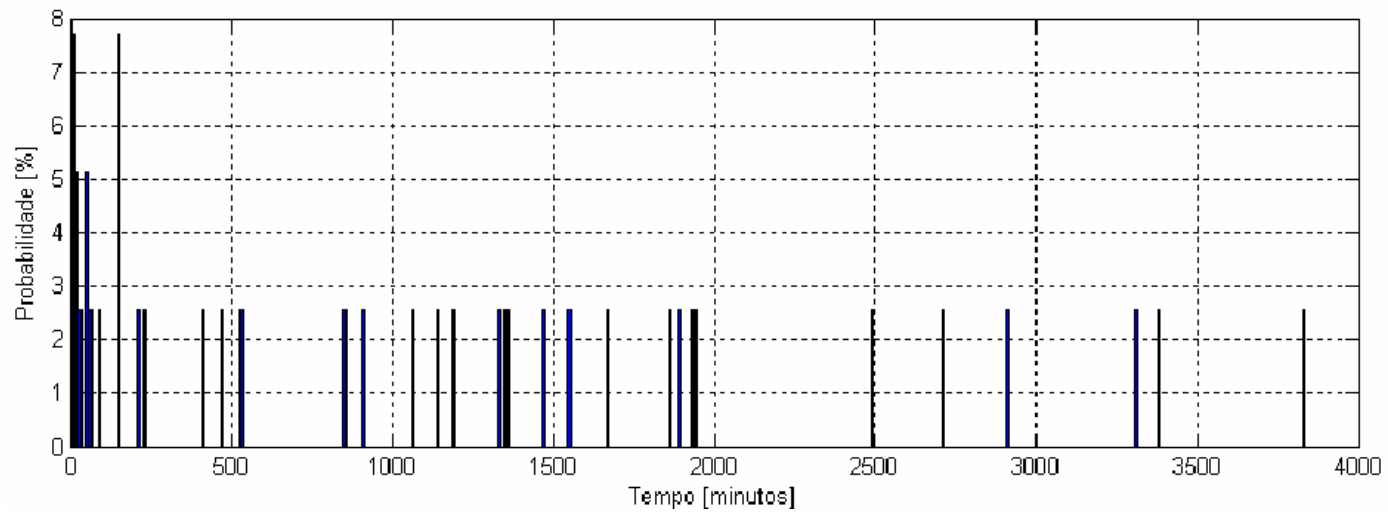

Figura 8.21 - Probabilidades de ocorrência dos intervalos ininterruptos de tempo com Pst $\leq$ 0,336 


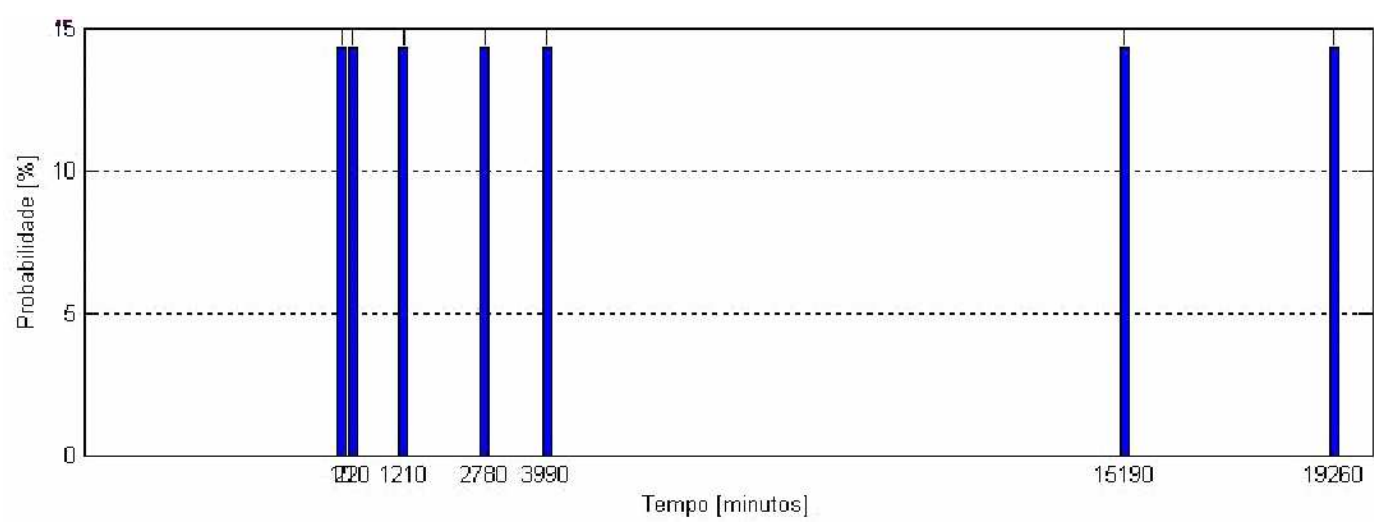

Figura 8.22 - Probabilidades de ocorrências dos intervalos ininterruptos de tempo com Plt $\leq 0,220$

Da figura 8.21, verifica-se a existência de dezessete intervalos ininterruptos de tempo com Pst $\leq$ 0,336 com mais de 1000 minutos de duração. Observa-se da figura 8.22 quatro intervalo ininterruptos de tempo com Plt $\leq 0,220$ com mais de 2000 minutos de duração, sendo que dois deles possuem mais de 15000 minutos (250 horas).

As tabelas 8.5 e 8.6 apresentam um resumo dos dados observados ao decorrer desta análise.

Tabela 8.5 - Resumo dos valores observados para o Pst quando a referência é o P99\%

\begin{tabular}{|c|c|c|}
\hline & \multicolumn{2}{|c|}{ Fase C } \\
\hline P99\% do Pst $=0,336$ & Duração (minutos) & Em \% do total \\
\hline Tempo total com Pst $\geq \mathbf{P 9 9 \%}$ & 430 & 1 \\
\hline $\begin{array}{l}\text { Máximo intervalo de tempo ininterrupto } \\
\text { com Pst } \geq \mathbf{P 9 9 \%}\end{array}$ & 30 & 0,07 \\
\hline $\begin{array}{l}\text { Probabilidade de ocorrência de intervalo } \\
\text { de tempo ininterrupto com Pst } \geq \mathbf{P 9 9 \%}\end{array}$ & 10 & 85 \\
\hline $\begin{array}{c}\text { Máximo intervalo de tempo ininterrupto } \\
\text { com Pst } \leq \text { P99\% }\end{array}$ & 3840 & 8,88 \\
\hline $\begin{array}{c}\text { Probabilidade de ocorrência de intervalo } \\
\text { de tempo ininterrupto com Pst } \leq \text { P99\% }\end{array}$ & até 550 & 45,9 \\
\hline
\end{tabular}


Tabela 8.6 - Resumo dos valores observados para o Plt quando a referência é o P99\%

\begin{tabular}{|c|c|c|}
\cline { 2 - 3 } \multicolumn{1}{c|}{} & \multicolumn{2}{c|}{ Fase C } \\
\hline P99\% do PIt = 0,220 & Duração (minutos) & Em \% do total \\
\hline $\begin{array}{c}\text { Máximo intervalo de tempo ininterrupto } \\
\text { com PIt } \geq \text { P99\% }\end{array}$ & 140 & 1 \\
\hline $\begin{array}{c}\text { Probabilidade de ocorrência de intervalo } \\
\text { de tempo ininterrupto com PIt } \geq \text { P99\% }\end{array}$ & até 30 & 0,32 \\
\hline $\begin{array}{c}\text { Máximo intervalo de tempo ininterrupto } \\
\text { com PIt } \leq \text { P99\% }\end{array}$ & 19260 & 50 \\
\hline $\begin{array}{c}\text { Probabilidade de ocorrência de intervalo } \\
\text { de tempo ininterrupto com PIt } \leq \text { P99\% }\end{array}$ & até 1210 & 44,7 \\
\hline
\end{tabular}

Evidencia-se, portanto, que para os 30 dias em estudo, os diversos valores de Pst $\geq$ 0,336 estão, predominantemente, concentrados em intervalos de 10 minutos de duração e que os diversos valores de Plt $\geq 0,220$ estão concentrados em intervalos de até 30 minutos de duração. Contudo, das análises gráficas dos valores destacam-se a existência de intervalos ininterruptos com Plt $\geq 0,220$ com 130 e 140 minutos de duração.

\subsubsection{ANÁLISE CONSIDERANDO-SE O VALOR MÉDIO QUADRÁTICO COMO REFERÊNCIA}

O valor médio quadrático calculado a partir dos dados em estudo foi de 0,198 para o Pst e de 0,132 para o Plt. As figuras 8.23 e 8.24 exibem os gráficos de Pst $\geq 0,198$ e Plt $\geq$ 0,132 , respectivamente, versus tempo total de medição em minutos.

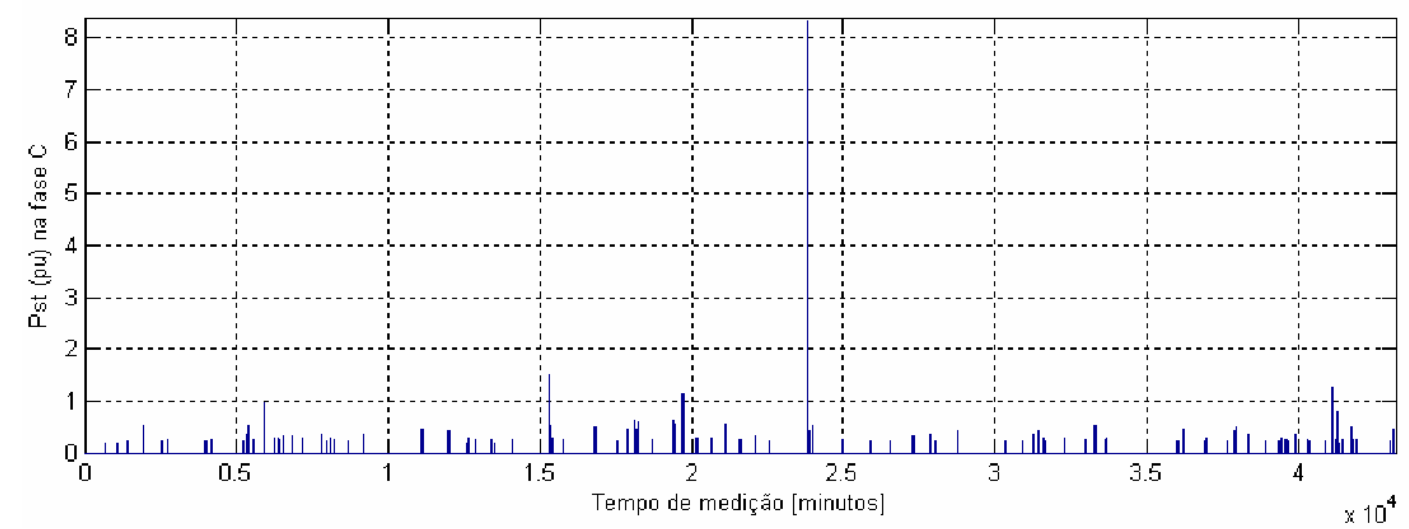

Figura 8.23 - Valores com Pst $\geq 0,198$ versus tempo total de medição em minutos 


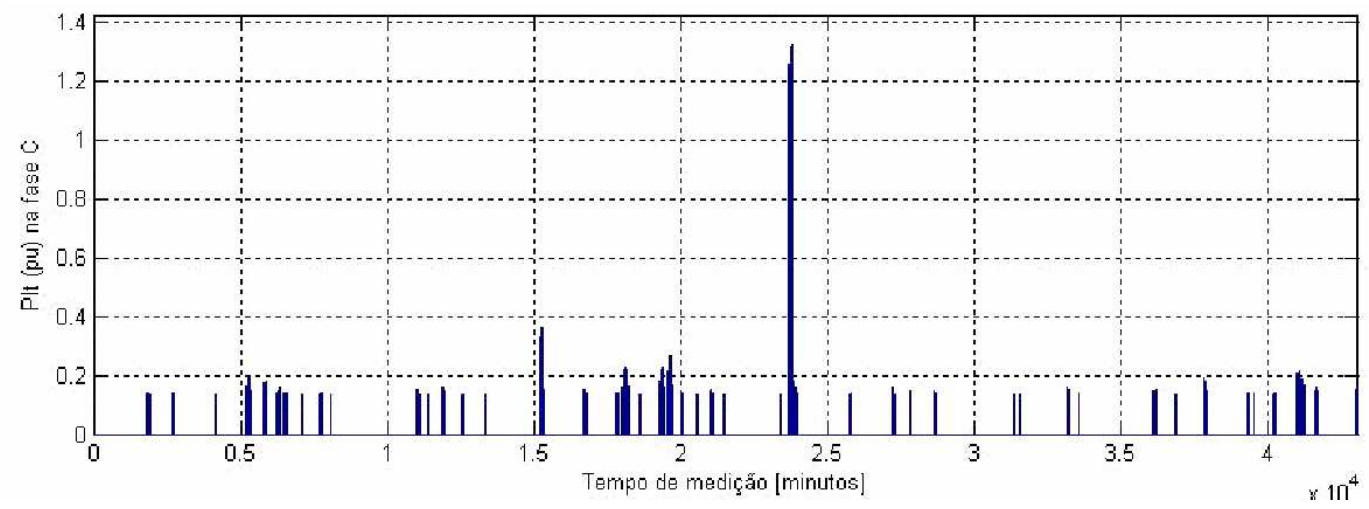

Figura 8.24 - Valores com Plt $\geq 0,132$ versus tempo total de medição em minutos

Da figura 8.23 e da análise numérica do programa, observa-se que, de todo o período de medição, aproximadamente 43210 minutos, cerca de 1240 minutos (20,6 horas), apresentam Pst $\geq 0,198$. Isto representa cerca de 2,9\% do tempo total analisado.

Da figura 8.24 e com a análise numérica disponível no programa, observa-se que, cerca de 3930 minutos dos 43090 minutos medidos, apresentam Plt $\geq 0,132$. Isto representa cerca de $9,1 \%$ do tempo total.

Nota-se, ainda destas figuras, que os valores de Pst $\geq 0,198$ e de Plt $\geq 0,132$ encontramse espalhados ao longo do período medido.

As figuras 8.25 e 8.26 mostram os gráficos com os intervalos ininterruptos de tempo com valores de Pst $\geq 0,198$ e Plt $\geq 0,132$, respectivamente.

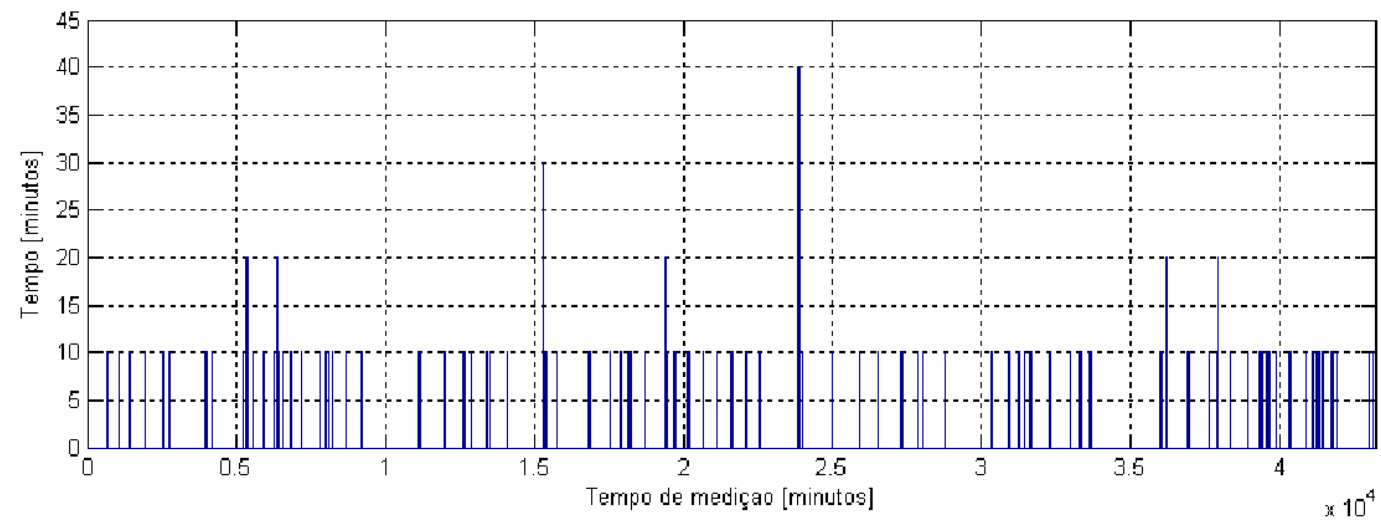

Figura 8.25 - Intervalos ininterruptos de tempo com valores de Pst $\geq 0,198$ 


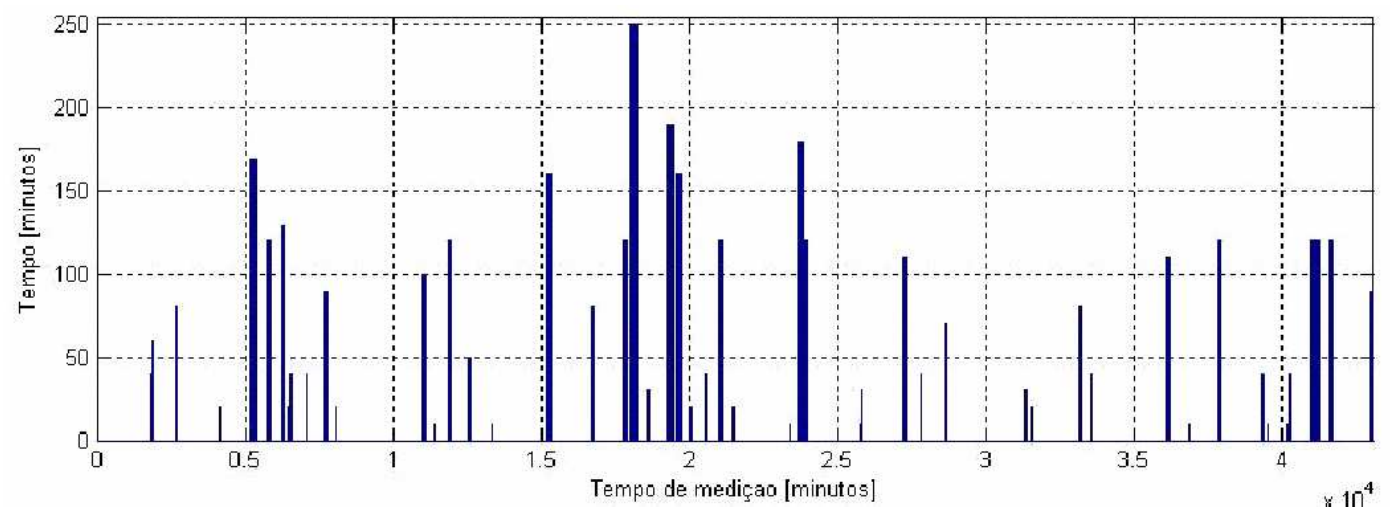

Figura 8.26 - Intervalos ininterruptos de tempo com valores de Plt $\geq 0,132$

Da figura 8.25 tem-se que o máximo intervalo ininterrupto de tempo com Pst $\geq 0,198$ é de aproximadamente 40 minutos, que representa 0,09\% do total de tempo da medição.

Da figura 8.26 tem-se que o máximo intervalo ininterrupto de tempo com Plt $\geq 0,132$ é de aproximadamente 250 minutos, que representa $0,58 \%$ do total de tempo da medição.

As figuras 8.27 e 8.28 apresentam os gráficos com intervalos ininterruptos de tempo com valores de Pst $\leq 0,198$ e Plt $\leq 0,132$, respectivamente.

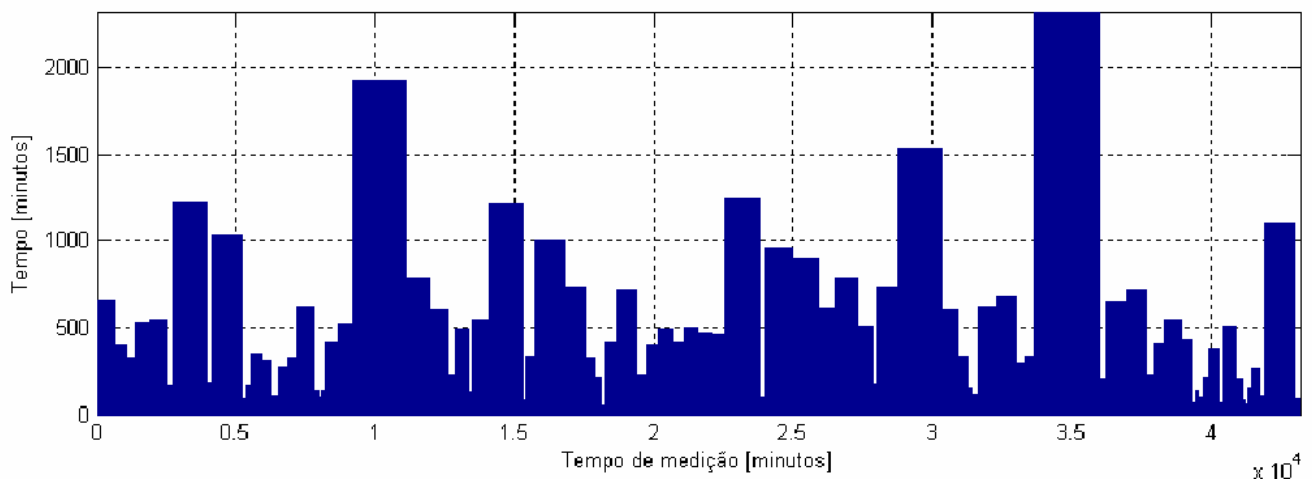

Figura 8.27 - Intervalos ininterruptos de tempo com valores de Pst $\leq 0,198$ 


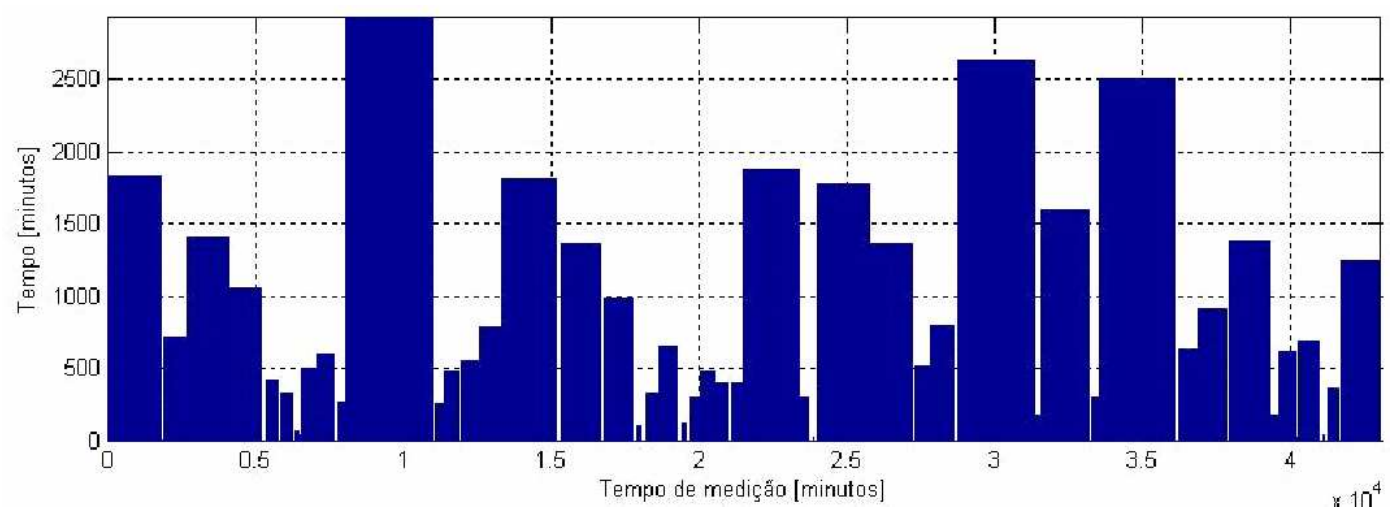

Figura 8.28 - Intervalos ininterruptos de tempo com valores de Plt $\leq 0,132$

Da figura 8.27 tem-se que o máximo intervalo ininterrupto de tempo com Pst $\leq 0,198$ é de 2320 , que representa $5,4 \%$ do total de tempo da medição. Da figura 8.28 tem-se que o máximo intervalo ininterrupto de tempo com Plt $\leq 0,132$ é de 2930, que representa $6,8 \%$ do total de tempo da medição.

Nota-se, ainda destas figuras, que há vários grupos com valores de Pst $\leq 0,198$ e com valores de Plt $\leq 0,132$.

As figuras 8.29 e 8.30 ilustram os gráficos com as probabilidades de ocorrência dos intervalos ininterruptos de tempo com valores de Pst $\geq 0,198$ e Plt $\geq 0,132$, respectivamente.

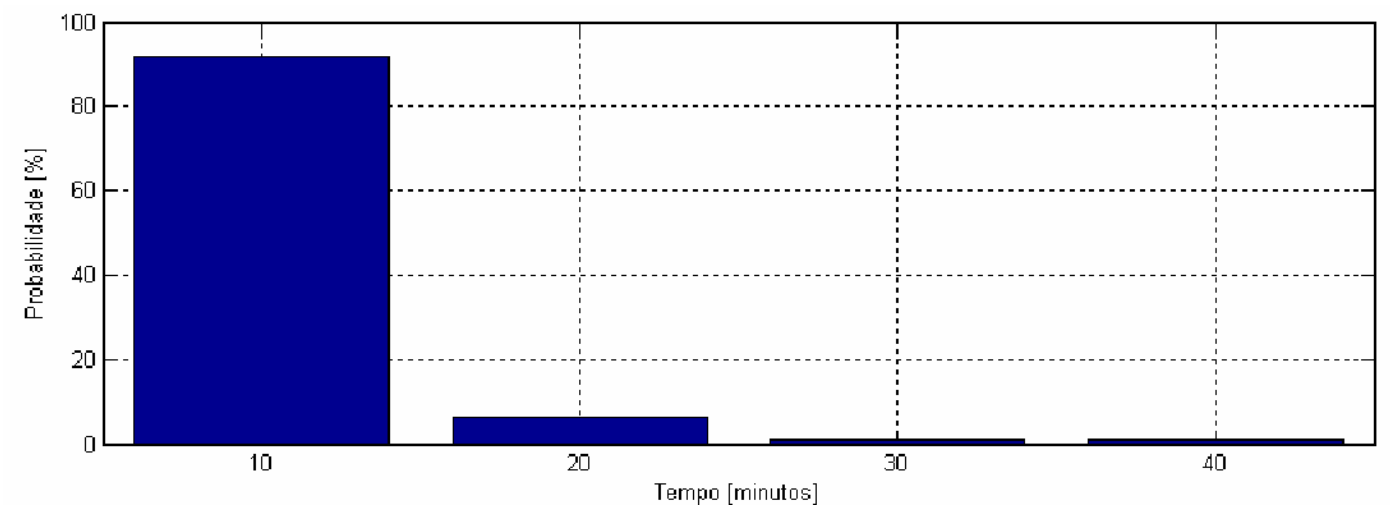

Figura 8.29 - Probabilidades de ocorrência dos intervalos ininterruptos de tempo com valores de Pst $\geq$ 0,198 


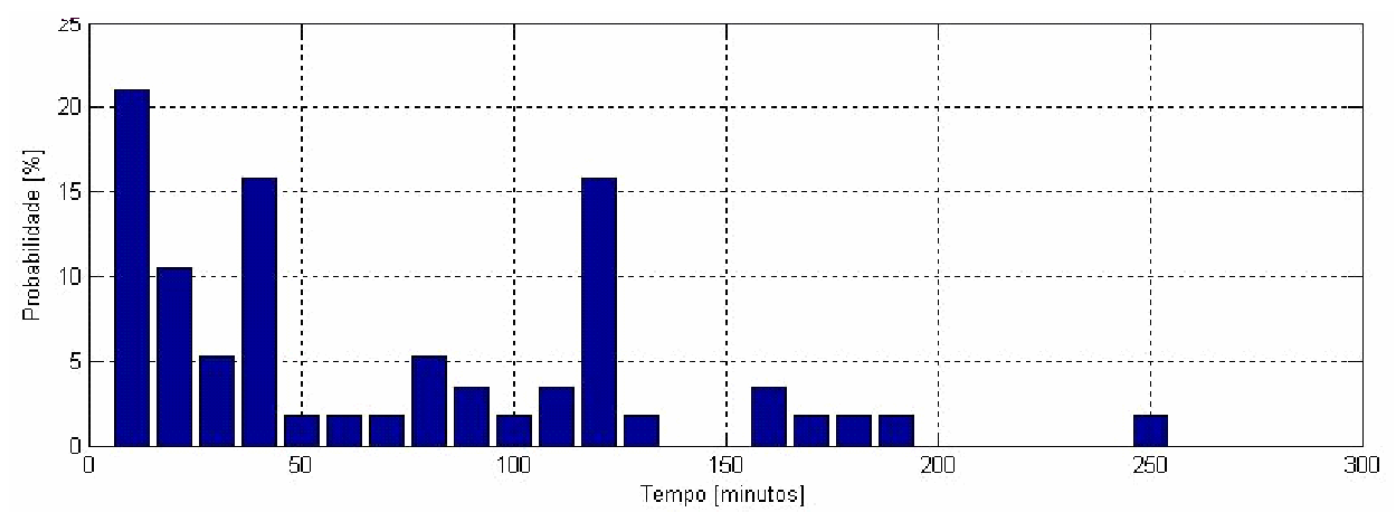

Figura 8.30 - Probabilidades de ocorrência dos intervalos ininterruptos de tempo com valores de Plt $\geq$

$$
0,132
$$

Nota-se da figura 8.29 que cerca de $95 \%$ dos intervalos ininterruptos de tempo com Pst $\geq 0,198$ duram até 20 minutos.

Da figura 8.30 tem-se que cerca de $54 \%$ dos intervalos ininterruptos de tempo com Plt $\geq$ 0,132 possuem até 50 minutos de duração.

As figuras 8.31 e 8.32 ilustram os gráficos com as probabilidades de ocorrência dos intervalos ininterruptos de tempo com valores de Pst $\leq 0,198$ e Plt $\leq 0,132$, respectivamente.

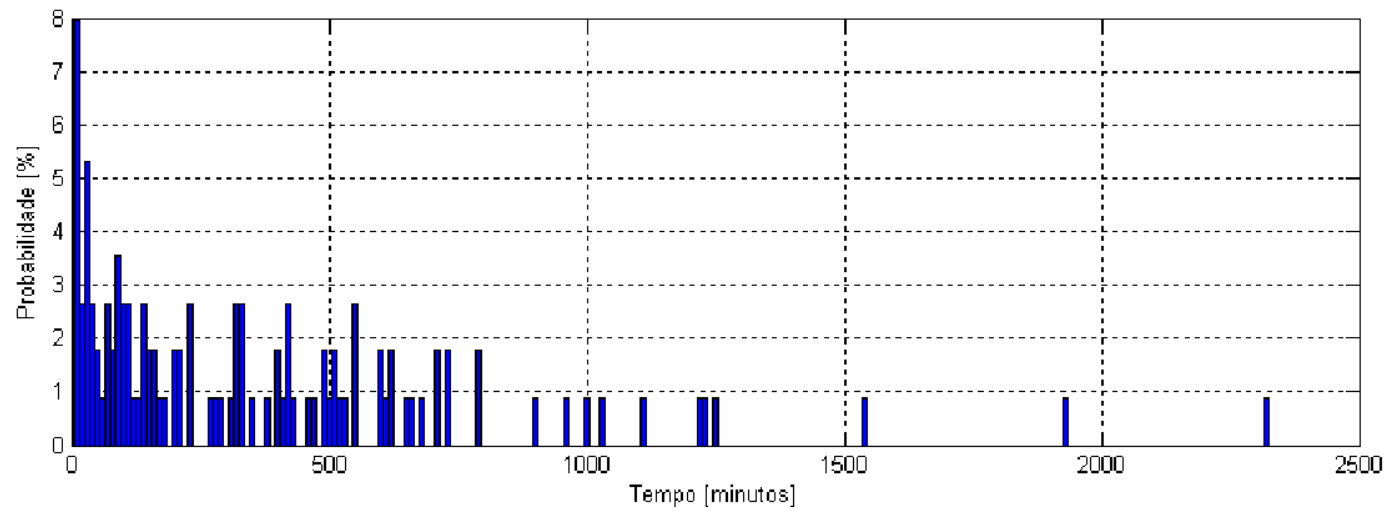

Figura 8.31 - Probabilidades de ocorrência dos intervalos ininterruptos de tempo com valores de Pst $\leq$ 0,198 


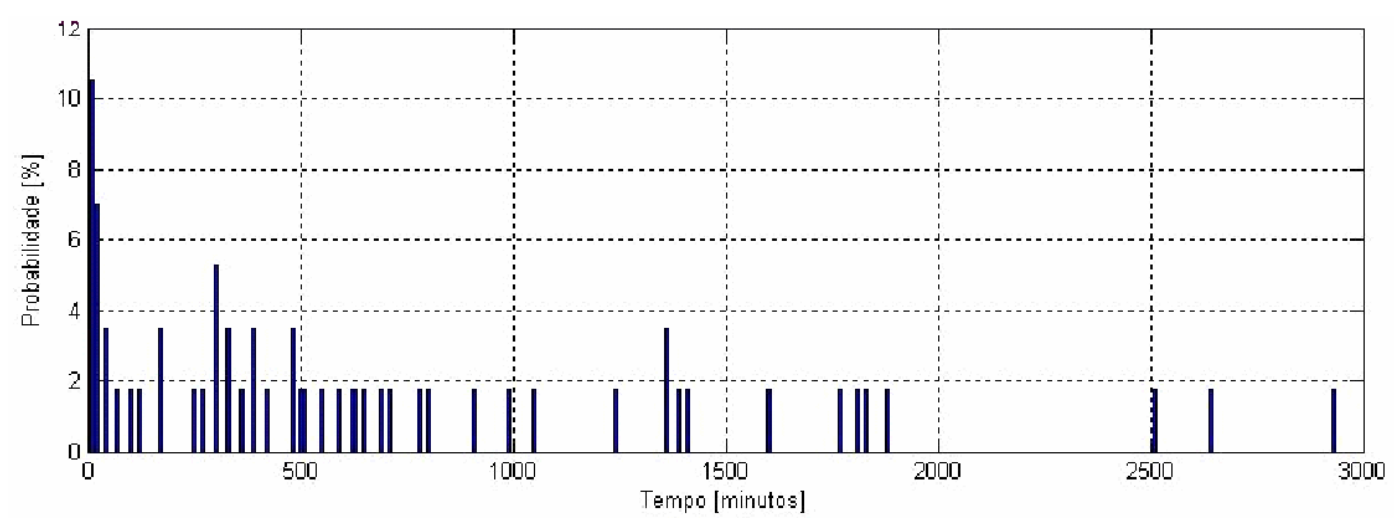

Figura 8.32 - Probabilidades de ocorrência dos intervalos ininterruptos de tempo com valores de Plt $\leq$

$$
0,132
$$

Para auxiliar nesta etapa da análise, foi realizado um zoom nas figuras acima. As figuras 8.33 e 8.34 exibem os resultados da aplicação do zoom nas figuras 8.31 e 8.32, respectivamente.

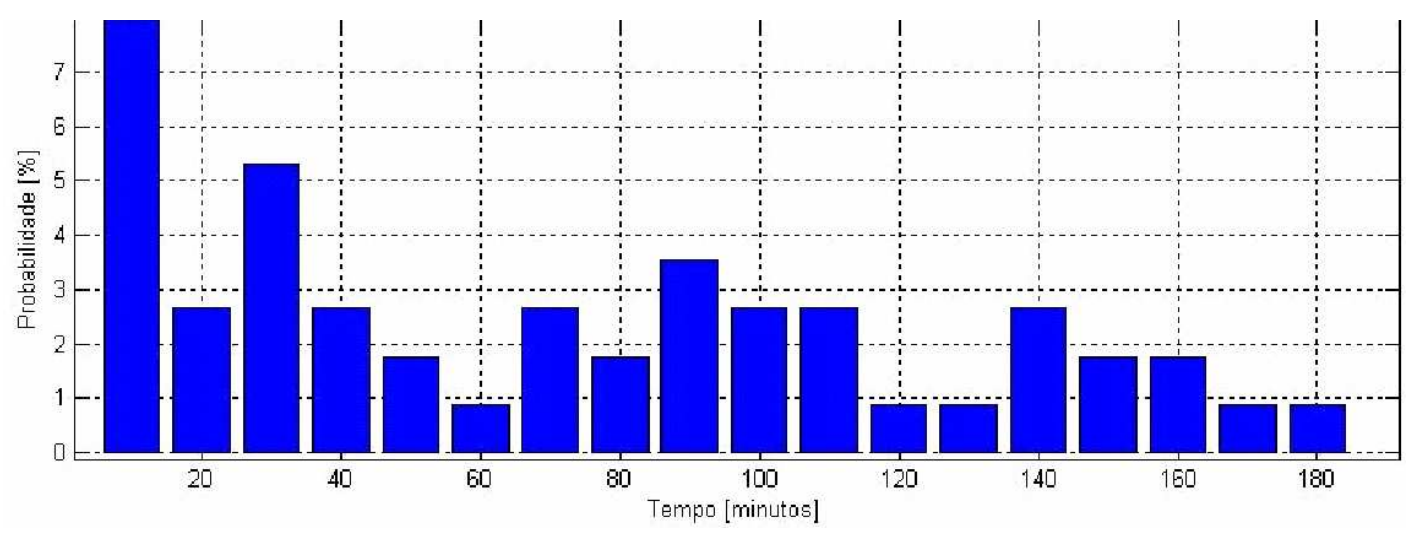

Figura 8.33 - Zoom na figura 8.31 na faixa de 0 a 190 minutos

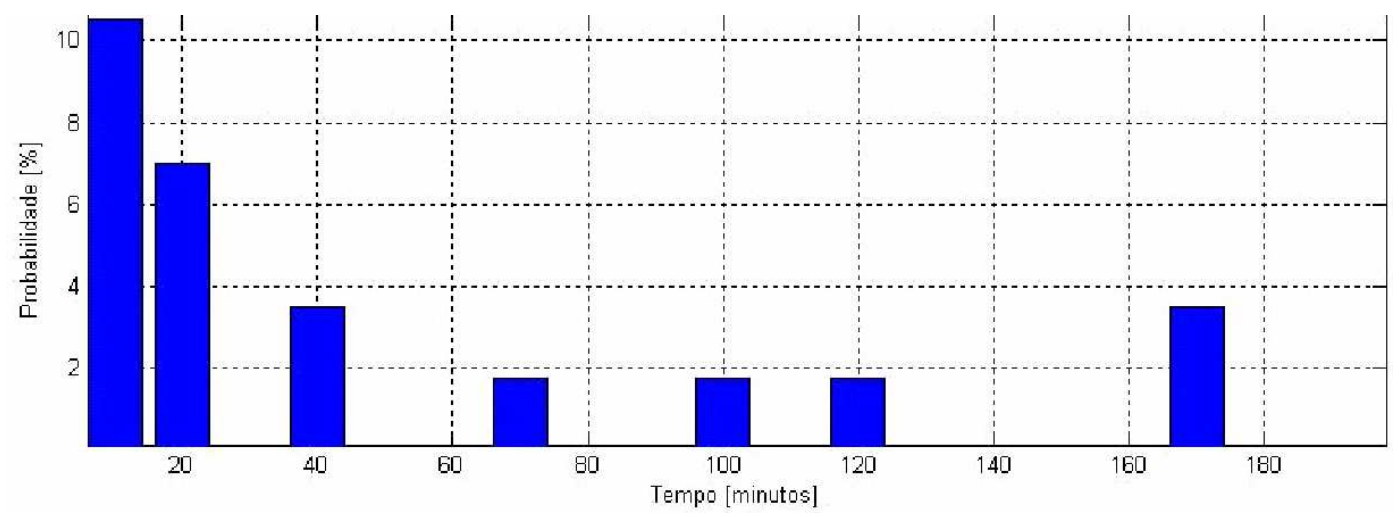

Figura 8.34 - Zoom da figura 8.32 na faixa de 0 a 200 minutos 
Nota-se da figura 8.33 que cerca de $32 \%$ dos intervalos ininterruptos de tempo com Pst $\leq 0,198$ tem até 100 minutos de duração.

Nota-se da figura 8.34 que cerca de $26 \%$ dos intervalos ininterruptos de tempo com Plt $\leq 0,132$ tem até 120 minutos de duração.

As tabelas 8.7 e 8.8 apresentam um resumo dos dados observados ao decorrer desta análise.

Tabela 8.7 - Resumo dos valores observados para o Pst quando a referência é a média quadrática.

\begin{tabular}{|c|c|c|}
\cline { 2 - 3 } \multicolumn{1}{c|}{} & \multicolumn{2}{c|}{ Fase C } \\
\hline Média quadrática do Pst $\mathbf{0} \mathbf{0 , 1 9 8}$ & Duração (minutos) & Em \% do total \\
\hline Tempo total com Pst $\geq \mathbf{0 , 1 9 8}$ & 1240 & 2,9 \\
\hline $\begin{array}{c}\text { Máximo intervalo ininterrupto de tempo } \\
\text { com Pst } \geq \mathbf{0 , 1 9 8}\end{array}$ & 40 & 0,09 \\
\hline $\begin{array}{c}\text { Probabilidade de ocorrência de intervalo } \\
\text { ininterrupto de tempo com Pst } \geq \mathbf{0 , 1 9 8}\end{array}$ & até 20 & 95 \\
\hline $\begin{array}{c}\text { Máximo ininterrupto intervalo de tempo } \\
\text { com Pst } \leq \mathbf{0 , 1 9 8}\end{array}$ & 2320 & 5,4 \\
\hline $\begin{array}{c}\text { Probabilidade de ocorrência de intervalo } \\
\text { ininterrupto de tempo com Pst } \leq \mathbf{0 , 1 9 8}\end{array}$ & até 100 & 32 \\
\hline
\end{tabular}

Tabela 8.8 - Resumo dos valores observados para o Plt quando a referência é a média quadrática.

\begin{tabular}{|r|c|c|}
\cline { 2 - 3 } \multicolumn{1}{c|}{} & \multicolumn{2}{c|}{ Fase C } \\
\hline Média quadrática do PIt $=\mathbf{0 , 1 3 2}$ & Duração (minutos) & Em \% do total \\
\hline Tempo total com PIt $\geq \mathbf{0 , 1 3 2}$ & 3930 & 9,1 \\
\hline $\begin{array}{r}\text { Máximo intervalo ininterrupto de tempo } \\
\text { com PIt } \geq \mathbf{0 , 1 3 2}\end{array}$ & 250 & 0,58 \\
\hline $\begin{array}{c}\text { Probabilidade de ocorrência de intervalo } \\
\text { ininterrupto de tempo com PIt } \geq \mathbf{0 , 1 3 2}\end{array}$ & até 50 & 54 \\
\hline $\begin{array}{c}\text { Máximo ininterrupto intervalo de tempo } \\
\text { com Plt } \leq \mathbf{0 , 1 3 2}\end{array}$ & 2930 & 6,8 \\
\hline $\begin{array}{c}\text { Probabilidade de ocorrência de intervalo } \\
\text { ininterrupto de tempo com PIt } \leq \mathbf{0 , 1 3 2}\end{array}$ & até 120 & 26 \\
\hline
\end{tabular}


Evidencia-se, portanto, que para os 30 dias em estudo, os diversos valores de Pst $\geq$ 0,198 estão, predominantemente, concentrados em intervalos de 10 minutos de duração e que os diversos valores de Plt $\geq 0,132$ estão concentrados em intervalos de até 40 minutos de duração. Contudo, das análises gráficas dos valores destacam-se a existência de 5 intervalos ininterruptos com Plt $\geq 0,132$ com mais de 150 minutos de duração, sendo que um deles possui 250 minutos.

As tabelas 8.9 e 8.10 trazem as comparações dos valores observados para os diferentes índices de Pst e Plt respectivamente.

Tabela 8.9 - Tabela comparativa entre os índices P95\%, P99\% e média quadrática do Pst da fase C.

\begin{tabular}{|c|c|c|c|c|c|c|}
\hline $\begin{array}{c}\text { Indice (valor em pu) } \\
\text { Duração }\end{array}$ & \multicolumn{2}{|c|}{ P95\% (0,156) } & \multicolumn{2}{c|}{ P99\% (0,336) } & \multicolumn{2}{c|}{ Média Quadrática } \\
\hline $\begin{array}{c}\text { Tempo total com Pst } \geq \\
\text { Máximo intervalo ininterrupto }\end{array}$ & 2190 & 5,07 & 430 & 1 & 1240 & 2,9 \\
\hline de tempo com Pst $\geq$ & 50 & 0,11 & 30 & 0,07 & 40 & 0,09 \\
\hline $\begin{array}{c}\text { Probabilidade de ocorrência de } \\
\text { intervalo ininterrupto de tempo } \\
\text { com Pst } \geq\end{array}$ & 10 & 80 & 10 & 85 & até 20 & 95 \\
\hline $\begin{array}{c}\text { Máximo ininterrupto intervalo } \\
\text { de tempo com Pst } \leq\end{array}$ & 1200 & 2,77 & 3840 & 8,88 & 2320 & 5,4 \\
\hline $\begin{array}{c}\text { Probabilidade de ocorrência de } \\
\text { intervalo ininterrupto de tempo } \\
\text { com Pst } \leq\end{array}$ & até 100 & 44 & até 550 & 45,9 & até 100 & 32 \\
\hline
\end{tabular}


Tabela 8.10 - Tabela comparativa entre os índices P95\%, P99\% e média quadrática do Plt da fase C.

\begin{tabular}{|c|c|c|c|c|c|c|}
\hline Índice (valor em pu) & \multicolumn{2}{|c|}{ P95\% (0,145) } & \multicolumn{2}{c|}{ P99\% (0,220) } & \multicolumn{2}{c|}{$\begin{array}{c}\text { Média Quadrática } \\
\text { (0,132) }\end{array}$} \\
\hline Duração & Minutos & $\%$ & Minutos & $\%$ & Minutos & $\%$ \\
\hline Tempo total com PIt $\geq$ & 2200 & 5,1 & 430 & 1 & 3930 & 9,1 \\
\hline $\begin{array}{c}\text { Máximo intervalo ininterrupto } \\
\text { de tempo com PIt } \geq\end{array}$ & 250 & 0,58 & 140 & 0,32 & 250 & 0,58 \\
\hline $\begin{array}{c}\text { Probabilidade de ocorrência de } \\
\text { intervalo ininterrupto de } \\
\text { tempo com PIt } \geq\end{array}$ & até 40 & 38,5 & até 30 & 50 & até 50 & 54 \\
\hline $\begin{array}{c}\text { Máximo ininterrupto intervalo } \\
\text { de tempo com Plt } \leq\end{array}$ & 5220 & 12,11 & 19260 & 44,7 & 2930 & 6,8 \\
\hline $\begin{array}{c}\text { Probabilidade de ocorrência de } \\
\text { intervalo ininterrupto de } \\
\text { tempo com Plt } \leq\end{array}$ & até 40 & 28 & até 1210 & 42,86 & até 120 & 26 \\
\hline
\end{tabular}

\subsection{CONSIDERAÇÕES FINAIS}

Das análises executadas nesta etapa, pode-se concluir que em se tratando dos valores acima de P95\% , de P99\% e da média quadrática, dos indicadores Pst e Plt, tem-se comportamentos semelhantes no que diz respeito à distribuição no tempo das amostras. No próximo capítulo será apresentado o módulo de comparação com a norma, através de uma análise dos dados da linha 1 da subestação SE ALBRAS, verificando se estes valores se encontram dentro dos limites estabelecidos pela recomendação do ONS. 


\section{CAPÍTULO 9}

\section{COMPARAÇÃO COM A NORMA}

O presente capítulo tem por interesse, apresentar o módulo do programa computacional que realiza a apreciação dos valores dos indicadores de severidade obtidos com os limites estabelecidos pela recomendação nacional.

O documento em análise foi o Procedimento de Rede do ONS, Submódulo 2.2. apresentado no capítulo 3 deste relatório.

\subsection{ESTRUTURA DO MÓDULO}

O módulo de comparação, apresentado na figura 9.1, pode ser acessado por meio do botão intitulado "Comparação com a norma", ou fazendo-se uso do menu "Análises", ambos presentes na tela de abertura da ferramenta.

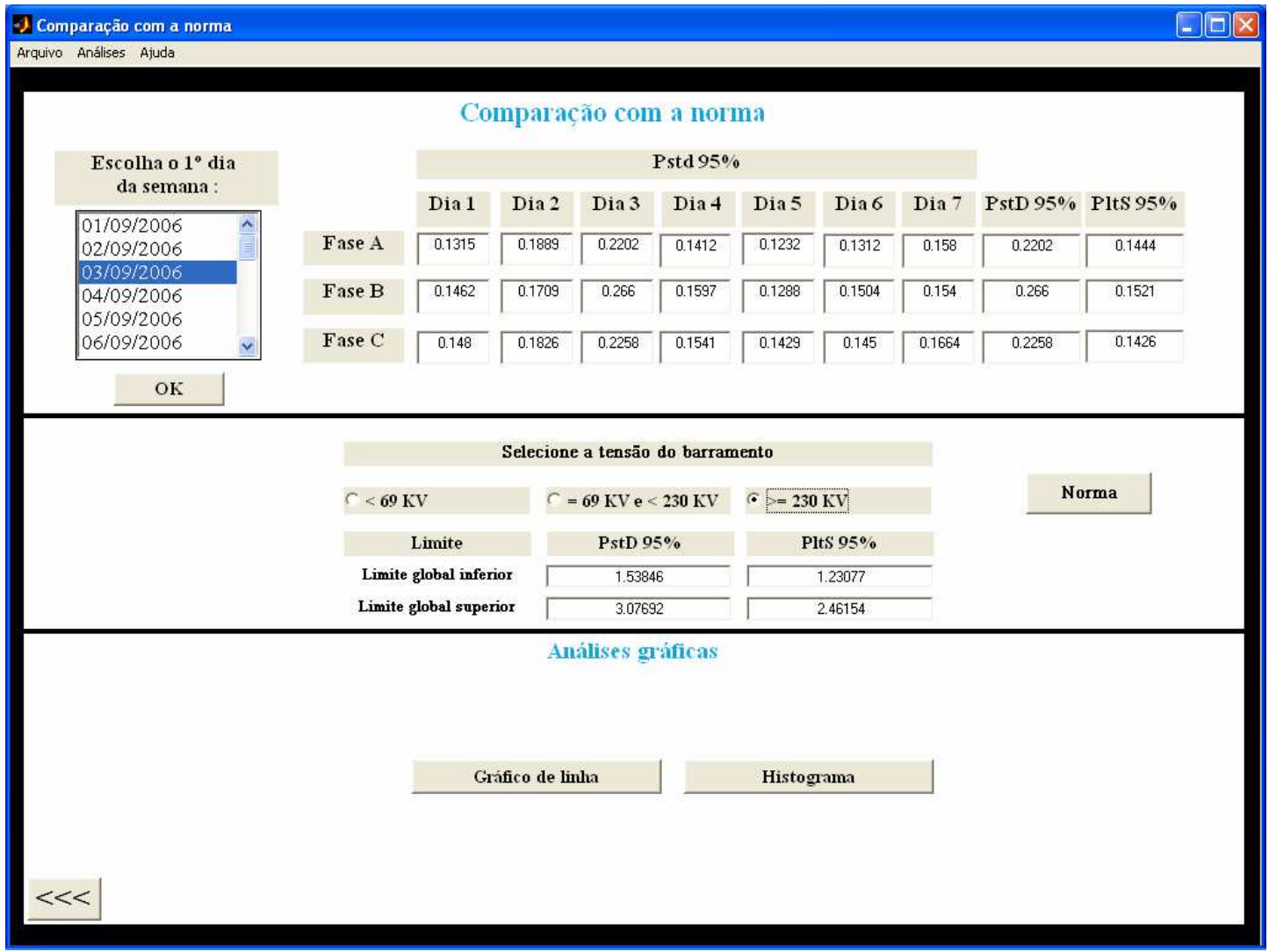

Figura 9.1 - Janela do módulo de comparação com a norma. 
O passo inicial na execução deste módulo é a escolha da semana a ser analisada. Para tanto, basta selecionar o primeiro dia da mesma e em seguida premir "Ok", logo abaixo da caixa de diálogo.

Ao realizar este procedimento, estarão disponíveis ao usuário, por meio de tabela, os valores do Pstd95\% de cada fase para os sete dias de medição, bem como o valor de PstD95\% e o valor do PltS95\%.

Como descrito anteriormente, o Pstd95\% correspondente ao percentil de 95\% das 144 amostras de Pst obtidas para cada fase em um dia de medição. Já o PstD95\% será o maior resultado de Pstd95\% encontrado durante a semana em estudo. O indicador de PltS95\% será o maior valor entre as três fases, correspondentes ao percentil de $95 \%$ das amostras de Plt obtidas para cada fase em uma semana de medição.

Abaixo da tabela, onde estão resumidos os indicadores de flutuação de tensão obtidos durante a campanha de medição são disponibilizados os valores dos limites globais, inferior e superior, com o intuito de possibilitar a comparação. Para se obter estes resultados, faz-se necessário a seleção da tensão do barramento em estudo. Esta informação pode ser alcançada utilizando o módulo de análise de carga que será apresentado no próximo capítulo.

$\mathrm{Na}$ parte inferior da presente tela, estão disponíveis dois botões, a partir dos quais é possível obter, tal qual a resolução exige, as curvas mostrando a tendência dos indicadores Pst e Plt em cada uma das fases durante os sete dias de medição. Bem como a distribuição probabilística dos dados alcançados para os índices.

\section{2 - ESTUDO DE CASO}

Deseja-se agora realizar uma análise comparativa acerca dos indicadores medidos na subestação ALBRAS da Eletronorte. Para tanto, será realizado um estudo sobre a semana iniciada no dia 3 de setembro de 2006. A tabela 9.1 exibe os resultados obtidos nesta etapa. 
Tabela 9.1 - Resumo dos indicadores obtidos na campanha de medição iniciada no dia 3.

\begin{tabular}{|c|c|c|c|c|c|c|c|c|c|}
\cline { 2 - 9 } \multicolumn{1}{c|}{} & \multicolumn{7}{c|}{ Pstd95\% } & \multicolumn{1}{c|}{} \\
\cline { 2 - 9 } \multicolumn{1}{c|}{} & Dia 1 & Dia 2 & Dia 3 & Dia 4 & Dia 5 & Dia 6 & Dia 7 & PstD95\% & PItS95\% \\
\hline $\begin{array}{c}\text { Fase } \\
\text { A }\end{array}$ & 0.1315 & 0.1889 & 0.2202 & 0.1412 & 0.1232 & 0.1312 & 0.158 & 0.2202 & 0.1444 \\
\hline $\begin{array}{c}\text { Fase } \\
\text { B }\end{array}$ & 0.1462 & 0.1709 & 0.266 & 0.1597 & 0.1288 & 0.1504 & 0.154 & 0.266 & 0.1521 \\
\hline $\begin{array}{c}\text { Fase } \\
\text { C }\end{array}$ & 0.148 & 0.1826 & 0.2258 & 0.1541 & 0.1429 & 0.145 & 0.1664 & 0.2258 & 0.1426 \\
\hline
\end{tabular}

A tensão da subestação é $230 \mathrm{kV}$. Os limites globais alcançados para este nível de tensão estão expostos na tabela 9.2.

Tabela 9.2 - Limite dos indicadores.

\begin{tabular}{|c|c|c|}
\hline Limites & PstD95\% & PItS95\% \\
\hline Limite global inferior & 1.53846 & 1.23077 \\
\hline Limite global superior & 3.07692 & 2.46154 \\
\hline
\end{tabular}

Dados os resultados expostos acima, pode-se inferir que a qualidade da tensão, no que tange a cintilação luminosa, está adequada, pois o maior PstD95\%, igual a 0,266 e o maior PltS95\%, igual a 0,1521, ambos encontrados na fase B, estão abaixo do limite global inferior.

Visando cumprir exigências do ONS quando da apresentação de relatórios sobre flutuações de tensão. Este módulo contempla a apresentação dos gráficos de linha dos indicadores e os histogramas dos mesmos.

As figuras 9.2, 9.3 e 9.4 ilustram os gráficos de linha para os valores de Pst das fases A, B e C, respectivamente. 


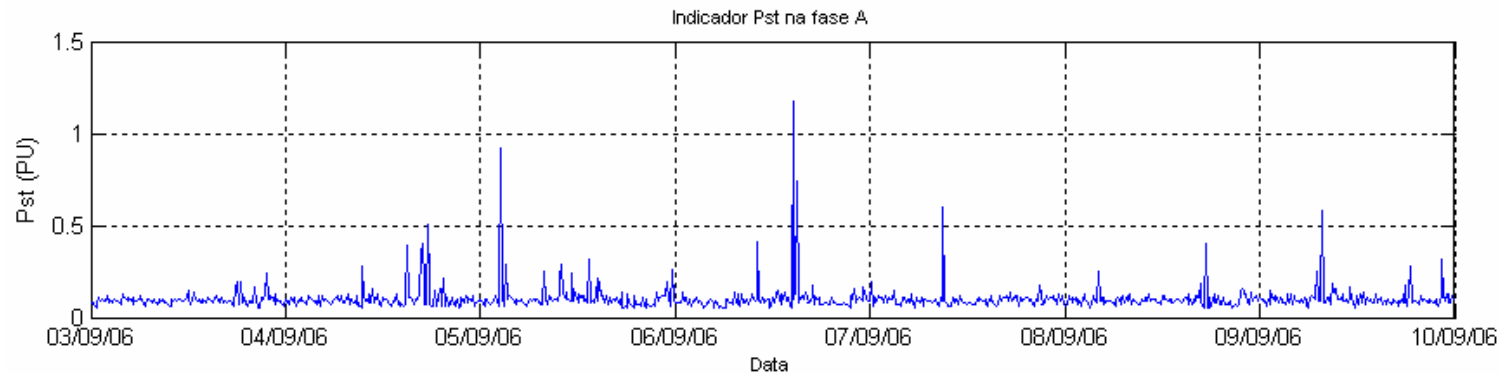

Figura 9.2 - Tendência do indicador Pst na fase A, durante a semana em estudo.

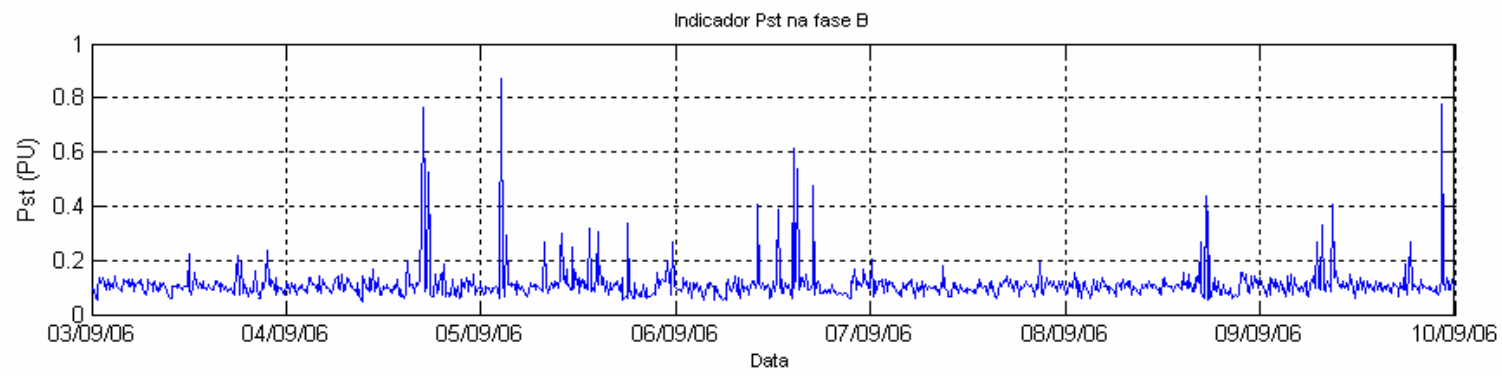

Figura 9.3 - Tendência do indicador Pst na fase B, durante a semana em estudo.

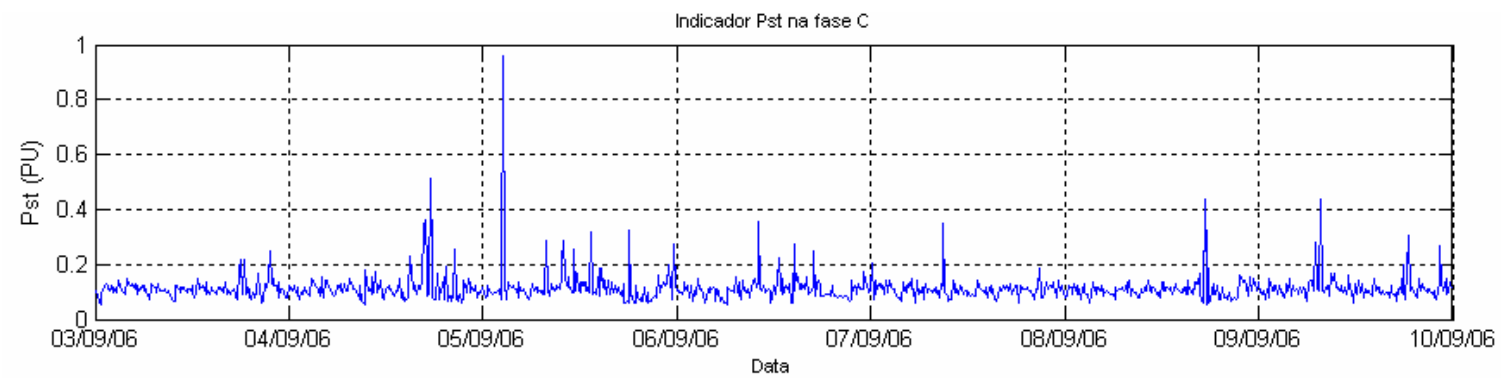

Figura 9.4 - Tendência do indicador Pst na fase C, durante a semana em estudo.

As curvas acima mostram que o Pst da subestação ALBRAS esteve, durante toda a semana, abaixo de níveis preocupantes, mantendo-se em média próximo a 0,1 pu. Nota-se, ainda das figuras 9.2, 9.3 e 9.4, a semelhança no comportamento das fases e que apesar da fase B apresentar o maior número de picos, somente a fase A ultrapassou o valor de 1 pu.

As figuras 9.5, 9.6 e 9.7 mostram os gráficos de linha para os valores de Plt das fases A, B e C, respectivamente. 


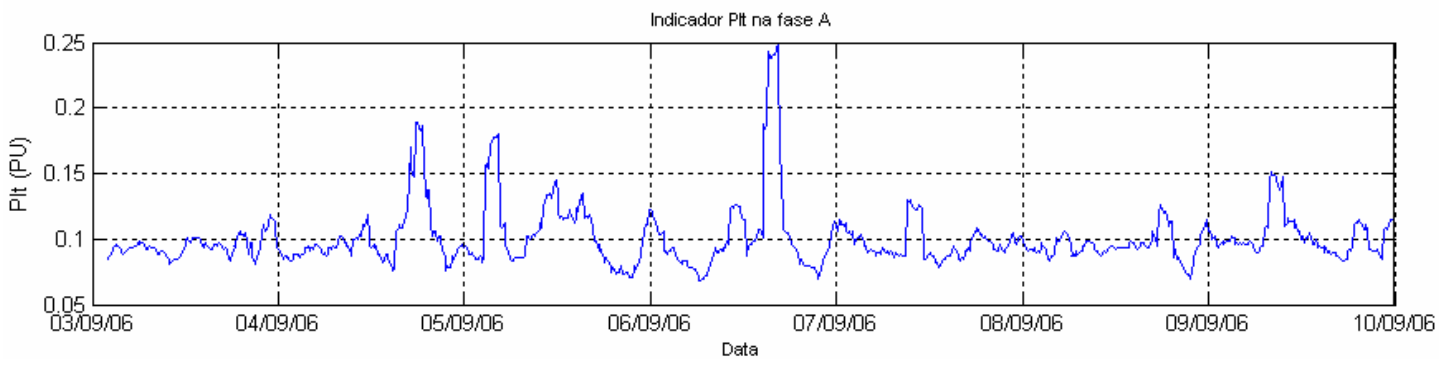

Figura 9.5 - Tendência do indicador Plt na fase A, durante a semana em estudo.

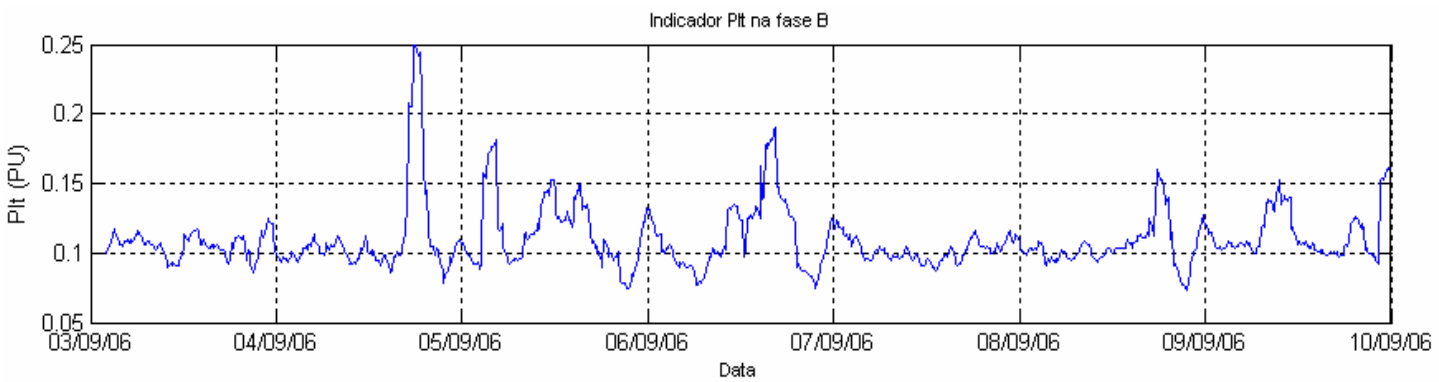

Figura 9.6 - Tendência do indicador Plt na fase B, durante a semana em estudo.

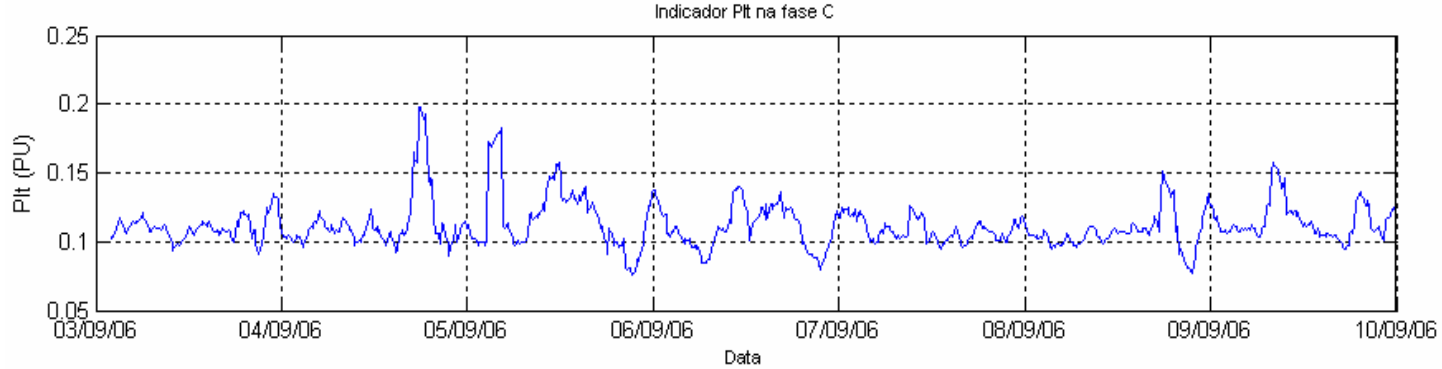

Figura 9.7 - Tendência do indicador Plt na fase C, durante a semana em estudo.

Fica claro, a partir dos gráficos das figuras 9.5, 9.6 e 9.7 que o indicador Plt manteve-se nas proximidades de 0,1 pu durante toda a campanha e que o valor de 0,25 pu não foi ultrapassado em nenhuma fase. Ainda das mesmas figuras, percebe-se que a fase $\mathrm{C}$ apresenta as menores variações do Plt e a semelhança no comportamento das fases fica mais uma vez evidenciada. Nem mesmo os picos encontrados estiveram próximos do limite global inferior, que é 1,23 pu.

As figuras 9.8, 9.9 e 9.10 ilustram os histogramas e as curvas de probabilidade acumulada para os valores de Pst das fases A, B e C, respectivamente. 


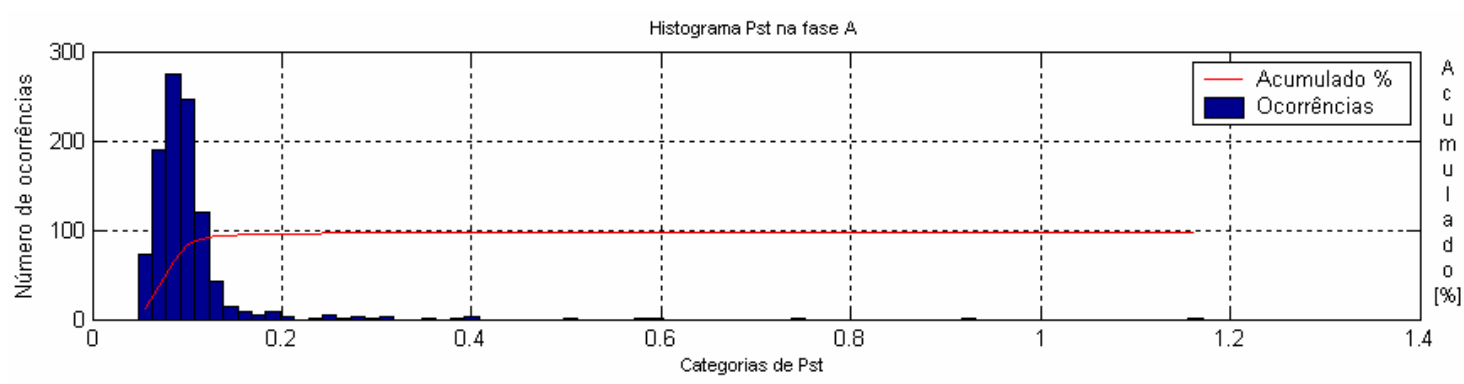

Figura 9.8 - Histograma e curva de probabilidade acumulada do indicador Pst na fase A.

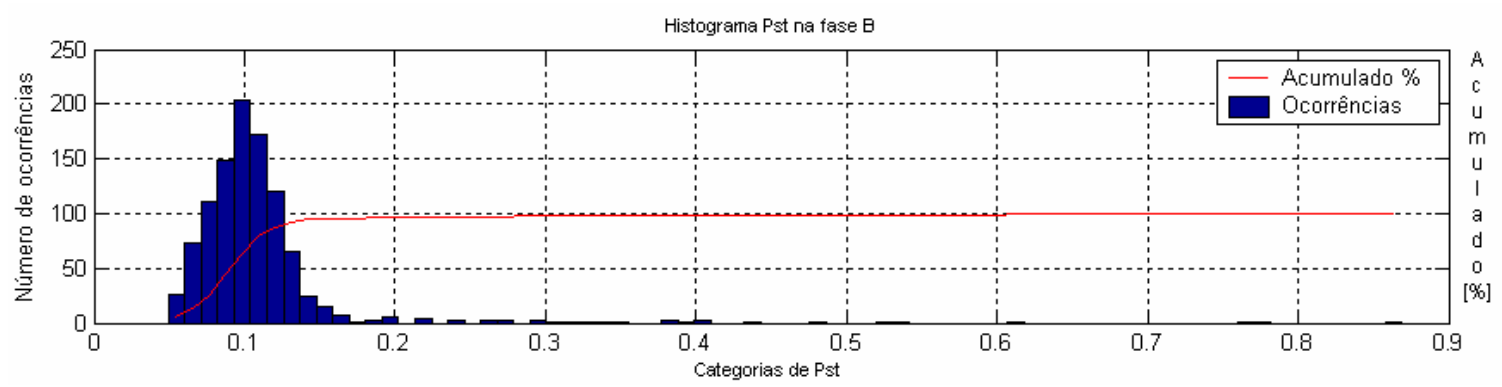

Figura 9.9 - Histograma e curva de probabilidade acumulada do indicador Pst na fase B.

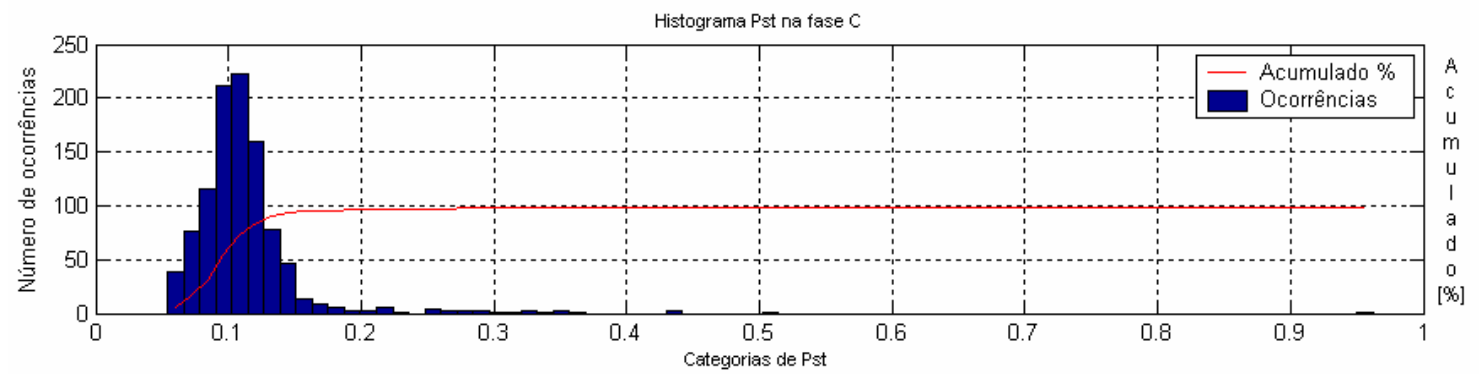

Figura 9.10 - Histograma e curva de probabilidade acumulada do indicador Pst na fase C.

Das figuras 9.8, 9.9 e 9.10, percebem-se o grande número de ocorrências de Pst com valores próximos a 0,1 pu. Nota-se, ainda desta figuras, que mais de $95 \%$ das ocorrências de Pst possuem valores inferiores a 0,2 pu e que o comportamento das fases são semelhante.

As figuras 9.11, 9.12 e 9.13 apresentam os histogramas e as curvas de probabilidade acumulada para os valores de Plt das fases A, B e C, respectivamente. 


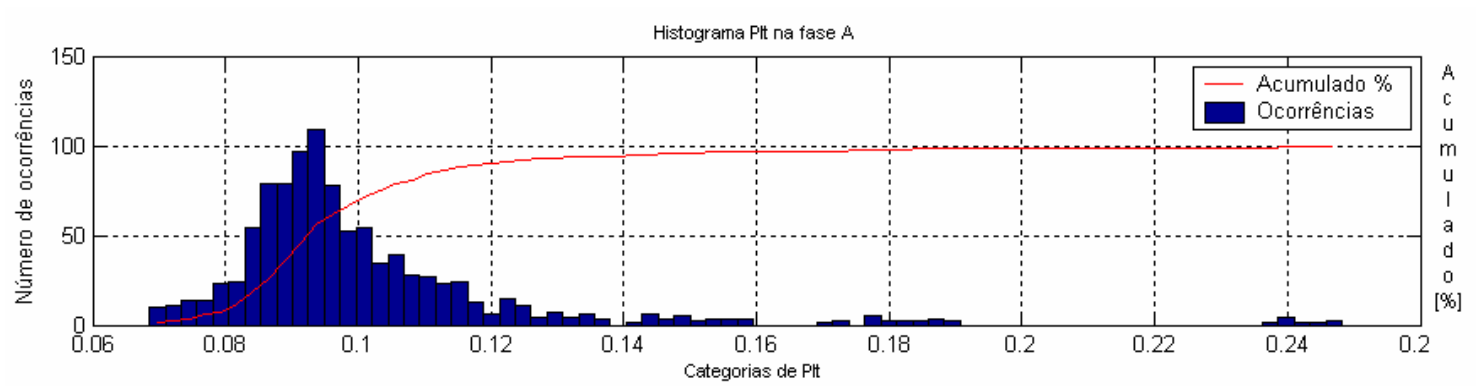

Figura 9.11 - Histograma e curva de probabilidade acumulada do indicador Plt na fase A.

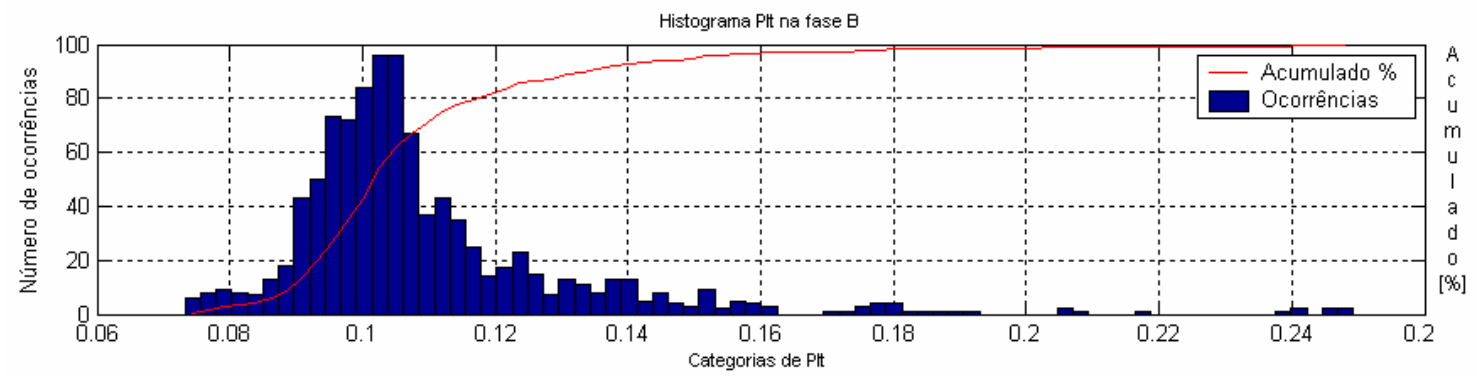

Figura 9.12 - Histograma e curva de probabilidade acumulada do indicador Plt na fase B.

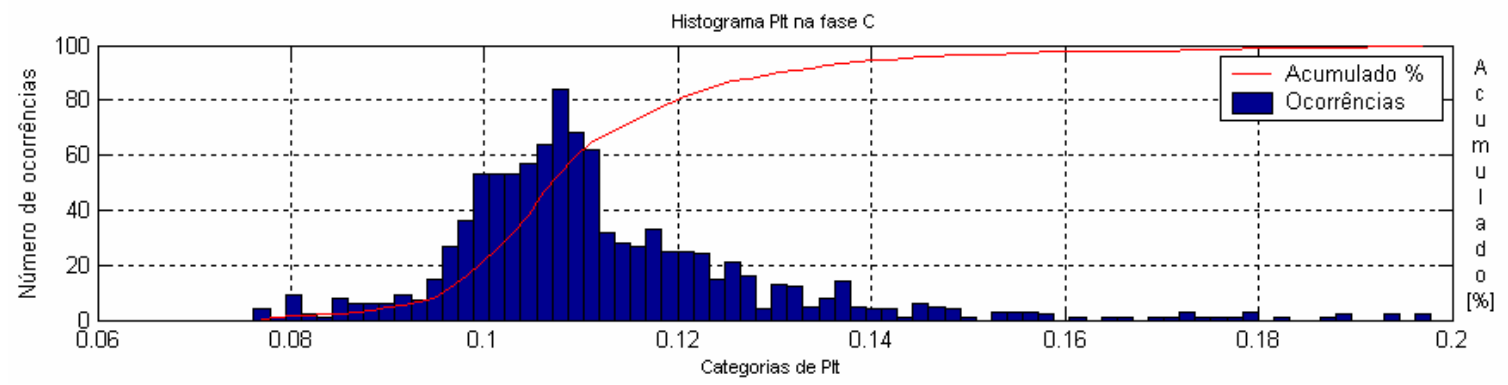

Figura 9.13 - Histograma e curva de probabilidade acumulada do indicador Plt na fase C.

Observando as figuras 9.11, 9.12 e 9.13, tem-se que o maior número de ocorrências de Plt possui valores entre 0,08 e 0,1 pu para a fase A, entre 0,09 e 0,11 pu para a fase B e entre 0,1 e 0,12 pu para a fase C. Mesmo ocorrendo esta variação, as fases são semelhantes, pois estes valores estão muito próximos entre si. Ainda das figuras supracitadas, nota-se que mais de $90 \%$ dos valores de Plt estão abaixo de 0,14pu. 


\section{3 - CONSIDERAÇÕES FINAIS}

Neste capítulo foi apresentado o módulo de comparação com norma do programa. Evidencia-se, a partir da análise elaborada, que a tensão medida na Subestação ALBRAS da Eletronorte obedece aos requisitos exigidos pela recomendação brasileira. No capítulo seguinte será apresentado o módulo de análise de carga, a partir do qual será possível comparar a ocorrência de cintilação luminosa com a manifestação de alterações na corrente, tensões, potência ou freqüência da subestação. 


\section{CAPÍtULO 10}

\section{ANÁLISE DE CARGA}

Este capítulo apresenta o módulo de análise carga. Com este tópico do programa é possível traçar os perfis de tensão, corrente e potência do local analisado, utilizando recursos gráficos e estatísticos. O objetivo principal é permitir ao usuário a verificação da existência de possíveis perturbações ou anomalias que alterem significativamente as medições de cintilação luminosa.

Para que o módulo esteja disponível para análise, é necessário que o banco de dados do usuário contenha as medições de tensões de linha e fase, correntes de linha, além de frequiência e de potências aparente, ativa e reativa totais.

\subsection{ESTRUTURA DO MÓDULO}

O módulo pode ser acessado pelo botão "Análise de Carga" na tela de entrada, ou a partir do menu superior “Análises”. Abrir-se-á a janela mostrada na figura 10.1.

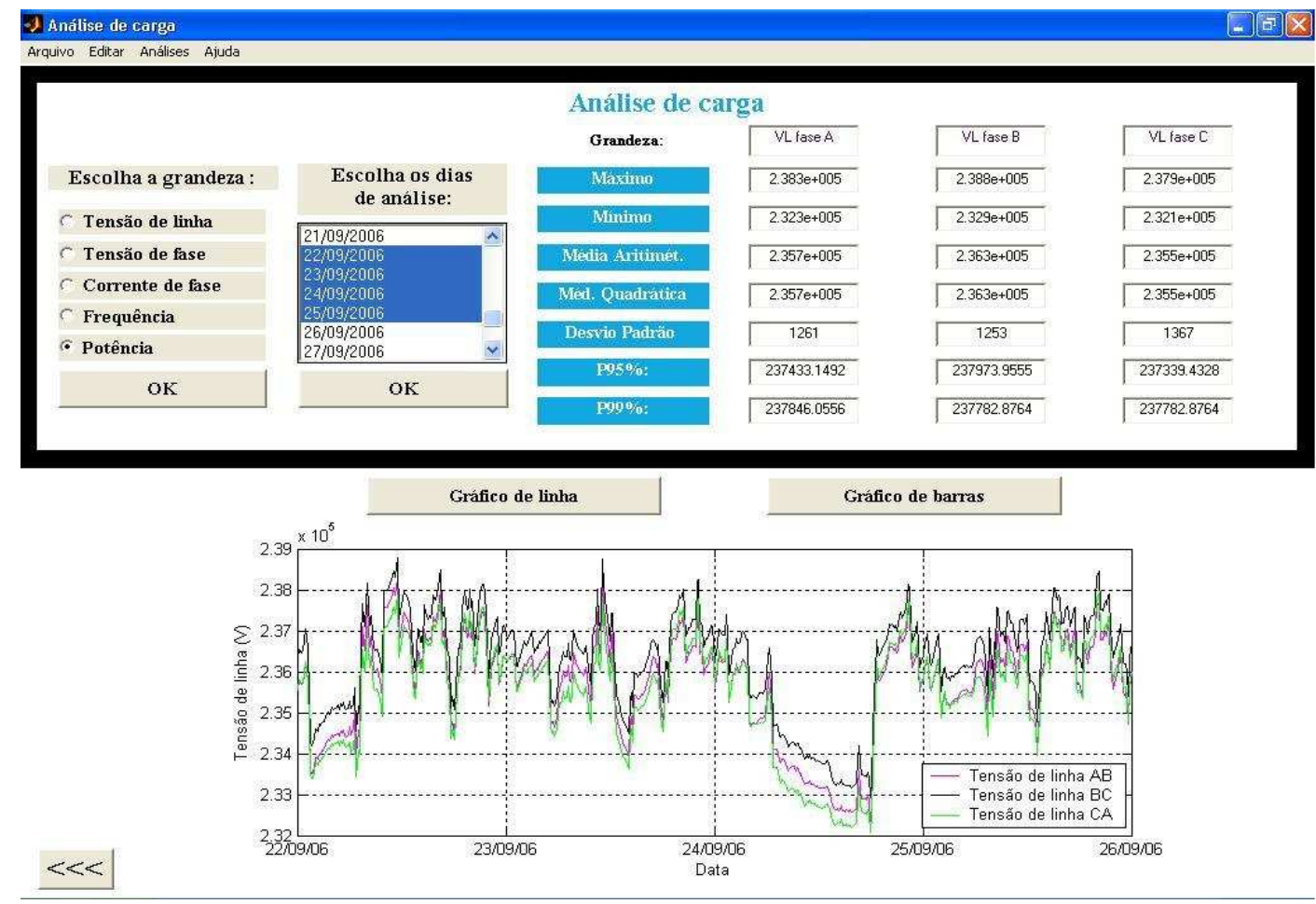

Figura 10.1 - Janela do módulo de análise de carga 
Acima à esquerda, ficam disponíveis as grandezas para análises: tensão de linha, tensão de fase, corrente de linha, freqüência e potência. Basta Selecionar uma delas e clicar no botão "OK" abaixo das mesmas. Escolha o dia ou período a ser analisado e aperte o botão "OK".

Para selecionar mais de um dia, clique com o botão esquerdo do mouse sobre o primeiro ou o último dia do período almejado e arraste até que todos os dias desejados estejam dentro do contorno azul.

Realizado este procedimento, os dados estatísticos são calculados automaticamente pelo software, para cada fase do sistema, e mostrados na tabela ao lado da data. Estão disponíveis valores máximo e mínimo, média aritmética, média quadrática, desvio padrão, P95\% e P99\%.

Ficam habilitadas também as análises gráficas, em dois botões abaixo da tabela, onde há opção de gráfico ponto a ponto das amostras e gráfico de barras dos valores estatísticos. Ao se clicar sobre qualquer um deles, aparece o gráfico correspondente abaixo desses botões.

Há ainda a possibilidade de se modificar e salvar o gráfico. Basta clicar no menu "Editar" e selecionar o tipo de gráfico a ser editado e salvo. A partir do menu pode-se ir para qualquer um dos módulos.

\subsection{ESTUDO DE CASO}

Objetivando exemplificar a utilização do módulo, será feita uma análise gráfica e estatística das amostras obtidas para tensões de linha, correntes de fase e potências. $\mathrm{O}$ banco de dados utilizado é o SE ALBRÁS L1 da Eletronorte.

\subsubsection{TENSÕES DE LINHA}

A tensão nominal na entrada da subestação é $230 \mathrm{kV}$. Ressalta-se que para esta análise, escolheram-se os sete primeiros dias do banco de dados: de 01 de setembro de 2006, uma sexta-feira, a 07 de setembro de 2006, uma quinta-feira.

A figura 10.2 apresenta o gráfico ponto a ponto das tensões de linha para as três fases captadas na primeira semana de monitoração. 


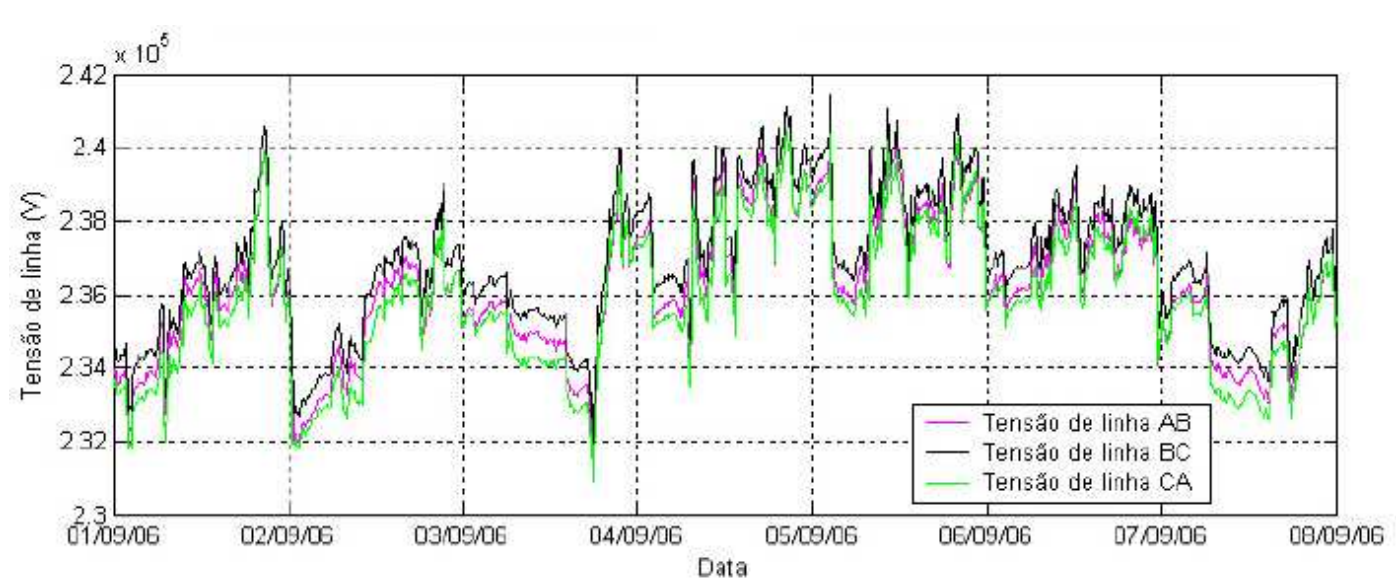

Figura 10.2 - Tensões de linha no intervalo de uma semana de medição

Nota-se que a tensão permanece acima do valor nominal em praticamente todo intervalo de medição. A resolução 505 da ANEEL, de 26 de novembro de 2001, estabelece como nível de tensão adequado para essa faixa valores entre $95 \%$ e $105 \%$ da tensão de referência. A tabela 10.1 e a figura 10.3 trazem os dados estatísticos para as três fases medidas.

Tabela 10.1 - Dados estatísticos das tensões medidas

\begin{tabular}{|c|c|c|c|}
\hline Tensões de Linha & $\mathbf{V a b}(\mathbf{k V})$ & $\mathbf{V b c ( k V )}$ & $\mathbf{V c a}(\mathbf{k V})$ \\
\hline Máximo & 240,8 & 241,4 & 240,5 \\
\hline Mínimo & 231,3 & 232,0 & 230,9 \\
\hline Média Aritmética & 236,2 & 236,8 & 235,9 \\
\hline Média Quadrática & 236,2 & 236,8 & 235,9 \\
\hline Desvio Padrão & 1,86 & 1,85 & 1,95 \\
\hline P95\% & 239,2 & 239,8 & 238,9 \\
\hline P99\% & 240,0 & 240,6 & 239,9 \\
\hline
\end{tabular}




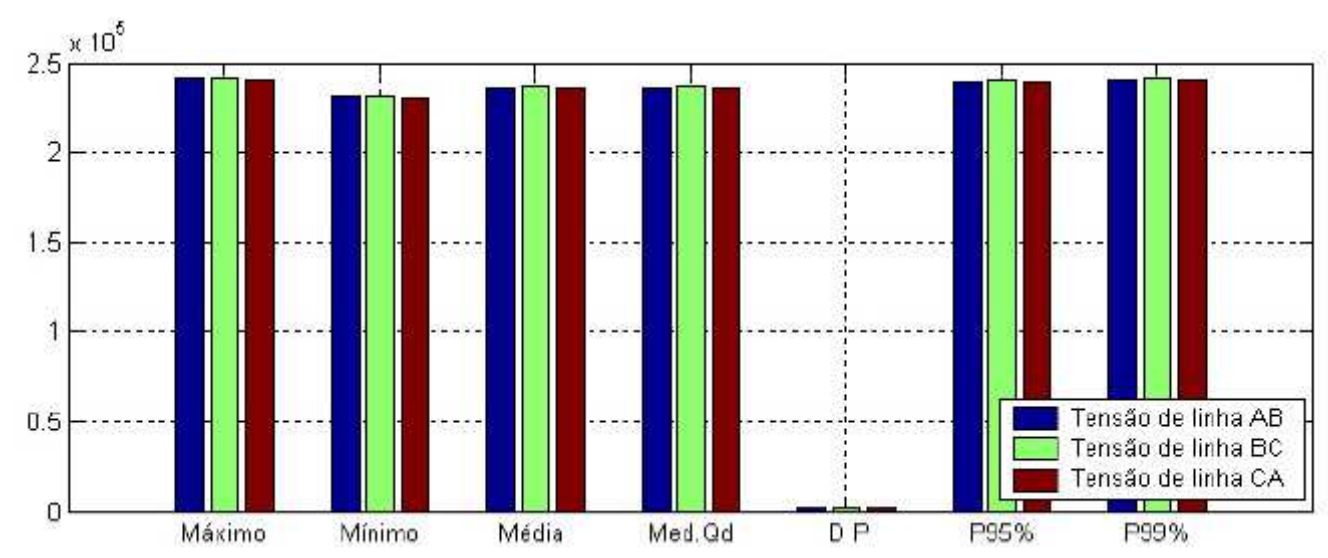

Figura 10.3 - Gráfico de barras com os dados da tabela 10.1

A partir da tabela 10.1 e da figura 10.3, percebe-se que as tensões se mantêm equilibradas com respeito à amplitude, embora a medida entre as fases C e A apresentase pouco abaixo das demais. A variação máxima entre as médias aritméticas é de apenas $0,38 \%$, mesmo valor calculado para as médias quadráticas.

O desvio padrão máximo foi calculado entre as fases c e a, sendo 1,95 kV. Esse valor representa apenas $0,83 \%$ da média aritmética desta tensão. Conclui-se que as amostras variam muito pouco em relação a esta medida estatística. Os valores de P95\% e P99\% apresentam variação máxima de $0,38 \%$ e $0,04 \%$, respectivamente.

O valor de $95 \%$ da tensão de referência representa $218,5 \mathrm{kV}$, enquanto $105 \%$ é igual a $241,5 \mathrm{kV}$. Conclui-se que a tensão medida encontra-se dentro da faixa adequada em todo o período de medição.

\subsubsection{CORRENTES DE FASE}

A figura 10.4 apresenta o gráfico ponto a ponto das três correntes de fase no intervalo de uma semana de medição. A partir dela nota-se variação da carga ao longo do dia. Percebe-se que no sábado, no domingo e no feriado, correspondentes aos dias 02/09, 03/09 e 07/09 a carga média é ligeiramente maior, mesmo tendo um pico negativo no sábado. 


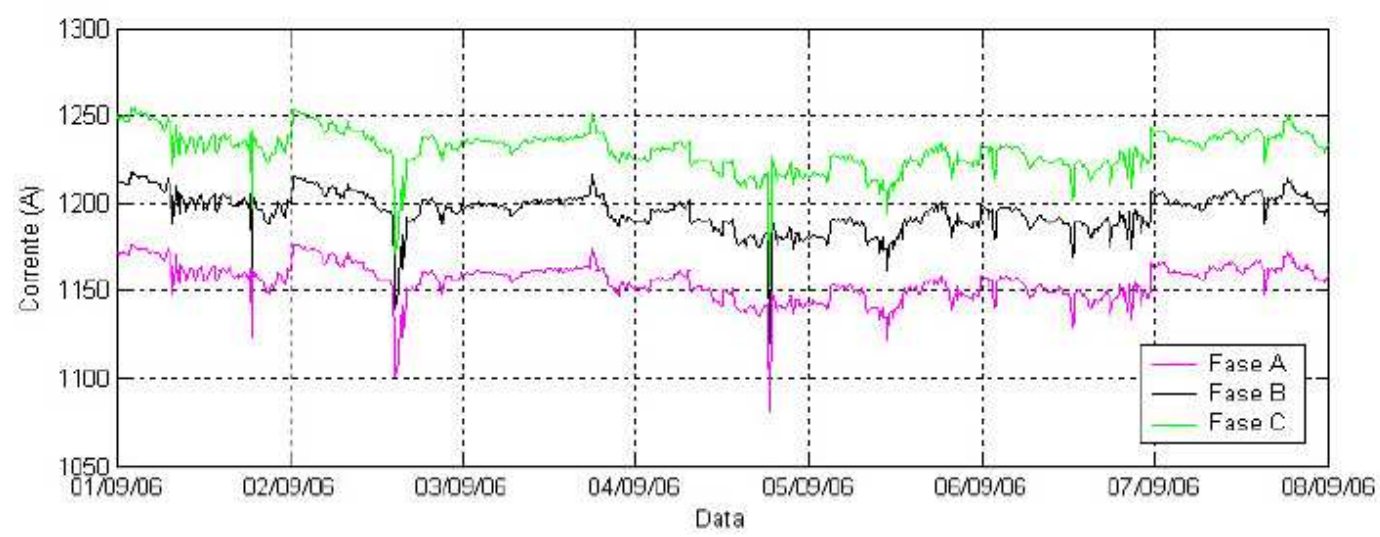

Figura 10.4 - Correntes de fase no intervalo de uma semana de medição

Por se tratar de uma subestação própria que atende exclusivamente as instalações de uma indústria de produção de alumínio, não faremos a análise separando o feriado e o fim de semana dos dias úteis da semana. A tabela 10.2 mostra os dados estatísticos das correntes. A figura 10.5 ilustra o gráfico de barras com os dados desta tabela.

Tabela 10.2 - Dados estatísticos das correntes medidas

\begin{tabular}{|c|c|c|c|}
\hline Correntes de Fase & $\mathbf{I a}(\mathbf{A})$ & $\mathbf{I b}(\mathbf{A})$ & $\mathbf{I c ( A )}$ \\
\hline Máximo & 1177 & 1218 & 1254 \\
\hline Mínimo & 1081 & 1120 & 1153 \\
\hline Média Aritmética & 1156 & 1195 & 1230 \\
\hline Média Quadrática & 1156 & 1196 & 1231 \\
\hline Desvio Padrão & 10,2 & 10,41 & 10,97 \\
\hline P95\% & 1171,286 & 1211,950 & 1248,248 \\
\hline P99\% & 1175,825 & 1215,262 & 1252,005 \\
\hline
\end{tabular}

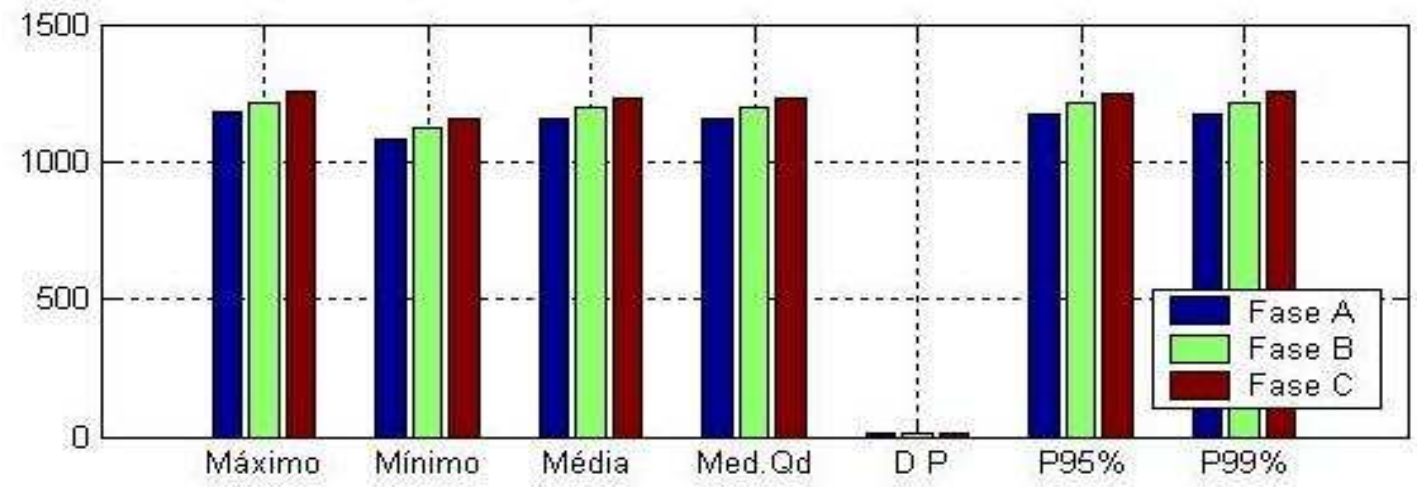

Figura 10.5 - Gráfico de barras com os dados da tabela 10.2 
Observando o gráfico ponto a ponto, percebe-se a semelhança no comportamento das correntes das três fases, porém com módulos diferentes. Fazendo-se a comparação entre os valores calculados na tabela anterior, verifica-se a grande diferença entre os valores máximos de correntes medidas, fato que se reflete nos valores de P95\% e P99\%. Esta diferença entre as fases se repete no valor mínimo, na média aritmética e na média quadrática. Entretanto as correntes variam pouco durante o período medido.

O desvio padrão é praticamente o mesmo para todas as fases e é bem pequeno. O maior desvio proporcional se dá na fase A e representa $0,88 \%$ da média aritmética. A variação entre as médias é de 6,48\% entre os P95\% é de 6,57\% e entre os P99\% é de 6,47\%. Conclui-se que há uma boa distribuição de carga entre as fases apesar da corrente na fase A apresentar sempre os mais baixos valores.

\subsubsection{POTÊNCIAS}

A figura 10.6 apresenta o gráfico ponto a ponto das potências ativa, reativa e aparente totais na primeira semana da medição. Nota-se que o comportamento das potências ativa, aparente e reativa são semelhantes e praticamente constantes, variando apenas a magnitude entre elas.

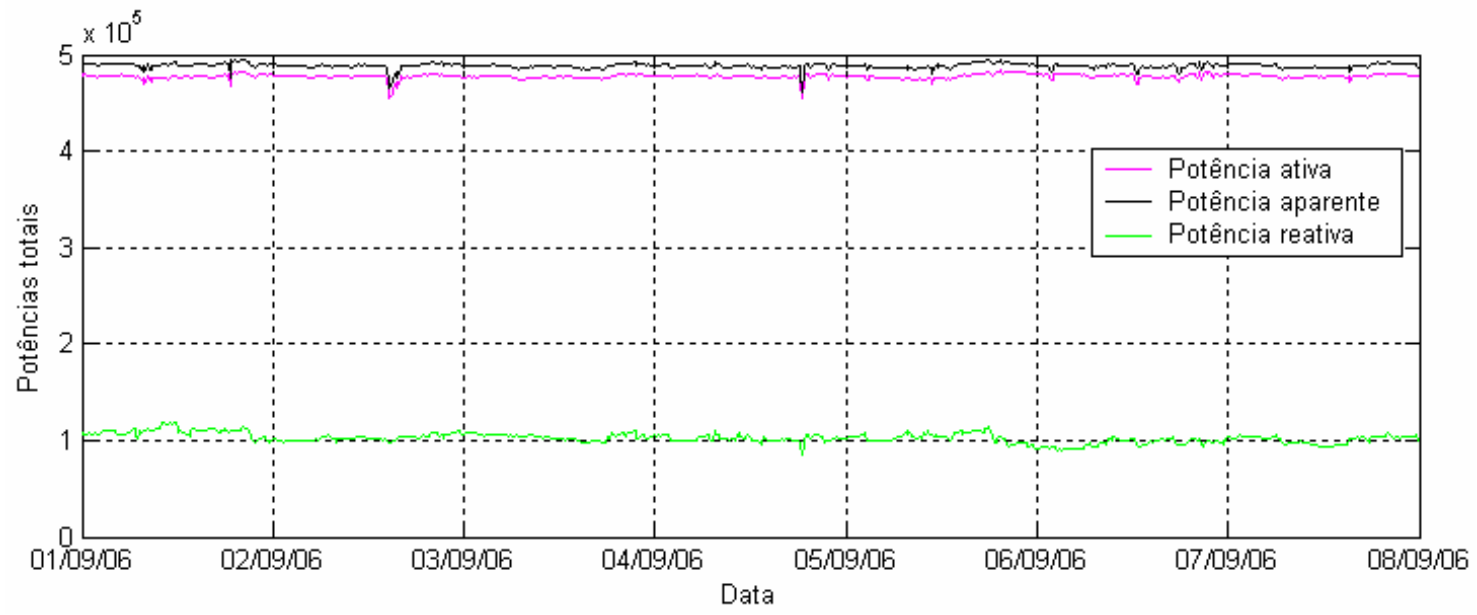

Figura 10.6 - Potências aparente, ativa e reativa no intervalo de uma semana de medição 
Mesmo com a tensão e com a corrente variando, o consumo de potência permanece quase que inalterado. A tabela 10.3 e a figura 10.7 mostram os dados estatísticos obtidos para o período de análise.

Tabela 10.3 - Dados estatísticos das correntes medidas

\begin{tabular}{|c|c|c|c|}
\hline Potências & P(MW) & Q(MVAr) & S(MVA) \\
\hline Máximo & 483,2 & 119,5 & 495,4 \\
\hline Mínimo & 454,3 & 84,6 & 462,1 \\
\hline Média Aritmética & 477,6 & 102,6 & 488,5 \\
\hline Média Quadrática & 477,6 & 102,7 & 488,5 \\
\hline Desvio Padrão & 2,432 & 5,039 & 2,663 \\
\hline P95\% & 480,6 & 110,7 & 491,8 \\
\hline P99\% & 481,8 & 116,5 & 493,7 \\
\hline
\end{tabular}

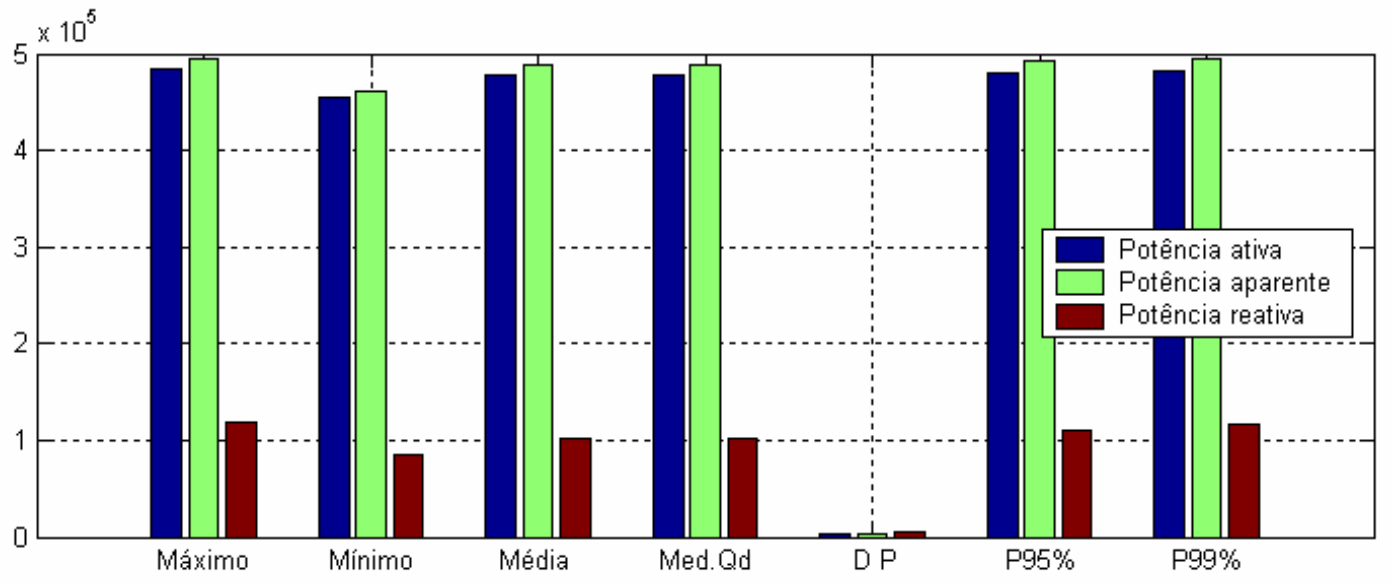

Figura 10.7 - Gráfico de barras com os dados da tabela 10.3

Através dos dados obtidos pode-se estimar o fator de potência na entrada da subestação. Utilizando-se a média aritmética das potências ativa e aparente chega-se a um fator de potência de 0,977 . O mesmo valor é encontrado utilizando a média quadrática. Concluise que o fator de potência da instalação mostrou-se adequado, próximo da unidade.

Da figura 10.7 tem-se que o desvio padrão apresenta uma variação insignificante para as potências ativa e aparente, sendo que o maior deles representa $0,54 \%$ da média aritmética. Entretanto, para a potência reativa o desvio padrão representa 4,91\% da média aritmética, que já é um valor significativo. 


\subsection{CONSIDERAÇÕES FINAIS}

Através das análises realizadas neste capítulo verificou-se que a linha 1 da subestação SE ALBRÁS apresentou-se com tensão dentro da faixa adequada em todo o período de medição, sem grandes variações entre os valores medidos para cada fase. Na análise de carga, verificou-se que esta também se mostrou bem distribuída nas três fases. $\mathrm{O}$ capítulo seguinte trará uma análise das cintilações luminosas para algumas subestações da Eletronorte, fazendo-se uma comparação entre elas. 


\section{CAPÍTULO 11}

\section{COMPARAÇÃO ENTRE LOCAIS}

Neste tópico objetiva-se analisar, quantificar e qualificar aspectos relacionados à Cintilação Luminosa em redes de $230 \mathrm{kV}$ da Eletronorte. Será efetuada uma apreciação simultânea dos níveis e perfis dos indicadores Pst e Plt de nove subestações (SE) do sistema Eletronorte:

- Albras L1 e L2 (Alumínio Brasileiro S.A.), circuito duplo de 1,6 km de extensão; produz alumínio; demanda de $800 \mathrm{MW}$; ligada a Alunorte. Tem ponto de entrega na SE Vila do Conde - PA.

- Alumar L1 e L2 (Consórcio de Alumínio do Maranhão), circuito duplo; Produz alumínio primário e alumina; demanda de $825 \mathrm{MW}$. Tem ponto de entrega na SE São Luis II - MA.

- Alunorte (Alumina do Norte do Brasil S.A.), circuito simples de 2,5 km de extensão; produz alumina; potência instalada de 180 MW; ligada a Albrás. Ponto de entrega na SE Vila do Conde - PA.

- CCM (Camargo Correa Metais), circuito simples; produz silício; potência instalada de 73 MW. Ponto de entrega na SE Tucuruí Linha - TCCA-LT6-01.

- Carajás, circuito simples; atente mina de cobre; potência instalada de 64 MW; ligada a Marabá. Ponto de entrega na SE Carajás - PA.

- CVLD (Companhia Vale do Rio Doce), designada para diferenciar a mineradora CVRD do estado do Maranhão das demais. Circuito simples.

- Marabá, atende duas mineradoras da CVRD, a mina de minério de ferro Serra dos Carajás e a mina de cobre Mineradora Serra do Sossego; Potência instalada de 144 MW; ligada a Carajás.

A análise será realizada a partir de medições de sete dias consecutivos. Os dados foram captados com uma frequiência de aquisição de dez minutos. A comparação dos resultados será feita por meio do estudo da média aritmética, do desvio padrão e do P95\%, considerando similares dados que apresentem erro relativo percentual entre o maior e menor valor inferior a 5\%. Serão avaliadas questões como a existência ou não de similaridade no comportamento da Cintilação entre os diversos dias de monitoramento. 
Será executada, ainda, uma análise comparativa dos valores mensurados com os patamares estabelecidos pela resolução brasileira. Vale ressaltar que o medidor utilizado em todos os locais foi o ION, variando apenas o modelo (ION 7600 e ION 8500).

Esta etapa é de importância evidente, tendo considerado que o conhecimento do comportamento de fenômenos como a Cintilação Luminosa culmina em ações que poderão minimizar os danosos efeitos dos mesmos sobre os sistemas de distribuição, bem como sobre os diversos tipos de equipamentos. Além disto, os gráficos expostos se prestam para formação de um banco de dados contendo valiosas informações quanto ao perfil das cintilações luminosas nos locais supracitados.

\section{1 - ESTUDO DE CASO}

Serão apresentadas, agora, as análises das amostras colhidas concomitantemente nos nove locais em estudo. Inicialmente, serão ilustrados os resultados da análise da freqüência de aquisição e da similaridade entre dias de ambos os indicadores de cintilação medidos no decorrer do intervalo total de monitoração. Em seguida, será exposta a análise de distribuição no tempo. Por final, efetuar-se-á um estudo sobre a tensão de linha e uma avaliação comparativa dos dados provenientes das medições, com a resolução em vigor no país.

\subsection{1 - ANÁLISE DA FREQÜÊNCIA DE AQUISIÇÃO DE DADOS}

Conforme realizado no capítulo cinco, busca-se identificar nesta análise, sem prejuízos aos resultados, intervalos de registro maiores que os dez minutos propostos pelas normas, que possam representar as amostras de determinado período. Isto possibilitará a utilização de equipamentos de medição com menor capacidade de memória e culminará na elevação da velocidade no processamento das informações.

As tabelas 11.1 e 11.2 e as figuras 11.1 e 11.2 trazem as médias aritméticas dos indicadores Pst e Plt, respectivamente, encontradas para as diferentes freqüências de aquisição e o erro relativo entre o maior e o menor valor. Para este estudo será analisada a terceira semana da fase A de cada uma das subestações, exceto a SE CCM que terá a quarta semana estudada, pois em sua terceira houve um período de interrupção no fornecimento. 
Tabela 11.1 - Média aritmética do indicador Pst para as diferentes freqüências de aquisição.

\begin{tabular}{|c|c|c|c|c|}
\cline { 2 - 5 } \multicolumn{1}{c|}{} & 10 minutos & 30 minutos & 60 minutos & Erro relativo \\
\hline Albras L1 & 0.1056 & 0.1152 & 0.1225 & $16,00 \%$ \\
\hline Albras L2 & 0.09854 & 0.103 & 0.1057 & $7,26 \%$ \\
\hline Alumar L1 & 0.257 & 0.2646 & 0.2695 & $4,86 \%$ \\
\hline Alumar L2 & 0.2171 & 0.2251 & 0.2306 & $6,21 \%$ \\
\hline Alunorte & 0.1068 & 0.1111 & 0.1136 & $6.36 \%$ \\
\hline Carajás & 0.2809 & 0.2885 & 0.2939 & $4,62 \%$ \\
\hline CCM & 0.08841 & 0.08963 & 0.09024 & $2,06 \%$ \\
\hline CVLD & 0.1041 & 0.115 & 0.1229 & $18,06 \%$ \\
\hline Marabá & 0.08019 & 0.08515 & 0.08867 & $10,57 \%$ \\
\hline
\end{tabular}

Tabela 11.2 - Média aritmética do indicador Plt para as diferentes frequiências de aquisição.

\begin{tabular}{|c|c|c|c|c|}
\cline { 2 - 5 } \multicolumn{1}{c|}{} & $\mathbf{1 0}$ minutos & $\mathbf{3 0}$ minutos & $\mathbf{6 0}$ minutos & Erro relativo \\
\hline Albras L1 & 0.1057 & 0.1063 & 0.1067 & $0,94 \%$ \\
\hline Albras L2 & 0.09852 & 0.09863 & 0.09894 & $0,42 \%$ \\
\hline Alumar L1 & 0.2572 & 0.2574 & 0.2578 & $0,23 \%$ \\
\hline Alumar L2 & 0.2169 & 0.2171 & 0.2176 & $0,07 \%$ \\
\hline Alunorte & 0.1069 & 0.107 & 0.1073 & $0,37 \%$ \\
\hline Carajás & 0.3181 & 0.3181 & 0.3181 & $0,00 \%$ \\
\hline CCM & 0.09344 & 0.09343 & 0.09343 & $0,01 \%$ \\
\hline CVLD & 0.1041 & 0.1044 & 0.1051 & $0,96 \%$ \\
\hline Marabá & 0.1051 & 0.1051 & 0.1051 & $0,00 \%$ \\
\hline
\end{tabular}

Devido ao fato do aplicativo não possibilitar a análise de vários locais simultaneamente, o Excel será utilizado para gerar os gráficos deste capítulo.

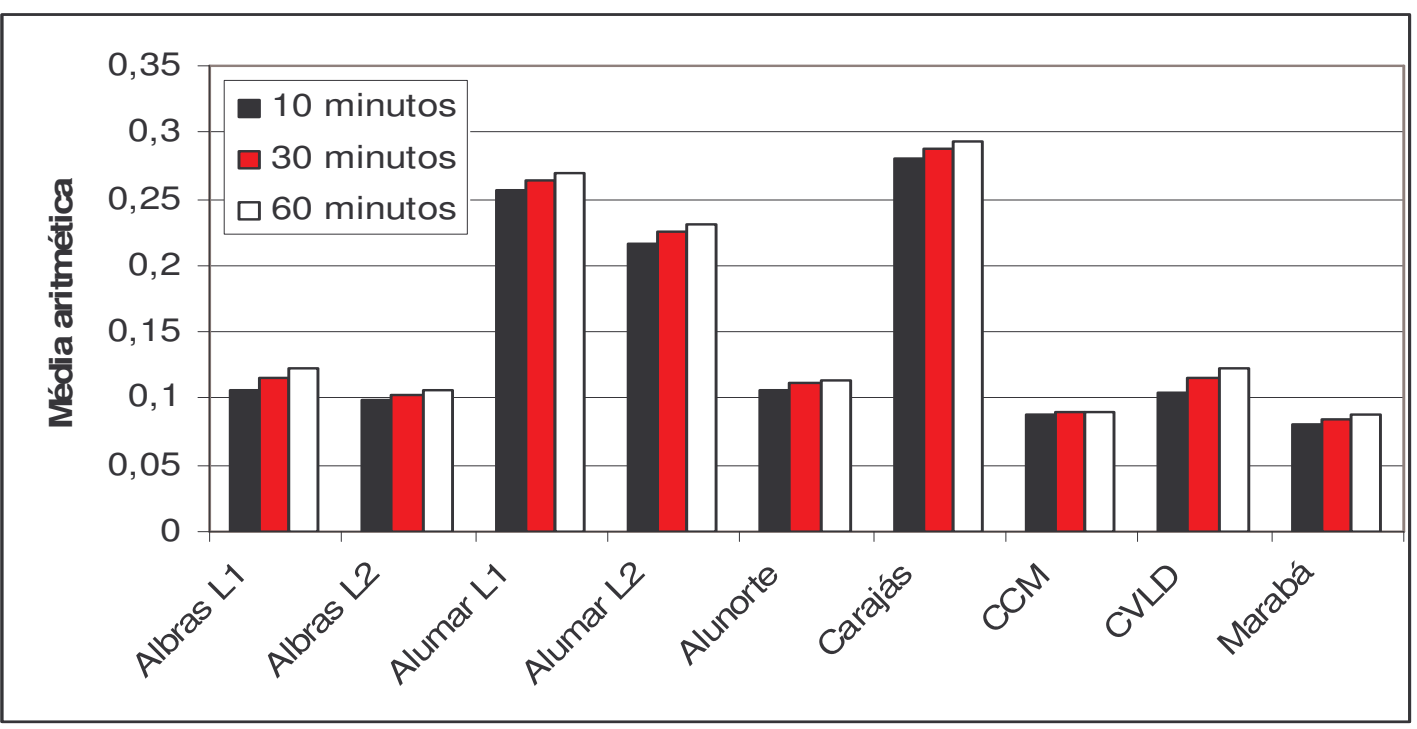

Figura 11.1 - Comparação entre a média aritmética indicador Pst das subestações para as diferentes freqüências de aquisição. 


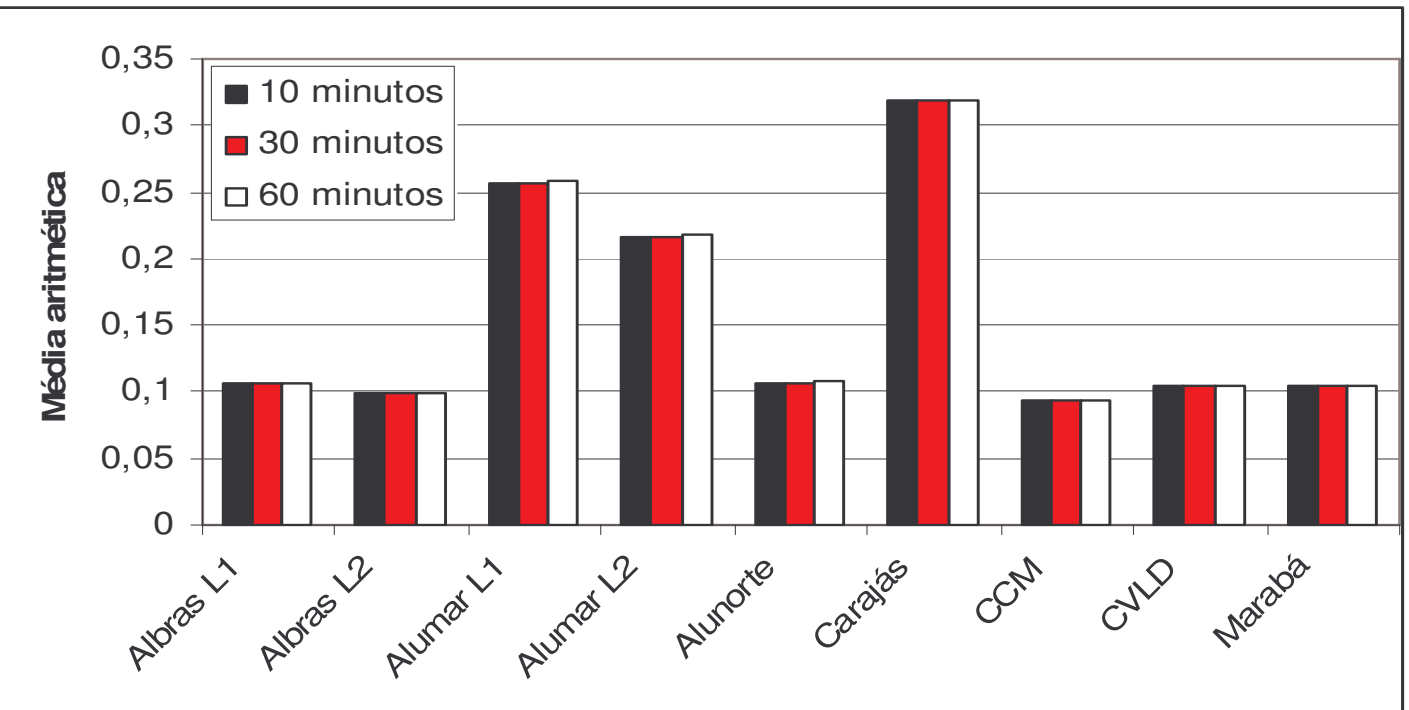

Figura 11.2 - Comparação entre a média aritmética do indicador Plt das subestações para as diferentes freqüências de aquisição.

Com auxílio dos dados apresentados acima, inferi-se que o indicador Pst não apresenta semelhanças para os diferentes intervalos de medição. Apenas as SE’s Alumar L1, Carajás e CCM apresentam erro relativo percentual inferior a 5\%, valor de referência escolhido, o que caracterizaria similaridade entre as freqüências. O pior resultado encontrado foi na SE CVLD, 18,06\% de discrepância. Já em relação ao Plt é possível afirmar que, considerandose a média aritmética, qualquer um dos intervalos de registro pode ser utilizado, pois todas as subestações apresentaram erro inferior a $1 \%$.

As tabelas 11.3 e 11.4 e as figuras 11.3 e 11.4 revelam os dados alcançados para o desvio padrão dos indicadores Pst e Plt, respectivamente, para os diferentes intervalos de aquisição.

Tabela 11.3 - Desvio padrão do indicador Pst para as diferentes frequiências de aquisição.

\begin{tabular}{|c|c|c|c|c|}
\cline { 2 - 5 } \multicolumn{1}{c|}{} & 10 minutos & 30 minutos & 60 minutos & Erro relativo \\
\hline Albras L1 & 0.2567 & 0.2529 & 0.2498 & $2,76 \%$ \\
\hline Albras L2 & 0.0714 & 0.06488 & 0.06048 & $18,05 \%$ \\
\hline Alumar L1 & 0.1456 & 0.1314 & 0.1213 & $20,03 \%$ \\
\hline Alumar L2 & 0.1492 & 0.137 & 0.1276 & $16,92 \%$ \\
\hline Alunorte & 0.07137 & 0.06463 & 0.06014 & $18,67 \%$ \\
\hline Carajás & 0.1494 & 0.1345 & 0.1224 & $22,05 \%$ \\
\hline CCM & 0.02356 & 0.01846 & 0.01517 & $55,30 \%$ \\
\hline CVLD & 0.1415 & 0.133 & 0.1259 & $12,39 \%$ \\
\hline Marabá & 0.07867 & 0.0734 & 0.0692 & $13,68 \%$ \\
\hline
\end{tabular}


Tabela 11.4 - Desvio padrão do indicador Plt para as diferentes freqüências de aquisição.

\begin{tabular}{|c|c|c|c|c|}
\cline { 2 - 5 } \multicolumn{1}{c|}{} & $\mathbf{1 0}$ minutos & $\mathbf{3 0}$ minutos & $\mathbf{6 0}$ minutos & Erro relativo \\
\hline Albras L1 & 0.08902 & 0.08844 & 0.08809 & $1,05 \%$ \\
\hline Albras L2 & 0.02612 & 0.02571 & 0.02452 & $6,52 \%$ \\
\hline Alumar L1 & 0.07004 & 0.06957 & 0.06803 & $2,95 \%$ \\
\hline Alumar L2 & 0.07258 & 0.07203 & 0.07037 & $3,14 \%$ \\
\hline Alunorte & 0.02682 & 0.02641 & 0.02523 & $6,30 \%$ \\
\hline Carajás & 0.1705 & 0.1708 & 0.171 & $0,29 \%$ \\
\hline CCM & 0.01618 & 0.0162 & 0.01622 & $0,24 \%$ \\
\hline CVLD & 0.04104 & 0.04029 & 0.03847 & $6,68 \%$ \\
\hline Marabá & 0.1014 & 0.1016 & 0.1017 & $0,29 \%$ \\
\hline
\end{tabular}

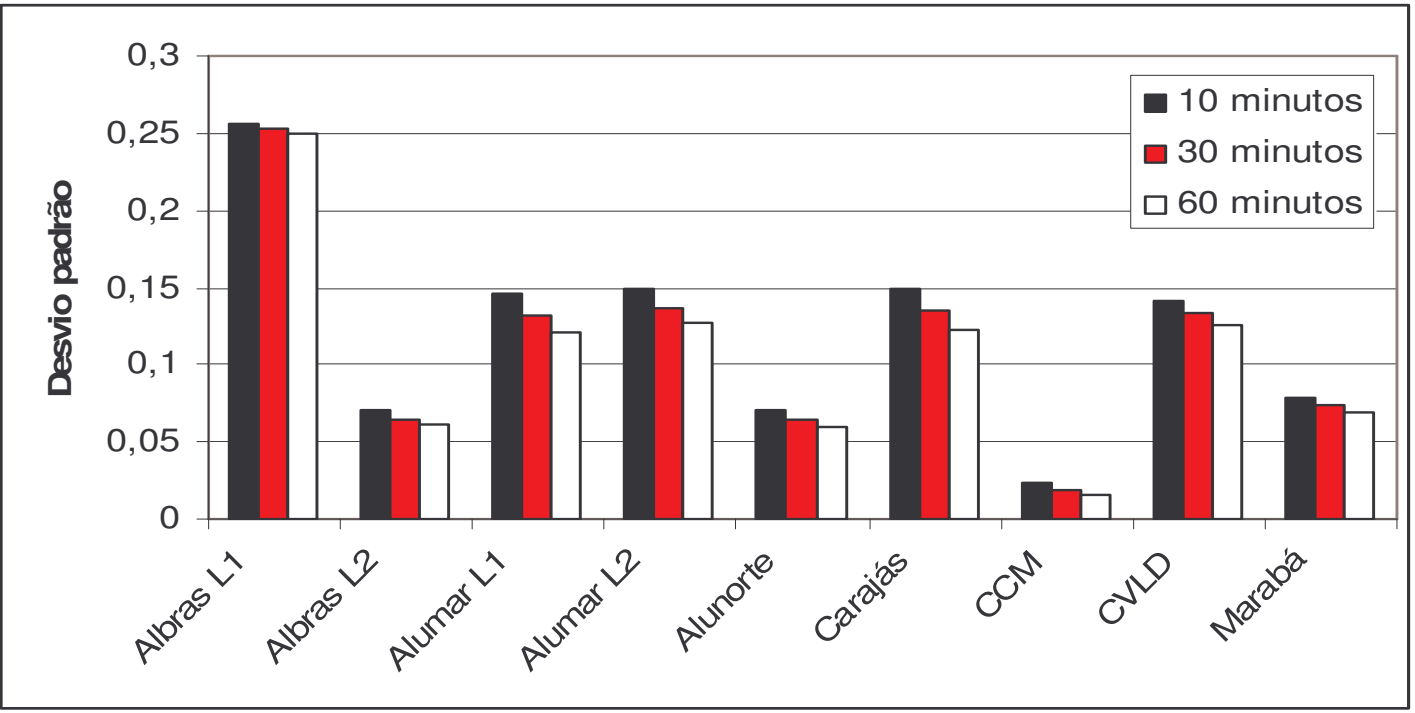

Figura 11.3 - Comparação entre o desvio padrão do indicador Pst das subestações para as diferentes freqüências de aquisição.

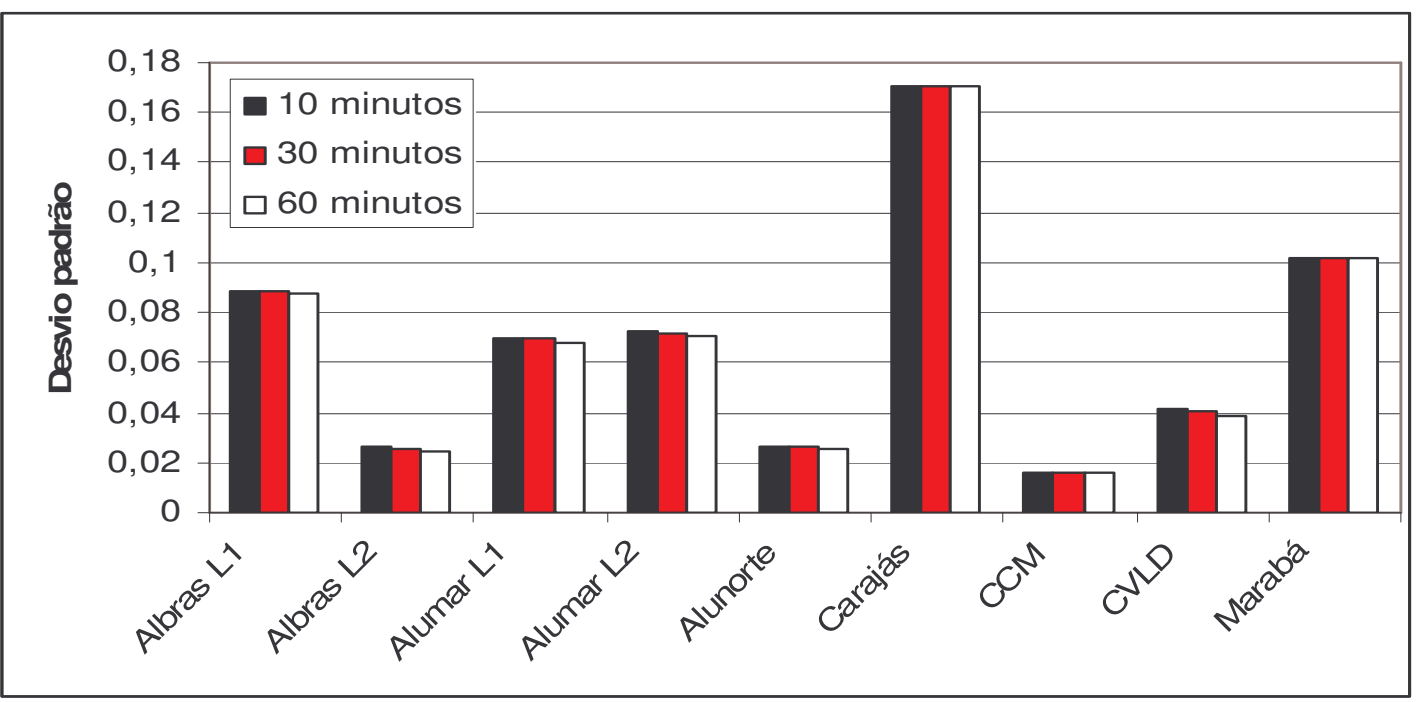

Figura 11.4 - Comparação entre o desvio padrão do indicador Plt das subestações para as diferentes freqüências de aquisição. 
Estes valores trazem maiores informações quando relacionados com a média aritmética, possibilitando uma comparação mais substancial entre os períodos. Isso será feito dividindo cada desvio das tabelas 11.3 e 11.4 pelo seu respectivo valor médio. As tabelas 11.5 e 11.6 trazem estes resultados.

Tabela 11.5 - Desvio padrão do indicador Pst dividido pelo respectivo valor médio.

\begin{tabular}{|c|c|c|c|}
\cline { 2 - 4 } \multicolumn{1}{c|}{} & $\mathbf{1 0}$ minutos & $\mathbf{3 0}$ minutos & $\mathbf{6 0}$ minutos \\
\hline Albras L1 & $243,08 \%$ & $219,53 \%$ & $203,91 \%$ \\
\hline Albras L2 & $72,45 \%$ & $62,99 \%$ & $57,21 \%$ \\
\hline Alumar L1 & $56,65 \%$ & $49,65 \%$ & $45,00 \%$ \\
\hline Alumar L2 & $68,72 \%$ & $60,86 \%$ & $55,33 \%$ \\
\hline Alunorte & $66,82 \%$ & $58,17 \%$ & $52,94 \%$ \\
\hline Carajás & $53,18 \%$ & $46,62 \%$ & $41,64 \%$ \\
\hline CCM & $26,64 \%$ & $20,59 \%$ & $16,81 \%$ \\
\hline CVLD & $135,92 \%$ & $115,65 \%$ & $102,44 \%$ \\
\hline Marabá & $98,10 \%$ & $86,20 \%$ & $78,04 \%$ \\
\hline
\end{tabular}

Tabela 11.6 - Desvio padrão do indicador Plt dividido pelo respectivo valor médio.

\begin{tabular}{|c|c|c|c|}
\cline { 2 - 4 } \multicolumn{1}{c|}{} & $\mathbf{1 0}$ minutos & $\mathbf{3 0}$ minutos & $\mathbf{6 0}$ minutos \\
\hline Albras L1 & $84,21 \%$ & $83,19 \%$ & $82,55 \%$ \\
\hline Albras L2 & $26,51 \%$ & $26,06 \%$ & $24,78 \%$ \\
\hline Alumar L1 & $27,23 \%$ & $27,02 \%$ & $26,38 \%$ \\
\hline Alumar L2 & $33,46 \%$ & $33,17 \%$ & $32,33 \%$ \\
\hline Alunorte & $25,08 \%$ & $24,68 \%$ & $23,51 \%$ \\
\hline Carajás & $53,59 \%$ & $53,69 \%$ & $53,75 \%$ \\
\hline CCM & $17,31 \%$ & $17,33 \%$ & $17,36 \%$ \\
\hline CVLD & $39,42 \%$ & $38,59 \%$ & $36,60 \%$ \\
\hline Marabá & $96,47 \%$ & $96,66 \%$ & $96,76 \%$ \\
\hline
\end{tabular}

A partir das tabelas $11.3,11.5$ e da figura 11.3 percebe-se a alta divergência entres as diferentes freqüências de aquisição, quando da análise do desvio padrão. Este fato vem corroborar com o estudo baseado na média aritmética, que concluiu acerca a não similaridade entre os períodos de medição. As tabelas 11.4, 11.6 e a figura 11.4, entretanto, revelam a possibilidade de escolha do intervalo de análise do índice Plt, sem que haja prejuízo. A maior diferença encontrada foi na CVLD, 2,82\%. 
Tabela 11.7 - P95\% do indicador Pst para as diferentes freqüências de aquisição.

\begin{tabular}{|c|c|c|c|c|}
\cline { 2 - 5 } \multicolumn{1}{c|}{} & $\mathbf{1 0}$ minutos & $\mathbf{3 0}$ minutos & $\mathbf{6 0}$ minutos & Erro relativo \\
\hline Albras L1 & 0.14097 & 0.17083 & 0.16914 & $21,18 \%$ \\
\hline Albras L2 & 0.13606 & 0.15502 & 0.17654 & $29,75 \%$ \\
\hline Alumar L1 & 0.38563 & 0.37896 & 0.38341 & $1,76 \%$ \\
\hline Alumar L2 & 0.38647 & 0.38429 & 0.37523 & $2,99 \%$ \\
\hline Alunorte & 0.15411 & 0.15851 & 0.18497 & $20,02 \%$ \\
\hline Carajás & 0.45701 & 0.47037 & 0.4397 & $6,97 \%$ \\
\hline CCM & 0.11685 & 0.12033 & 0.11742 & $2,97 \%$ \\
\hline CVLD & 0.20921 & 0.19438 & 0.23364 & $20,19 \%$ \\
\hline Marabá & 0.12198 & 0.12873 & 0.13587 & $11,38 \%$ \\
\hline
\end{tabular}

Tabela 11.8 - P95\% do indicador Plt para as diferentes freqüências de aquisição.

\begin{tabular}{|c|c|c|c|c|}
\cline { 2 - 5 } \multicolumn{1}{c|}{} & $\mathbf{1 0}$ minutos & $\mathbf{3 0}$ minutos & $\mathbf{6 0}$ minutos & Erro relativo \\
\hline Albras L1 & 0.1277 & 0.12734 & 0.12583 & $1,48 \%$ \\
\hline Albras L2 & 0.13921 & 0.13583 & 0.13994 & $3,02 \%$ \\
\hline Alumar L1 & 0.37163 & 0.37246 & 0.37113 & $0,35 \%$ \\
\hline Alumar L2 & 0.36901 & 0.3663 & 0.36569 & $0,90 \%$ \\
\hline Alunorte & 0.14917 & 0.14765 & 0.1503 & $0,75 \%$ \\
\hline Carajás & 0.4649 & 0.4649 & 0.46993 & $1,08 \%$ \\
\hline CCM & 0.12365 & 0.12365 & 0.12373 & $0,06 \%$ \\
\hline CVLD & 0.16829 & 0.16735 & 0.16261 & $3,49 \%$ \\
\hline Marabá & 0.22708 & 0.22708 & 0.2375 & $4,58 \%$ \\
\hline
\end{tabular}

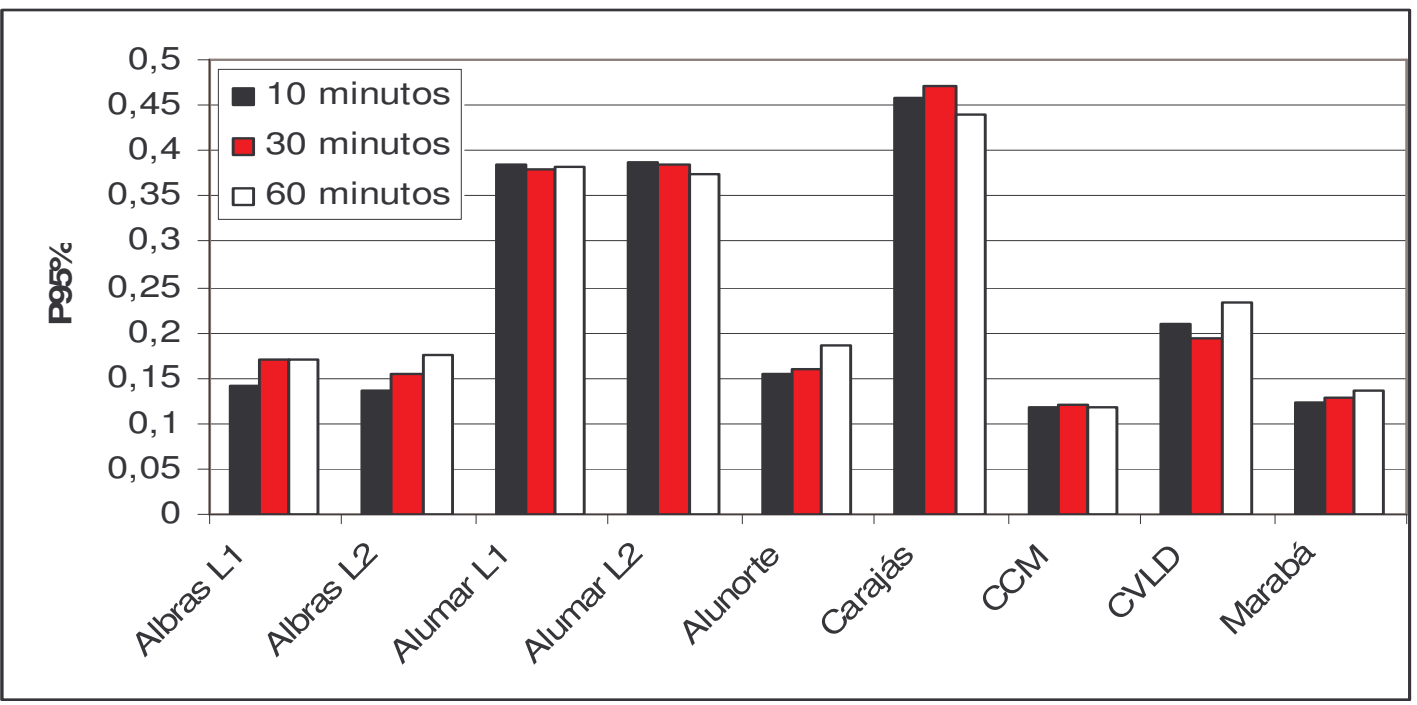

Figura 11.5 - Comparação entre o P95\% do indicador Pst das subestações para as diferentes freqüências de aquisição. 


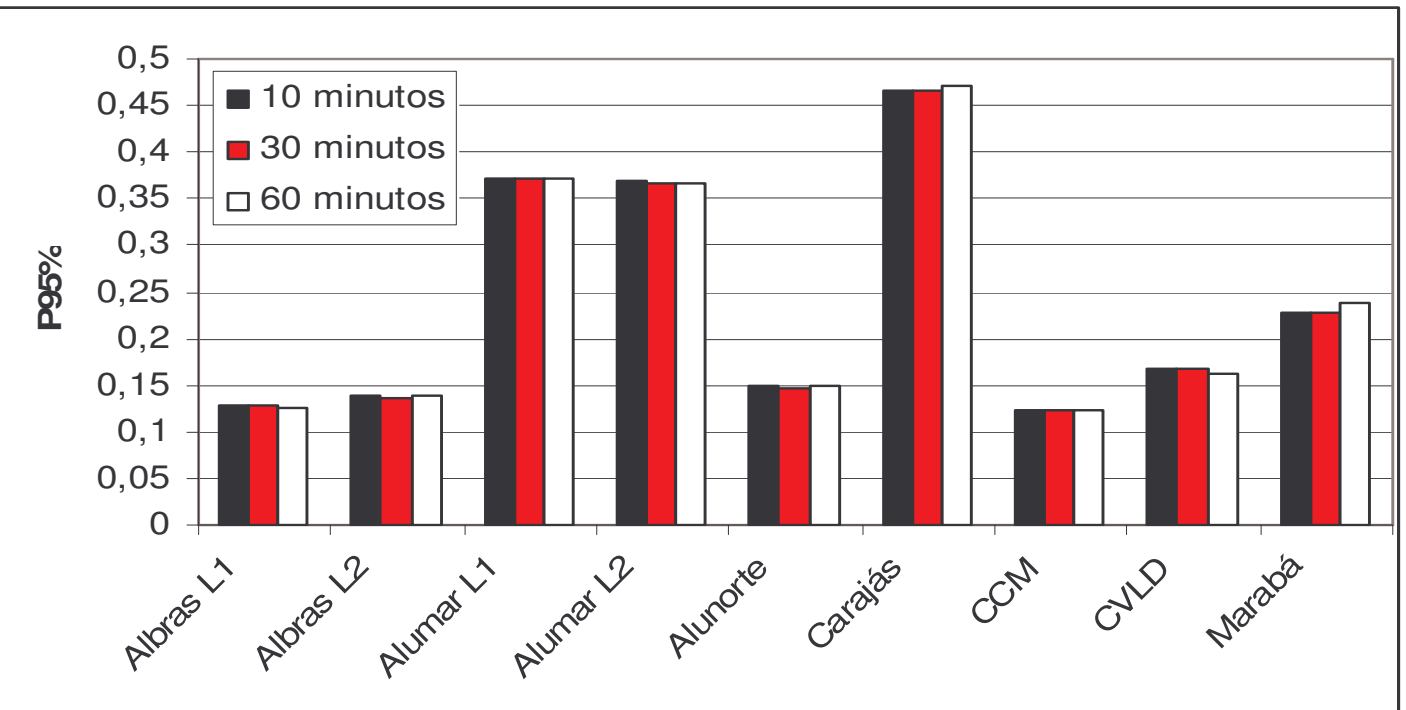

Figura 11.6 - Comparação entre o P95\% do indicador Plt das subestações para as diferentes freqüências de aquisição.

Mais uma vez, de acordo com a tabela 11.7 e a figura 11.5, percebe-se que não é possível afirmar que a escolha do período de aquisição possa recair sobre qualquer um dos estudados, sem que haja prejuízo a análise. Apenas as SE's Alumar L1 e L2 e CCM apresentaram erro relativo inferior a $5 \%$.

Analisando a tabela 11.8 e a figura 11.6, conclui-se que o estudo do índice P95\%, para o indicador Plt, confirma a possibilidade de escolha de qualquer uma das freqüências de aquisição, sem prejuízo ao resultado. A subestação Marabá obteve erro relativo próximo a $4,5 \%$, mas como todas as outras permaneceram abaixo do limite de $5 \%$.

Logo, quanto à média aritmética, ao desvio padrão e ao P95\%, valor sobre o qual a norma adotada no Brasil impõe limite, a freqüência de aquisição de dados de 60 minutos é suficiente para o indicador Plt. Todavia, em se tratando do índice Pst, há acentuadas discrepâncias entre os resultados alcançados com cada um dos intervalos estudados. 


\subsection{2 - ANÁLISE DA SIMILARIDADE ENTRE DIAS}

Esta análise busca constatar se um intervalo menor de medição, mais especificamente um dia, é suficiente para a tomada de conclusões acertadas acerca dos índices representativos da cintilação luminosa. Caso seja constatada similaridade entre dias, a discussão prosseguirá estudando a possibilidade de se tomar períodos cada vez menores que representem toda a semana. Para esta análise será escolhida a fase A e as mesmas semanas estudadas na subseção 11.1.1.

As tabelas 11.9 e 11.10 e as figuras 11.7 e 11.8 trazem a média aritmética dos indicadores Pst e Plt, respectivamente, calculados para os sete dias de semana, nas diferentes subestações estudadas.

Tabela 11.9 - Média aritmética do indicador Pst para os diferentes dias da semana.

\begin{tabular}{|c|c|c|c|c|c|c|c|}
\cline { 2 - 8 } \multicolumn{1}{c|}{} & Domingo & Segunda & Terça & Quarta & Quinta & Sexta & Sábado \\
\hline Albras L1 & 0.1699 & 0.09752 & 0.0904 & 0.09567 & 0.09193 & 0.09904 & 0.09513 \\
\hline Albras L2 & 0.09605 & 0.09865 & 0.09471 & 0.1077 & 0.0929 & 0.09683 & 0.103 \\
\hline Alumar L1 & 0.3107 & 0.269 & 0.2327 & 0.2605 & 0.2683 & 0.2399 & 0.2144 \\
\hline Alumar L2 & 0.1849 & 0.196 & 0.2082 & 0.244 & 0.2553 & 0.2199 & 0.2086 \\
\hline Alunorte & 0.1044 & 0.1071 & 0.104 & 0.1174 & 0.1005 & 0.1044 & 0.1099 \\
\hline Carajás & 0.3127 & 0.2796 & 0.3107 & 0.2578 & 0.2485 & 0.2941 & 0.2626 \\
\hline CCM & 0.09113 & 0.09088 & 0.09167 & 0.08463 & 0.08989 & 0.08462 & 0.08586 \\
\hline CVLD & 0.1036 & 0.1129 & 0.1007 & 0.119 & 0.09029 & 0.1065 & 0.09702 \\
\hline Marabá & 0.08713 & 0.08558 & 0.08641 & 0.07884 & 0.07154 & 0.07906 & 0.07282 \\
\hline
\end{tabular}

Tabela 11.10 - Média aritmética do indicador Plt para os diferentes dias da semana.

\begin{tabular}{|c|c|c|c|c|c|c|c|}
\cline { 2 - 8 } \multicolumn{1}{c|}{} & Domingo & Segunda & Terça & Quarta & Quinta & Sexta & Sábado \\
\hline Albras L1 & 0.1701 & 0.09664 & 0.09006 & 0.0959 & 0.09217 & 0.09883 & 0.09545 \\
\hline Albras L2 & 0.09559 & 0.09922 & 0.09504 & 0.1069 & 0.09259 & 0.09693 & 0.1026 \\
\hline Alumar L1 & 0.3125 & 0.2668 & 0.2323 & 0.2649 & 0.2657 & 0.2407 & 0.2118 \\
\hline Alumar L2 & 0.1861 & 0.1959 & 0.2078 & 0.2503 & 0.2511 & 0.221 & 0.2027 \\
\hline Alunorte & 0.1043 & 0.1075 & 0.1035 & 0.1171 & 0.1004 & 0.1046 & 0.1096 \\
\hline Carajás & 0.3476 & 0.3044 & 0.4239 & 0.2839 & 0.2592 & 0.3198 & 0.2816 \\
\hline CCM & 0.09763 & 0.09442 & 0.09657 & 0.09075 & 0.09852 & 0.08688 & 0.08888 \\
\hline CVLD & 0.1031 & 0.1114 & 0.1005 & 0.1179 & 0.09042 & 0.1081 & 0.09722 \\
\hline Marabá & 0.09455 & 0.1406 & 0.1274 & 0.1038 & 0.09171 & 0.09272 & 0.08054 \\
\hline
\end{tabular}




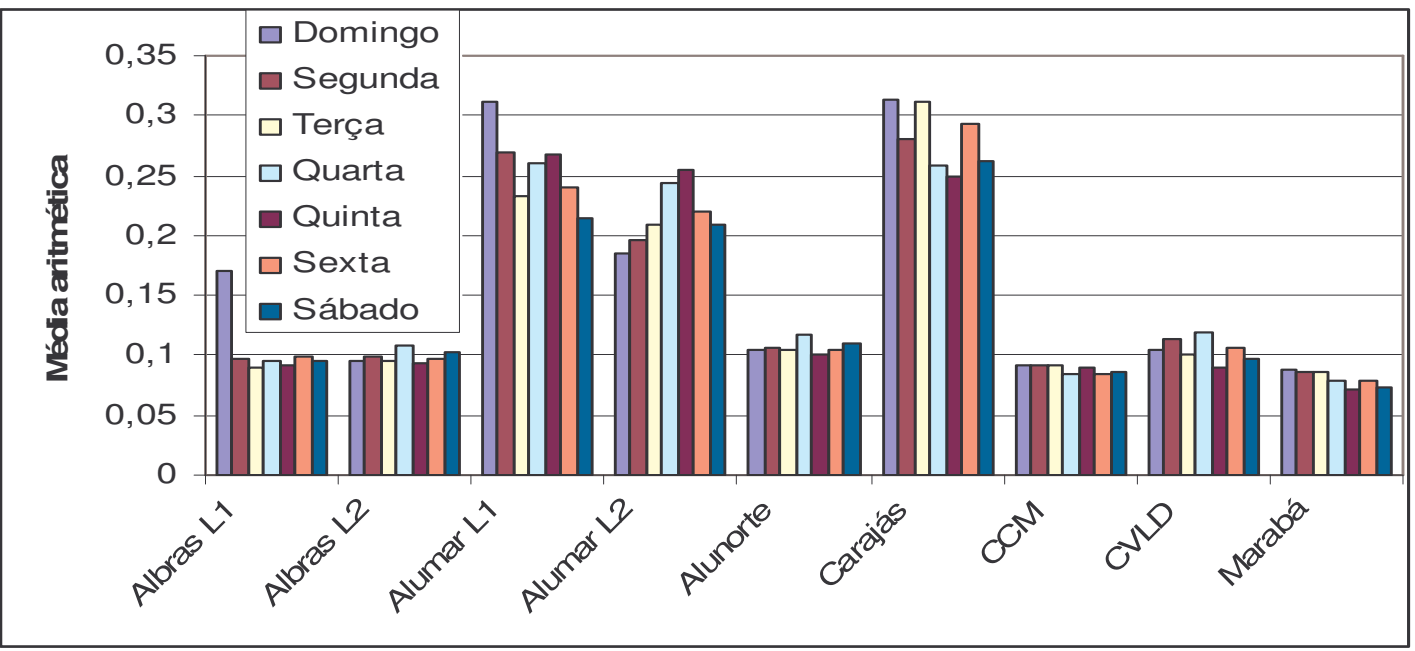

Figura 11.7 - Comparação entre média aritmética do indicador Pst das subestações para os diferentes dias da semana.

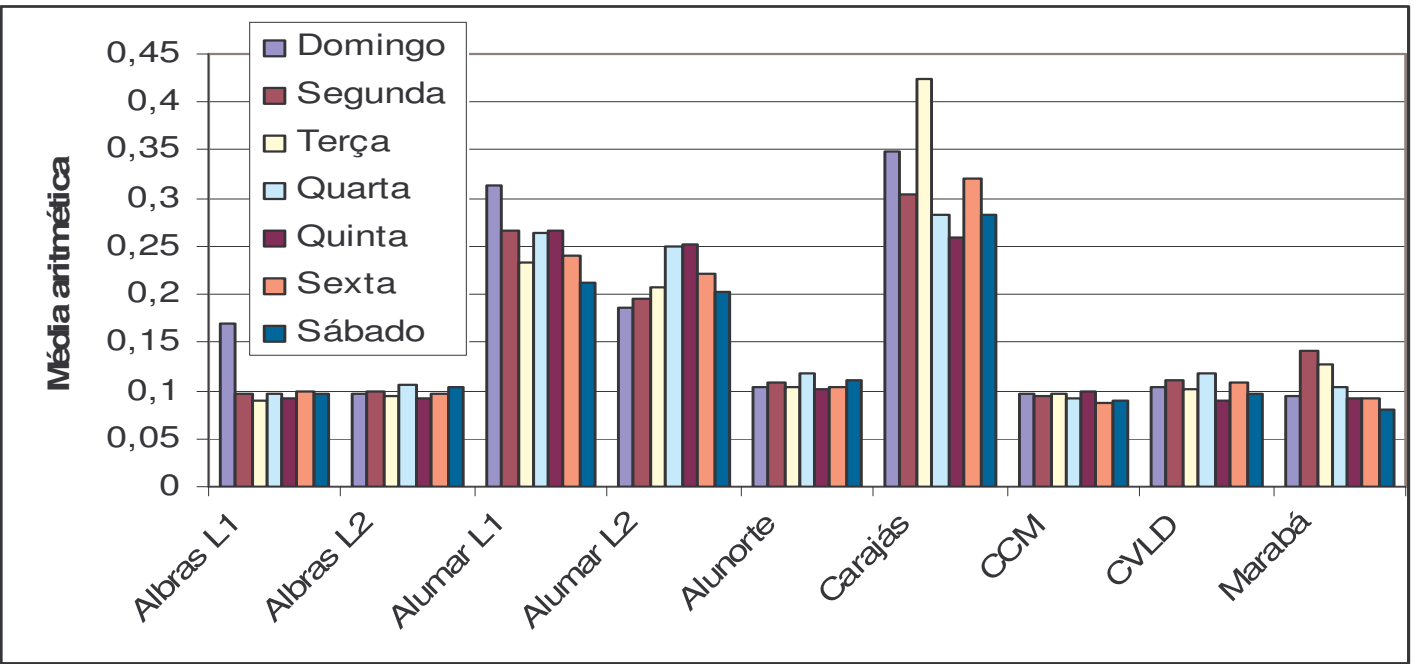

Figura 11.8 - Comparação entre média aritmética do indicador Plt das subestações para os diferentes dias da semana.

As tabelas 11.11 e 11.12 apresentam o erro relativo percentual entre os valores máximo e mínimo de cada uma das SE's, levando em consideração os sete dias analisados. 
Tabela 11.11 - Desvio percentual máximo do indicador Pst dentro dos sete dias consecutivos.

\begin{tabular}{|c|c|c|c|}
\cline { 2 - 4 } \multicolumn{1}{c|}{} & Máximo & Mínimo & Erro relativo \\
\hline Albras L1 & 0.1699 & 0.0904 & $87,9 \%$ \\
\hline Albras L2 & 0.1077 & 0.0929 & $15,93 \%$ \\
\hline Alumar L1 & 0.3107 & 0.2144 & $44,91 \%$ \\
\hline Alumar L2 & 0.2553 & 0.1849 & $38,07 \%$ \\
\hline Alunorte & 0.1174 & 0.1005 & $16,81 \%$ \\
\hline Carajás & 0.3127 & 0.2485 & $25,83 \%$ \\
\hline CCM & 0.09167 & 0.08462 & $8,33 \%$ \\
\hline CVLD & 0.119 & 0.09029 & $31,79 \%$ \\
\hline Marabá & 0.08713 & 0.07154 & $21,79 \%$ \\
\hline
\end{tabular}

Tabela 11.12 - Desvio percentual máximo do indicador Plt dentro dos sete dias consecutivos.

\begin{tabular}{|c|c|c|c|}
\cline { 2 - 4 } \multicolumn{1}{c|}{} & Máximo & Mínimo & Erro relativo \\
\hline Albras L1 & 0.1701 & 0.09006 & $88,87 \%$ \\
\hline Albras L2 & 0.1069 & 0.09259 & $15,45 \%$ \\
\hline Alumar L1 & 0.3125 & 0.2118 & $47,54 \%$ \\
\hline Alumar L2 & 0.2511 & 0.1861 & $34,92 \%$ \\
\hline Alunorte & 0.1171 & 0.1004 & $16,63 \%$ \\
\hline Carajás & 0.4239 & 0.2592 & $63,54 \%$ \\
\hline CCM & 0.09852 & 0.08688 & $13,39 \%$ \\
\hline CVLD & 0.1179 & 0.09042 & $30,39 \%$ \\
\hline Marabá & 0.1406 & 0.08054 & $74,57 \%$ \\
\hline
\end{tabular}

A partir do exposto nas tabelas $11.9,11.10,11.11$ e 11.12 e nas figuras 11.7 e 11.8 , inferise que baseado no estudo da média aritmética, não há similaridade entre os dias em questão, para nenhum dos indicadores de cintilação luminosa. Fato comprovado pelos acentuados erros relativos encontrados.

As tabelas 11.13 e 11.14 e as figuras 11.9 e 11.10 revelam os dados alcançados para o desvio padrão dos indicadores Pst e Plt, respectivamente, para os diferentes dias da semana.

Tabela 11.13 - Desvio padrão do indicador Pst para os diferentes dias da semana.

\begin{tabular}{|c|c|c|c|c|c|c|c|}
\cline { 2 - 8 } \multicolumn{1}{c|}{} & Domingo & Segunda & Terça & Quarta & Quinta & Sexta & Sábado \\
\hline Albras L1 & 0.667 & 0.0639 & 0.0384 & 0.0442 & 0.0307 & 0.0477 & 0.0314 \\
\hline Albras L2 & 0.0889 & 0.107 & 0.0403 & 0.102 & 0.0339 & 0.0401 & 0.037 \\
\hline Alumar L1 & 0.0853 & 0.234 & 0.112 & 0.196 & 0.115 & 0.108 & 0.0697 \\
\hline Alumar L2 & 0.0638 & 0.232 & 0.122 & 0.205 & 0.122 & 0.119 & 0.0929 \\
\hline Alunorte & 0.0883 & 0.106 & 0.0418 & 0.103 & 0.0339 & 0.0398 & 0.037 \\
\hline Carajás & 0.114 & 0.0939 & 0.315 & 0.101 & 0.0606 & 0.102 & 0.0867 \\
\hline CCM & 0.0268 & 0.0199 & 0.0224 & 0.0246 & 0.031 & 0.0155 & 0.0202 \\
\hline CVLD & 0.0621 & 0.238 & 0.112 & 0.203 & 0.0871 & 0.11 & 0.075 \\
\hline Marabá & 0.0273 & 0.162 & 0.0798 & 0.0689 & 0.0523 & 0.039 & 0.0293 \\
\hline
\end{tabular}


Tabela 11.14 - Desvio padrão do indicador Plt para os diferentes dias da semana.

\begin{tabular}{|c|c|c|c|c|c|c|c|}
\cline { 2 - 8 } \multicolumn{1}{c|}{} & Domingo & Segunda & Terça & Quarta & Quinta & Sexta & Sábado \\
\hline Albras L1 & 0.22 & 0.0217 & 0.0189 & 0.0159 & 0.012 & 0.0109 & 0.00878 \\
\hline Albras L2 & 0.0301 & 0.0294 & 0.0129 & 0.0436 & 0.0109 & 0.0192 & 0.0158 \\
\hline Alumar L1 & 0.0625 & 0.0992 & 0.0505 & 0.058 & 0.0613 & 0.0593 & 0.0333 \\
\hline Alumar L2 & 0.0355 & 0.0736 & 0.0644 & 0.0708 & 0.0872 & 0.0743 & 0.0605 \\
\hline Alunorte & 0.0295 & 0.0296 & 0.0138 & 0.0456 & 0.0113 & 0.02 & 0.0166 \\
\hline Carajás & 0.0885 & 0.0808 & 0.392 & 0.0776 & 0.0479 & 0.0612 & 0.0528 \\
\hline CCM & 0.0203 & 0.0125 & 0.013 & 0.0157 & 0.0233 & 0.00907 & 0.00899 \\
\hline CVLD & 0.0241 & 0.0638 & 0.0326 & 0.0593 & 0.0233 & 0.0286 & 0.024 \\
\hline Marabá & 0.0173 & 0.223 & 0.0837 & 0.0808 & 0.0583 & 0.0352 & 0.0208 \\
\hline
\end{tabular}

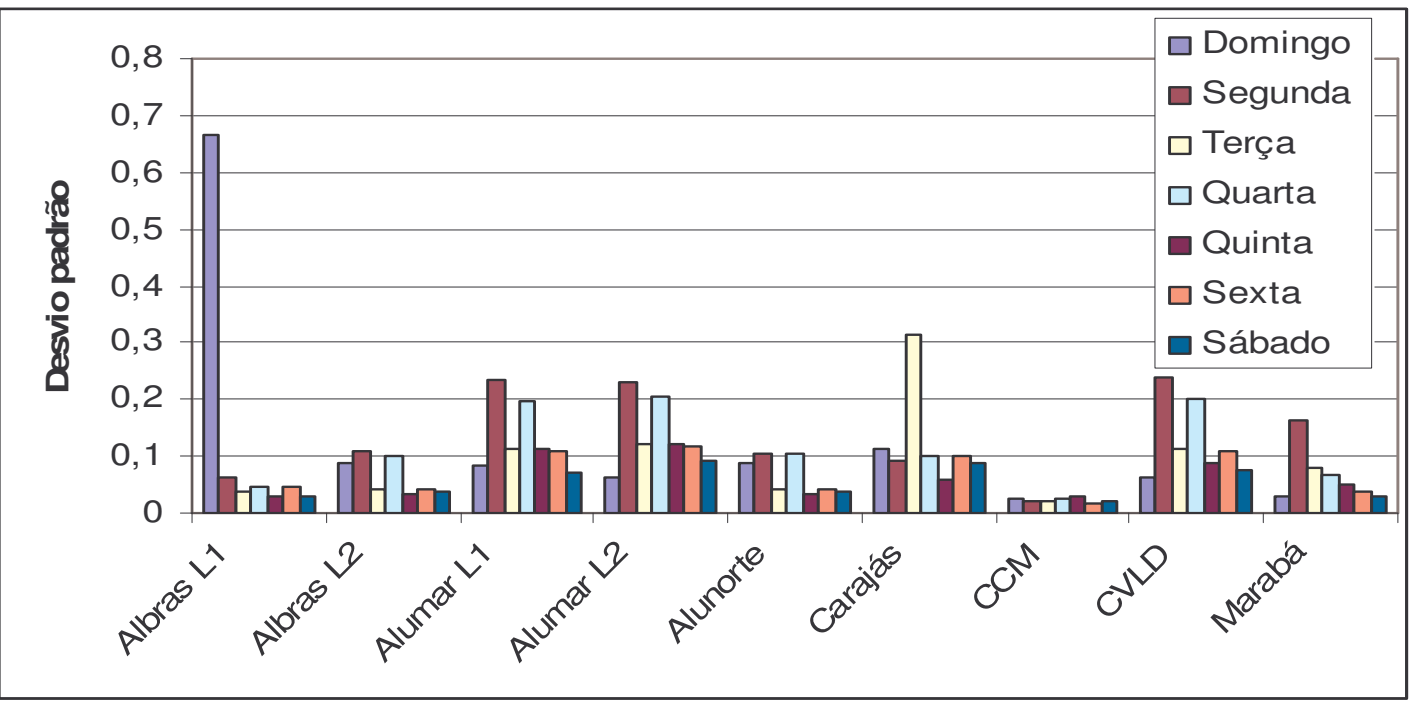

Figura 11.9 - Comparação entre o desvio padrão do indicador Pst das subestações para os diferentes dias da semana.

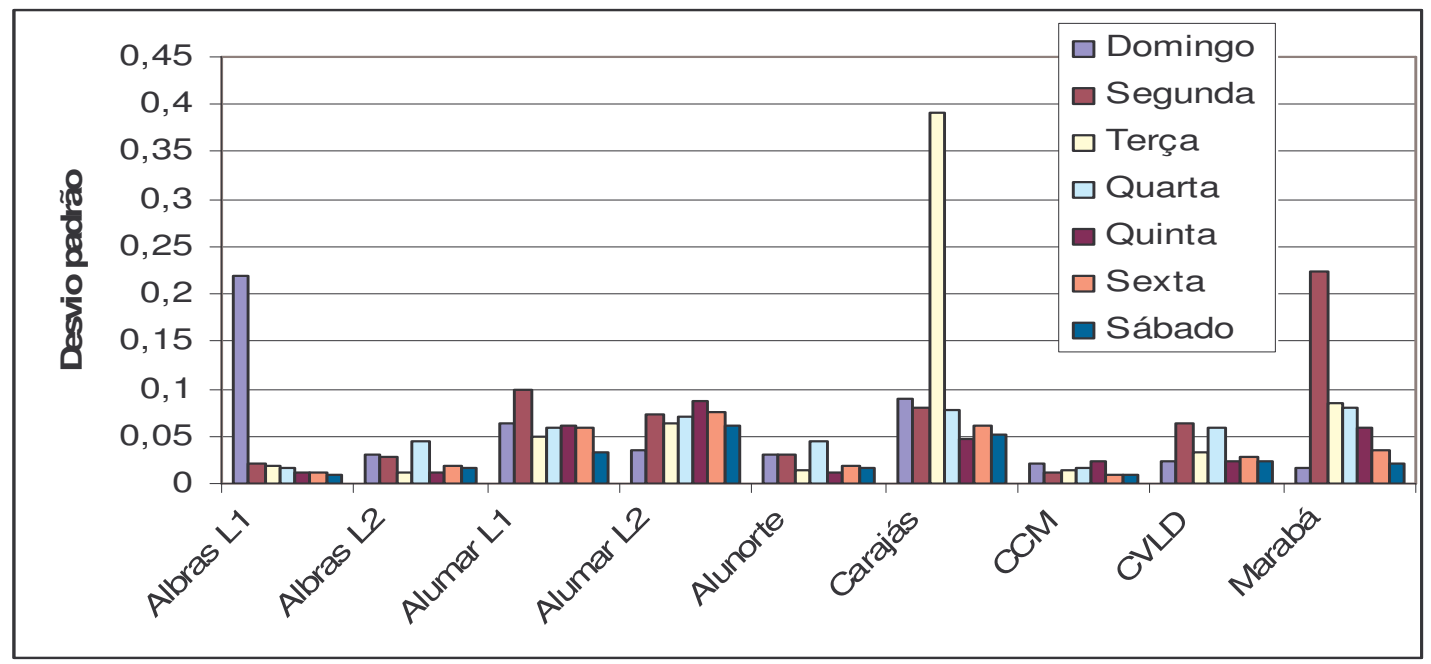

Figura 11.10 - Comparação entre o desvio padrão do indicador Plt das subestações para os diferentes dias da semana. 
A fim de conseguir maiores informações a partir dos dados de desvio padrão, relacionarse-á estes valores com a média aritmética, possibilitando uma comparação mais substancial entre os dias. Isso será feito dividindo cada desvio das tabelas 11.13 e 11.14 pelo seu respectivo valor médio. As tabelas 11.15 e 11.16 trazem estes resultados.

Tabela 11.15 - Desvio padrão do indicador Pst dividido pelo respectivo valor médio.

\begin{tabular}{|c|c|c|c|c|c|c|c|}
\cline { 2 - 8 } \multicolumn{1}{c|}{} & Domingo & Segunda & Terça & Quarta & Quinta & Sexta & Sábado \\
\hline Albras L1 & $392,58 \%$ & $65,52 \%$ & $42,47 \%$ & $46,20 \%$ & $33,39 \%$ & $48,16 \%$ & $33,00 \%$ \\
\hline Albras L2 & $92,55 \%$ & $108,46 \%$ & $42,55 \%$ & $94,70 \%$ & $36,49 \%$ & $41,41 \%$ & $35,92 \%$ \\
\hline Alumar L1 & $27,45 \%$ & $86,98 \%$ & $48,13 \%$ & $75,23 \%$ & $42,86 \%$ & $45,01 \%$ & $32,50 \%$ \\
\hline Alumar L2 & $34,50 \%$ & $118,36 \%$ & $58,59 \%$ & $84,01 \%$ & $47,78 \%$ & $54,11 \%$ & $44,53 \%$ \\
\hline Alunorte & $84,57 \%$ & $98,97 \%$ & $40,19 \%$ & $87,73 \%$ & $33,73 \%$ & $38,12 \%$ & $33,66 \%$ \\
\hline Carajás & $36,45 \%$ & $33,58 \%$ & $101,38 \%$ & $39,17 \%$ & $24,38 \%$ & $34,68 \%$ & $33,01 \%$ \\
\hline CCM & $29,40 \%$ & $21,89 \%$ & $24,43 \%$ & $29,06 \%$ & $34,48 \%$ & $18,31 \%$ & $23,52 \%$ \\
\hline CVLD & $59,94 \%$ & $210,80 \%$ & $111,22 \%$ & $170,58 \%$ & $96,46 \%$ & $103,28 \%$ & $77,30 \%$ \\
\hline Marabá & $31,33 \%$ & $189,29 \%$ & $92,35 \%$ & $87,39 \%$ & $73,10 \%$ & $49,32 \%$ & $40,23 \%$ \\
\hline
\end{tabular}

Tabela 11.16 - Desvio padrão do indicador Plt dividido pelo respectivo valor médio.

\begin{tabular}{|c|c|c|c|c|c|c|c|}
\cline { 2 - 8 } \multicolumn{1}{c|}{} & Domingo & Segunda & Terça & Quarta & Quinta & Sexta & Sábado \\
\hline Albras L1 & $129,33 \%$ & $22,45 \%$ & $20,98 \%$ & $16,57 \%$ & $13,01 \%$ & $11,02 \%$ & $9,19 \%$ \\
\hline Albras L2 & $31,48 \%$ & $29,63 \%$ & $13,57 \%$ & $40,78 \%$ & $11,77 \%$ & $19,80 \%$ & $15,39 \%$ \\
\hline Alumar L1 & $20,00 \%$ & $37,18 \%$ & $21,73 \%$ & $21,89 \%$ & $23,07 \%$ & $24,63 \%$ & $15,72 \%$ \\
\hline Alumar L2 & $19,07 \%$ & $37,57 \%$ & $30,99 \%$ & $28,28 \%$ & $34,72 \%$ & $33,61 \%$ & $29,84 \%$ \\
\hline Alunorte & $28,28 \%$ & $27,53 \%$ & $13,33 \%$ & $38,94 \%$ & $11,25 \%$ & $19,12 \%$ & $15,14 \%$ \\
\hline Carajás & $25,46 \%$ & $26,54 \%$ & $92,47 \%$ & $27,33 \%$ & $18,47 \%$ & $19,13 \%$ & $18,75 \%$ \\
\hline CCM & $20,79 \%$ & $13,23 \%$ & $13,46 \%$ & $17,30 \%$ & $23,65 \%$ & $10,43 \%$ & $10,11 \%$ \\
\hline CVLD & $23,37 \%$ & $57,27 \%$ & $32,43 \%$ & $50,29 \%$ & $25,76 \%$ & $26,45 \%$ & $24,68 \%$ \\
\hline Marabá & $18,29 \%$ & $158,60 \%$ & $65,69 \%$ & $77,84 \%$ & $63,56 \%$ & $37,96 \%$ & $25,82 \%$ \\
\hline
\end{tabular}

A partir das tabelas $11.13,11.14,11.15$ e 11.16 e das figuras 11.9 e 11.10 percebe-se que o comportamento dos indicadores de cintilação luminosa apresentados se alteram muito de um dia para o outro em todos os locais. Isso pode ser inferido a partir da grande diferença observada entre o maior e o menor valor apresentados pelo coeficiente de variação dentro do período de uma semana. Com os desvios elevados, as amostras se distribuem de forma irregular, e se distanciam do valor da média. O local que apresentou menor diferença foi a SE CCM, 16,17\% e 13,54\% para os índices Pst e Plt, respectivamente. Na subestação Albras L1 ocorreram os piores resultados, ou seja, a menor semelhança entre os dias.

As tabelas 11.17 e 11.18 e as figuras 11.11 e 11.12 revelam os dados alcançados para o P95\% dos indicadores Pst e Plt, respectivamente, para os diferentes dias da semana. 
Tabela 11.17 - P95\% do indicador Pst para os diferentes dias da semana.

\begin{tabular}{|c|c|c|c|c|c|c|c|}
\cline { 2 - 8 } \multicolumn{1}{c|}{} & Domingo & Segunda & Terça & Quarta & Quinta & Sexta & Sábado \\
\hline Albras L1 & 0.1984 & 0.1705 & 0.1383 & 0.1471 & 0.1292 & 0.1798 & 0.1286 \\
\hline Albras L2 & 0.127 & 0.1264 & 0.1325 & 0.1864 & 0.125 & 0.1578 & 0.1487 \\
\hline Alumar L1 & 0.403 & 0.3942 & 0.3602 & 0.3703 & 0.3831 & 0.3744 & 0.3209 \\
\hline Alumar L2 & 0.2474 & 0.2539 & 0.3797 & 0.3826 & 0.4041 & 0.3917 & 0.3928 \\
\hline Alunorte & 0.1371 & 0.1562 & 0.1495 & 0.1919 & 0.1413 & 0.1593 & 0.1487 \\
\hline Carajás & 0.4526 & 0.3662 & 0.4561 & 0.4949 & 0.3119 & 0.4799 & 0.477 \\
\hline CCM & 0.111 & 0.1124 & 0.1259 & 0.1165 & 0.1432 & 0.105 & 0.12 \\
\hline CVLD & 0.2036 & 0.2041 & 0.2114 & 0.2304 & 0.2033 & 0.2113 & 0.2099 \\
\hline Marabá & 0.1438 & 0.09706 & 0.1497 & 0.1279 & 0.1062 & 0.1219 & 0.1243 \\
\hline
\end{tabular}

Tabela 11.18 - P95\% do indicador Plt para os diferentes dias da semana.

\begin{tabular}{|c|c|c|c|c|c|c|c|}
\cline { 2 - 8 } \multicolumn{1}{c|}{} & Domingo & Segunda & Terça & Quarta & Quinta & Sexta & Sábado \\
\hline Albras L1 & 0.8959 & 0.1385 & 0.1401 & 0.1257 & 0.1138 & 0.118 & 0.1112 \\
\hline Albras L2 & 0.1923 & 0.1884 & 0.1174 & 0.2362 & 0.1123 & 0.1394 & 0.1376 \\
\hline Alumar L1 & 0.376 & 0.5322 & 0.3305 & 0.3999 & 0.3521 & 0.3812 & 0.2839 \\
\hline Alumar L2 & 0.2316 & 0.4226 & 0.3477 & 0.3686 & 0.3756 & 0.3954 & 0.3486 \\
\hline Alunorte & 0.1965 & 0.1931 & 0.1931 & 0.2466 & 0.1186 & 0.149 & 0.1484 \\
\hline Carajás & 0.5687 & 0.5481 & 1.708 & 0.4649 & 0.4038 & 0.4461 & 0.3962 \\
\hline CCM & 0.1569 & 0.1241 & 0.1236 & 0.1334 & 0.1677 & 0.1012 & 0.1133 \\
\hline CVLD & 0.1519 & 0.3192 & 0.1914 & 0.3087 & 0.1563 & 0.1699 & 0.1331 \\
\hline Marabá & 0.1305 & 0.8788 & 0.3602 & 0.3574 & 0.2792 & 0.2012 & 0.1357 \\
\hline
\end{tabular}

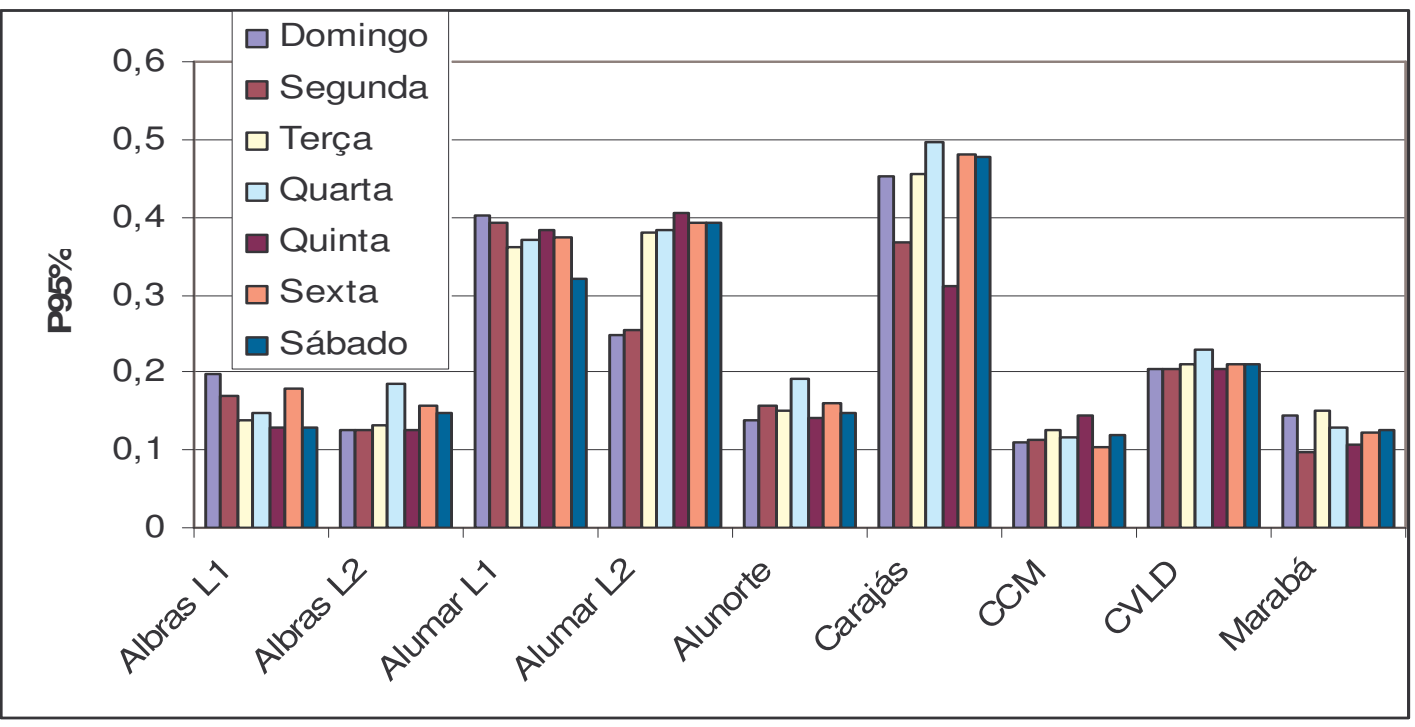

Figura 11.11 - Comparação entre o P95\% do indicador Pst das subestações para os diferentes dias da semana. 


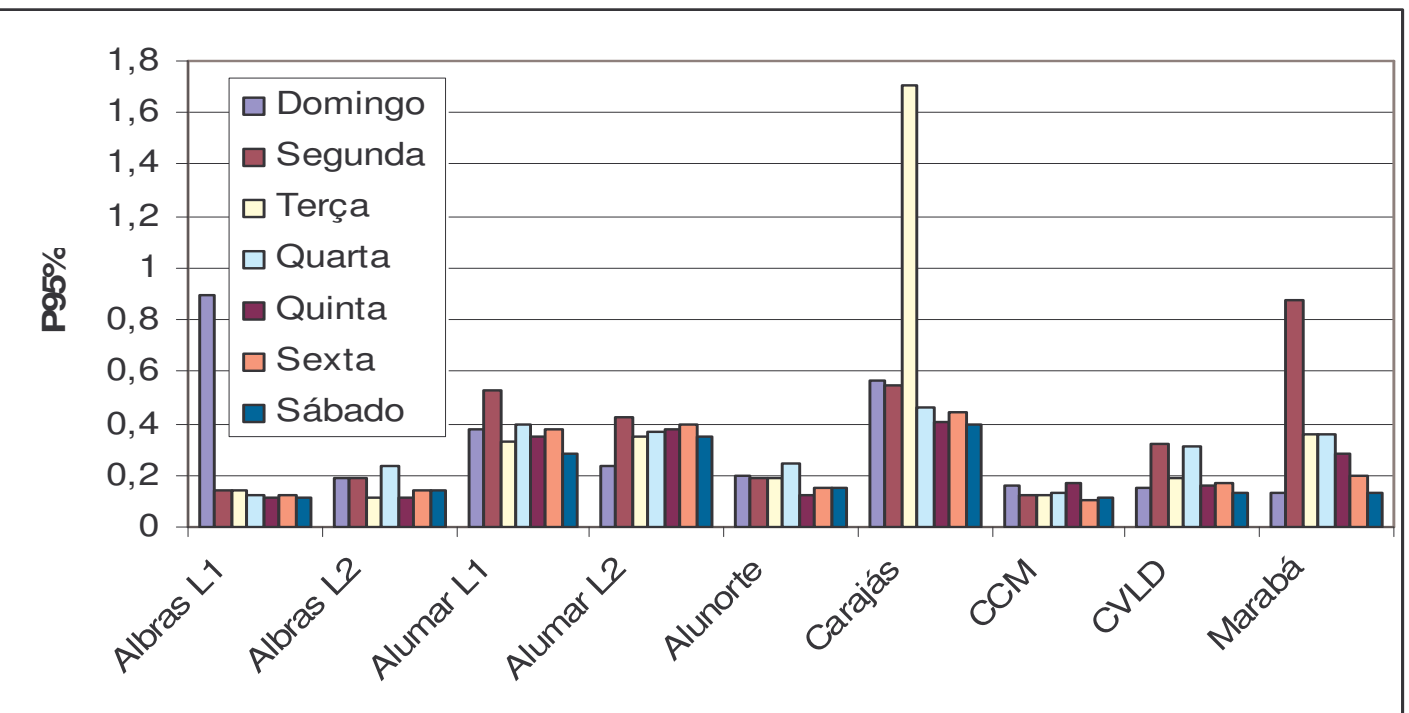

Figura 11.12 - Comparação entre o P95\% do indicador Plt das subestações para os diferentes dias da semana.

As tabelas 11.19 e 11.20 apresentam o erro relativo percentual entre os valores máximos e mínimos do P95\% encontrados durante a semana de medição, para os indicadores de cintilação luminosa.

Tabela 11.19 - Desvio percentual máximo do P95\% do indicador Pst dentro dos sete dias consecutivos.

\begin{tabular}{|c|c|c|c|}
\cline { 2 - 4 } \multicolumn{1}{c|}{} & Máximo & Mínimo & Erro relativo \\
\hline Albras L1 & 0,1984 & 0,1286 & $54,27 \%$ \\
\hline Albras L2 & 0,1864 & 0,1250 & $49,12 \%$ \\
\hline Alumar L1 & 0,4030 & 0,3209 & $25,58 \%$ \\
\hline Alumar L2 & 0,4041 & 0,2474 & $63,33 \%$ \\
\hline Alunorte & 0,1919 & 0,1371 & $39,97 \%$ \\
\hline Carajás & 0,4949 & 0,3119 & $58,67 \%$ \\
\hline CCM & 0,1432 & 0,1050 & $36,38 \%$ \\
\hline CVLD & 0,2304 & 0,2033 & $13,33 \%$ \\
\hline Marabá & 0,1497 & 0,09706 & $54,23 \%$ \\
\hline
\end{tabular}

Tabela 11.20 - Desvio percentual máximo do P95\% do indicador Plt dentro dos sete dias consecutivos.

\begin{tabular}{|c|c|c|c|}
\cline { 2 - 4 } \multicolumn{1}{c|}{} & Máximo & Mínimo & Erro relativo \\
\hline Albras L1 & 0,8959 & 0,1112 & $705,6 \%$ \\
\hline Albras L2 & 0,2362 & 0,1123 & $110,3 \%$ \\
\hline Alumar L1 & 0,5322 & 0,2839 & $87,46 \%$ \\
\hline Alumar L2 & 0,4226 & 0,2316 & $82,46 \%$ \\
\hline Alunorte & 0,2466 & 0,1186 & $107,9 \%$ \\
\hline Carajás & 1,708 & 0,3962 & $331,1 \%$ \\
\hline CCM & 0,1677 & 0,1012 & $65,71 \%$ \\
\hline CVLD & 0,3192 & 0,1331 & $139,8 \%$ \\
\hline Marabá & 0,8788 & 0,1305 & $573,4 \%$ \\
\hline
\end{tabular}


Mais uma vez, em relação ao P95\%, o limite de 5\% foi excedido em todos os locais, para ambos os indicadores. Portanto, para as três análises, média aritmética, desvio padrão e P95\%, o limite considerado razoável foi ultrapassado, caracterizando a não similaridade entre os dias da semana. Logo, não possível tomar um dia como representante dos demais.

Como não foi constatada a similaridade entre dias, não cabe buscar um período menor que represente toda a semana.

\subsection{3 - ANÁLISE DE SIMILARIDADE ENTRE FASES}

No capítulo sete, concluiu-se que não havia similaridade entre as fases de Albrás L1 para o período contemplado naquela ocasião. Entretanto, ficou decidido que a partir daquele ponto seria utilizado apenas uma das fases para as análises seguintes. Aquela que apresentar o pior resultado representará as demais.

Em geral, a fases que apresentam as maiores médias aritméticas são as que possuem os maiores índices P95\%, portanto, a partir da avaliação das médias aritméticas dos valores observados na semana em estudo será determinada a fase que representará as demais em cada local.

As tabelas 11.21 e 11.22 as figuras 11.13 e 11.14 mostram os valores das médias aritméticas do Pst e do Plt, respectivamente, observados para cada uma das fases.

Tabela 11.21 - Média aritmética dos valores de Pst

\begin{tabular}{|c|c|c|c|}
\cline { 2 - 4 } \multicolumn{1}{c|}{} & Fase A & Fase B & Fase C \\
\hline Albras L1 & 0,105612 & 0,110922 & 0,122581 \\
\hline Albras L2 & 0,098548 & 0,104964 & 0,105744 \\
\hline Alumar L1 & 0,256993 & 0,368316 & 0,222111 \\
\hline Alumar L2 & 0,217147 & 0,40227 & 0,633056 \\
\hline Alunorte & 0,106853 & 0,135517 & 0,161724 \\
\hline Carajás & 0,28096 & 0,288456 & 0,288735 \\
\hline CCM & 0,088425 & 0,089874 & 0,088638 \\
\hline CVLD & 0,104013 & 0,108658 & 0,105797 \\
\hline Marabá & 0,080205 & 0,082111 & 0,081155 \\
\hline
\end{tabular}


Tabela 11.22 - Média aritmética dos valores de Plt

\begin{tabular}{|c|c|c|c|}
\cline { 2 - 4 } \multicolumn{1}{c|}{} & Fase A & Fase B & Fase C \\
\hline Albras L1 & 0,105697 & 0,110991 & 0,122631 \\
\hline Albras L2 & 0,098432 & 0,104832 & 0,105658 \\
\hline Alumar L1 & 0,256775 & 0,367845 & 0,221514 \\
\hline Alumar L2 & 0,216082 & 0,402819 & 0,632031 \\
\hline Alunorte & 0,106774 & 0,135553 & 0,161645 \\
\hline Carajás & 0,31789 & 0,324131 & 0,333117 \\
\hline CCM & 0,09343 & 0,097632 & 0,094395 \\
\hline CVLD & 0,104194 & 0,108819 & 0,105768 \\
\hline Marabá & 0,104824 & 0,108297 & 0,09913 \\
\hline
\end{tabular}

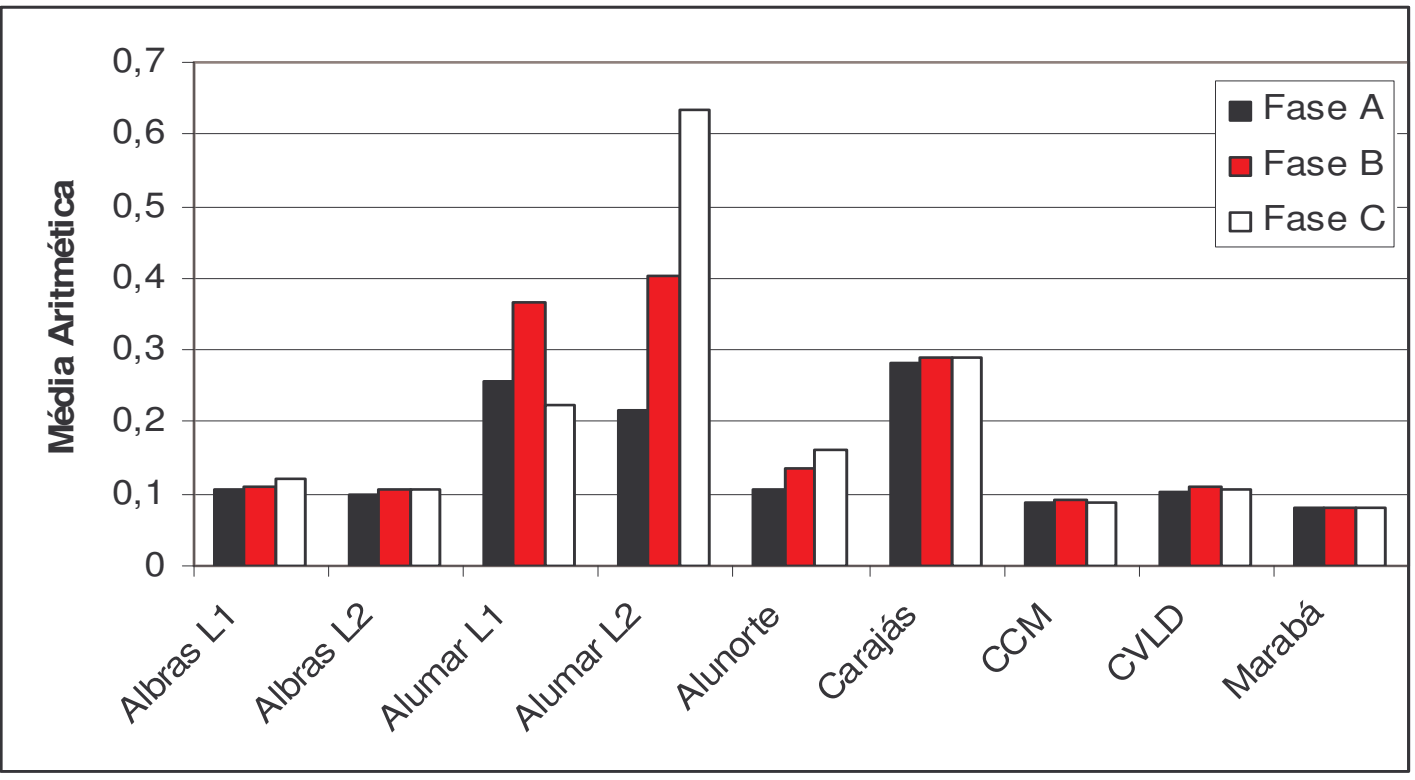

Figura 11.13 - Valor médio das amostras de Pst.

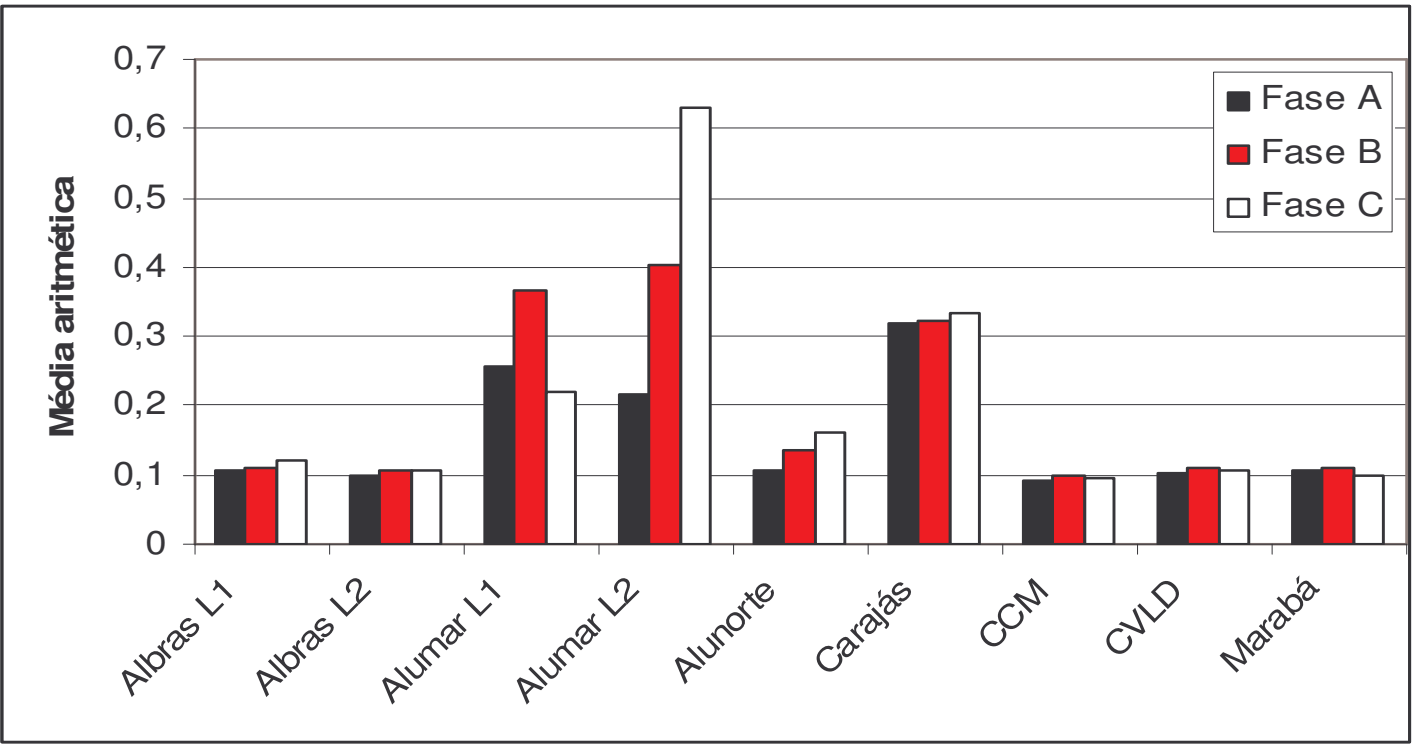

Figura 11.14 - Valor médio das amostras de Plt. 
Observando as figuras 11.13 e 11.14 percebe-se mais claramente qual fase possui o valor médio superior ao das demais.

A partir das tabelas 11.21 e 11.22 foram construídas as tabelas 11.23 e 11.24 que resumem os casos onde ocorrem as maiores médias aritméticas de Pst e de Plt, respectivamente.

\begin{tabular}{|c|c|c|}
\multicolumn{1}{c|}{ Tabela $11.23-$ Maiores médias aritméticas do Pst } \\
\cline { 2 - 3 } \multicolumn{1}{c|}{} & Fase & Valor médio \\
\hline Albras L1 & C & 0,122581 \\
\hline Albras L2 & C & 0,105744 \\
\hline Alumar L1 & B & 0,368316 \\
\hline Alumar L2 & C & 0,633056 \\
\hline Alunorte & C & 0,161724 \\
\hline Carajás & C & 0,288735 \\
\hline CCM & B & 0,089874 \\
\hline CVLD & B & 0,108658 \\
\hline Marabá & B & 0,082111 \\
\hline
\end{tabular}

Tabela 11.24 - Maiores médias aritméticas do Plt

\begin{tabular}{|c|c|c|}
\cline { 2 - 3 } \multicolumn{1}{c|}{} & Fase & Valor médio \\
\hline Albras L1 & C & 0,122631 \\
\hline Albras L2 & C & 0,105658 \\
\hline Alumar L1 & B & 0,367845 \\
\hline Alumar L2 & C & 0,633056 \\
\hline Alunorte & C & 0,161724 \\
\hline Carajás & C & 0,288735 \\
\hline CCM & B & 0,097632 \\
\hline CVLD & B & 0,108819 \\
\hline Marabá & B & 0,108297 \\
\hline
\end{tabular}

Das tabelas 11.23 e 11.24 tem-se que os maiores valores médios de Pst e de Plt, de um mesmo local, ocorrem na mesma fase. Este resultado era esperado, haja visto que o Plt é a média cúbica dos 12 últimos valores de Pst.

\subsection{4 - ANÁLISE DA DISTRIBUIÇÃO NO TEMPO}

Nesta etapa, as diversas análises efetuadas no capítulo 8 não serão contempladas, pois abordam questões específicas e de alto grau de complexidade quando da tentativa de comparação entre locais. 
A metodologia a ser utilizada aqui consiste na análise dos índices de probabilidade P90\%, P95\%, P99\%, médias aritméticas e desvio padrão das amostram que superaram índices supracitados.

As tabelas $11.25,11.26,11.27,11.28,11.29$ e 11.30 exibem o $\mathrm{P} 90 \%$, o $\mathrm{P} 95 \%$ e o $\mathrm{P} 99 \%$, as médias aritméticas, os desvios padrão e a razão entre os desvios e as médias dos valores que superaram os índices, para o Pst e para o Plt respectivamente.

Tabela 11.25 - P90\%, médias aritméticas, desvios padrão e razões entre os desvios e as médias dos valores superiores ao P90\% do Pst.

\begin{tabular}{|c|c|c|c|c|}
\cline { 2 - 5 } \multicolumn{1}{c|}{} & $\mathbf{P 9 0 \%}$ & $\begin{array}{c}\text { Média } \\
\text { Aritmética }\end{array}$ & $\begin{array}{c}\text { Desvio } \\
\text { Padrão }\end{array}$ & $\begin{array}{c}\text { Desvio Padrão / } \\
\text { Méd. Aritm. [\%] }\end{array}$ \\
\hline ALBRÁS L1 & 0,138402 & 0,319694 & 0,972617 & 304,2339 \\
\hline ALBRÁS L2 & 0,13411 & 0,192457 & 0,112749 & 58,58388 \\
\hline ALUMAR L1 & 0,534972 & 0,628784 & 0,328377 & 52,22406 \\
\hline ALUMAR L2 & 1,273744 & 1,409837 & 0,231065 & 16,38945 \\
\hline ALUNORTE & 0,204612 & 0,24943 & 0,094407 & 37,84909 \\
\hline CARAJÁS & 0,359548 & 0,548294 & 0,531895 & 97,00913 \\
\hline CVLD & 0,153391 & 0,330612 & 0,384024 & 116,1555 \\
\hline MARABÁ & 0,100986 & 0,188981 & 0,200862 & 106,2871 \\
\hline CCM & 0,107151 & 0,148488 & 0,070101 & 47,21003 \\
\hline
\end{tabular}

Tabela 11.26 - P95\%, médias aritméticas, desvios padrão e razões entre os desvios e as médias dos valores superiores ao P95\% do Pst.

\begin{tabular}{|c|c|c|c|c|}
\cline { 2 - 5 } \multicolumn{1}{c|}{} & $\mathbf{P 9 5 \%}$ & $\begin{array}{c}\text { Média } \\
\text { Aritmética }\end{array}$ & $\begin{array}{c}\text { Desvio } \\
\text { Padrão }\end{array}$ & $\begin{array}{c}\text { Desvio Padrão / } \\
\text { Méd. Aritm. [\%] }\end{array}$ \\
\hline ALBRÁS L1 & 0,154405 & 0,491325 & 1,353239 & 275,4262 \\
\hline ALBRÁS L2 & 0,150405 & 0,243392 & 0,141641 & 58,19446 \\
\hline ALUMAR L1 & 0,563267 & 0,707261 & 0,450445 & 63,68864 \\
\hline ALUMAR L2 & 1,371937 & 1,493341 & 0,302692 & 20,26947 \\
\hline ALUNORTE & 0,221636 & 0,284471 & 0,123576 & 43,44053 \\
\hline CARAJÁS & 0,450801 & 0,694382 & 0,721868 & 103,9584 \\
\hline CVLD & 0,217678 & 0,456661 & 0,511872 & 112,0903 \\
\hline MARABÁ & 0,119584 & 0,268239 & 0,260231 & 97,01438 \\
\hline CCM & 0,118866 & 0,184219 & 0,084777 & 46,01948 \\
\hline
\end{tabular}


Tabela 11.27 - P99\%, médias aritméticas, desvios padrão e razões entre os desvios e as médias dos valores superiores ao P99\% do Pst.

\begin{tabular}{|c|c|c|c|c|}
\cline { 2 - 5 } \multicolumn{1}{c|}{} & $\mathbf{P 9 9 \%}$ & $\begin{array}{c}\text { Média } \\
\text { Aritmética }\end{array}$ & $\begin{array}{c}\text { Desvio } \\
\text { Padrão }\end{array}$ & $\begin{array}{c}\text { Desvio Padrão / } \\
\text { Méd. Aritm. [\%] }\end{array}$ \\
\hline ALBRÁS L1 & 0,274046 & 1,577498 & 2,738102 & 173,5725 \\
\hline ALBRÁS L2 & 0,293234 & 0,440089 & 0,200877 & 45,6446 \\
\hline ALUMAR L1 & 0,616984 & 1,155866 & 0,855313 & 73,99754 \\
\hline ALUMAR L2 & 1,507788 & 1,726476 & 0,614249 & 35,57818 \\
\hline ALUNORTE & 0,302866 & 0,446433 & 0,194978 & 43,67455 \\
\hline CARAJÁS & 0,674969 & 1,392442 & 1,382287 & 99,27074 \\
\hline CVLD & 0,519821 & 1,073533 & 0,865776 & 80,64738 \\
\hline MARABÁ & 0,308851 & 0,647089 & 0,358833 & 55,45343 \\
\hline CCM & 0,209379 & 0,309872 & 0,105993 & 34,20535 \\
\hline
\end{tabular}

Tabela 11.28 - P90\%, médias aritméticas, desvios padrão e razões entre os desvios e as médias dos valores superiores ao $\mathrm{P} 90 \%$ do Plt.

\begin{tabular}{|c|c|c|c|c|}
\cline { 2 - 5 } \multicolumn{1}{c|}{} & $\mathbf{P 9 0 \%}$ & $\begin{array}{c}\text { Média } \\
\text { Aritmética }\end{array}$ & $\begin{array}{c}\text { Desvio } \\
\text { Padrão }\end{array}$ & $\begin{array}{c}\text { Desvio Padrão / } \\
\text { Méd. Aritm. [\%] }\end{array}$ \\
\hline ALBRÁS L1 & 0,126488 & 0,274498 & 0,367934 & 134,0391 \\
\hline ALBRÁS L2 & 0,124901 & 0,152028 & 0,027635 & 18,1777 \\
\hline ALUMAR L1 & 0,507188 & 0,553258 & 0,074963 & 13,54936 \\
\hline ALUMAR L2 & 1,234996 & 1,306592 & 0,046698 & 3,573997 \\
\hline ALUNORTE & 0,192595 & 0,207589 & 0,015248 & 7,345272 \\
\hline CARAJÁS & 0,398777 & 0,766681 & 0,59713 & 77,88509 \\
\hline CVLD & 0,146302 & 0,198414 & 0,07194 & 36,25777 \\
\hline MARABÁ & 0,164715 & 0,330132 & 0,142825 & 43,26301 \\
\hline CCM & 0,125052 & 0,158166 & 0,04145 & 26,20661 \\
\hline
\end{tabular}

Tabela 11.29 - P95\%, médias aritméticas, desvios padrão e razões entre os desvios e as médias dos valores superiores ao P95\% do Plt.

\begin{tabular}{|c|c|c|c|c|}
\cline { 2 - 5 } \multicolumn{1}{c|}{} & $\mathbf{P 9 5 \%}$ & $\begin{array}{c}\text { Média } \\
\text { Aritmética }\end{array}$ & $\begin{array}{c}\text { Desvio } \\
\text { Padrão }\end{array}$ & $\begin{array}{c}\text { Desvio Padrão / } \\
\text { Méd. Aritm. [\%] }\end{array}$ \\
\hline ALBRÁS L1 & 0,136214 & 0,416103 & 0,478987 & 115,1127 \\
\hline ALBRÁS L2 & 0,146412 & 0,171448 & 0,026685 & 15,56441 \\
\hline ALUMAR L1 & 0,528148 & 0,58789 & 0,093419 & 15,8905 \\
\hline ALUMAR L2 & 1,295147 & 1,346276 & 0,028972 & 2,151988 \\
\hline ALUNORTE & 0,203612 & 0,217851 & 0,015407 & 7,07236 \\
\hline CARAJÁS & 0,455028 & 1,107048 & 0,688527 & 62,19489 \\
\hline CVLD & 0,174551 & 0,238207 & 0,083845 & 35,19824 \\
\hline MARABÁ & 0,284208 & 0,432375 & 0,130348 & 30,1469 \\
\hline CCM & 0,151948 & 0,182299 & 0,041674 & 22,86029 \\
\hline
\end{tabular}


Tabela 11.30 - P99\%, médias aritméticas, desvios padrão e razões entre os desvios e as médias dos valores superiores ao P99\% do Plt.

\begin{tabular}{|c|c|c|c|c|}
\cline { 2 - 5 } \multicolumn{1}{c|}{} & $\mathbf{P 9 9 \%}$ & $\begin{array}{c}\text { Média } \\
\text { Aritmética }\end{array}$ & $\begin{array}{c}\text { Desvio } \\
\text { Padrão }\end{array}$ & $\begin{array}{c}\text { Desvio Padrão / } \\
\text { Méd. Aritm. [\%] }\end{array}$ \\
\hline ALBRÁS L1 & 1,22651 & 1,293368 & 0,028088 & 2,171715 \\
\hline ALBRÁS L2 & 0,200695 & 0,220485 & 0,007206 & 3,268249 \\
\hline ALUMAR L1 & 0,713619 & 0,75725 & 0,027351 & 3,611833 \\
\hline ALUMAR L2 & 1,372095 & 1,382899 & 0,008838 & 0,63908 \\
\hline ALUNORTE & 0,223529 & 0,244293 & 0,010026 & 4,103971 \\
\hline CARAJÁS & 1,940583 & 1,940583 & 0 & 0 \\
\hline CVLD & 0,374658 & 0,38751 & 0,011083 & 2,859942 \\
\hline MARABÁ & 0,631359 & 0,631359 & 0 & 0 \\
\hline CCM & 0,251445 & 0,251445 & 0 & 0 \\
\hline
\end{tabular}

A partir das tabelas 11.25, 11.26 e 11.27 (referentes ao Pst), observa-se que aumentando o valor do índice, a média e o desvio padrão das amostras aumentam também. Já das tabelas 11.28, 11.29 e 11.30 (referentes ao Plt) nota-se que acontece uma situação diferente, a média se comporta da mesma maneira, mas o desvio sempre é maior para o P95\% e menor para o P99\%, isto ocorre devido ao fato do Plt ser mais conservador que o Pst.

As figuras 11.15 e 11.16 ilustram as médias aritméticas, para os diferentes locais, dos valores acima do P90\%, P95\% e P99\% do Pst e do Plt respectivamente.

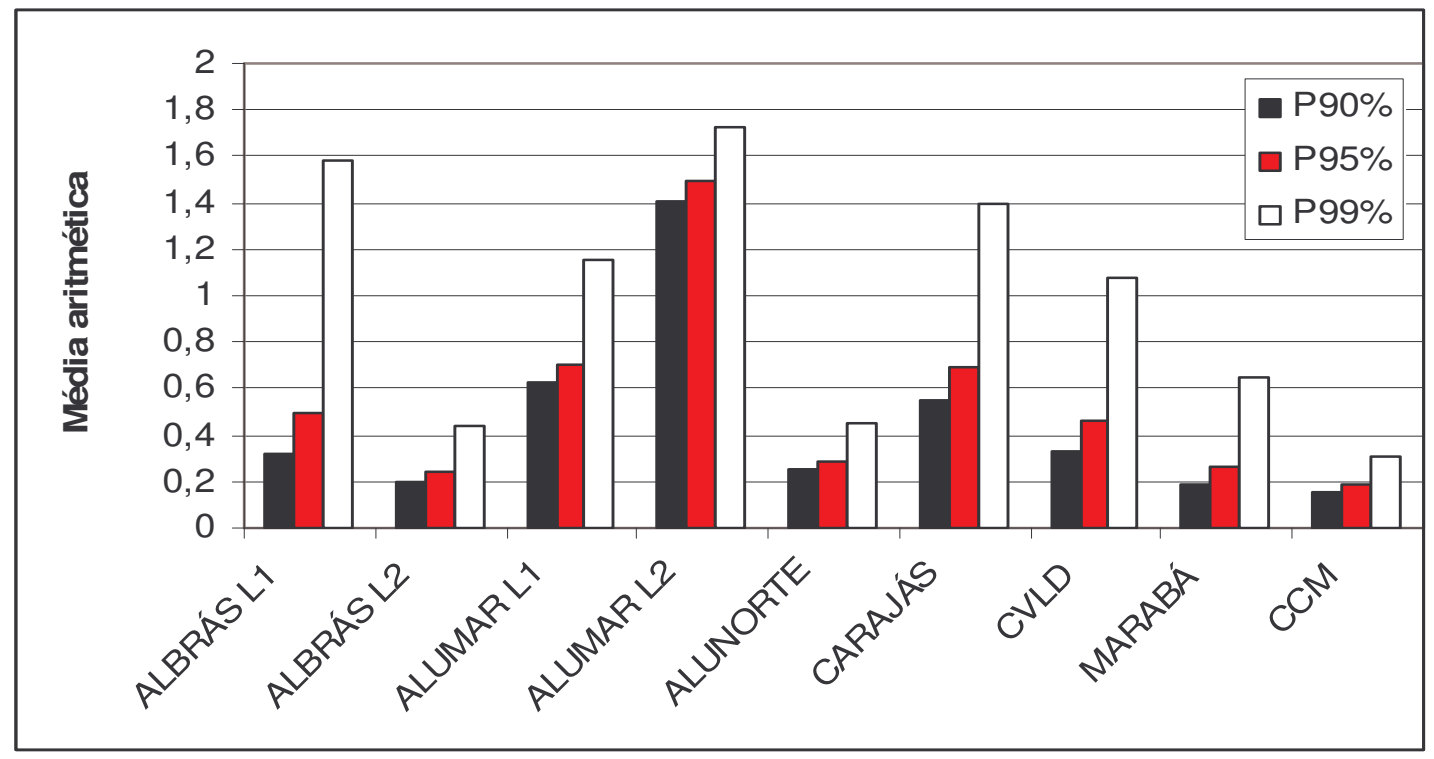

Figura 11.15 - Médias aritméticas dos valores de Pst que ultrapassaram os índices. 


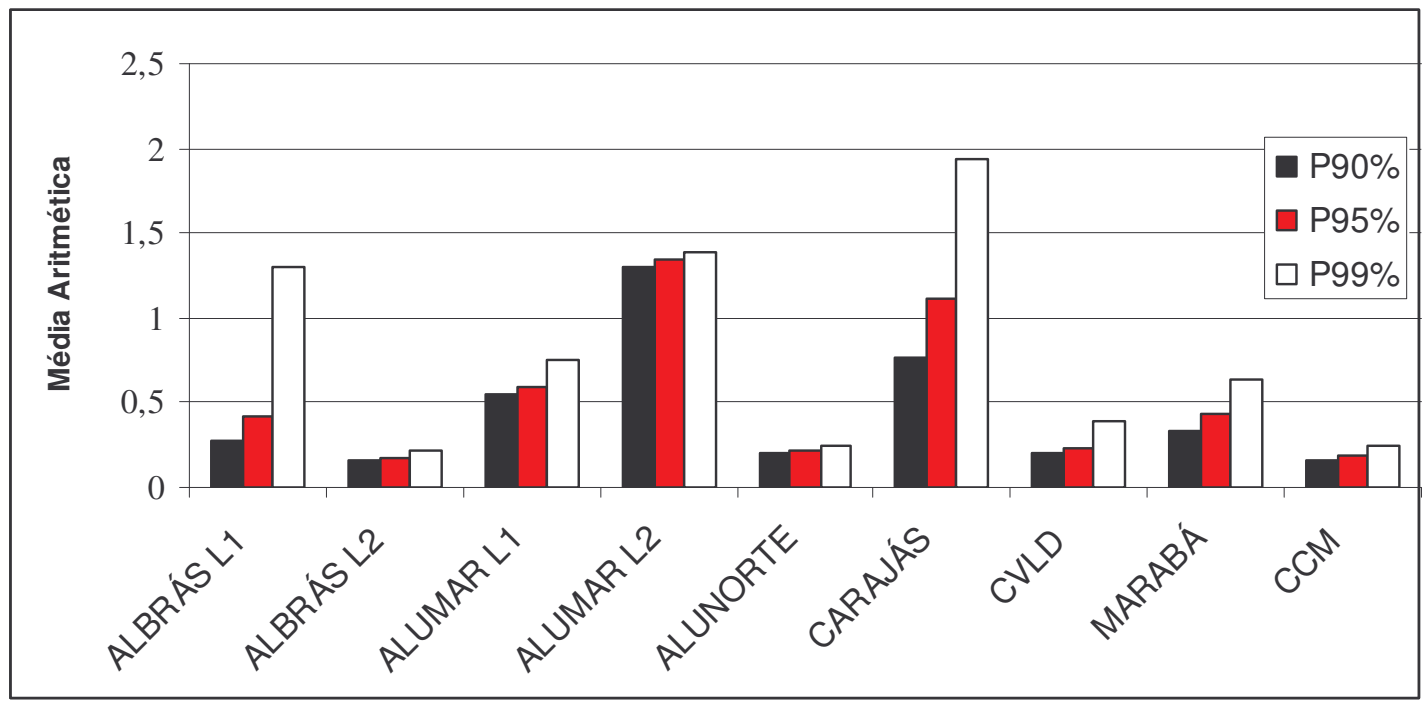

Figura 11.16 - Médias aritméticas dos valores de Plt que ultrapassaram os índices.

Das figuras $11.15,11.16$ tem-se que quanto maior o valor do índice, maior o valor da média aritmética dos valores acima dele. Isto acontece porque o número de amostras fica reduzido, aumento a influência dos valores de pico no valor da média.

As figuras 11.17 e 11.18 mostram os valores de desvio padrão das amostras acima dos três parâmetros para o Pst e para o Plt respectivamente.

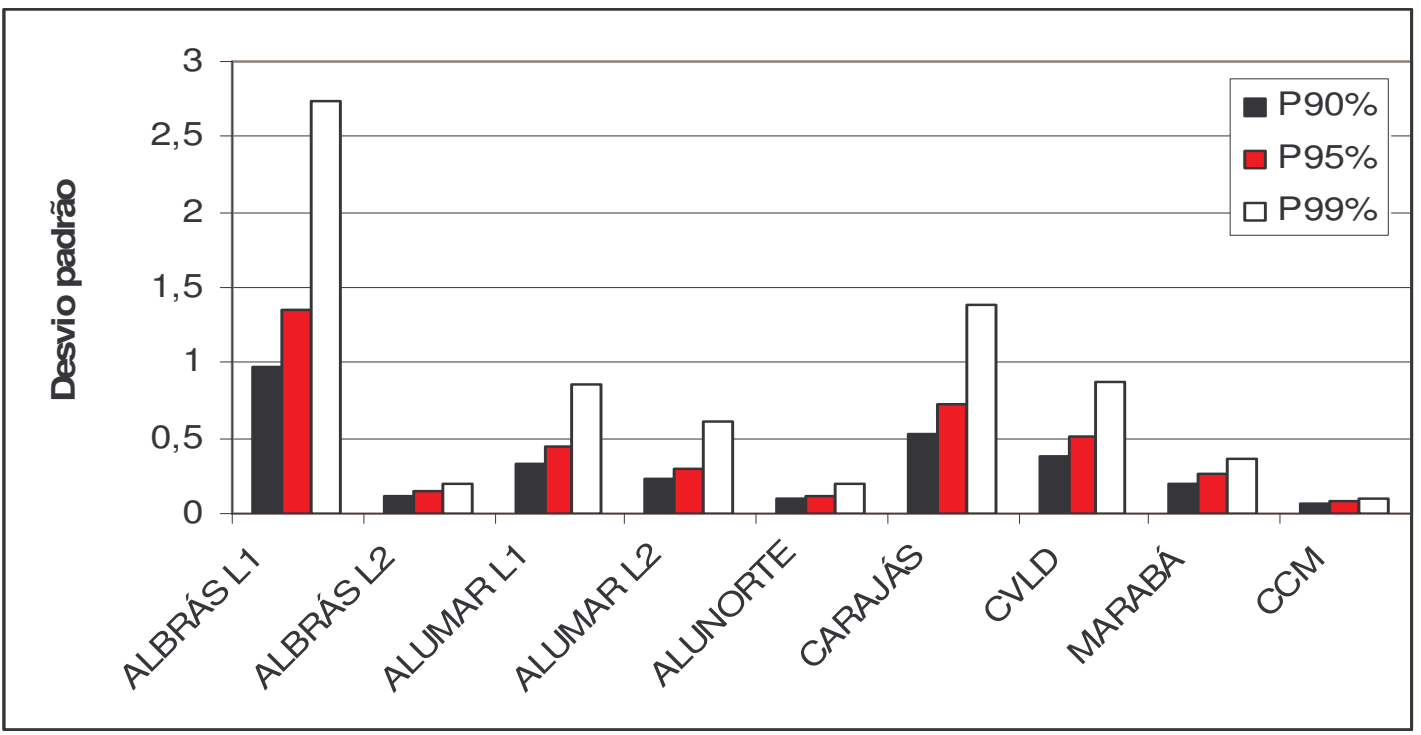

Figura 11.17 - Desvio Padrão dos valores de Pst que ultrapassaram os índices. 


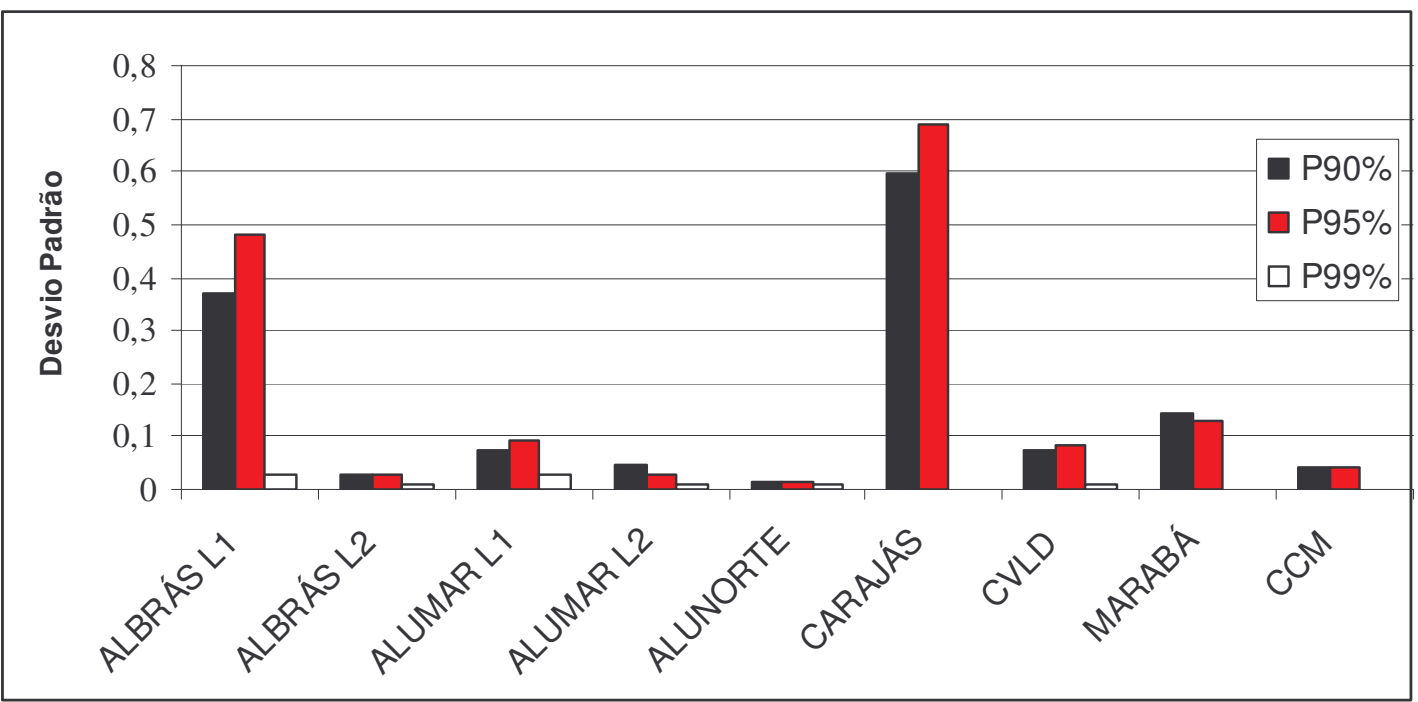

Figura 11.18 - Desvio padrão dos valores de Plt que ultrapassaram os índices.

Da figura 11.17 (referente ao Pst) tem-se que quanto maior o índice, maior o desvio padrão. A partir das figuras 11.18 nota-se que para o Plt o desvio padrão se comporta de uma maneira diferente, tendo o maior desvio alternando-se entre os índices P90\% e o P95\% e o menor sempre em P99\%.

A presença de elevados desvios denota do fato de existirem picos de Pst e Plt muito superiores do que a média apresentada para o local.

As tabelas 11.30 e 11.31 exibem o erro relativo entre as médias aritméticas dos valores acima dos índices encontrados para cada local, do Pst e do Plt respectivamente.

Tabela 11.30 - Erro relativo entre as médias aritméticas dos valores superiores aos índices do Pst.

\begin{tabular}{|c|c|c|c|}
\cline { 2 - 4 } \multicolumn{1}{c|}{} & Entre P90\% e P95\% & Entre P95\% e P99\% & Entre P90\% e P99\% \\
\hline ALBRÁS 1 & 10,36428 & 43,65725 & 49,49677 \\
\hline ALBRÁS 2 & 10,8343 & 48,70821 & 54,26532 \\
\hline ALUMAR 1 & 5,02344 & 8,706386 & 13,29247 \\
\hline ALUMAR 2 & 7,157292 & 9,009914 & 15,52234 \\
\hline ALUNORTE & 7,680666 & 26,82052 & 32,44119 \\
\hline CARAJÁS & 20,24239 & 33,21163 & 46,73119 \\
\hline CVLD & 29,533 & 58,12453 & 70,49162 \\
\hline MARABÁ & 15,55294 & 61,2808 & 67,30278 \\
\hline CCM & 9,855645 & 43,22892 & 48,82408 \\
\hline
\end{tabular}


Tabela 11.31 - Erro relativo entre as médias aritméticas dos valores superiores aos índices do Plt.

\begin{tabular}{|c|c|c|c|}
\cline { 2 - 4 } \multicolumn{1}{c|}{} & Entre P90\% e P95\% & Entre P95\% e P99\% & Entre P90\% e P99\% \\
\hline ALBRÁS 1 & 7,140649 & 88,89416 & 89,68718 \\
\hline ALBRÁS 2 & 14,69184 & 27,04773 & 37,76576 \\
\hline ALUMAR 1 & 3,968532 & 25,99021 & 28,92731 \\
\hline ALUMAR 2 & 4,644336 & 5,60804 & 9,991919 \\
\hline ALUNORTE & 5,410664 & 8,910427 & 13,83898 \\
\hline CARAJÁS & 12,36207 & 76,55198 & 79,45064 \\
\hline CVLD & 16,18396 & 53,41044 & 60,95048 \\
\hline MARABÁ & 42,04436 & 54,98476 & 73,91113 \\
\hline CCM & 25,7228 & 99,08468 & 99,32013 \\
\hline
\end{tabular}

Das tabelas 11.30 e 11.31 observa-se que o erro relativo entre os índices é muito alto para todo o banco, tendo seu maior valor entre o P90\% e o P99\% do Plt de CCM, com 99,32\%, seguido de Albrás L1 com 89,69\%. Em geral o maior erro relativo de cada local é entre o P90\% е о $\mathrm{P} 99 \%$.

Para um banco de dados com amostras bem comportadas espera-se um erro relativo pequeno entre os índices. Grandes erros significam uma grande variação nas amostras e a existência de valores muitos distantes entre as mesmas.

\subsection{5 - ANÁLISE DA TENSÃO DE FASE}

A tabela 11.32 ilustra a média aritmética das tensões de fase dos nove locais em estudo e o erro relativo entre o maior e o menor valor médio observado. A figura 11.19 ilustra a comparação entres os dados alcançados.

Tabela 11.32 - Média aritmética das tensões de fase.

\begin{tabular}{|c|c|c|c|c|}
\cline { 2 - 5 } \multicolumn{1}{c|}{} & Va & Vb & Vc & Erro relativo \\
\hline Albras L1 & 136042,1 & 136644,8 & 136108,1 & $0,44 \%$ \\
\hline Albras L2 & 134853,4 & 136777,9 & 136347,2 & $1,41 \%$ \\
\hline Alumar L1 & 136559,4 & 136618,7 & 136689,2 & $0,09 \%$ \\
\hline Alumar L2 & 136827,2 & 136498,5 & 136335 & $0,36 \%$ \\
\hline Alunorte & 136384,1 & 136320,1 & 136455 & $0,10 \%$ \\
\hline Carajás & 135992,5 & 135693 & 135265,4 & $0,53 \%$ \\
\hline CCM & 130069,8 & 130596 & 130561,3 & $0,40 \%$ \\
\hline CVLD & 136263,2 & 135748,5 & 135708,3 & $0,41 \%$ \\
\hline Marabá & 139589,1 & 140055,9 & 143704,2 & $2,86 \%$ \\
\hline
\end{tabular}




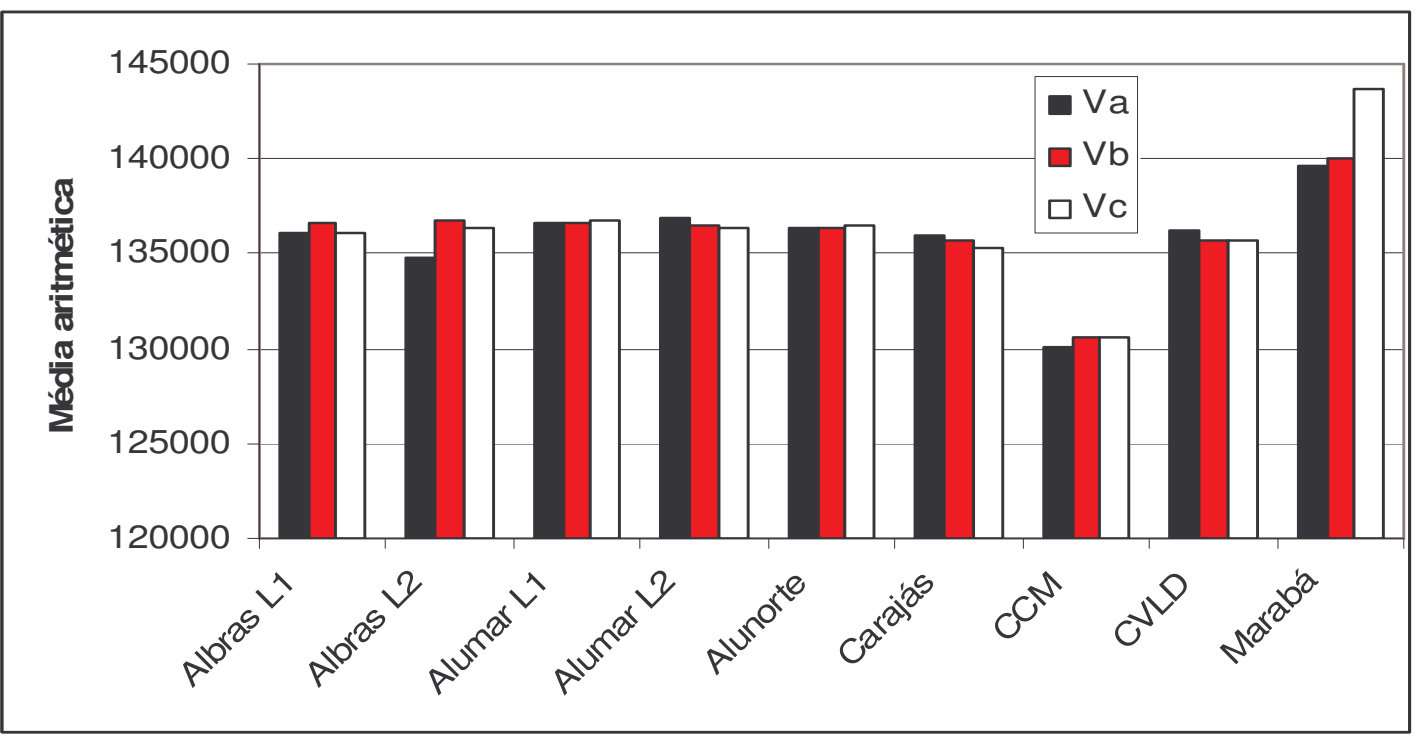

Figura 11.19 - Comparação entre a média aritmética da tensão de fase para as diferentes subestações.

Da tabela 11.32 e da figura 11.19 , tem-se que, para o mesmo local, as tensões de fase apresentam valores próximos entre si. O maior erro relativo observado foi em Marabá, com 2,86\%, seguido de Albrás L2, com 1,41\%. Os valores médios são superiores à tensão nominal, $132,8 \mathrm{kV}$, em todas as fases, exceto para CCM onde as tensões se encontram um pouco abaixo da nominal.

A tabela 11.33 e a figura 11.20 apresentam os valores de desvio padrão das amostras de tensão de fase, nos diferentes locais em estudo.

Tabela 11.33 - Desvio padrão das amostras de tensão de fase

\begin{tabular}{|c|c|c|c|}
\cline { 2 - 4 } \multicolumn{1}{c|}{} & $\mathbf{V a}$ & $\mathbf{V b}$ & $\mathbf{V c}$ \\
\hline Albras L1 & 823,8309 & 769,6682 & 809,9647 \\
\hline Albras L2 & 846,6091 & 819,5097 & 790,1693 \\
\hline Alumar L1 & 1674,427 & 1641,008 & 1589,062 \\
\hline Alumar L2 & 1697,329 & 1645,943 & 1583,675 \\
\hline Alunorte & 847,4434 & 790,4485 & 831,3892 \\
\hline Carajás & 2060,393 & 2114,355 & 2126,913 \\
\hline CCM & 913,4399 & 921,3562 & 912,751 \\
\hline CVLD & 1553,44 & 1528,968 & 1526,163 \\
\hline Marabá & 815,4974 & 795,6388 & 1071,387 \\
\hline
\end{tabular}




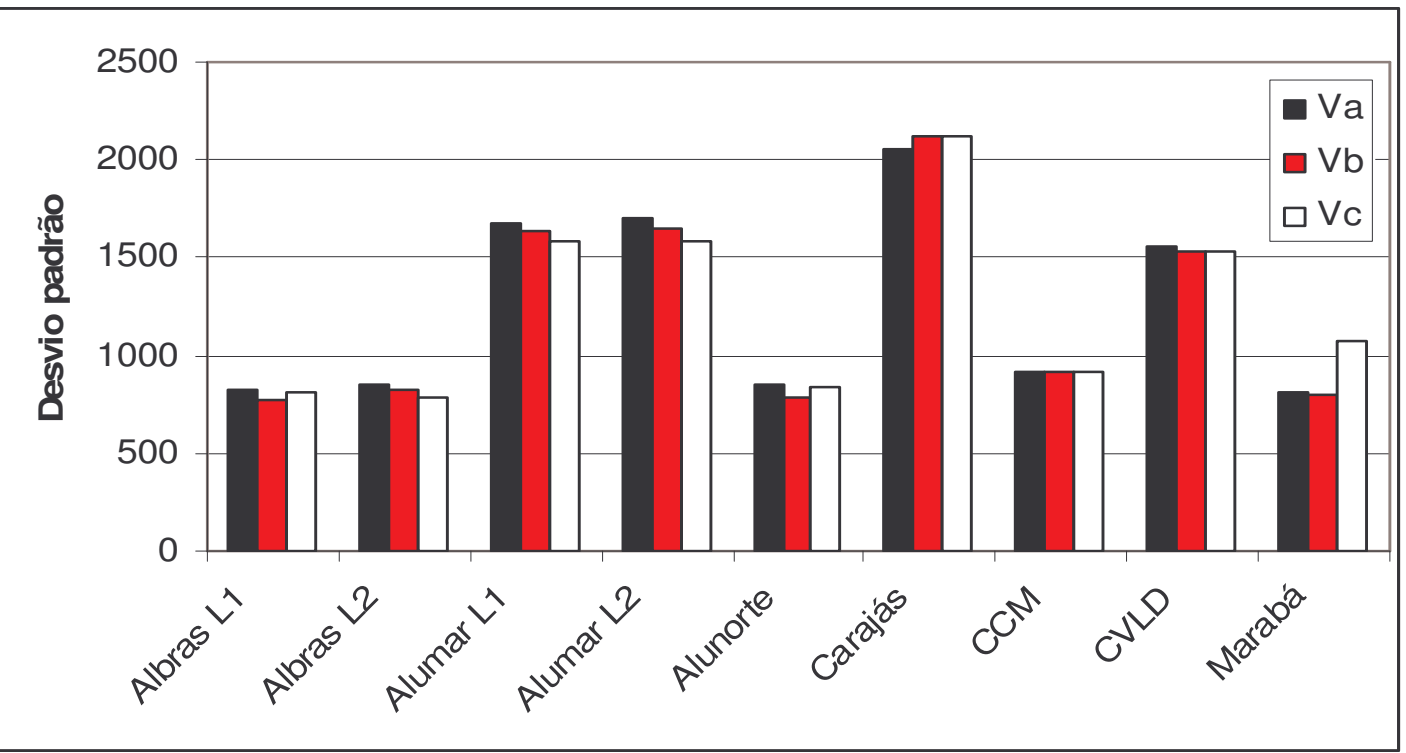

Figura 11.20 - Comparação entre o desvio padrão das amostras de tensão de fase.

A partir da tabela 11.33 e da figura 11.20 tem-se que os valores de desvio padrão das amostras de tensão observadas são próximos entre si, para um mesmo ponto de medição.

A tabela 11.34 ilustra a razão entre os desvios padrão e suas respectivas médias aritméticas, para as três fases de cada local.

Tabela 11.34 - Razão entre os desvios padrão e suas respectivas médias aritméticas

\begin{tabular}{|c|c|c|c|}
\cline { 2 - 4 } \multicolumn{1}{c|}{} & $\mathbf{V a}[\%]$ & $\mathbf{V b}[\%]$ & $\mathbf{V c}[\%]$ \\
\hline Albras L1 & 0,605571 & 0,563262 & 0,595089 \\
\hline Albras L2 & 0,6278 & 0,599154 & 0,579527 \\
\hline Alumar L1 & 1,226153 & 1,201159 & 1,162537 \\
\hline Alumar L2 & 1,240491 & 1,205832 & 1,161605 \\
\hline Alunorte & 0,621365 & 0,579847 & 0,609277 \\
\hline Carajás & 1,515078 & 1,55819 & 1,5724 \\
\hline CCM & 0,702269 & 0,705501 & 0,699098 \\
\hline CVLD & 1,140029 & 1,126324 & 1,12459 \\
\hline Marabá & 0,584213 & 0,568087 & 0,74555 \\
\hline
\end{tabular}

Observando-se a tabela 11.34 percebe-se que os desvios padrão percentuais apresentados foram muito pequenos, tendo $1,5724 \%$ como o maior desvio, medido em Carajás. Concluise que as amostram se distanciaram pouco da média. 
A tabela 11.35 e a figura 11.21 exibem os valores de P95\% para as tensões de fase durante a semana em questão, nos diferentes locais.

Tabela 11.35 - P95\% das tensões de fase nos diferentes locais

\begin{tabular}{|c|c|c|c|c|}
\cline { 2 - 5 } \multicolumn{1}{c|}{} & Va & Vb & Vc & Erro relativo \\
\hline Albras L1 & 137325,9 & 137880,7 & 137308,1 & $0,41 \%$ \\
\hline Albras L2 & 135958,5 & 137884,1 & 137378,6 & $1,40 \%$ \\
\hline Alumar L1 & 139702 & 139677,8 & 139645,6 & $0,04 \%$ \\
\hline Alumar L2 & 139967,5 & 139548,2 & 139287,9 & $0,48 \%$ \\
\hline Alunorte & 137499,7 & 137400,8 & 137517,9 & $0,08 \%$ \\
\hline Carajás & 139127,8 & 138952,5 & 138618,7 & $0,37 \%$ \\
\hline CCM & 131429,3 & 132059 & 132000,9 & $0,48 \%$ \\
\hline CVLD & 139179,4 & 138649 & 138587,9 & $0,42 \%$ \\
\hline Marabá & 140870,8 & 141240,7 & 145315,3 & $3,06 \%$ \\
\hline
\end{tabular}

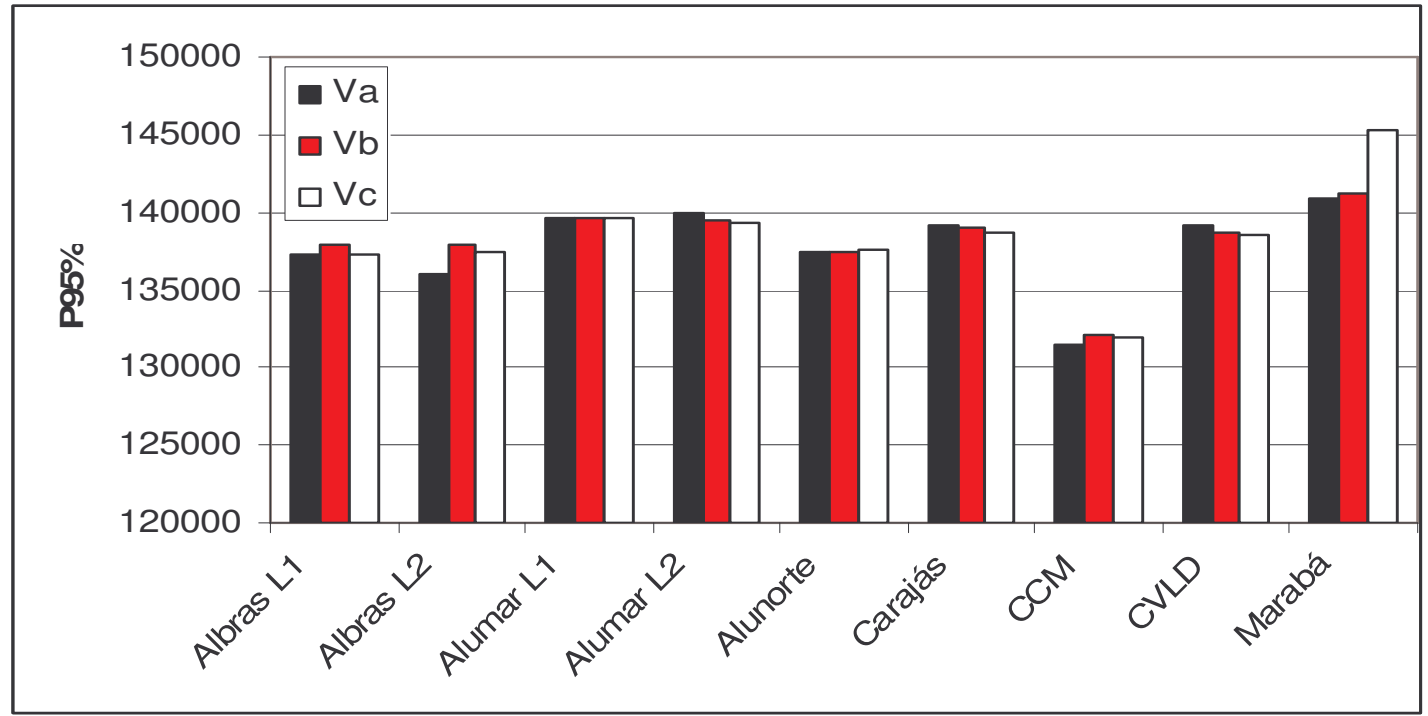

Figura 11.21 - Comparação entre o P95\% das amostras de tensão de fase.

Da tabela 11.35 e da figura 11.21 tem-se que os valores de P95\% observados para as três fases de cada local estão próximos entre si. O maior erro relativo é ocorreu em Marabá, com 3,06\%, seguido de Albrás L2, com 1,4\%.

As figuras 11.22, 11.23 e 11.24 apresentam os gráficos, em p.u., de distribuição de ocorrências das tensões $\mathrm{Va}, \mathrm{Vb}$ e $\mathrm{Vc}$ respectivamente, considerando-se todo o banco de dados. 


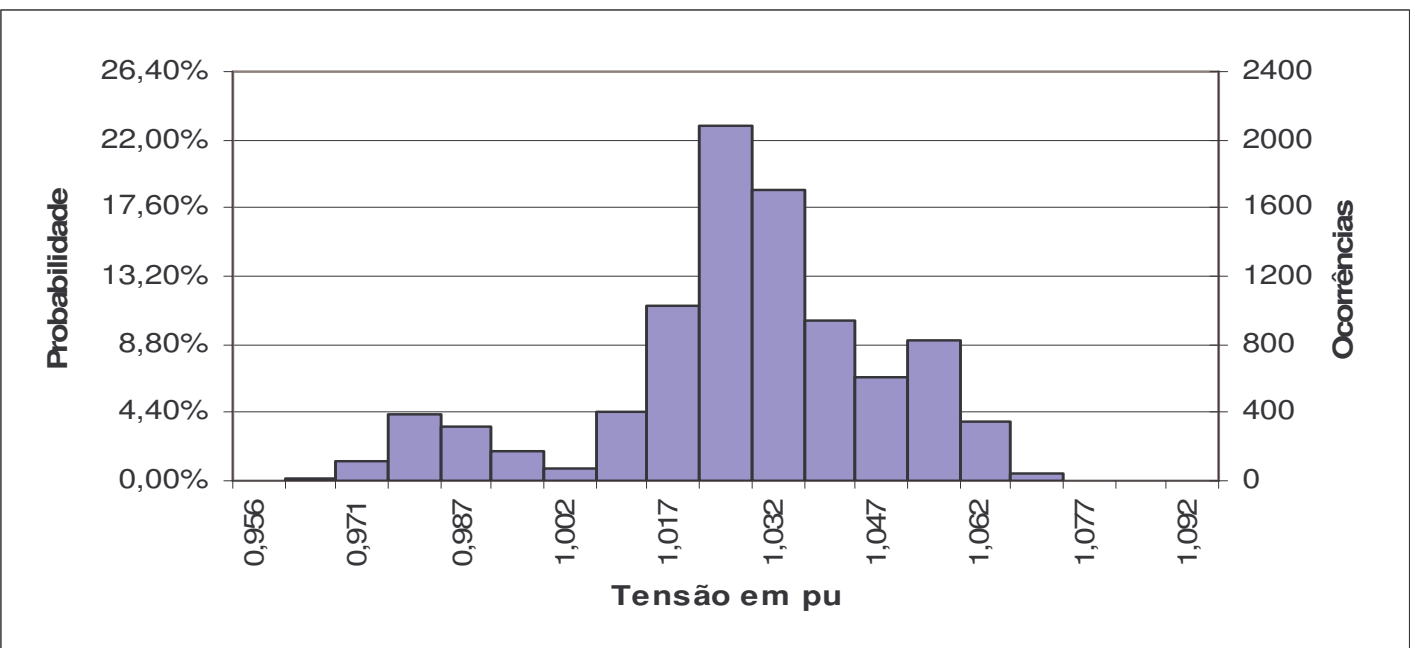

Figura 11.22 - Distribuição de ocorrências da tensão de fase Va em p.u.

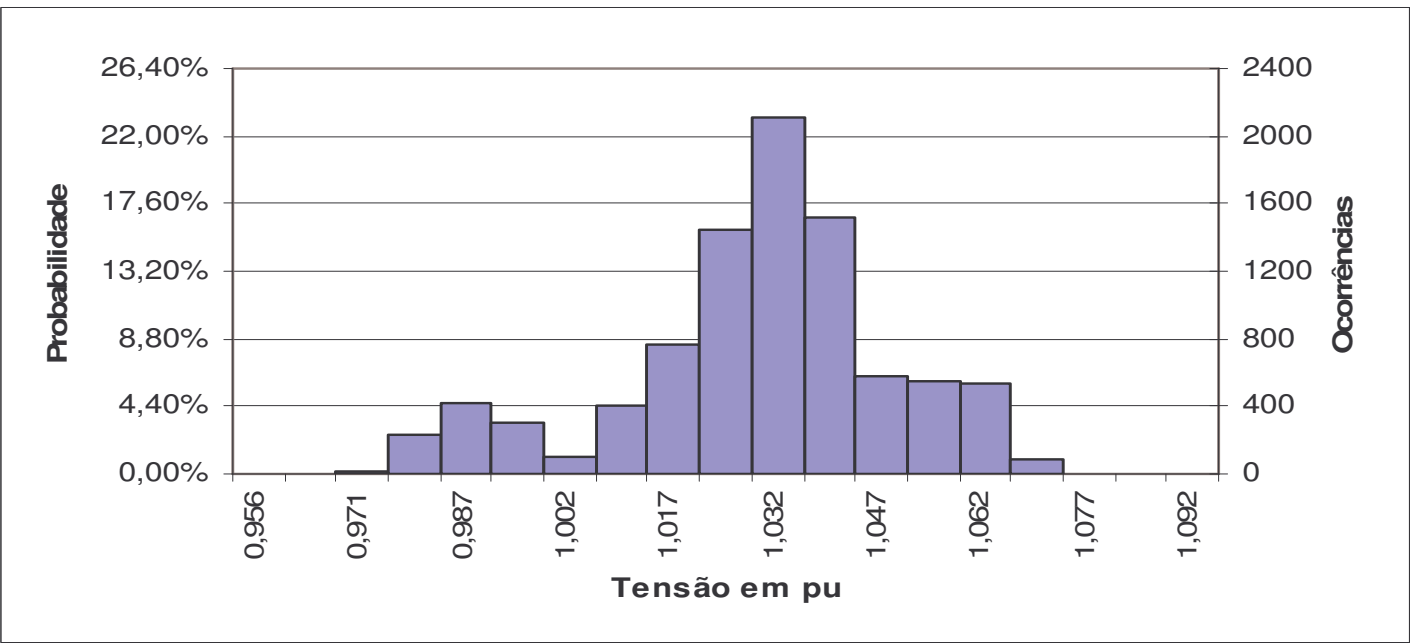

Figura 11.23 - Distribuição de ocorrências da tensão de fase Vb em p.u.

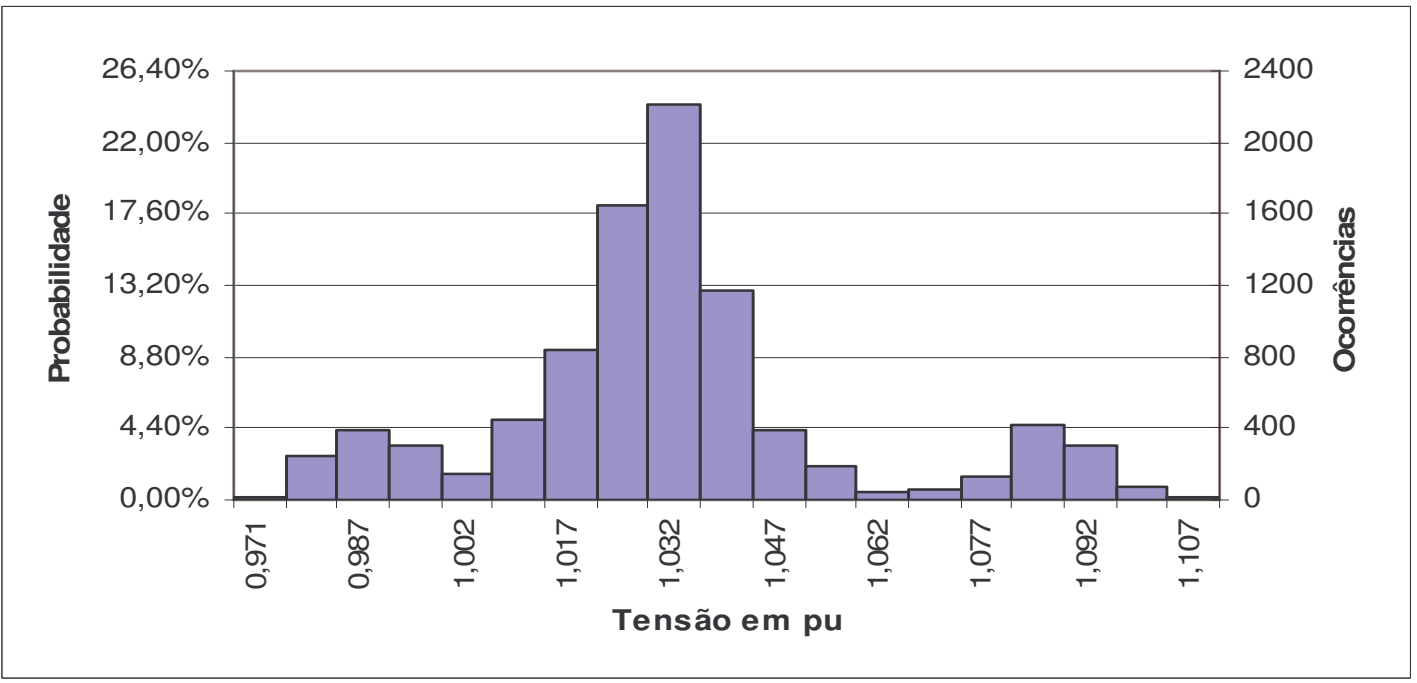

Figura 11.24 - Distribuição de ocorrências da tensão de fase Vc em p.u. 
Como o período analisado corresponde a sete dias consecutivos com intervalo de aquisição de dados de 10 minutos, cada local apresentará 1008 valores para cada fase, totalizando 9072 amostras para os nove locais. Da figura 11.22 tem-se que a tensão Va apresenta 64,1\% de seus valores (5815 amostras) entre 1,017 p.u. e 1,039 p.u. Já da figura 11.23, percebe-se que cerca de $64,4 \%$ do total das amostras de Vb se mostram entre 1,017 p.u e 1,039 p.u. Por fim, observa-se da figura 11.24 que $64,8 \%$ dos dados colhidos para a fase C possuem sua magnitude entre 1,017 p.u. e 1,039 p.u.

Conclui-se que durante a semana observada, a maioria dos valores estiveram um pouco acima de 1 p.u.

\subsection{6 - ANÁLISE DA TENSÃO DE LINHA}

A tabela 11.36 exibe a média aritmética das tensões de linha dos nove locais em estudo, bem como o erro relativo entre o maior e o menor valor observados para o mesmo ponto de medição. A figura 11.25 ilustra a comparação entre as médias encontrada.

\begin{tabular}{|c|c|c|c|c|}
\hline & Vab & Vbc & Vea & Erro relativo \\
\hline Albras L1 & 235872,8 & 236475,6 & 235682 & $0,33 \%$ \\
\hline Albras L2 & 234890,1 & 236715,7 & 235011,1 & $0,77 \%$ \\
\hline Alumar L1 & 236791,4 & 236636,8 & 236476,6 & $0,13 \%$ \\
\hline Alumar L2 & 236972 & 236377,1 & 236198 & $0,33 \%$ \\
\hline Alunorte & 236053,7 & 236111 & 236452,2 & $0,17 \%$ \\
\hline Carajás & 235515,3 & 234425,8 & 234898,5 & $0,46 \%$ \\
\hline CCM & 225704,8 & 226288,9 & 225630,7 & $0,29 \%$ \\
\hline CVLD & 235593 & 234867,7 & 235725,5 & $0,36 \%$ \\
\hline Marabá & 241528,1 & 245845,6 & 245904,3 & $1,78 \%$ \\
\hline
\end{tabular}




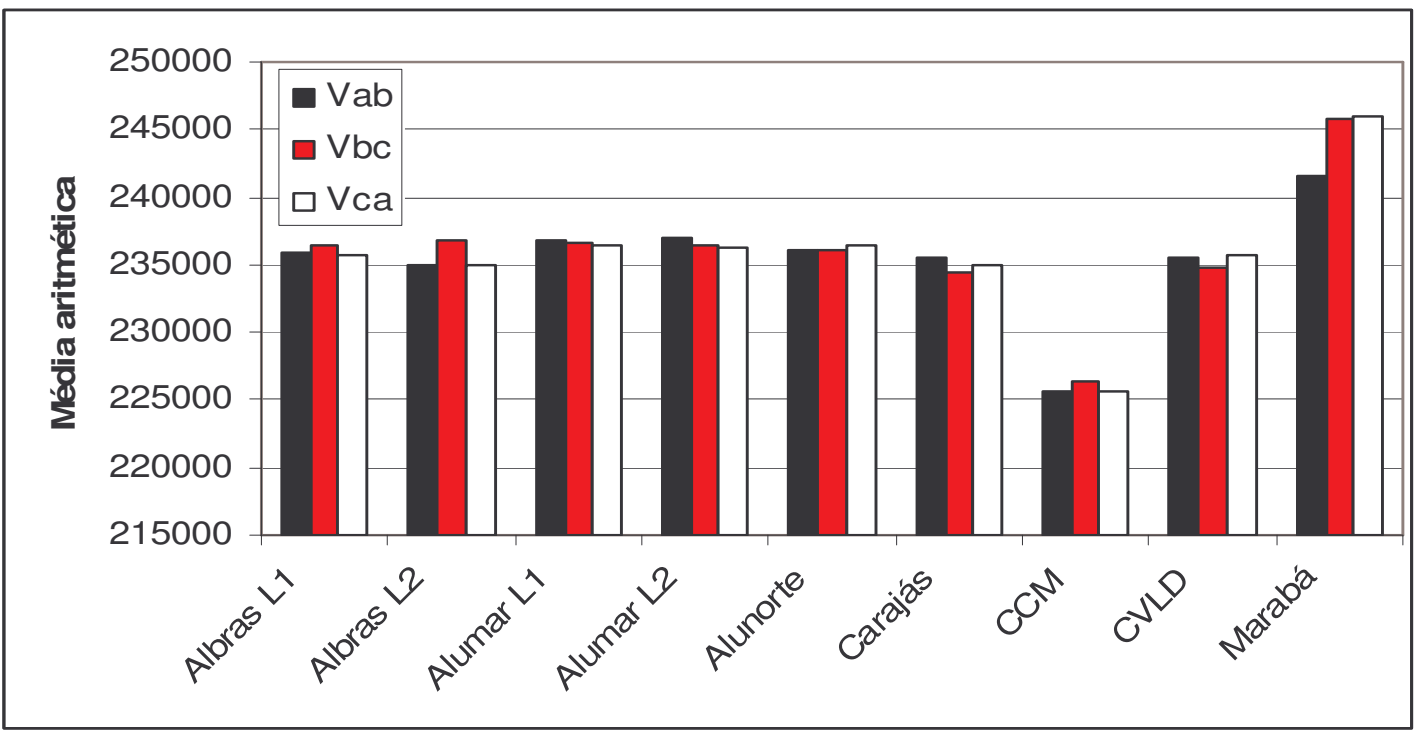

Figura 11.25 - Comparação entre a média aritmética da tensão de linha para as diferentes subestações.

A partir da tabela 11.36 e da figura 11.25, percebe-se que as tensões médias dos locais em questão apresentam-se acima da tensão nominal, exceto em CCM, onde as tensões observadas estão um pouco abaixo da nominal.

Ainda da tabela 11.36 tem-se que o maior erro relativo entre as tensões do mesmo local foi encontrada em Marabá, com 1,78\%, seguido de Albrás L2, com 0,77\%. Baseado neste parâmetro afirma-se que as tensões médias são próximas entre si, considerando-se o mesmo ponto de medição. A tabela 11.37 e a figura 11.26 mostram o desvio padrão das amostras.

Tabela 11.37 - Desvio padrão das amostras de tensão de linha

\begin{tabular}{|c|c|c|c|}
\cline { 2 - 4 } \multicolumn{1}{c|}{} & Vab & Vbc & Vca \\
\hline Albras L1 & 1370,857 & 1336,067 & 1455,346 \\
\hline Albras L2 & 1404,224 & 1393,932 & 1457,476 \\
\hline Alumar L1 & 2714,919 & 2693,093 & 2705,961 \\
\hline Alumar L2 & 2714,096 & 2690,707 & 2698,466 \\
\hline Alunorte & 1402,837 & 1385,559 & 1487,078 \\
\hline Carajás & 3605,375 & 3695,953 & 3607,619 \\
\hline CCM & 1591,116 & 1588,118 & 1580,108 \\
\hline CVLD & 2681,081 & 2628,186 & 2669,706 \\
\hline Marabá & 1369,55 & 1557,482 & 1589,582 \\
\hline
\end{tabular}




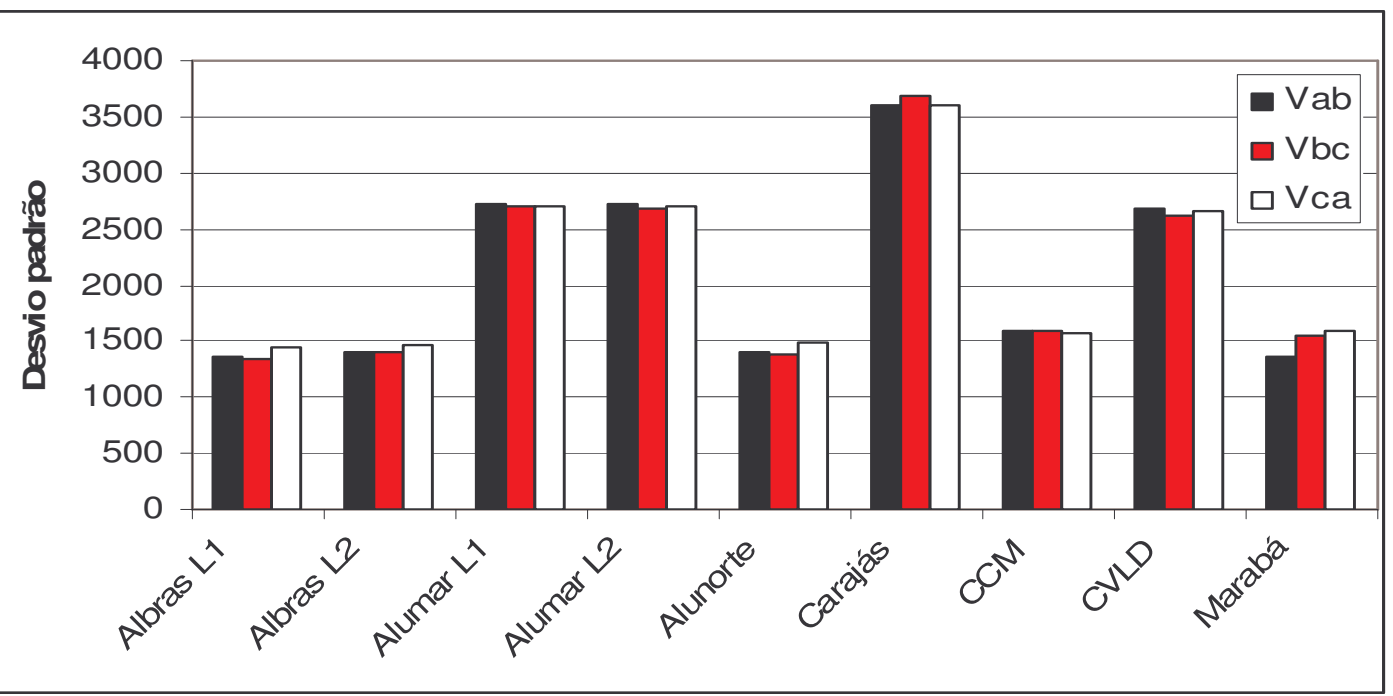

Figura 11.26 - Comparação entre o desvio padrão das amostras de tensão de linha

Com auxílio da tabela 11.37 e da figura 11.26 nota-se que o local que apresenta o maior desvio padrão é Carajás, superando $3500 \mathrm{~V}$ de desvio padrão, seguido de Alumar L1, Alumar L2 e CVLD, com desvio um pouco maior que $2500 \mathrm{~V}$.

A tabela 11.38 ilustra a razão entre os desvios padrão e suas respectivas médias aritméticas.

Tabela 11.38 - Desvio padrão das amostras de tensão de linha

\begin{tabular}{|c|c|c|c|}
\cline { 2 - 4 } \multicolumn{1}{c|}{} & Vab [\%] & Vbc [\%] & Vca [\%] \\
\hline Albras L1 & 0,581185 & 0,564991 & 0,617504 \\
\hline Albras L2 & 0,597822 & 0,588863 & 0,620173 \\
\hline Alumar L1 & 1,146545 & 1,13807 & 1,144282 \\
\hline Alumar L2 & 1,145324 & 1,138311 & 1,142459 \\
\hline Alunorte & 0,594287 & 0,586825 & 0,628913 \\
\hline Carajás & 1,530845 & 1,576598 & 1,53582 \\
\hline CCM & 0,704954 & 0,70181 & 0,700307 \\
\hline CVLD & 1,138014 & 1,119007 & 1,132548 \\
\hline Marabá & 0,567035 & 0,63352 & 0,646423 \\
\hline \multicolumn{2}{|c}{} \\
\end{tabular}

Da tabela 11.38 tem-se que a razão entre o desvio padrão e a média aritmética observada é muito pequena, tendo seu maior valor apresentado em Carajás, com 1,58\%, o que caracteriza que as amostras pouco se distanciaram do valor médio.

A tabela 11.39 e a figura 11.27 trazem o P95\% das tensões de linha, medido durante sete dias consecutivos nos nove locais em estudo. A tabela 11.39 mostra também o erro relativo entre o maior e o menor valor de $\mathrm{P} 95 \%$ de um mesmo ponto. 
Tabela 11.39 - P95\% das tensões de linha

\begin{tabular}{|c|c|c|c|c|}
\cline { 2 - 5 } \multicolumn{1}{c|}{} & Vab & Vbc & Vca & Erro relativo \\
\hline Albras L1 & 238043,2 & 238557,1 & 237803 & $0,32 \%$ \\
\hline Albras L2 & 236727,8 & 238566,6 & 236922,5 & $0,77 \%$ \\
\hline Alumar L1 & 241807,3 & 241691,2 & 241515,2 & $0,12 \%$ \\
\hline Alumar L2 & 242051,5 & 241456,4 & 241289,4 & $0,31 \%$ \\
\hline Alunorte & 237890,1 & 237970,5 & 238371 & $0,20 \%$ \\
\hline Carajás & 241046 & 240132,2 & 240476 & $0,38 \%$ \\
\hline CCM & 228147,9 & 228876,1 & 227996,8 & $0,38 \%$ \\
\hline CVLD & 240652,5 & 239879,6 & 240799,8 & $0,38 \%$ \\
\hline Marabá & 243582,4 & 248046,3 & 248255,1 & $1,88 \%$ \\
\hline
\end{tabular}

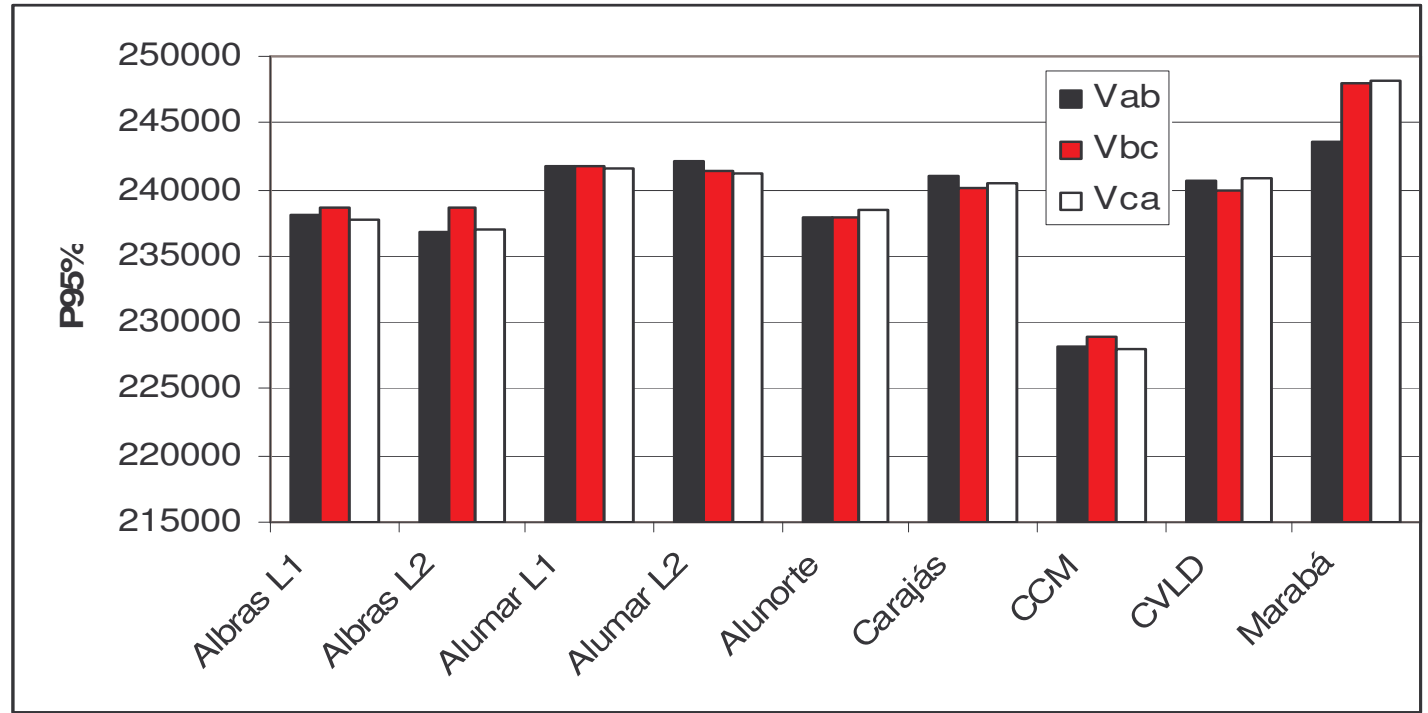

Figura 11.27 - Comparação entre o P95\% das tensões de linha

A partir da tabela 11.39 e com ajuda da figura 11.27, percebe-se que o P95\% é semelhante para as fases do mesmo local. Mais uma vez o maior erro relativo foi encontrado em Marabá, com 1,88\%, seguido de Albrás L2, com 0,77\%.

As figuras 11.28, 11.29 e 11.30 apresentam os gráficos, em p.u., de distribuição de ocorrências das tensões Vab, Vbc e Vca respectivamente, considerando-se todo o banco de dados. 


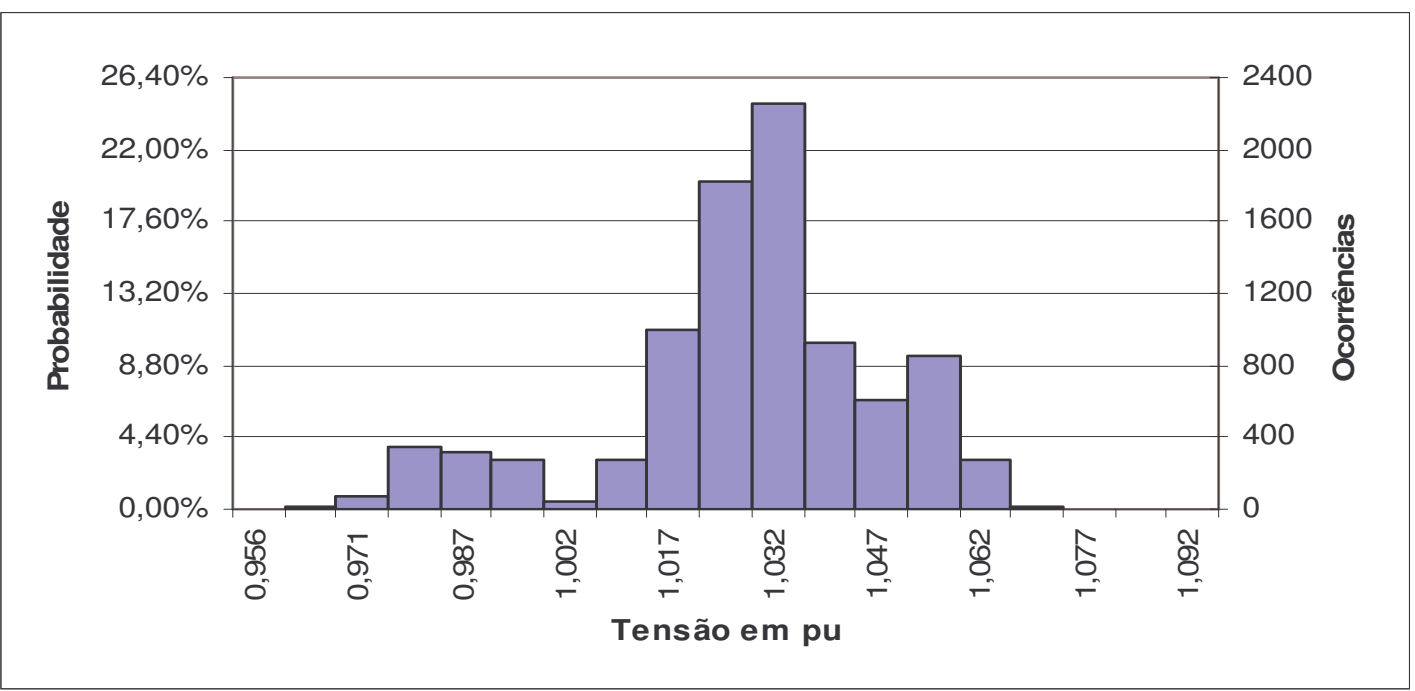

Figura 11.28 - Distribuição de ocorrências da tensão Vab em p.u.

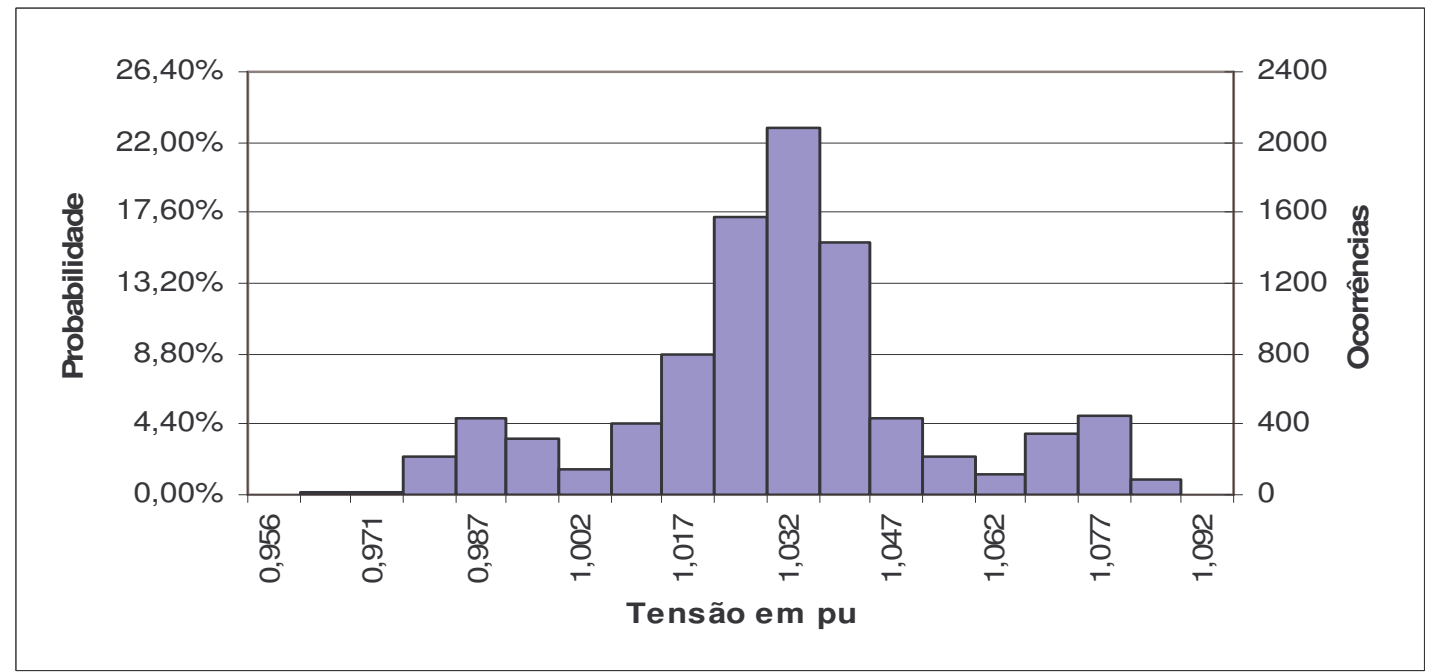

Figura 11.29 - Distribuição de ocorrências da tensão Vbc em p.u.

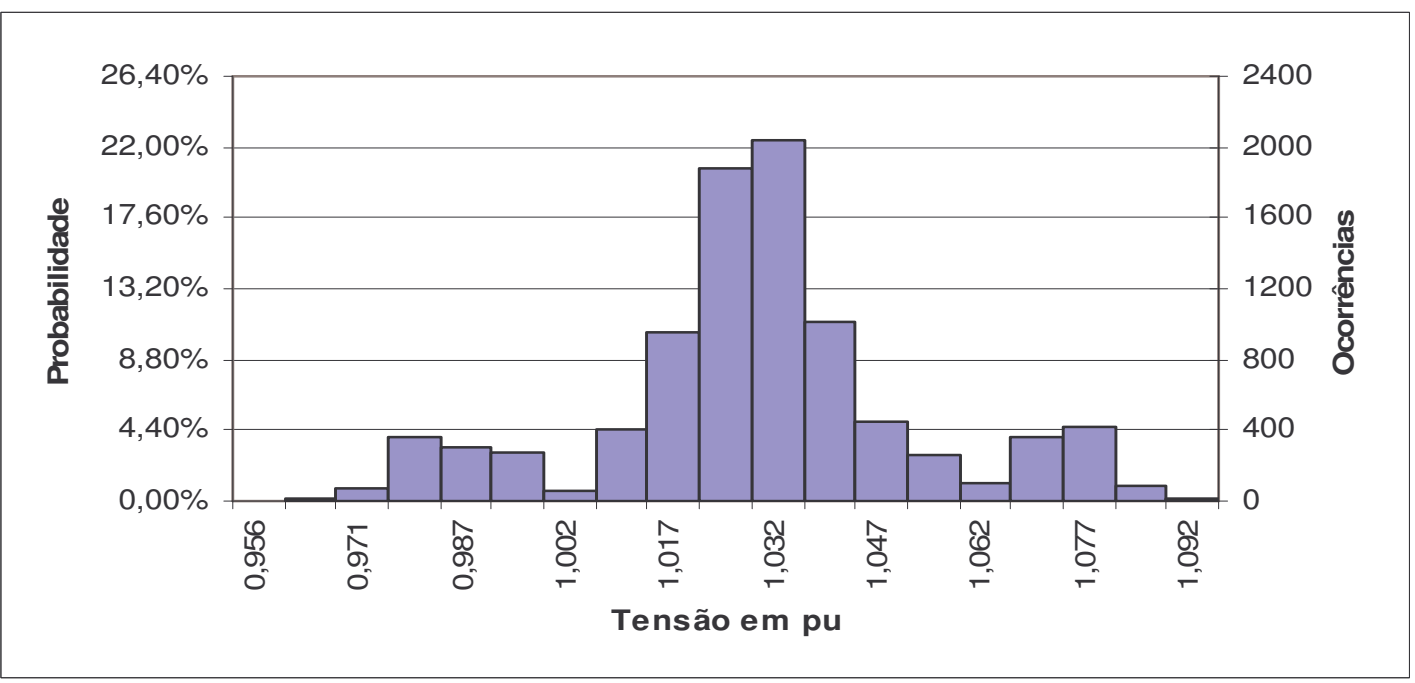

Figura 11.30 - Distribuição de ocorrências da tensão Vca em p.u. 
Da figura 11.28 tem-se que a tensão Vab apresenta 66\% de seus valores (5991 amostras) entre 1,017 p.u. e 1,039 p.u. A partir da figura 11.29 percebe-se que cerca de $64,9 \%$ do total das amostras de Vbc se mostram entre 1,017 p.u e 1,039 p.u.Já da figura 11.30 é possível concluir que $64,9 \%$ dos dados colhidos para Vca possuem sua magnitude entre 1,017 p.u. e 1,039 p.u.

A distribuição dos valores das tensões fase-fase é muito próxima da distribuição observada para as tensões fase-neutro, fato já esperado, visto que a relação entre estes valores é uma constante. Mais de $80 \%$ das amostras estão com valores acima do nominal. Considerando que CCM contribua com $11,11 \%$ do total, tem-se que em média menos de $1 \%$ das amostras dos demais locais apresentaram valores abaixo de 1 p.u.

\subsection{7 - COMPARAÇÃO COM A NORMA}

A presente subseção tem por interesse realizar a apreciação dos valores dos indicadores de severidade obtidos para as nove subestações estudadas com os limites estabelecidos pela recomendação nacional. Para tanto, será estudada a quarta semana da subestação CCM e a terceira semana das demais, como foi feito em outras análises. As tabelas 11.40 a 11.48 apresentam um resumo dos indicadores obtidos durante a campanha de medição.

Tabela 11.40 - Resumo dos indicadores obtidos na campanha de medição na SE Albras L1.

\begin{tabular}{|c|c|c|c|c|c|c|c|c|c|}
\hline & \multicolumn{7}{|c|}{ Pstd95\% } & \\
\hline & Dia 1 & Dia 2 & Dia 3 & Dia 4 & Dia 5 & Dia 6 & Dia 7 & PstD95\% & PltS95\% \\
\hline $\begin{array}{c}\text { Fase } \\
\text { A }\end{array}$ & 0.1984 & 0.1705 & 0.1383 & 0.1471 & 0.1292 & 0.1798 & 0.1288 & 0.1984 & 0.1277 \\
\hline $\begin{array}{c}\text { Fase } \\
\text { B }\end{array}$ & 0.2091 & 0.159 & 0.148 & 0.1516 & 0.141 & 0.1823 & 0.1327 & 0.2091 & 0.1336 \\
\hline $\begin{array}{c}\text { Fase } \\
\text { C }\end{array}$ & 0.2124 & 0.1601 & 0.162 & 0.166 & 0.143 & 0.1685 & 0.1491 & 0.2124 & 0.1365 \\
\hline
\end{tabular}

Tabela 11.41 - Resumo dos indicadores obtidos na campanha de medição na SE Albras L2.

\begin{tabular}{|c|c|c|c|c|c|c|c|c|c|}
\hline & \multicolumn{7}{|c|}{ Pstd95\% } & \multicolumn{2}{|c|}{ (1) } \\
\hline & Dia 1 & Dia 2 & Dia 3 & Dia 4 & Dia 5 & Dia 6 & Dia 7 & PstD95\% & PltS95\% \\
\hline $\begin{array}{c}\text { Fase } \\
\text { A }\end{array}$ & 0.127 & 0.1264 & 0.1325 & 0.1864 & 0.125 & 0.1578 & 0.1493 & 0.1864 & 0.1392 \\
\hline $\begin{array}{c}\text { Fase } \\
\text { B } \\
\end{array}$ & 0.1328 & 0.1342 & 0.1454 & 0.1943 & 0.1348 & 0.1666 & 0.1485 & 0.1943 & 0.1415 \\
\hline $\begin{array}{c}\text { Fase } \\
\text { C }\end{array}$ & 0.1339 & 0.1433 & 0.1463 & 0.2214 & 0.1393 & 0.2092 & 0.1617 & 0.2214 & 0.147 \\
\hline
\end{tabular}


Tabela 11.42 - Resumo dos indicadores obtidos na campanha de medição na SE Alumar L1.

\begin{tabular}{|c|c|c|c|c|c|c|c|c|c|}
\cline { 2 - 10 } \multicolumn{1}{c|}{} & \multicolumn{8}{c|}{ Pstd95\% } \\
\cline { 2 - 10 } \multicolumn{1}{c|}{} & Dia 1 & Dia 2 & Dia 3 & Dia 4 & Dia 5 & Dia 6 & Dia 7 & PstD95\% & PItS95\% \\
\hline $\begin{array}{c}\text { A } \\
\text { Fase } \\
\text { B }\end{array}$ & 0.403 & 0.3942 & 0.3602 & 0.3703 & 0.3831 & 0.3744 & 0.3211 & 0.403 & 0.3716 \\
\hline $\begin{array}{c}\text { Fase } \\
\text { C }\end{array}$ & 0.267 & 0.2661 & 0.3367 & 0.3571 & 0.3619 & 0.366 & 0.3087 & 0.366 & 0.3292 \\
\hline
\end{tabular}

Tabela 11.43 - Resumo dos indicadores obtidos na campanha de medição na SE Alumar L2.

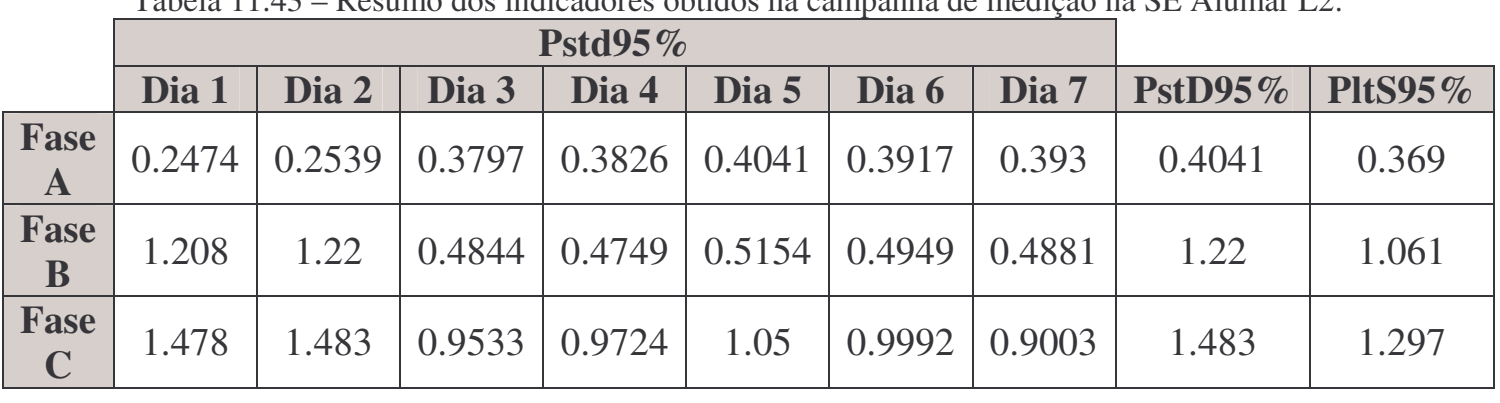

Tabela 11.44 - Resumo dos indicadores obtidos na campanha de medição na SE Alunorte.

\begin{tabular}{|c|c|c|c|c|c|c|c|c|c|}
\cline { 2 - 10 } \multicolumn{1}{c|}{} & \multicolumn{7}{c|}{ Pstd95\% } \\
\cline { 2 - 10 } \multicolumn{1}{c|}{} & Dia 1 & Dia 2 & Dia 3 & Dia 4 & Dia 5 & Dia 6 & Dia 7 & PstD95\% & PItS95\% \\
\hline $\begin{array}{c}\text { Fase } \\
\text { A }\end{array}$ & 0.1371 & 0.1562 & 0.1495 & 0.1919 & 0.1413 & 0.1593 & 0.1488 & 0.1919 & 0.1492 \\
\hline $\begin{array}{c}\text { Fase } \\
\text { B }\end{array}$ & 0.1835 & 0.2012 & 0.2039 & 0.2349 & 0.1709 & 0.2036 & 0.1862 & 0.2349 & 0.1746 \\
\hline $\begin{array}{c}\text { Fase } \\
\text { C }\end{array}$ & 0.1938 & 0.1899 & 0.2131 & 0.2369 & 0.2295 & 0.2198 & 0.2203 & 0.2369 & 0.2039 \\
\hline
\end{tabular}

Tabela 11.45 - Resumo dos indicadores obtidos na campanha de medição na SE Carajás.

\begin{tabular}{|c|c|c|c|c|c|c|c|c|c|}
\cline { 2 - 10 } \multicolumn{1}{c|}{} & \multicolumn{7}{c|}{ Pstd95\% } \\
\cline { 2 - 10 } \multicolumn{1}{c|}{ Dia 1 } & Dia 2 & Dia 3 & Dia 4 & Dia 5 & Dia 6 & Dia 7 & PstD95\% & PItS95\% \\
\hline $\begin{array}{c}\text { Fase } \\
\text { A }\end{array}$ & 0.4526 & 0.3662 & 0.4561 & 0.4949 & 0.3119 & 0.4799 & 0.4785 & 0.4949 & 0.4649 \\
\hline $\begin{array}{c}\text { Fase } \\
\text { B }\end{array}$ & 0.4739 & 0.3848 & 0.4973 & 0.4702 & 0.3249 & 0.4894 & 0.465 & 0.4973 & 0.4666 \\
\hline $\begin{array}{c}\text { Fase } \\
\text { C }\end{array}$ & 0.4583 & 0.3834 & 0.4739 & 0.3972 & 0.2887 & 0.4679 & 0.4684 & 0.4739 & 0.455 \\
\hline
\end{tabular}

Tabela 11.46 - Resumo dos indicadores obtidos na campanha de medição na SE CCM.

\begin{tabular}{|c|c|c|c|c|c|c|c|c|c|}
\hline & \multicolumn{7}{|c|}{ Pstd95\% } & \multicolumn{2}{|l|}{ (n) } \\
\hline & Dia 1 & Dia 2 & Dia 3 & Dia 4 & Dia 5 & Dia 6 & Dia 7 & PstD95\% & PltS95\% \\
\hline $\begin{array}{c}\text { Fase } \\
\text { A }\end{array}$ & 0.111 & 0.1124 & 0.1259 & 0.1165 & 0.1432 & 0.105 & 0.1207 & 0.1432 & 0.1236 \\
\hline $\begin{array}{c}\text { Fase } \\
\text { B }\end{array}$ & 0.1193 & 0.1124 & 0.1172 & 0.1495 & 0.1157 & 0.1096 & 0.1276 & 0.1495 & 0.1519 \\
\hline $\begin{array}{c}\text { Fase } \\
\text { C }\end{array}$ & 0.1158 & 0.132 & 0.1274 & 0.1364 & 0.1201 & 0.0991 & 0.1151 & 0.1364 & 0.134 \\
\hline
\end{tabular}


Tabela 11.47 - Resumo dos indicadores obtidos na campanha de medição na SE CVLD.

\begin{tabular}{|c|c|c|c|c|c|c|c|c|c|}
\cline { 2 - 9 } \multicolumn{1}{c|}{} & Dia 1 & Dia 2 & Dia 3 & Dia 4 & Dia 5 & Dia 6 & Dia 7 & PstD95\% & PItS95\% \\
\hline $\begin{array}{c}\text { Fase } \\
\text { A }\end{array}$ & 0.2036 & 0.2041 & 0.2114 & 0.2304 & 0.2033 & 0.2113 & 0.2103 & 0.2304 & 0.1683 \\
\hline $\begin{array}{c}\text { Fase } \\
\text { B }\end{array}$ & 0.2077 & 0.2099 & 0.214 & 0.2452 & 0.2077 & 0.2238 & 0.2222 & 0.2452 & 0.1754 \\
\hline $\begin{array}{c}\text { Fase } \\
\text { C }\end{array}$ & 0.2032 & 0.2036 & 0.2152 & 0.2284 & 0.203 & 0.2248 & 0.2323 & 0.2323 & 0.165 \\
\hline
\end{tabular}

Tabela 11.48 - Resumo dos indicadores obtidos na campanha de medição na SE Marabá.

\begin{tabular}{|c|c|c|c|c|c|c|c|c|c|}
\hline & \multicolumn{7}{|c|}{ Pstd95\% } & \multicolumn{2}{|l|}{ ( } \\
\hline & Dia 1 & Dia 2 & Dia 3 & Dia 4 & Dia 5 & Dia 6 & Dia 7 & PstD95\% & PltS95\% \\
\hline $\begin{array}{c}\text { Fase } \\
\text { A }\end{array}$ & 0.1438 & 0.09706 & 0.1497 & 0.1279 & 0.1062 & 0.1219 & 0.1249 & 0.1497 & 0.2271 \\
\hline $\begin{array}{c}\text { Fase } \\
\text { B }\end{array}$ & 0.1226 & 0.1042 & 0.1673 & 0.1264 & 0.107 & 0.1169 & 0.1201 & 0.1673 & 0.2842 \\
\hline $\begin{array}{c}\text { Fase } \\
\text { C }\end{array}$ & 0.1163 & 0.09919 & 0.1454 & 0.1302 & 0.1097 & 0.1277 & 0.1209 & 0.1454 & 0.1702 \\
\hline
\end{tabular}

Como a tensão das subestações é $230 \mathrm{kV}$, os limites globais alcançados para elas estão expostos na tabela 11.49 .

Tabela 11.49 - Limite dos indicadores.

\begin{tabular}{|c|c|c|}
\hline Limites & PstD95\% & PltS95\% \\
\hline Limite global inferior & 1.53846 & 1.23077 \\
\hline Limite global superior & 3.07692 & 2.46154 \\
\hline
\end{tabular}

De acordo com as tabelas 11.40 a 11.49 , percebe-se que todas as SE's apresentam PstD95\% abaixo do limite global inferior. O pior resultado encontrado foi em Alumar L2, 1.483 pu na fase C. Nesta mesma subestação encontra-se um PltS95\% igual a 1.297 pu, acima do limite inferior, o que coloca Alumar L2 sob estado de observação, fazendo com que providências sejam tomadas em caso de queixas dos consumidores. Todas as demais apresentam PltS95\% abaixo do limite inferior.

Evidencia-se, a partir da análise elaborada, que a tensão medida nas nove subestações da Eletronorte obedecem aos requisitos exigidos pela recomendação brasileira, no tocante a cintilação luminosa. Apenas Alumar L2 encontra-se em estado de observação. 


\section{2 - CONSIDERAÇÕES FINAIS}

Neste capítulo foi realizada uma comparação entre nove subestações do sistema

Eletronorte. A partir dele foi possível inferir sobre a inexistência de similaridade entre as fases e os dias dos locais estudados. Impossibilitando assim, a diminuição do banco de dados. 


\section{CAPÍTULO 12}

\section{CONCLUSÃO}

\section{1 - CONCLUSÕES}

O presente capítulo pretende tecer as conclusões obtidas ao longo deste trabalho, que apresentou uma ferramenta computacional para análise, quantificação e qualificação das cintilações luminosas.

O capítulo 1 trouxe à tona a questão da qualidade da energia elétrica, dando ênfase na importância de se debater este tema. Verificou-se, com a criação do MAE e com o uso cada vez maior de equipamentos eletrônicos sensíveis à qualidade da tensão, a necessidade de estabelecerem valores limites para os fenômenos relacionados a QEE, visando as implicações técnicas e econômicas de um fornecimento inadequado. Em relação às cintilações luminosas, salientou-se o fato de que mesmo com a normatização vigente há questões que devem ser discutidas, como limites para médias e altas tensões. Destacou-se também a importância de mecanismos que auxiliem no tratamento estatístico dos dados procedentes das medições.

O capítulo 2 apresentou os aspectos gerais sobre os distúrbios relacionados à qualidade da energia. Para cada fenômeno foram destacados os fundamentos teóricos, suas causas e seus efeitos.

No capítulo 3 a cintilação luminosa foi definida, sendo apontadas as características e as causas deste distúrbio. Foram apresentados os métodos de medição mais conhecidos, enfatizando o Método Padrão, e na sequiência são expostas estratégias e tecnologias que visam atenuar as flutuações de tensão nos barramentos elétricos de potência. No final deste capítulo, foi exibida uma síntese das principais normas e recomendações referentes a este tema.

O capítulo 4 introduziu o objeto deste trabalho, denominado "Programa de Qualidade da Energia Elétrica - Módulo de Análise de Flicker", um aplicativo que permite de maneira simples e objetiva, valendo-se de recursos gráficos e estatísticos, estudar o fenômeno 
supracitado. Foram descritos os fundamentos matemáticos utilizados no programa e teve-se uma visão geral de cada um dos módulos que o compõem. Atentou-se para a necessidade de um estudo de caso para atestar a aplicabilidade do software, tendo sido escolhido a linha 1 da subestação SE Albrás da Eletronorte, para as análises realizadas nos capítulos de 5 a 10 .

O capítulo 5 foi dedicado ao módulo de análise da frequiência de aquisição dos dados. Um estudo foi realizado, comparando-se as amostras tomadas em três diferentes freqüências: 10, 30 e 60 minutos. Os resultados desta análise comprovaram que o Plt é mais conservador do que o Pst. O Plt se mostrou praticamente idêntico nas três frequiências de aquisição. Já o Pst apresentou uma variação significativa, principalmente em se tratando do P95\%, com $21,2 \%$ de diferença entre o maior e o menor valor de amostragem. Ainda para o Pst, o maior erro relativo entre as médias aritméticas foi de $6 \%$ e entre as médias quadráticas foi de $0,08 \%$.

No capítulo 6, os módulos de análise de similaridade entre dias e de similaridade entre períodos do dia foram detalhados. Para a subestação analisada, notou-se que mesmo com valores muito abaixo do permitido, as médias, os máximos, os desvios padrão, os P95\% e os P99\% variaram significativamente de um dia para o outro, tanto para o Pst quanto para o Plt, suprimindo a possibilidade de similaridade entre os mesmos. Observou-se ainda a inexistência de similaridade entre diferentes intervalos de um mesmo dia.

O capítulo 7 descreveu o funcionamento do módulo de similaridade entre fases. Investigouse a existência ou não de semelhança entre as fases da linha 1 da SE Albrás. A variação máxima da média aritmética e do P95\% entre as fases foi de 10,8\% e de 7,1 \%, respectivamente. O maior desvio padrão foi observado para o Pst da fase A e seu valor representa 67,6\% de seu valor médio. Conclui-se então que não há similaridade entre fases. Vale ressaltar que o pior caso foi utilizado para representar os demais, neste caso, a fase C.

O módulo de distribuição no tempo foi exibido no capítulo 8. Apresentou-se uma metodologia para análise da distribuição no tempo da amostras da linha 1 da SE Albrás, tendo com referência os valores da médias quadrática e dos indicadores $\mathrm{P} 95 \%$ e P99\%. Constatou-se para os 30 dias em estudo que: 
- Para o Pst: $80 \%$ dos intervalos com valores acima do índice P95\% e $85 \%$ dos que superaram o P99\% duraram 10 minutos. 95\% das amostras maiores que a média possuem até 20 minutos de duração. O máximo intervalo ininterrupto de tempo com valor acima de P95\% é de 50 minutos.

- Para o Plt: os máximos intervalos de tempo ininterruptos com valor acima de P95\% e da média quadrática, respectivamente, são de 250 minutos. $50 \%$ dos intervalos com valores acima do P99\% possuem até 30 minutos de duração e $54 \%$ dos intervalos com valores acima da média possuem até 50 minutos de duração.

O capítulo 9 apresentou o módulo de comparação com a norma. A partir dele efetuou-se um avaliação dos dados oriundos das medições na linha 1 da SE Albrás, quanto à adequação aos limites estabelecidos pelo Método Padrão. Constatou-se que a tensão medida nesta linha é adequada no que tange às cintilações luminosas. O módulo mostrou sua importância, por permitir uma avaliação imediata da conformidade do banco de dados com a norma vigente e por gerar os gráficos necessários para a elaboração de relatórios, além de possibilitar a consulta às recomendações do ONS.

O módulo de análise de carga foi descrito no capítulo 10. Foi verificado que as tensões exibiram valores médios próximos entre si durante o período em estudo. Notou-se também que a carga esteve bem distribuída. A relevância deste módulo está na possibilidade de se investigar as tensões, a corrente, a freqüência e as potências do sistema analisado, indicando possíveis causas das cintilações luminosas.

No capítulo 11 foi proposta uma comparação entre nove bancos de dados diferentes. Para as análises aqui realizadas utilizou-se o programa em questão e o Excel, pois o aplicativo foi desenvolvido para avaliar um banco por vez. Os locais escolhidos fazem parte do sistema elétrico da Eletronorte. São eles: Albrás 1, Albrás 2, Alumar 1, Alumar 2, Alunorte, Carajás, CCM, CVLD e Marabá. Verificou-se:

- A não existência entre similaridade entre dias;

- A distribuição dos valores das tensões de linha é muito próxima da distribuição observada para as tensões de fase. Mais de $80 \%$ das amostras estão com valores 
acima do nominal. A CCM sempre se manteve abaixo desta referência. Como a CCM representa 1/9 do banco de dados, conclui-se que, em média, para cada um dos demais locais, pouco mais de $1 \%$ de suas amostras estavam abaixo da tensão nominal;

- Exceto para Alumar 2, os indicadores medidos se mostraram abaixo dos limites definidos pelo ONS. O valores de P95\% do Pst e do Plt encontrados em Alumar 2 são, respectivamente, 1.483 e 1.297. Este estudo coloca a SE sob estado de observação. Nos demais locais os maiores valores foram apresentados em Alumar 1 seguido de Carajás.

A ferramenta computacional apresentada no decorrer deste trabalho constitui uma significativa contribuição no estudo e avaliação das cintilações luminosas presentes na rede elétrica. O conhecimento do comportamento de fenômenos como flicker culmina em ações que poderão minimizar os efeitos danosos dos mesmos sobre o sistema de potência. Neste propósito, o trabalho revela-se um instrumento de grande utilidade nos processos de acompanhamento e monitoração da rede. 


\section{REFERÊNCIAS BIBLIOGRÁFICAS}

AFONSO J.L E MARTINS, J.S.. (2004). .Qualidade da Energia Elétrictrica. Departamento de Electrónica Industrial. Universidade do Minho In: Revista o Electricista n. 9 p66-71.

ANEEL, Agência Nacional de Energia Elétrica. (2005). .Procedimentos de Distribuição de Energia Elétrica no Sistema Elétrico Nacional. PRODIST. Módulo 08, Qualidade da Energia Elétrica.

BRONZEADO, H. (2000). Qualidade da Energia Elétrica - Conceitos, Problemas e Soluções. Maio de 2000.

CARVAlHO, P.L. (1997). .Uma Contribuição ao Estudo da Depressão de Tensão. Dissertação de Mestrado. Escola Federal de Engenharia de Itajubá.

DECKMANN, S. M. ANEEL - Estudos Sobre Qualidade de Energia Elétrica - Flutuações de Tensão na Rede Elétrica - Relatório parcial-1, 21p, 1999.

DECKMANN, S. M. ANEEL - Estudos Sobre Qualidade de Energia Elétrica - Flutuações de Tensão: Metodologia de Avaliação da Cintilação - Relatório parcial-2, 23p, 1999.

DECKMANN, S. M. ANEEL - Estudos Sobre Qualidade de Energia Elétrica - Flutuações de Tensão: Indicadores de Avaliação - Relatório Final, 26p, 2000.

DELMONT, O.F. (2003). .Utilização da Transformada Wavelet para Caracterização de Distúrbios na Qualidade da Energia Elétrica.. Dissertação de Mestrado. Escola de Engenharia de São Carlos, Universidade de São Paulo, São Carlos, 2003.

DUGAN, R. C., MCGRANAGHAN, M. F. e BEATY, H. W. Electrical Power Systems Quality. McGraw-Hill, Nova Iorque, E.U.A., 1996.

FERNANDES, D. E. B., Uma Metodologia de Gerenciamento da qualidade da Energia Elétrica, Dissertação de Mestrado, Belo Horizonte: PPGEE / PUC-MG, CDU: 621.3, abr., 1999, 130p.

GARCIA, M. P. (2006). Uma Contribuição para o Estudo do Desequilíbrio de Tensão nos Sistemas Elétricos de Potência. Projeto Final de Graduação em Engenharia Elétrica, Publicação ENE-1/06, Departamento de Engenharia Elétrica, Universidade de Brasília, Brasília, DF, 198p.

GARCIA, M. S. P.; ROLIM, T. S. (2005a). .Fundamentos de MATLAB 6.5., Curso Departamento de Engenharia Elétrica. ENE. UnB, Outubro, Brasília.

GARCIA, M. S. P.; ROLIM, T. S. (2005b), Manual do ION Enterprise, Curso Departamento de Engenharia Elétrica. ENE. UnB, Outubro, Brasília.

MEDEIROS, C. A. G. Contribuição para Conceituação, Medição, Efeitos e Análise dos Limites Relacionados a Flutuação de Tensão. Tese de Doutorado, Departamento de Engenharia Elétrica, Universidade Federal de Uberlândia, Uberlândia, MG, 184p. 2003. 
MEYER, P. L. Probabilidade: Aplicações à Estatística. 2. ed. Rio de Janeiro: LTC, 1983.

OLESKOVIXZ, M. (2004). .Qualidade da Energia Elétrica. Curso, USP, São Paulo.

OLIVEIRA, F. A. Uma Proposta Para a Quantificação do Efeito de Cintilação Luminosa. Dissertação de Mestrado, Departamento de Engenharia Elétrica, Universidade Federal de Uberlândia, Uberlândia, MG, 1994.

OLIVEIRA, J.C (2005). .A Qualidade da Energia Elétrica. $7^{a}$ Semana de Engenharia Elétrica, UnB, Brasília.

OLIVEIRA, M. A. (2005). .Apostila de Qualidade da Energia Elétrica. Universidade de Brasília, Faculdade de Tecnologia, Departamento de Engenharia Elétrica.

OPERADOR NACIONAL DO SISTEMA ELÉTRICO - ONS. Procedimentos de redes, Sub-módulo 2.2: Padrões de desempenho da rede básica e requisitos mínimos para suas instalações, 2002.

PONTES, M. G. S. R. Contribuições à Análise da Propagação das Flutuações de Tensão sob o Enfoque do Fenômeno Flicker. Dissertação de Mestrado, Departamento de Engenharia Elétrica, Universidade Federal de Uberlândia, Uberlândia, MG, 2000.

RAMOS, A.J.P. (2000a). .Monitoração, Avaliação e Controle da Qualidade da Energia Elétrica. Procedimentos de Medição e Monitoração. ANEEL, Recife.

ROLA, D. V., ROLIM Jr., T. S. (2006). Ferramenta Computacional Para Análise de Distorções Harmônicas de Tensão. Projeto Final de Graduação em Engenharia Elétrica, Publicação ENE-1/06, Departamento de Engenharia Elétrica, Universidade de Brasília, Brasília, DF, 124p.

XAVIER, P.A. (2005). .Avaliação das Características Elétricas de Reatores Eletrônicos Utilizados em Lâmpadas Fluorescentes Tubulares. Dissertação. Universidade de Brasília, Brasília. 